\title{
Supramolecular assemblies based on glycoconjugated dyes
}

Bettina Schmidt
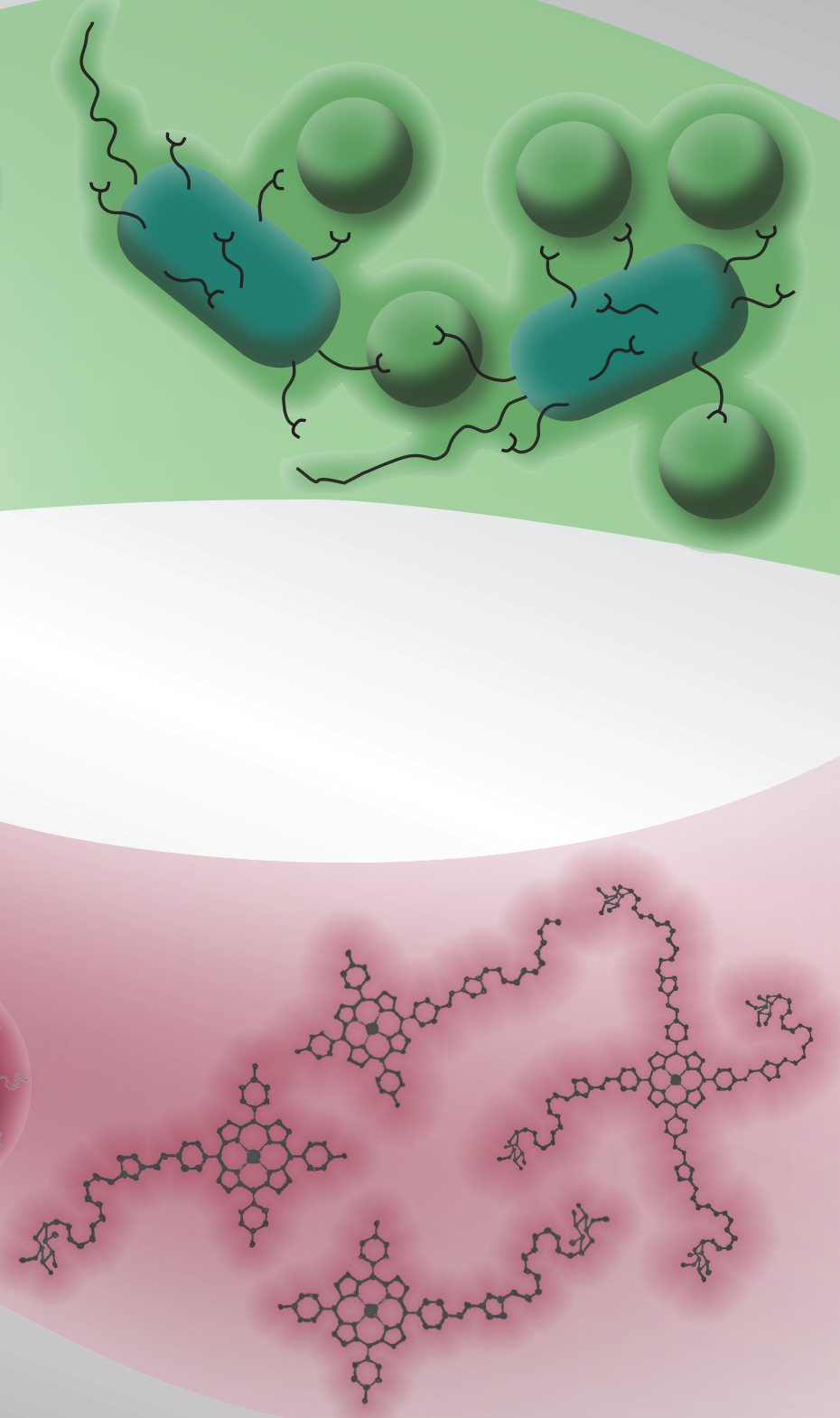


\section{Supramolecular assemblies based on glycoconjugated dyes}

Bettina Schmidt 


\section{Members of the committee:}

$\begin{array}{lll}\text { Chairman: } & \text { Prof. Dr. Ir. J.W.M. Hilgenkamp, } & \text { Universiteit Twente } \\ \text { Promotor: } & \text { Prof. Dr. Ir. P. Jonkheijm, } & \text { Universiteit Twente } \\ \text { Members: } & \text { Prof. Dr. J.J.L.M. Cornelissen, } & \text { Universiteit Twente } \\ & \text { Prof. Dr. Ir. J. Huskens, } & \text { Universiteit Twente } \\ & \text { Priv.-Doz. Dr. C.A. Strassert, } & \text { Westfälische Wilhelms- } \\ & & \text { Universität Münster } \\ & \text { Dr. W. Verboom, } & \text { Universiteit Twente } \\ & \text { Jun.-Prof. Dr. J. Voskuhl, } & \text { Universität Duisburg-Essen }\end{array}$

The research described in this thesis was performed within the laboratories of the Bioinspired Molecular Engineering Laboratory (BMEL), MIRA Institute for Biomedical Technology and Technical Medicine, and the Molecular Nanofabrication (MnF) group, MESA ${ }^{+}$ Institute for Nanotechnology, Department of Science and Technology (TNW) of the University of Twente (UT). This research was supported by the European Research Council through Starting Grant Sumoman (259183).

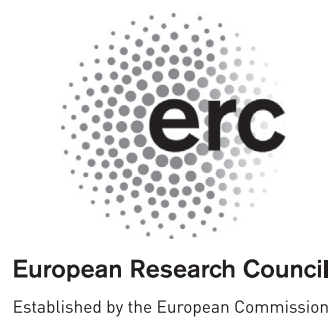

\section{Supramolecular assemblies based on glycoconjugated dyes}

Copyright (c) 2016, Bettina Schmidt, Enschede, The Netherlands.

All rigths reserved. No part of this thesis may be reproduced or transmitted in any form, by any means, electronic or mechanical without prior written permission of the author.

ISBN: 978-90-365-4124-4

DOI: $10.3990 / 1.9789036521244$

Cover art: Josefine Petrenz

Printed by: Gildeprint Drukkerijen - The Netherlands 


\title{
SUPRAMOLECULAR ASSEMBLIES BASED ON GLYCOCONJUGATED DYES
}

\section{DISSERTATION}

\author{
to obtain \\ the degree of doctor at the University of Twente, \\ on the authority of the rector magnificus \\ Prof. Dr. H. Brinksma, \\ on account of the decision of the graduation committee, \\ to be publicly defended \\ on Wednesday $6^{\text {th }}$ of July 2016 at $14.45 \mathrm{~h}$
}

by

Bettina Schmidt

born on $27^{\text {th }}$ of April 1988

in Rostock, Germany 
This dissertation has been approved by:

Promotor: Prof. Dr. Ir. P. Jonkheijm 
"It is always the facts that will not fit in that are significant."

- Hercule Poirot in Death on the Nile by Agatha Christie 



\section{Contents}

1 Diagnostic and Therapeutic Applications of Supramolecular Assemblies based on Glycoconjugated Dyes

1.1 Self-assembly of dyes .......................... 2

1.2 Application of assemblies of glvcoconjugated dves for diagnostics . . . . . . 3

1.2.1 Carbohvdrate targeting ..................... 3

1.2.2 Emploving fluorescence for diagnostic use ............ 4

1.3 Application of assemblies of glycoconjugated dves for therapeutics . . . . . 12

1.3.1 Employing singlet oxygen for therapeutic use . . . . . . . . . . . . 12

1.3.2 Theranostics . . . . . . . . . . . . . . . . . 17

1.4 Outline of thesis . . . . . . . . . . . . . . . . . 18

1.5 Bibliography . . . . . . . . . . . . . . . . . . . . 19

2 Synthesis of Glycoconjugated Porphyrins 23

2.1 Introduction . . . . . . . . . . . . . . . . . . . . 24

2.2 Results and discussion $\ldots \ldots \ldots \ldots \ldots \ldots \ldots$

2.2.1 Svnthesis of porphvrin alkvne derivatives . . . . . . . . . . . . 26

2.2.2 Svnthesis of azido-modified carbohvdrates . . . . . . . . . . 27

2.2.3 Copper(I)-catalyzed azide-alkyne cycloaddition of monosaccharides

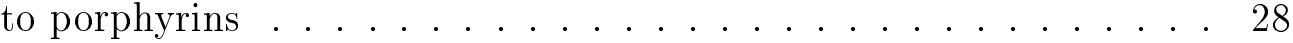

2.2.4 Characterization of the porphyrins . . . . . . . . . . 28

2.3 Conclusions . . . . . . . . . . . . . . . . . . . 32

2.4 Acknowledgments . . . . . . . . . . . . . . . . . . . . 32

2.5 Experimental section . . . . . . . . . . . . . . . . 32

2.5.1 Materials and equipment . . . . . . . . . . . . . . 32

2.5 .2 Svnthetic procedures . . . . . . . . . . . . . . . 33

2.6 Bibliography . . . . . . . . . . . . . . . . . . . . . . . . 42

3 Self-Assembly Properties of Glycoconjugated Porphyrins $\quad 45$

3.1 Introduction . . . . . . . . . . . . . . . . 46 


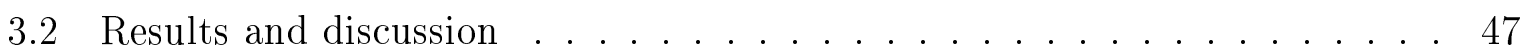

3.2.1 Optical properties of porphvrin self-assemblies in water . . . . . . 47

3.2.2 Morphologv properties of porphvrin self-assemblies in water . . . 50

3.2.3 Stability of porphyrin assemblies . . . . . . . . . . . . . 52

3.3 Conclusions . . . . . . . . . . . . . . . . . . . 53

3.4 Acknowledgments . . . . . . . . . . . . . . . . . . 54

3.5 Experimental section . . . . . . . . . . . . . . . . 54

3.5 .1 Materials and equipment . . . . . . . . . . . . . . 54

3.5 .2 Methods . . . . . . . . . . . . . . . . . 55

3.6 Bibliography . . . . . . . . . . . . . . . . . . 57

4 Photoinduced Activity and Binding Study of Glycoconjugated Porphyrins 59

4.1 Introduction . . . . . . . . . . . . . . . . 60

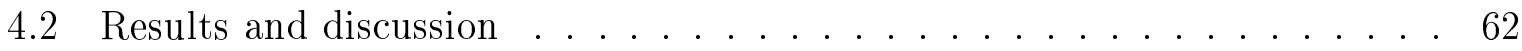

4.2.1 Singlet oxvgen quantum vield . . . . . . . . . . . . . . 62

4.2.2 Binding of porphyrin assemblies to lectins . . . . . . . . . . 64

4.2.3 Photoinduced activity of porphyrin assemblies in the presence of $E$. coli bacteria cells . . . . . . . . . . . . . . . 66

4.3 Conclusions . . . . . . . . . . . . . . . . . . 69

4.4 Experimental section . . . . . . . . . . . . . . . . . 69

4.4.1 Materials and equipment . . . . . . . . . . . . . 69

4.4 .2 Methods . . . . . . . . . . . . . . . . 70

4.5 Bibliography . . . . . . . . . . . . . . . . . 72

5 Aggregation-Induced Emission Properties of 4,5-Bis(phenylthio)phthalonitriles

5.1 Introduction . . . . . . . . . . . . . . . . 76

5.2 Results and Discussion . . . . . . . . . . . . . . . 77

5.2 .1 Svnthesis of phthalonitriles . . . . . . . . . . . . . 77

5.2 .2 Photophvsical properties of phthalonitriles . . . . . . . . . . 79

5.2 .3 Morphological properties of phthalonitrile assemblies . . . . . . . 83

5.2 .4 Manipulating the phthalonitrile assemblies . . . . . . . . . 85

5.3 Conclusions . . . . . . . . . . . . . . . . . . 88

5.4 Acknowledgments $\ldots \ldots \ldots \ldots \ldots \ldots$

5.5 Experimental section . . . . . . . . . . . . . . . . 88

5.5 .1 Materials and equipment . . . . . . . . . . . . 88

5.5 .2 Svnthetic procedures . . . . . . . . . . . . . . 89

5.5 .3 Methods . . . . . . . . . . . . . . . . . . 92

5.6 Bibliography . . . . . . . . . . . . . . . . . . . 94 
6 Selective Targeting of Lectins and Bacteria by Supramolecular Assemblies of 4,5-Bis(phenylthio)phthalonitriles $\quad 97$

6.1 Introduction . . . . . . . . . . . . . . . . . . . 98

6.2 Results and discussion $\ldots \ldots \ldots \ldots \ldots \ldots$

6.2.1 Specific binding of SPn assemblies to Concanavalin A . . . . . . . 99

6.2.2 Specific binding of SPn assemblies to E. coli bacteria . . . . . . . 102

6.2.3 Influence of SPn assembly concentration and mannose density on specific E. coli binding . . . . . . . . . . . . . . . . . . . 103

6.2.4 Reversibility of the specific binding of SPn-(TEG-Man) $)_{2}$ assemblies to E. coli . . . . . . . . . . . . . . . . . . . . . 104

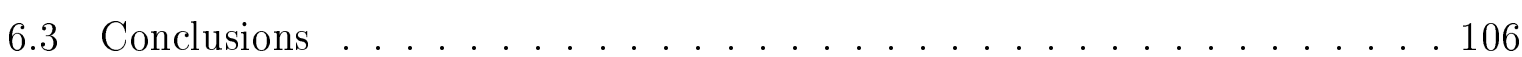

6.4 Acknowledgments . . . . . . . . . . . . . . . . . . . 106

6.5 Experimental section . . . . . . . . . . . . . . . 107

6.5 .1 Materials and equipment . . . . . . . . . . . . . 107

6.5 .2 Methods . . . . . . . . . . . . . . . . . 107

6.6 Bibliography . . . . . . . . . . . . . . . . . . . 109

$\begin{array}{ll}\text { Summary } & 111\end{array}$

$\begin{array}{ll}\text { Samenvatting } & 113\end{array}$

$\begin{array}{ll}\text { Acknowledgments } & 115\end{array}$

$\begin{array}{ll}\text { About the author } & 119\end{array}$ 



\section{Diagnostic and Therapeutic Applications of Supramolecular Assemblies based on Glycoconjugated Dyes}

$\pi$-Conjugated molecules can self-assemble in aqueous media due to $\pi$ - $\pi$-stacking and hydrophobic forces. Equipping those molecules with peripheral carbohydrates leads to multivalent assemblies that can bind to receptor proteins on cells. Furthermore the electronic properties of the $\pi$-system makes fluorescent read-out in diagnostic applications possible and some dyes enable the generation of singlet oxygen, which can be used for therapeutic purposes. In this chapter different applications of glycoconjugated dyes are discussed with a special focus on processes involving fluorescent assemblies and singlet oxygen. Fluorescent read-out systems serve to visualize e.g. diseased cells, while singlet oxygen can destroy such cells. 


\subsection{Self-assembly of dyes}

Supramolecular chemistry employs non-covalent interactions, such as hydrogen bonds, van der Waals forces, or $\pi-\pi$ interactions, to reversibly assemble molecules into larger structures [1-4]. Such supramolecular assemblies have been used in a wide range of applications, among them electronic devices [5, 6], biological platforms [7-9], selective catalysts, extracting agents, and gas storage units [4, 10].

Molecules that have connected p-orbitals forming extended linear or cyclic $\pi$-conjugated systems with delocalized electrons are able to self-assemble in aqueous media due to $\pi$ - $\pi$ stacking and hydrophobic forces [11]. To facilitate assembly in water, hydrophilic parts, such as poly(ethylene glycol) chains, charged groups, peptides, or carbohydrates, can be attached to the $\pi$-conjugate, resulting in amphiphilic molecules. Upon self-assembly the hydrophobic parts interact with each other and are shielded by the hydrophilic parts that interact with the surrounding water. The interaction between the aromatic parts of the dyes is mainly due to the quadrupole moments of the $\pi$-conjugated systems [12]. For aromatic rings either parallelly displaced, edge-to-face or sandwich arrangements are known [12]. Sandwich arrangements are only possible in the case of opposed quadrupole moments [13]. Various self-assemblies using monodisperse $\pi$-conjugated dyes have been described, such as thiophenes, $p$-phenyleneethylenes, $p$-phenylenevinylenes, annulenes, porphyrins, phthalocyanines, fluorenes and perylene bisimides [11, 14, 15].

Biomedical applications that rely on targeting cells require recognition moieties on the selfassemblies. Possible moieties are charges, peptides and carbohydrates. While positively and negatively charged molecules interact with cell membranes [16] and secure cell entry, the use of generic electrostatic interactions lacks exact recognition patterns. For a more specific interaction with cells, cell surface receptors can be targeted using for example peptides and carbohydrates as targeting ligands. When dyes are coupled to peptides that are folded into $\alpha$-helices or $\beta$-sheets, final assemblies are determined by the $\pi$-conjugated part and the peptide. Changing a single amino acid can yield different structures [17]. In contrast, when carbohydrates are conjugated to dyes the self-assembled structures are generally unaffected, yet the number, type and position of the connectivity of carbohydrates onto the dyes can affect the assembled structures (Fig. 1.1) [18 20]. Dyes with an amphiphilic character self-assemble in aqueous solutions into organized nanostructures, such as micelles, cylinders, hollow vesicles and polymers [21, 22]. The relative volume ratio between the rigid hydrophobic and the flexible hydrophilic part is determining the nanostructure morphology [23]. Smaller ratios result in more compact structures and higher ratios result in more elongated structures [23].

Assemblies of glycoconjugated dyes are of interest for biomedical applications. When those assemblies are decorated with a multivalent display of carbohydrates, they can be 


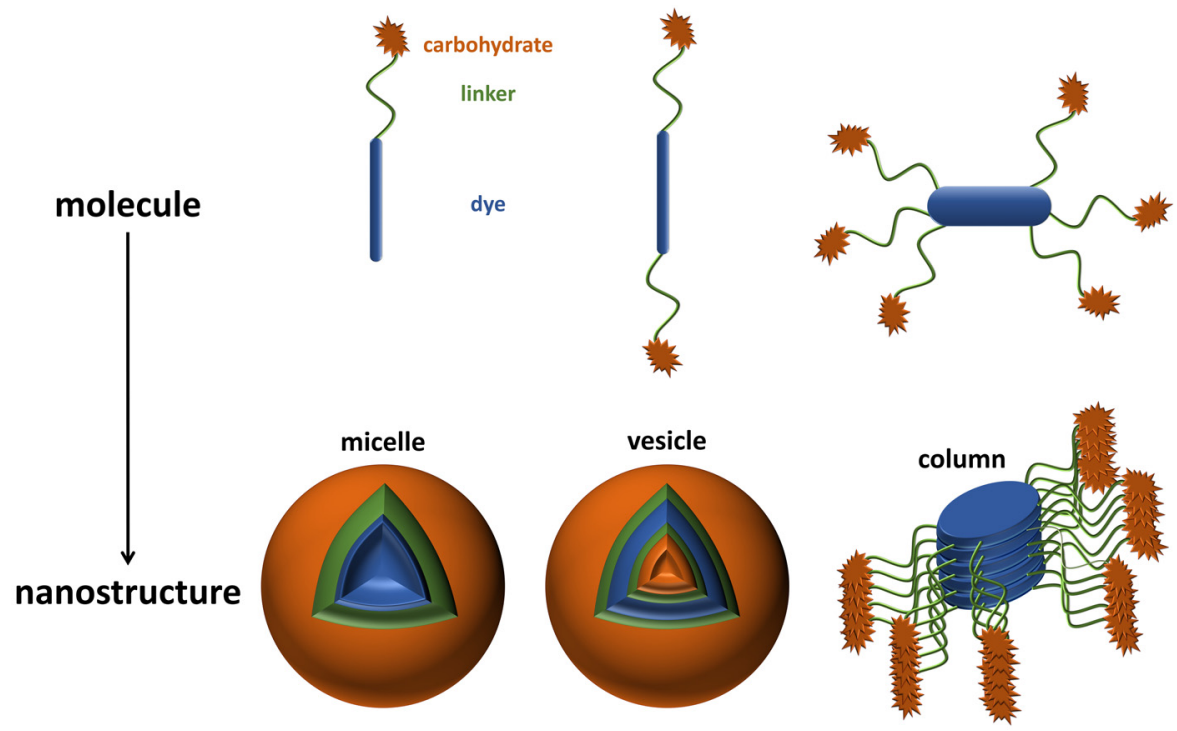

Figure 1.1 - Possible nanostructure morphologies of supramolecular assemblies of glycoconjugated dyes based on the number and orientation of peripheral carbohydrate units. Inspired by [19].

used to target surface receptors of cells. The emissive properties of the assemblies enable non-invasive read-out of the targeting process while appropriate therapeutic elements can be introduced in the assemblies as well.

\subsection{Application of assemblies of glycoconjugated dyes for diagnostics}

In diagnostics sensing [24] and visualization [25] of diseased cells is important. In this section examples using the fluorescence of supramolecular assemblies as a detection method are described. Fluorescence-based methods are an alternative to other methods where supramolecular assemblies have been used, such as magnetic resonance imaging (MRI) [26] and photoacoustic imaging [27].

\subsubsection{Carbohydrate targeting}

Carbohydrate-protein interactions are part of numerous important biological processes, such as cell-cell recognition, cell-matrix interaction as well as viral and bacterial infections [28]. Binding of carbohydrates to proteins is mainly taking place by the formation of hydrogen bonds [29]. The proteins that recognize carbohydrates are called lectins and they are ubiquitously present in nature and can be found in animals, plants and 
bacteria [30]. Lectins bind strongly with carbohydrates, however, they usually bind to two or three carbohydrate motifs. For selectivity studies the plant lectins ConcanavalinA (ConA), extracted from jack beans, and peanut agglutinin (PNA), extracted from peanuts, are often used. The tetrameric ConA is recognizing $\alpha$-D-mannosyl and $\alpha$-D-glucosyl moieties [31], while galactosyl units are recognized by PNA. Disaccharides consisting of the suitable monosaccharides are also recognized by lectins, e.g. maltose by ConA or lactose by PNA [32]. The binding of carbohydrate-conjugated molecules to these lectins is a recognition event that is comparable to the one that occurs between the carbohydrateconjugated molecules and surface receptors on cells. For example, bacteria feature adhesin proteins on their surfaces that can bind to carbohydrates. The FimH adhesin on Escherichia coli (E. coli) bacteria is able to bind to mannose that is usually found in glycoproteins and glycolipids on the surface of target cells [33]. In this way the bacteria are able to adhere for example to the urothelium causing urinary tract infections [34]. Due to the composition of supramolecular assemblies of several units the formed assemblies display the carbohydrates in a multivalent manner. Multivalent display enhances carbohydrate-protein interactions [35].

\subsubsection{Employing fluorescence for diagnostic use}

Fluorescence is interesting for biomedical applications since it allows an easy and noninvasive read-out 24]. Fluorescence is according to the International Union of Pure and Applied Chemistry "the spontaneous emission of radiation (luminescence) from an excited molecular entity with the formation of a molecular entity of the same spin multiplicity" [36]. First, molecular absorption of light energy (photon) at a specific wavelength occurs. After internal non-radiative conversions the photon is emitted at another, usually longer, wavelength (Stoke's shift) (Fig. 1.2a). It is also possible that the energy is lost through non-radiative relaxations and the molecule is returning to the ground state without emitting. The fluorescence quantum yield $\left(\Phi_{F}\right)$ describes the ratio between the number of fluorescence photons emitted and the number of photons absorbed.

The excitation wavelength and emitted light of dye assemblies is depending on the optical bandgap. A variety of fluorescent colours are interesting for parallel detection of different cells. The conjugation of the $\pi$-electrons results in a smaller gap between the highest occupied molecular orbital (HOMO) and the lowest unoccupied molecular orbital (LUMO) compared with molecules only featuring $\sigma$-electrons. The higher the conjugation, the smaller the gap is. The energy for excitation is decreasing with decreasing gap size, which leads to a bathochromic shift in the absorption and fluorescence spectra. This means that by tuning the bandgap the colour of the emitted light can be tuned. Often the exact structure of the aromatic molecule determines the colour of the emitted light. It was shown, for example, in bolaamphilic fluorene-based oligomers that by switching the aromatic 


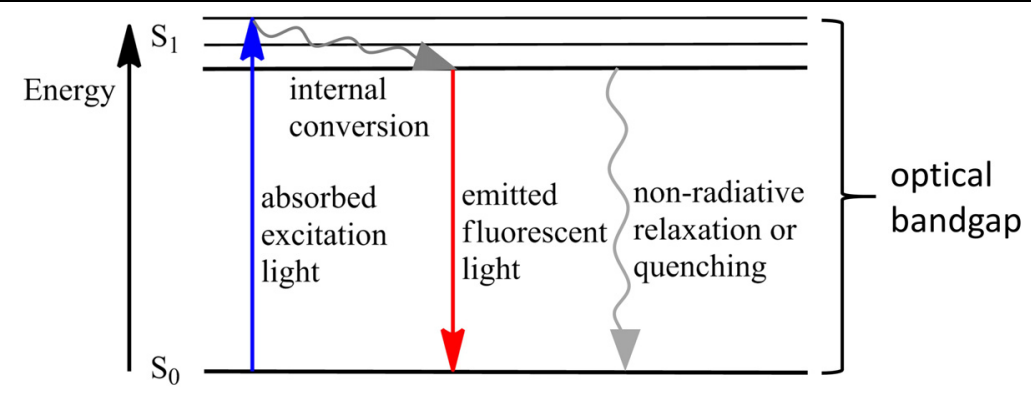

(a)

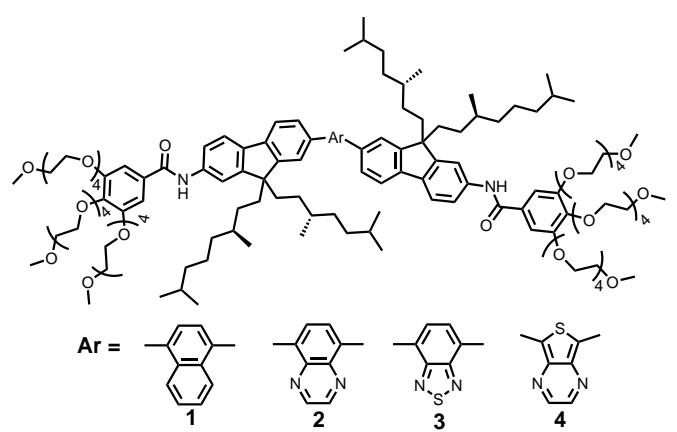

(b)

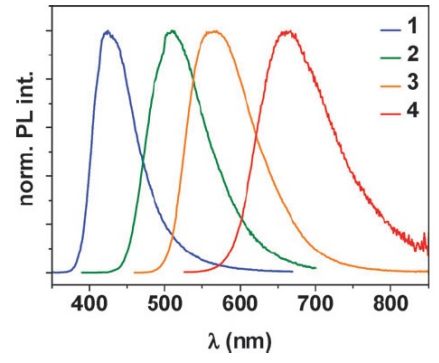

(c)

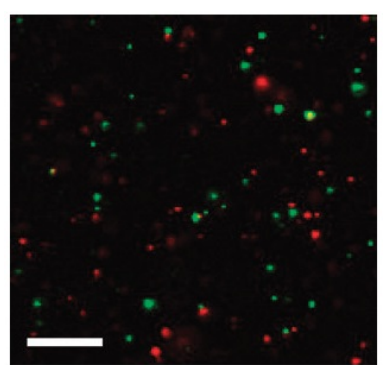

(d)

Figure 1.2 - Simplified Jablonski diagram describing the fluorescence process (a). Chemical structure of bolaamphilic fluorene-based molecule with different aromatic center units (b) [37]. Fluorescence spectra of the molecules in water showing different emission wavelengths (c) [37]. Fluorescence image of a mixture of the molecules $\mathbf{3}$ and 4 (d) [37]. Scale bar is $10 \mu \mathrm{m}$. Reprinted with permission from [37]. Copyright 2009, Royal Society of Chemistry.

unit, located between two fluorenes, from naphthalene, to quinoxaline, benzothiadiazole and thienopyrazine, respectively, blue, green, yellow and red fluorescent self-assembled nanoparticles could be created (Fig. 1.2b- 1.2d) [37]. The self-assembly behaviour was not affected by the exchange of the aromatic unit. Introduction of an azide group to the benzothiadiazole fluorene-based oligomer allowed the pre- and postfunctionalization of the nanoparticles [38], e.g. with mannose and/or biotin for selective binding to proteins, bacteria and streptavidin-covered magnetic beads [38] or with positively charged amine groups for cellular uptake [39].

Quenching describes the loss of fluorescence intensity. Generally, two different mechanisms are present: dynamic and static quenching [24]. In the dynamic quenching the energy of an excited molecule is transferred non-radiatively to another molecule, the quencher [25]. The energy is then either lost as thermal energy or by emission of the quencher (Förster resonance energy transfer - FRET). Charge transfer is another possible mechanism for dynamic quenching. Static quenching or contact quenching happens when molecule and quencher form a complex before the excitation, preventing the absorption and fluorescence process. Aggregation and proximity of planar aromatic dyes can cause quenching [40] known as aggregation-caused quenching (ACQ) and proximity-caused quenching 
(PCQ) [41], which restrict their application in fluorescence imaging. However, when dyes assemble following aggregation-induced emission (AIE) or disaggregation-induced emission (DIE) principles, fluorescence imaging under physiological conditions becomes possible [41]. AIE dyes are non-fluorescent in the molecularly dissolved state, whereas these dyes become fluorescent in the confined state due to hindered intramolecular rotations [4245]. DIE dyes, which show quenching in the aggregated state, become fluorescent upon binding to a biological object, because the aggregation is reduced [41].

\section{Protein sensing using carbohydrate targeting}

The phenomena AIE and DIE can both be used as "turn-on" sensors for the detection of lectins. Important is whether a difference between the bound and the unbound state yields a measurable change in the fluorescence signal.

One of the AIE dyes that is widely used is tetraphenylethene (TPE) [42]. A mannosefunctionalized derivative was able to specifically bind to ConA, even in the presence of another protein (Fig. 1.3a) [46]. The increased blue fluorescent emission was not observed when the molecule was mixed with other proteins, such as PNA, bovine serum albumin (BSA), bandeiraea simplicifolia (BS-I, galactose-binding lectin), thyroglobulin (Tg, glycoprotein), and wheat germ agglutinin (WGA, N-acetyl- $\beta$-D-glucosaminyl residue-binding lectin) [46]. Concerning the structure, the use of a flexible linker between the TPE core and mannose or the increase from four to eight mannose moieties resulted in a higher binding selectivity and stronger fluorescence (Fig. 1.3a) [46]. Other studies showed as well that the length of the linker and the density of the carbohydrates on the assembly can affect the binding to lectins [47]. The influence of the number of mannose units on the binding and therefore the fluorescence intensity was also studied by Han and co-workers by comparing the photophysical properties of the binding of a disubstituted TPE with a glycodendrimeric TPE featuring six mannose units (Fig. 1.3b and 1.3c) [48]. It was shown that the glycoclustered molecule featured a higher binding affinity to ConA [48]. A fluorescent ConA sensor based on DIE was developed by the group of Král (Fig. 1.4a) [49]. In their work mannose-functionalized sapphyrins and porphyrins were showing only weak fluorescence in water due to ACQ. However, upon binding to the lectin ConA the fluorescence was increased because the assemblies became less tight [49]. After the addition of the competitor D-mannose the fluorescence decreased due to the replacement of the ligand in ConA and the re-formation of the dye aggregates [49].

The group of Hatano created a "turn-off" sensor for PNA that was based on a silole-core carbosilane dendrimer, which was peripherally functionalized with lactose (Fig. 1.4b and 1.4c) [50]. In a control experiment with WGA no sensor activity was observed confirming the selctivity of the PNA sensor [50]. 


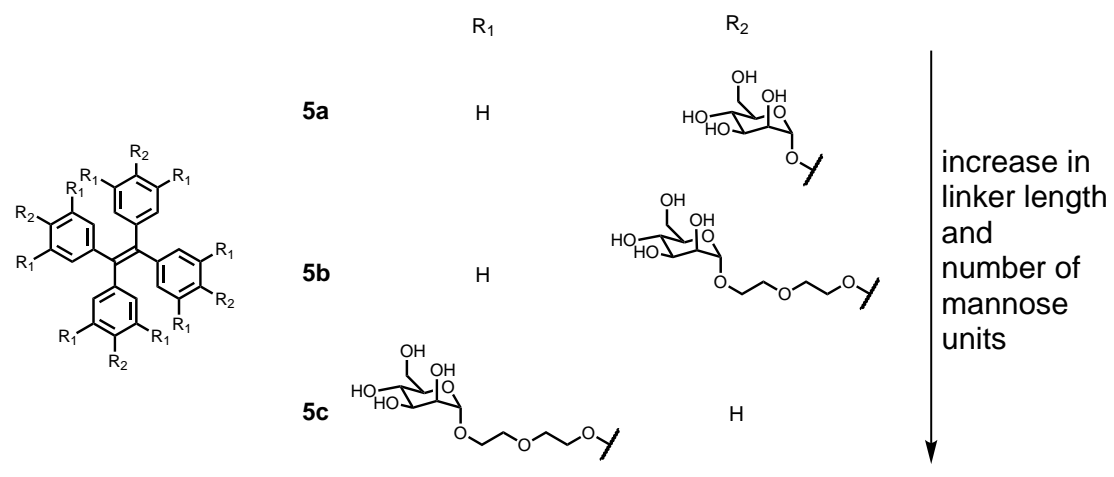

(a)

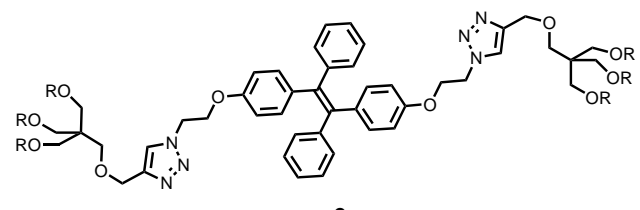

$6 a$

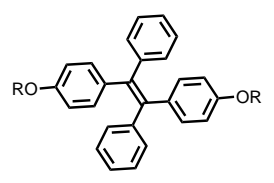

$6 b$

(b)

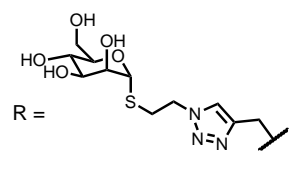

Figure 1.3 - Mannose-functionalized TPE with different linker lengths and different number of mannose moieties (a) [46]. Chemical strcuture of disubstituted TPE and TPEbased glycodendrimer (b) [48]. Illustration of the ConA binding of $\mathbf{6 a}$ and $\mathbf{6 b}$ (left path) and $\beta$-glucosidase inspired hydrolysis of cellobiosyl-TPE (right path) (c) [48]. Reprinted with permission from [48]. Copyright 2010, Royal Society of Chemistry.

Han and co-workers investigated disubstituted cellobiosyl- and lactosyl-TPE for the detection of the enzyme $\beta$-glucosidase [48]. Upon interaction with $\beta$-glucosidase the watersoluble cellobiosyl-TPE is hydrolysed to unsubstituted TPE that aggregates in water into fluorescesent structures (Fig. [1.3c, right path) [48]. The sensor was selective as concluded from a control experiment using lactosyl-TPE that is not hydrolysable by $\beta$ glucosidase [48].

A further diagnostic method is a displacement assay that is composed of glycoconjugates and corresponding lectins, which are replaced by other proteins yielding a change in fluorescent signal [51]. BS-I, BSA, cytochrome C (Cyto), histone (His), PNA, soybean agglutinin (SBA), Tg, and WGA were tested to what extent they cause quenching when these proteins were added to solutions containing mannosyl-TPE (Fig. 1.3a) and ConA or $\alpha$-lactopyranoside conjugated TPE with RCA120 (RCA120: ricinus communis agglutinin, a galactose-binding lectin) (Fig. 1.4d) [51]. While BS-I, Cyto, SBA and Tg showed for all combinations at least $40 \%$ quenching, His showed almost no quenching and BSA, PNA 


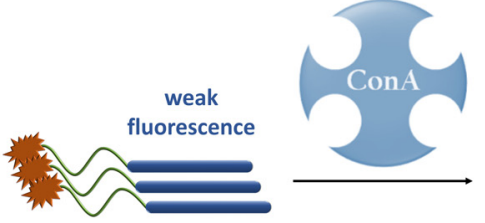

(a)

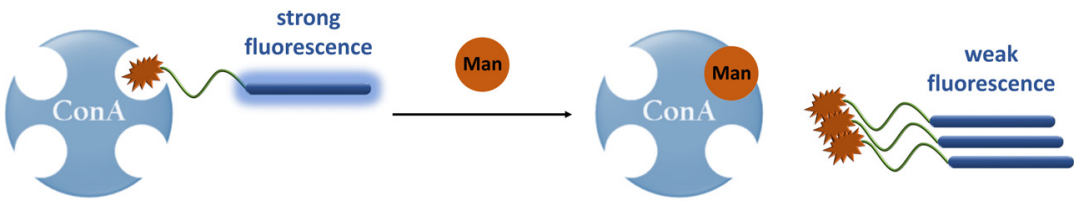

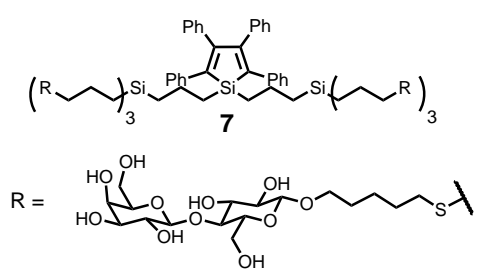

(b)

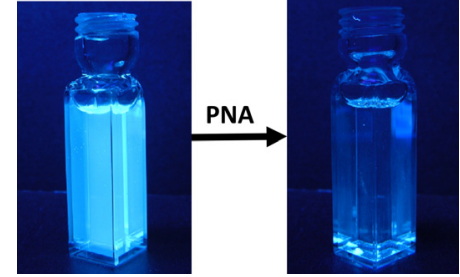

(c)

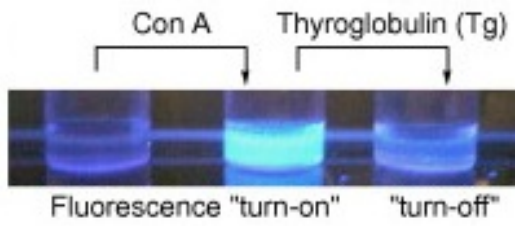

(d)

Figure 1.4 - Interaction of glycoconjugated, weakly fluorescent sapphyrin and porphyrin aggregates with ConA results in stronger fluorescence and the displacement of the glycoconjugate with mannose decreases the fluorescence intensity again (a) [49]. Chemical structure of the silole-core carbosilane dendrimer peripherally functionalized with lactose (b) [50]. Photograph of PNA "turn-off" sensor using 7 (c) [50]. Reprinted with permission from [50]. Copyright 2009, Elsevier. Photograph showing the idea for the displacement assay using mannose-functionalized TPE (d) [51]. Reprinted with permission from [51]. Copyright 2010, Elsevier.

and WGA showed different results for the different sensor combinations with always less quenching for lactosyl-TPE/RCA120 [51]. The differently observed fluorescence quenching patterns could be used to identify those proteins.

Not only proteins but also disease causing microorganisms can be detected by sensors composed of glycoconjugated TPE. Equipping TPE with 6'-sialyllactosyl moieties allowed the binding to the hemagglutinin (HA), a glycoprotein located on the surface of influenza viruses [52]. Comparable to the sensors described above the fluorescence intensity is increasing with increasing virus concentration [52]. A similar study with lactosyl-TPE did not show this effect [52]. On the other hand lactosyl-TPE has been found to be a sensor for cholera toxin detection [53].

In a hemagglutination inhibition assay with ConA Lee and co-workers showed the influence of the self-assembled nanostructure of glycoconjugated rod-coil amphiphiles on the binding affinity [54]. While the short-coiled amphiphile assembled into a vesicle, the long-coiled one showed spherical micellar structures and in case of a twin-rod segment a cylindrical micelle was formed [54]. From those three structures the spherical micelles showed the highest binding affinity for ConA [54]. 


\section{Bacteria sensing using carbohydrate targeting}

Fluorescence microscopy is a non-invasive technique suitable to study samples in vitro, such as cells or bacteria. Supramolecular assemblies that are intensely emissive upon binding to the object, but with a low level of background fluorescence, are most interesting for those applications.

Disc-shaped dyes have been used by Brunsveld and co-workers for fabricating fluorescent nanostructures that can be used for interaction with bacteria (Fig. 1.5) [55]. Their discotics consist of an extended aromatic core of three 2,20-bipyridine-3,30-diamines linked to a central benzene-1,3,5-tricarbonyl unit (Fig. 1.5a) [55]. These discotics can self-assemble in water to form a fluorescent columnar polymer (Fig. 1.5b) [55]. The peripheral hydrophilic ethylene glycol chains provide water-solubility and shield the hydrophobic core to promote hydrogen bonding and $\pi$ - $\pi$-stacking between adjacent discotics. Functionalization of the peripheral ethylene oxide tails with mannose groups led to selective binding of the supramolecular polymers to E. coli bacteria (Fig. 1.5c) [55]. Binding to E. coli strains took place when the polymer consisted of a mixture of unfunctionalized and mannose-featured monomers (down to $1 \%$ ) [55]. Facile change of the functionalized discs allowed the use of the supramolecular columns for other purposes, such as introduction of peripheral amine groups for cellular uptake [56] or introduction of peripheral biotin groups for protein binding [57].

The group of Lee used similarly structured amphiphiles to control the fiber length [58]. By co-assembly of carbohydrate-functionalized rod-like dyes based on pyrene units or pentaphenylenes the length of the nanofibers could be tuned (Fig. 1.6a) [58]. With

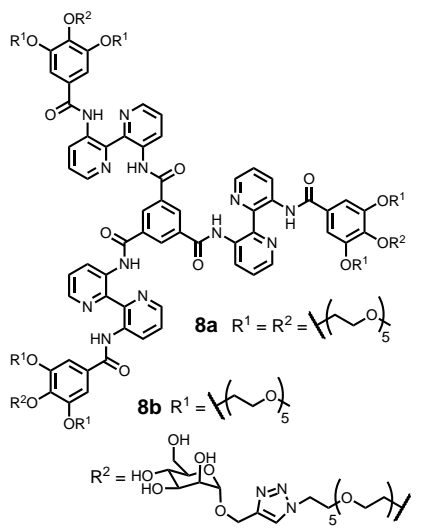

(a)

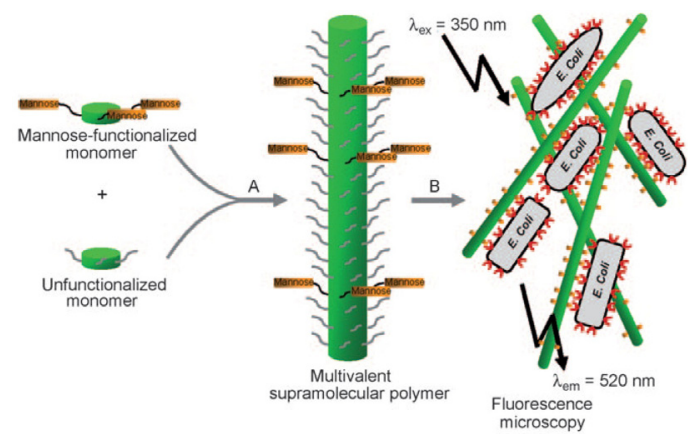

(b)

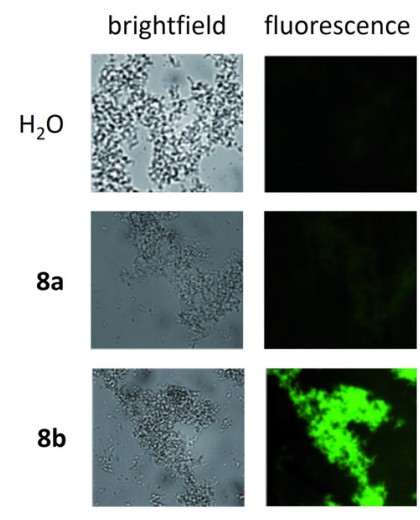

(c)

Figure 1.5 - Chemical structure of discotic molecules with and without mannose functionality (a) [55]. Schematic illustration of polyvalent columnar supramolecular polymers as well as interaction with E. coli (b) [55]. Microscopy pictures in brightfield and fluorescence mode of $E$. coli incubated with water, inert discotic molecule $\mathbf{8 a}$, and mannose discotic molecule $\mathbf{8 b}$ (c) [55]. Reprinted with permission from [55]. Copyright 2009, John Wiley and Sons. 


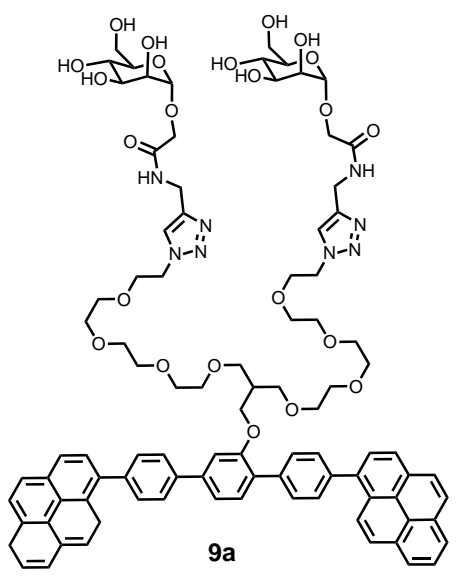

(a)

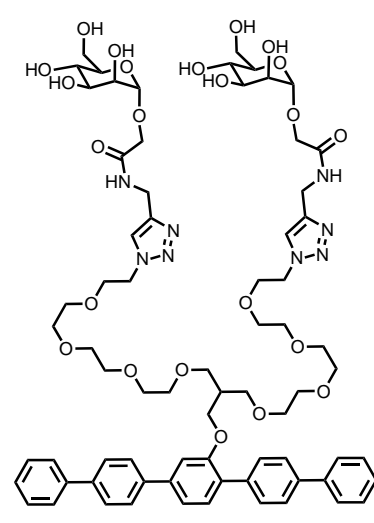

9b

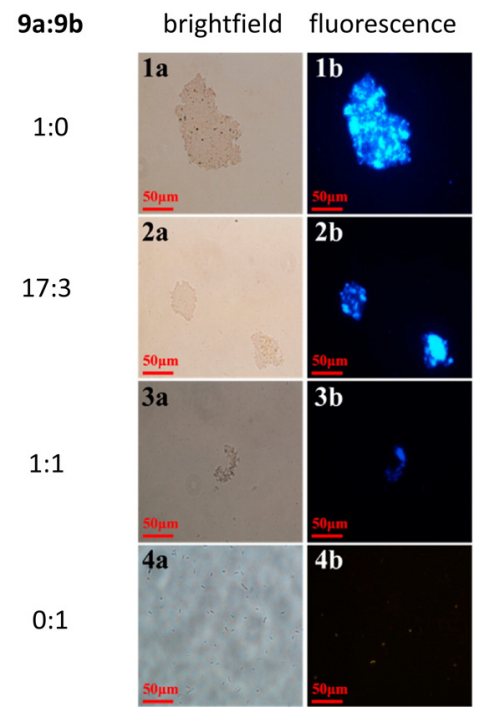

(b)

Figure 1.6 - Chemical structure of mannose-functionalized amphiphiles based on perylene or pentaphenylene (a) [58]. Brightfield and fluorescence microscopy images show colocalization of $E$. coli with nanofibers formed of $\mathbf{9 a}$ and $\mathbf{9 b}$ (b) [58]. Reprinted with permission from [58]. Copyright 2012, American Chemical Society.

decreasing 9a content and therefore decreasing fiber length the size of bound bacterial clusters decreased, demonstrating the importance of the length of mannose nanofibers in the agglutination of bacterial cells (Fig. 1.6b) [58].

The connection between carbohydrate and aromatic part can also be organized noncovalently by assembly via oligonucleotide sequences [59]. The fibers formed by the DNA-dendron are decorated with mannose and therefore can be recognized by E. coli bacterial strain [59]. Although the molecules contained an aromatic part, detection by fluorescence was in this case only possible by loading of the assembled nanostructures with a fluorescent cargo (Nile Red and Syto9) [59].

The binding of fluorescent carbohydrate-functionalized assemblies to bacteria can be visualized by fluorescence imaging, but can also be used to prevent bacterial infections. Triazatruxene-based glycocluster were used to inhibit E. coli-induced haemagglutination [60].

\section{Cell sensing using carbohydrate targeting}

Since eukaryotic cells are bigger in size than bacteria, not so many fluorescent cell-dye aggregates are observed, but the fluorescence can be usually localized inside the cells in different cell organelles. While examples for sensing bacteria are mainly revolving around the binding of mannose moieties, sensing cells allows a wider range of carbohydrates. 
Wang and co-workers were able to synthesize and self-assemble perylene bisimides carrying glycodendrimers with either 12 or 18 mannose moieties (Fig. 1.7a and 1.7b) |61, 62]. Upon self-assembly in water the fluorescence of the dyes was partly quenched [61, 62]. However, when these assemblies interacted with murine macrophage cells strong fluorescence inside the cells in endosomal vesicles was detected as a result from deaggregation of the assemblies (Fig. 1.7c and 1.7d) [61, 62]. These observations demonstrate the use of these assemblies as "turn on" sensors. Although both molecules feature perylene bisimides as the $\pi$-conjugated part, different fluorescence colours and binding affinities were observed, presumably caused by the different substitution pattern on the perylene core. While the bay-substituted perylene bisimide derivative with 12 mannose units gave a binding constant to ConA of $8.2 \cdot 10^{5} \mathrm{M}^{-1}$ and displayed red fluorescence $\left(\lambda_{e m}=610 \mathrm{~nm}\right)$, the other, imide-functionalized derivative with 18 moieties showed a binding constant to ConA of $3.8 \cdot 10^{7} \mathrm{M}^{-1}$ and displayed green fluorescence $\left(\lambda_{e m}=535 \mathrm{~nm}\right)[61,62]$.

The fluorescence of the assemblies can also be used to visualize the uptake and follow the localization in the cells before the actual treatment. Vicente and co-workers showed

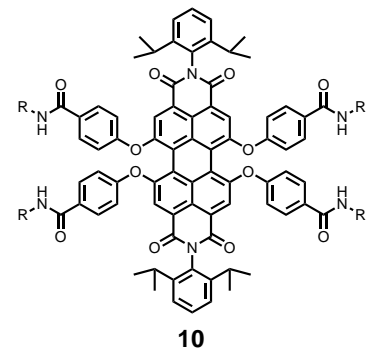

(a)
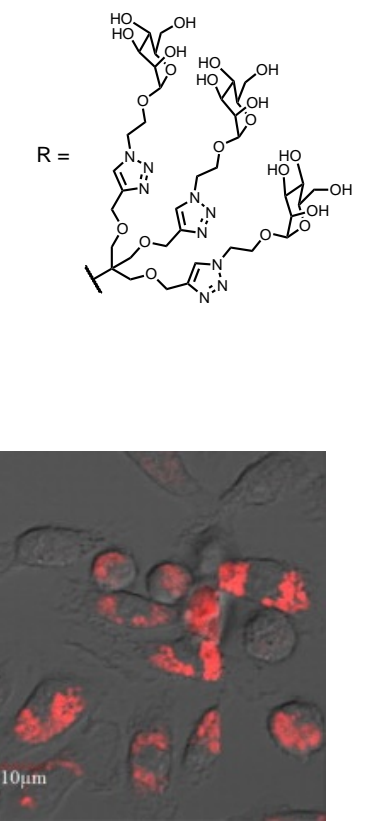

(c)
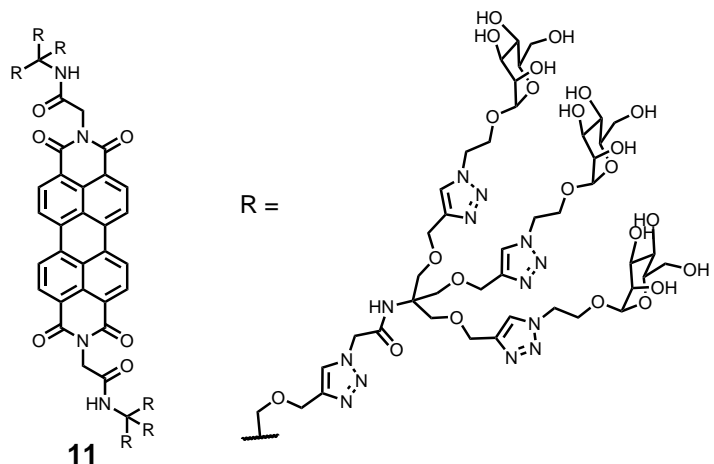

(b)

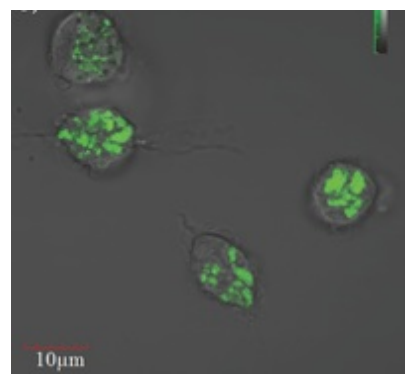

(d)

Figure 1.7 - Chemical structures of glycodendrimeric functionalized perylene-bisimides with the functionalization at the bay region (a) [61] or at the imide position (b) [62]. Adapted from the given sources. Confocal microscopic images of murine macrophage cells after incubation with the molecules in buffer at $37{ }^{\circ} \mathrm{C}$ for $1 \mathrm{~h}$ : (c) incubation with 10 [61], (d) incubation with 11 [62]. Reprinted with permission from [61]. Copyright 2014, Elsevier. Reprinted with permission from [62]. Copyright 2014, John Wiley and Sons. 
that galactose- and lactose-conjugated monosubstituted tetraphenylporphyrins were found mainly in the endoplasmic reticulum, while the more hydrophilic tetragalactose-porphyrin accumulated within the lysosomes of human carcinoma cells (HEp2) [63]. The uptake of the molecules into the cells was determined by their hydrophilicity [63]. Addition of four $\beta, \beta$ 'fused benzene rings lead to a more hydrophobic platform which resulted in a higher uptake than the "normal" porphyrins [63].

A glucose-conjugated zinc phthalocyanine dye that self-assembled in water was used in liver tumor-bearing mice [64]. The photophysical properties of this dye allowed for nearinfrared imaging of the distribution of the assemblies in the mouse organs, such as lung, kidney, and liver [64]. Histological experiments showed no damage to the organs confirming the safety of the NIR-probe [64].

Not only examples where mono- or oligosaccharides on the assemblies target cells have been described in literature, but also polysaccharides have been used. Cervical cancer cells (HeLa) were imaged using TPE-labelled chitosan [65, 66]. After internalization the chitosan chains formed microparticles, which triggered the AIE properties and as a result bright blue fluorescence was observed in the cells [65]. The authors were able to show that by co-culturing stained and unstained cells (of two different cell types for distinguishable morphologies) no leakage was detected [65]. Furthermore the microparticles kept their fluorescence level for 15 cell passages, making the assemblies suitable as long term fluorescent trackers [65].

\subsection{Application of assemblies of glycoconjugated dyes for therapeutics}

Self-assembled structures are not only useful to image bacteria and cells, but can also be used to treat a disease. For example, the use of singlet oxygen is of interest for cancer treatment. Further diseases that can be treated are age-related macular degeneration and skin conditions, e.g. acne or psoriasis [67, 68].

\subsubsection{Employing singlet oxygen for therapeutic use}

Singlet oxygen is created when an electron in the highest occupied molecular orbital (HOMO) of molecular oxygen is flipped (Fig. 1.8a). There are two electron configurations for singlet oxygen $\left({ }^{1} \Delta_{g}\right.$ and $\left.{ }^{1} \Sigma_{g}^{+}\right)$, but due to a longer lifetime usually only the one with the paired electrons is discussed $\left({ }^{1} \Delta_{g}\right)$ [69]. Singlet oxygen is generated in the presence of photosensitizers (Fig.1.8b). For the energy transfer to molecular oxygen an excited triplet 

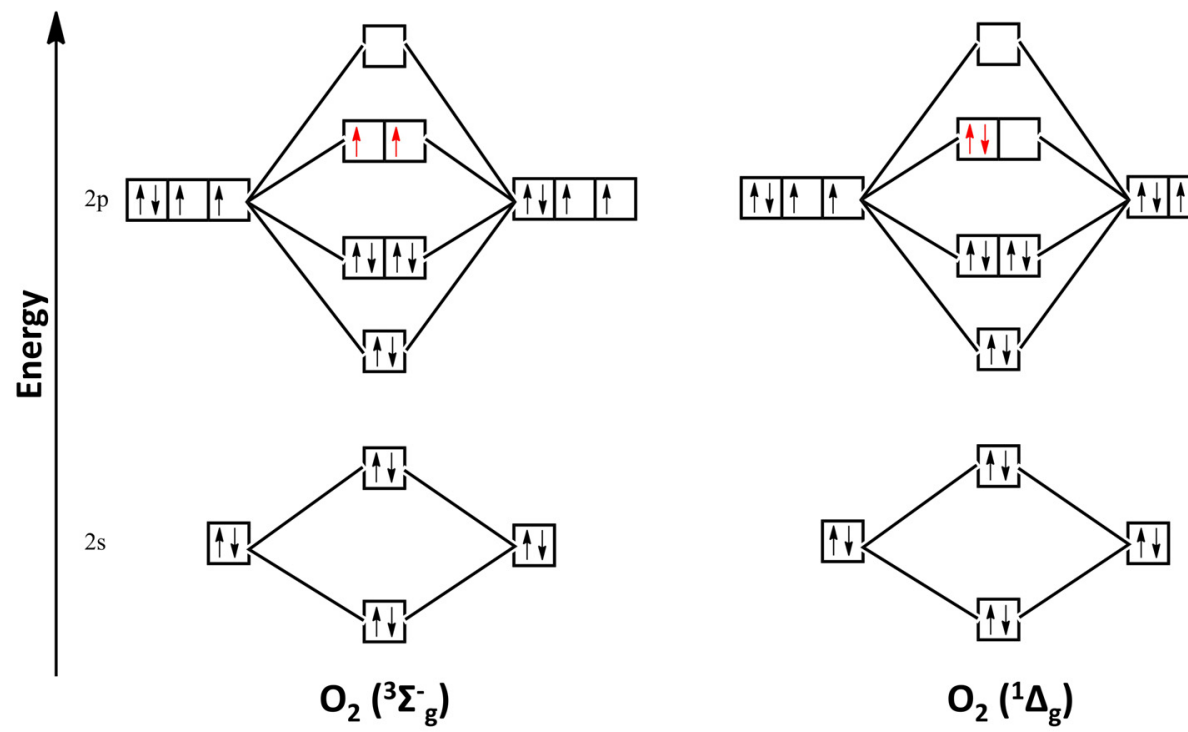

(a)

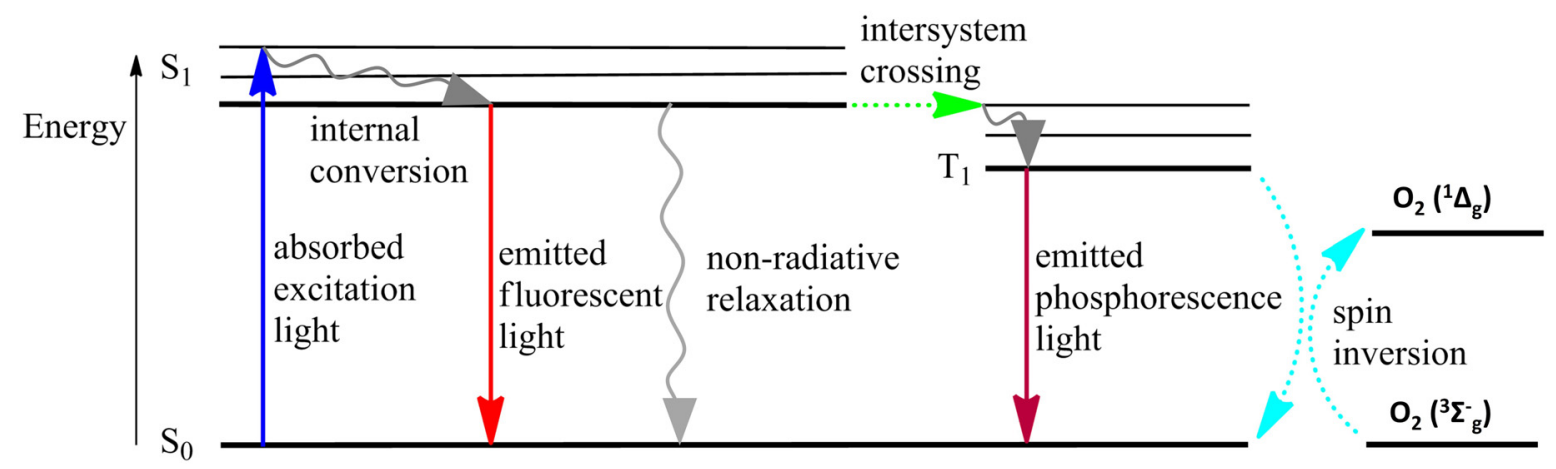

(b)

Figure 1.8 - Electron configuration of the molecule orbitals of stable triplet molecular oxygen (left) and reactive singlet molecular oxygen (right) (a). Simplified Jablonski diagram describing the connection between fluorescence process, phosphorescence process and singlet oxygen generation (b).

state is necessary [70]. In the singlet state the oxygen molecule is highly reactive. Together with other oxygen-based reactive species (ROS) singlet oxygen is a cause of oxidative stress, which describes the imbalance between the production of radicals and the cell's ability to eliminate them [71]. As a consequence, cellular biomolecules, such as DNA, proteins, sugars, and lipids, become heavily damaged [72]. Therefore oxidative stress can lead to various diseases in living organisms. These diseases include atherosclerosis, cardiovascular disease, rheumatoid arthritis, neurological diseases (e.g. Parkinson's) and a wide range of tumour types [71, 72]. Yet, singlet oxygen is also used to destroy malignant cells. The advantages of such treatment are low residual toxicity and low side-effects. Singlet oxygen is forming secondary ROS, oxidation products with surrounding organic molecules or collids with another singlet oxygen molecule transforming into two triplet oxygen molecules by electron exchange without spin inversion under light emission [73]. 


\section{Photodynamic therapy (PDT)}

Photodynamic therapy uses a light-excited photosensitizer (PS) in an oxygen-rich environment to cause cell death for localized medical treatment in cancer therapy. The excited PS reacts either with surrounding organic substrates, usually mediated by free radicals or electron transfer processes (type I photochemical reaction), or with oxygen species generating ROS (type II) [73]. The type of cell death depends on the localization of the PS inside the cell: mitochondrial-localized PS may induce apoptosis and PS in lysosomes and cell membranes can cause necrosis [67, 74]. The advantages of PDT in comparison with conventional cancer treatments are: non-invasive, moderate side-effects, reduced long-term morbidity, selectivity and low equipment costs [74-76]. Since singlet oxygen can only diffuse $0.02 \mu \mathrm{m}$ cell death is only happening within the penetration depth of the light that is necessary to activate the PS (usually not more than a few millimeters) [67, 68, 77 ]. Interesting cancer forms for this kind of therapy are therefore types of skin cancer or other tissue accessible without surgery, e.g bronchial tissue [68, 74, 77].

The PS to be used should have no or low dark toxicity and high phototoxicity. Porphyrins, phthalocyanines and related dyes are very often used as photosensitizers [70, 74]. They are capable of creating a long-living excited triplet state necessary for the singlet oxygen production [70]. Their large $\pi$-systems allow for the production of the singlet oxygen using light in the near-infrared region, which is preferred when working with biological tissues. High selectivity for tumor tissue is another requirement for effecient treatments. Since cancer cells usually overexpress sugar receptors, the use of glycoconjugated molecules has an advantage [76]. The photodynamic activity of a PS is related to several aspects of its structure: carbohydrate moiety, type of photosensitizer, position and type of attachment of sugars to core [67].

The specificity of a photosensitizer and its penetration into cancerous cells are crucial for achieving tumor necrosis. The selection of PS such as porphyrin derivatives by tumor cells thus depends to a large extent on their ability to interact with the biological membrane. Maillard and Rosilio designed a mannose-conjugated porphyrin that was incorporated in liposome membranes as carriers (Fig. 1.9a) [78]. Retinoblastoma cells express a mannosebinding protein. Model studies with immobilized ConA layers [79] and phospholipid monoand bilayers [80] showed the feasibility of interaction and penetration of cell membranes. Later on the authors could show that glycoconjugated porphyrins could be indeed used for photocytotoxic experiments with retinoblastoma tumour cells (Y79) and colorectal cells (HT29) and in in vivo studies [81, 82].

In contrast to the usually used pattern of meso-substituted porphyrins with linkers between porphyrin core and carbohydrate Vedachalam and co-workers used galactofused porphyrins [83]. Especially the glycofused tetrakis-porphyrin showed good uptake and phototoxicity (Fig. 1.9b) [83]. Cancer cells, here HeLa and colon cancer (HCT116) cells, 
were killed caused by the presence of the porphyrin [83]. The cell viability decreased with increasing light dose [83]. The authors emphasized that their molecules were mainly found in the lysosome of the cells, in contrast to the usual localization in mitochondria or endoplasmic reticulum [83].

A study comparing three different carbohydrates (mannose, galactose, lactose) attached to phthalocyanines showed the best photodynamic activity in human colon tumour cells (HT29) in the case of the mannose derivative (Fig. 1.9c) [84]. Interestingly the intracellular concentration of the other two derivatives was higher, so that the effect cannot be attributed to a higher uptake [84]. Furthermore the study showed that a triazole group located next to the sugar in the molecule can have a negative influence on the photodynamic activity [84]. It might sterically hinder the efficient recognition of the carbohydrates [84].

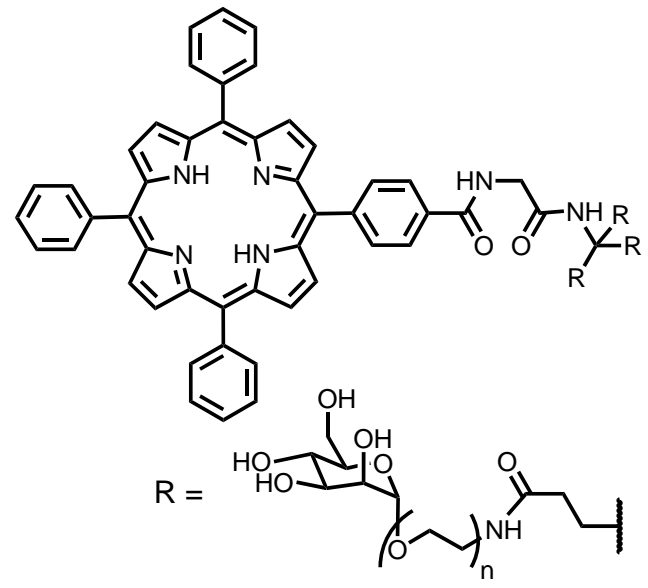

(a)

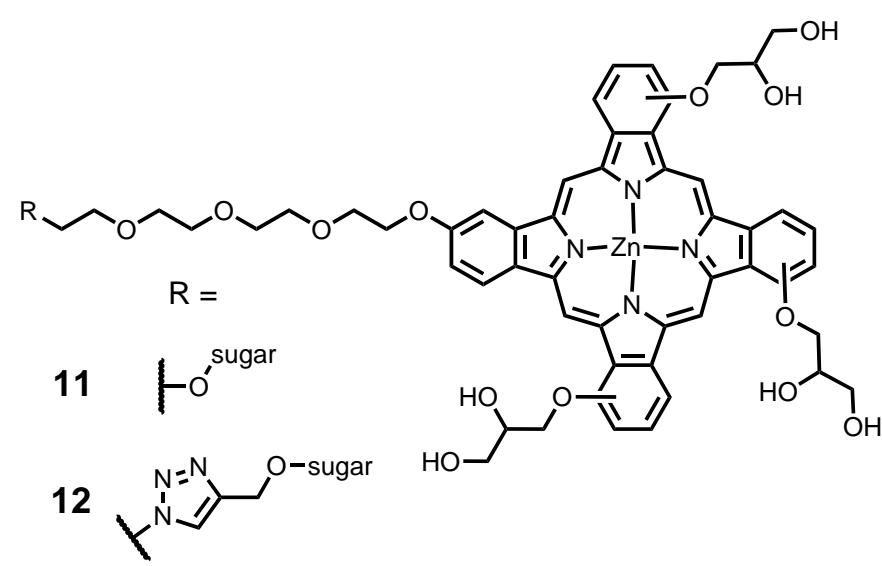

(c)

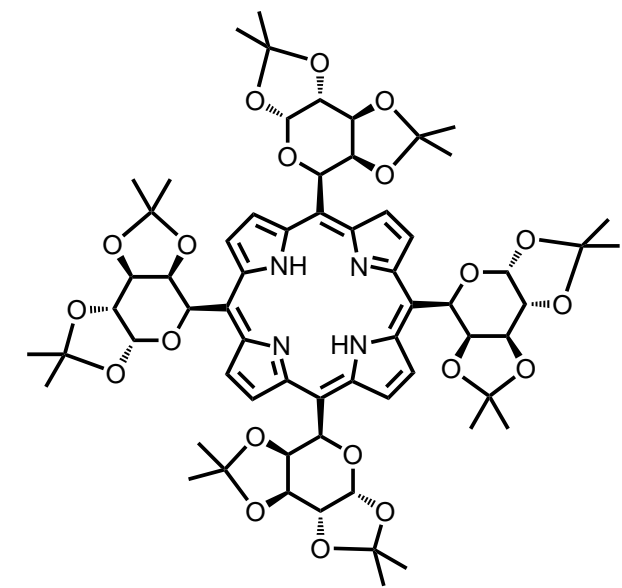

(b)

Figure 1.9 - Chemical structures of glycodendrimeric phenylporphyrins with different linker lengths $(\mathrm{n}=1$ or $\mathrm{n}=2$ ) (a) [78], of galactose-conjugated tetrakis-porphyrin (b) [83], of monoglycoconjugated phthalocyanines with different types of linkers $(\mathrm{R})$ and carbohydrates (mannose, galactose, lactose) (c) [84], and of a galactodendritic phthalocyanine featuring 16 moieties (d) [85]. Structures are adapted from the given sources. 
Not only the type of carbohydrate or linker has an influence on the photodynamic ability, but also the number of attached side chains to the dye can be important. In comparison with tetrasubstituted phthalocyanines monoglycoconjugated derivatives exhibited a higher cellular uptake, lower aggregation tendency and higher in vitro photocytotoxicity with $\mathrm{IC}_{50}$ values as low as $0.9 \mu \mathrm{M}$ [86]. In contrast, the successful treatment of human bladder cancer cells with a 16-galactodendritic phthalocyanine with $\mathrm{IC}_{50}$ values of about $3 \mu \mathrm{M}$ has been reported (Fig. 1.9d) [85].

Glucose transporters (GLUT) are generally up-regulated on tumor cells, therefore the conjugation of glucose to dyes can be beneficial. Interestingly a fully protected glucoseconjugated zinc (II) phthalocyanine showed higher uptake and photodynamic cytotoxicity in human breast adenocarcinoma cells (MCF-7) than its unprotected equivalent [87]. The authors attribute this fact to stronger aggregation in the unprotected molecule, although it showed higher water solubility [87]. The stronger aggregation is presumably related to intermolecular hydrogen bonding [87].

Aggregation, in general, is a problem for PDT photosensitizers since it leads to quenching, not only of the fluorescence but also of the singlet oxygen yield. Interestingly it was observed that a nonhydrolysable thioglycoconjugated porphyrinoid had a quenched fluorescent signal in water, but uptake in breast cancer cells lead to disaggregation and therefore increased fluorescence and probably also increased photodynamic activity [88]. This behaviour is similar to the DIE fluorescence "turn-on" protein sensors in section 1.2.2. A new research line in PDT to overcome the limitation of small tissue penetration depth is the adoption of two-photon absorption processes in which two photons are absorbed simultaneously and thus enable a greater spatial resolution [89]. The PS necessary for this technique feature the conjugation of two $\pi$-conjugated molecules, e.g. porphyrinporphyrin [89] or porphyrin-triphenylamine [90].

Contrary to the approaches of maximizing the singlet oxygen yield are methods to suppress photoactivity [91]. Fluorescence imaging of tumors using porphyrins can else lead in case of high photooxidative activity to skin sensitizing [91].

\section{Photodynamic antimicrobial chemotherapy (PACT)}

The treatment of bacterial, fungal, parasitic, and viral infections with singlet oxygen is called photodynamic antimicrobial chemotherapy (PACT) [74]. PACT is especially interesting for drug-resistant organisms [74]. The risk of resistance development for PACT is unlikely since ROS are interacting with different cell structures and via various metabolic pathways [74]. Due to the light application PACT is especially interesting for localized infections of the skin and the oral cavity [74].

For a successful treatment of bacterial infections the PS need to accumulate in or at the 
cytoplasmic membrane since corruption of the membrane leads to irreversible damage of the bacteria cell [92]. While Gram $(+)$-positive bacteria feature a thicker, but porous cell wall, which enables the uptake of PS, Gram(-)-negative bacteria have an outer membrane with only narrow channels, which prevent the uptake of the usually quite big PS [92]. Photoinactivation of Gram(-)-negative bacteria has been reported especially with cationic PS [92 95], while Gram(+)-positive bacteria have been also treated by anionic or neutral, glycoconjugated molecules [96].

The photoinactivation of Herpes simplex virus in Vero cells using glycoporphyrins has been reported [97]. In this study acetylprotected and unprotected glycoporphyrins were tested with the unprotected ones given the better results [97]. Some of the tested compounds showed antiviral activity far below their maximum noncytotoxic concentrations which is desirable to protect the surrounding cells [97].

Not only infections can be treated by employing PS but also the preparation of photobactericidal material is possible following the same principles [98]. Acetylenic phenyltritolylporphyrin was coupled to azido cellulose using "click chemistry" and the success of the reaction was proven by AFT-FTIR [98]. White light irradiation of the fabric resulted in an $80 \%$ decrease of colony forming units of the Gram $(+)$-positive bacteria Staphylococcus aureus (S. aureus) and Gram(-)-negative bacteria E. coli [98]. Untreated fabric did not show this effect and also no dark toxicity was found [98]. In a similar way porphyrin-cellulose nanocrystals were prepared [99]. The nanocrystals showed excellent photoinactivation of Mycobacterium smegmatis and $S$. aureus and moderate photoinactivation of E. coli [99]. The modificated cellulose particles could be e.g. used as coatings in the health care and food preparation industries [99].

\subsubsection{Theranostics}

Theranostics combines diagnostic and therapeutic properties in one system [100, 101]. The advantage is that only one system is needed and this prevents differences in biodistribution and selectivity and supplies information about the trafficking pathways and the therapeutic efficiency [100]. Next to the combination of diagnostic and therapeutic properties also the combination of several therapeutic approaches for combined therapy has been reported, which is especially interesting for cancer treatment, e.g. combination of chemotherapeutical and phototoxic treatment [102, 103].

The photosensitizers used in PDT are usually also fluorescent. A combination of both imaging and PDT treatment would be therefore feasible [67]. Furthermore the tetrapyrrolics are able to coordinate metal ions, so that the application of radioimaging, e.g. PET, would be possible [67]. However, in most cases the two functionalities originate from different molecules that are coupled covalently or non-covalently. 
The group of He reported a theranostic system where two molecules with each their own diagnostic or therapeutic input assemble into one ensemble [104]. A glycoconjugated, red-emitting dicyanomethylene and a singlet-oxygen producing diazobenzene-containing poly ( $p$-phenylethynylene) were interlocked [104]. Upon interlocking they were suppressing each others diagnostic and therapeutic property, respectively [104]. When the glycoprobe of the ensemble is recognized by its transmembrane receptors on cancer cells, the ensemble is unlocked and both, fluorescence and ROS production, were activated [104]. It was shown that the effect was smaller when the specific transmembrane receptors were absent on the cancer cells [104].

\subsection{Outline of thesis}

In this thesis supramolecular assemblies of two different dyes, equipped with monosaccharides, are studied for labelling and/or photodynamic treatment of bacteria. In chapters 2,4 zinc porphyrins are described while in the chapters 5 and 6 phthalonitriles are studied.

Chapter 2 describes the synthesis and characterization of four different zinc porphyrins. Using microwave-assisted copper(I)-catalyzed Huisgen cycloaddition glycoconjugated and non-glycoconjugated porphyrins are synthesized. The synthesized porphyrins do not only differ in the type of sugar but also in the number of attached side chains. The influence of those differences on photophysical properties and assembly sizes is investigated in chapter 3 where the self-assembly of the synthesized porphyrins in water is in the focus of interest. The extended $\pi$-system of the porphyrins can be used for singlet oxygen production. In chapter 4 the ability to produce singlet oxygen and the bactericidal properties of the porphyrins are studied. Furthermore the binding properties between glycoconjugated porphyrins and lectins are investigated.

Chapter 5 presents a new class of AIE dyes based on phthalonitrile derivatives. The photophysical properties and the structure of the assemblies are discussed with a focus on whether the peripheral substitution influences the photophysical properties and assembly sizes. The possibilities to use the peripheral mannose of the assemblies of thiophthalonitrile dyes for targeting of bacteria and proteins are demonstrated in chapter 6. Studies on the selectivity and reversibility as well as the influence of the mannose density in the assemblies and the assembly concentration are discussed. 


\subsection{Bibliography}

[1] Lehn, J.-M. Angew. Chem. 1988, 100, 91-116.

[2] Lehn, J.-M. In Supramolecular Chemistry: Concepts and Perspectives; Lehn, J.-M., Ed.; Wiley-VCH, 1995.

[3] Steed, J. W.; Atwood, J. L. In Supramolecular Chemistry; Steed, J. W., Atwood, J. L., Eds.; Wiley, 2009; Vol. 2; p 1002.

[4] Gloe, K.; Gloe, K.; Heßke, H.; Lindoy, L. F. Wiss. Z. TU Dresden 2007, 56, 32-38.

[5] Hoeben, F. J. M.; Jonkheijm, P.; Meijer, E. W.; Schenning, A. P. H. J. Chem. Rev. 2005, $105,1491-1546$.

[6] Miyashita, N.; Kurth, D. G. J. Mater. Chem. 2008, 18, 2636-2649.

[7] Brinkmann, J.; Cavatorta, E.; Sankaran, S.; Schmidt, B.; van Weerd, J.; Jonkheijm, P. Chem. Soc. Rev. 2014, 43, 4449-4469.

[8] Sankaran, S.; Kiren, M. C.; Jonkheijm, P. ACS Nano 2015, 9, 3579-3586.

[9] An, Q.; Brinkmann, J.; Huskens, J.; Krabbenborg, S.; de Boer, J.; Jonkheijm, P. Angew. Chem. Int. Ed. 2012, 51, 12233-12237.

[10] Drain, C. M.; Varotto, A.; Radivojevic, I. Chem. Rev. 2009, 109, 1630-1658.

[11] Kaeser, A.; Schenning, A. P. H. J. Adv. Mater. 2010, 22, 2985-2997.

[12] Hunter, C. A.; Sanders, J. K. M. J. Am. Chem. Soc. 1990, 112, 5525-5534.

[13] Martinez, C. R.; Iverson, B. L. Chem. Sci. 2012, 3, 2191-2201.

[14] Görl, D.; Zhang, X.; Würthner, F. Angew. Chem. Int. Ed. 2012, 51, 6328-6348.

[15] Drain, C. M.; Smeureanu, G.; Patel, S.; Gong, X. C.; Garno, J.; Arijeloye, J. New J. Chem. 2006, 30, 1834-1843.

[16] Bristow, C.-A.; Hudson, R.; Paget, T. A.; Boyle, R. W. Photodiagn. Photodyn. 2006, 3, $162-167$.

[17] Lehrman, J. A.; Cui, H.; Tsai, W.-W.; Moyer, T. J.; Stupp, S. I. Chem. Commun. 2012, 48, 9711-9713.

[18] Titov, D. V.; Gening, M. L.; Tsvetkov, Y. E.; Nifantiev, N. E. Russ. Chem. Rev. 2014, 83, $523-554$.

[19] Lim, Y.-B.; Moon, K.-S.; Lee, M. Chem. Soc. Rev. 2009, 38, 925-934.

[20] Percec, V. et al. J. Am. Chem. Soc. 2013, 135, 9055-9077.

[21] Ryu, J.-H.; Hong, D.-J.; Lee, M. Chem. Commun. 2008, 1043-1054.

[22] Krieg, E.; Bastings, M. M. C.; Besenius, P.; Rybtchinski, B. Chem. Rev. 2016, 116, 24142477.

[23] Lim, Y.-B.; Moon, K.-S.; Lee, M. J. Mater. Chem. 2008, 18, 2909-2918.

[24] Demchenko, A. P. In Introduction to Fluorescence Sensing; Demchenko, A. P., Ed.; Springer, 2009.

[25] Hof, M.; Hutterer, R.; Fidler, V. In Fluorescence Spectroscopy in Biology - Advanced Methods and their Applications to Membranes, Proteins, DNA, and Cells; Wolfbeis, O. S., Ed.; Springer, 2005.

[26] Bull, S. R.; Guler, M. O.; Bras, R. E.; Meade, T. J.; Stupp, S. I. Nano Lett. 2005, 5, 1-4.

[27] Li, L.-L.; Ma, H.-L.; Qi, G.-B.; Zhang, D.; Yu, F.; Hu, Z.; Wang, H. Adv. Mater. 2016, 28, $254-262$.

[28] Vedala, H.; Chen, Y.; Cecioni, S.; Imberty, A.; Vidal, S.; Star, A. Nano Lett. 2011, 11, $170-175$.

[29] Gabius, H.-J.; André, S.; Jiménez-Barbero, J.; Romero, A.; Solís, D. Trends Biochem. Sci. 2011, 36, 298-313.

[30] Miura, Y.; Hoshino, Y.; Seto, H. Chem. Rev. 2016, 116, 1673-1692.

[31] Schmid, S.; Mishra, A.; Bauerle, P. Chem. Commun. 2011, 47, 1324-1326.

[32] Voskuhl, J.; Stuart, M. C. A.; Ravoo, B. J. Chem. Eur. J. 2010, 16, 2790-2796. 
[33] Gross, L. PLoS Biol. 2006, 4, e314.

[34] Cecioni, S.; Imberty, A.; Vidal, S. Chem. Rev. 2015, 115, 525-561.

[35] Delbianco, M.; Bharate, P.; Varela-Aramburu, S.; Seeberger, P. H. Chem. Rev. 2016, 116, 1693-1752.

[36] Oppenländer, T. Photochemical Purification of Water and Air; Wiley-VCH Verlag GmbH \& Co. KGaA, 2007; pp 299-352.

[37] Abbel, R.; van der Weegen, R.; Meijer, E. W.; Schenning, A. P. H. J. Chem. Commun. 2009, 1697-1699.

[38] Petkau, K.; Kaeser, A.; Fischer, I.; Brunsveld, L.; Schenning, A. P. H. J. J. Am. Chem. Soc. 2011, 133, 17063-17071.

[39] Fischer, I.; Petkau-Milroy, K.; Dorland, Y. L.; Schenning, A. P. H. J.; Brunsveld, L. Chem. Eur. J. 2013, 19, 16646-16650.

[40] Wang, K.-R.; An, H.-W.; Han, D.; Qian, F.; Li, X.-L. Chin. Chem. Lett. 2013, 24, 467-470.

[41] Battistelli, G.; Cantelli, A.; Guidetti, G.; Manzi, J.; Montalti, M. WIREs Nanomed. Nanobiotechnol. 2016, 8, 139-150.

[42] Mei, J.; Leung, N. L. C.; Kwok, R. T. K.; Lam, J. W. Y.; Tang, B. Z. Chem. Rev. 2015, $115,11718-11940$.

[43] Hong, Y.; Lam, J. W. Y.; Tang, B. Z. Chem. Commun. 2009, 4332-4353.

[44] Mei, J.; Hong, Y.; Lam, J. W. Y.; Qin, A.; Tang, Y.; Tang, B. Z. Adv. Mater. 2014, 26, $5429-5479$.

[45] Liang, J.; Tang, B. Z.; Liu, B. Chem. Soc. Rev. 2015, 44, 2798-2811.

[46] Sanji, T.; Shiraishi, K.; Nakamura, M.; Tanaka, M. Chem. Asian J. 2010, 5, 817-824.

[47] Deniaud, D.; Julienne, K.; Gouin, S. G. Org. Biomol. Chem. 2011, 9, 966-979.

[48] Wang, J.-X.; Chen, Q.; Bian, N.; Yang, F.; Sun, J.; Qi, A.-D.; Yan, C.-G.; Han, B.-H. Org. Biomol. Chem. 2011, 9, 2219-2226.

[49] Rusin, O.; Král, V.; Escobedo, J. O.; Strongin, R. M. Org. Lett. 2004, 6, 1373-1376.

[50] Hatano, K.; Saeki, H.; Yokota, H.; Aizawa, H.; Koyama, T.; Matsuoka, K.; Terunuma, D. Tetrahedron Lett. 2009, 50, 5816-5819.

[51] Shiraishi, K.; Sanji, T.; Tanaka, M. Tetrahedron Lett. 2010, 51, 6331-6333.

[52] Kato, T.; Kawaguchi, A.; Nagata, K.; Hatanaka, K. Biochem. Biophys. Res. Commun. 2010, 394, 200-204.

[53] Hu, X.-M.; Chen, Q.; Wang, J.-X.; Cheng, Q.-Y.; Yan, C.-G.; Cao, J.; He, Y.-J.; Han, B.-H. Chem. Asian J. 2011, 6, 2376-2381.

[54] Kim, B.-S.; Hong, D.-J.; Bae, J.; Lee, M. J. Am. Chem. Soc. 2005, 127, 16333-16337.

[55] Müller, M. K.; Brunsveld, L. Angew. Chem. Int. Ed. 2009, 48, 2921-2924.

[56] Petkau-Milroy, K.; Sonntag, M. H.; van Onzen, A. H. A. M.; Brunsveld, L. J. Am. Chem. Soc. 2012, 134, 8086-8089.

[57] Müller, M. K.; Petkau, K.; Brunsveld, L. Chem. Commun. 2011, 47, 310-312.

[58] Lee, D.-W.; Kim, T.; Park, I.-S.; Huang, Z.; Lee, M. J. Am. Chem. Soc. 2012, 134, 14722 14725.

[59] Wu, F.; Jin, J.; Wang, L.; Sun, P.; Yuan, H.; Yang, Z.; Chen, G.; Fan, Q.-H.; Liu, D. ACS Appl. Mater. Interfaces 2015, 7, 7351-7356.

[60] Wang, K.-R.; Wang, Y.-Q.; An, H.-W.; Zhang, J.-C.; Li, X.-L. Chem. Eur. J. 2013, 19, 2903-2909.

[61] Wang, K.-R.; An, H.-W.; Rong, R.-X.; Cao, Z.-R.; Li, X.-L. Biosensors and Bioelectronics 2014, $58,27-32$.

[62] Wang, K.-R.; An, H.-W.; Rong, R.-X.; Cao, Z.-R.; Li, X.-L. Macromol. Rapid Commun. 2014, 35, 727-734.

[63] Hao, E.; Jensen, T. J.; Vicente, M. G. H. JPP 2009, 13, 51-59.

[64] Lv, F.; He, X.; Lu, l.; Wu, L.; Liu, T. JPP 2012, 16, 77-84. 
[65] Wang, Z.; Chen, S.; Lam, J. W. Y.; Qin, W.; Kwok, R. T. K.; Xie, N.; Hu, Q.; Tang, B. Z. J. Am. Chem. Soc. 2013, 135, 8238-8245.

[66] Li, M.; Hong, Y.; Wang, Z.; Chen, S.; Gao, M.; Kwok, R. T. K.; Qin, W.; Lam, J. W. Y.; Zheng, Q.; Tang, B. Z. Macromol. Rapid Commun. 2013, 34, 767-771.

[67] Josefsen, L. B.; Boyle, R. W. Theranostics 2012, 2, 916-966.

[68] Singh, S.; Aggarwal, A.; Bhupathiraju, N. V. S. D. K.; Arianna, G.; Tiwari, K.; Drain, C. M. Chem. Rev. 2015, 115, 10261-10306.

[69] Adam, W. Chem. Unserer Zeit 1981, 15, 190-196.

[70] Ion, R.-M.; Suica-Bunghez, I.-R. In Oxidative Stress-Based Photodynamic Therapy with Synthetic Sensitizers and/or Natural Antioxidants, Basic Principles and Clinical Significance of Oxidative Stress; Gowder, S. J. T., Ed.; InTech, 2015.

[71] Halliwell, B. Biochem. Soc. Trans. 2007, 35, 1147-1150.

[72] Sesti, F.; Tsitsilonis, O. E.; Kotsinas, A.; Trougakos, I. P. In Vivo 2012, 26, 395-402.

[73] Turro, N. J.; Ramamurthy, V.; Scaiano, J. Modern Molecular Photochemistry of Organic Molecules; University Science Books, 2010; p 1121.

[74] Konopka, K.; Goslinski, T. J. Dent. Res. 2007, 86, 694-707.

[75] Lucky, S. S.; Soo, K. C.; Zhang, Y. Chem. Rev. 2015, 115, 1990-2042.

[76] Chen, X.; Drain, C. M. Drug Design Reviews - Online 2004, 1, 215-234.

[77] Nyst, H. J.; Tan, I. B.; Stewart, F. A.; Balm, A. J. Photodiagn. Photodyn. 2009, 6, 3-11.

[78] Ballut, S.; Makky, A.; Loock, B.; Michel, J.-P.; Maillard, P.; Rosilio, V. Chem. Commun. 2009, 224-226.

[79] Makky, A.; Michel, J. P.; Kasselouri, A.; Briand, E.; Maillard, P.; Rosilio, V. Langmuir 2010, 26, 12761-12768.

[80] Makky, A.; Michel, J. P.; Ballut, S.; Kasselouri, A.; Maillard, P.; Rosilio, V. Langmuir 2010, 26, 11145-11156.

[81] Ballut, S.; Makky, A.; Chauvin, B.; Michel, J.-P.; Kasselouri, A.; Maillard, P.; Rosilio, V. Org. Biomol. Chem. 2012, 10, 4485-4495.

[82] Makky, A.; Daghildjian, K.; Michel, J.-P.; Maillard, P.; Rosilio, V. Biochimica et Biophysica Acta (BBA) - Biomembranes 2012, 1818, 2831-2838.

[83] Vedachalam, S.; Choi, B.-H.; Pasunooti, K. K.; Ching, K. M.; Lee, K.; Yoon, H. S.; Liu, X.W. Med. Chem. Commun. 2011, 2, 371-377.

[84] Lafont, D.; Zorlu, Y.; Savoie, H.; Albrieux, F.; Ahsen, V.; Boyle, R. W.; Dumoulin, F. Photodiagn. Photodyn. 2013, 10, 252-259.

[85] Pereira, P. M. R.; Silva, S.; Cavaleiro, J. A. S.; Ribeiro, C. A. F.; Tomé, J. P. C.; Fernandes, R. PLoS ONE 2014, 9, e95529.

[86] Choi, C.-F.; Huang, J.-D.; Lo, P.-C.; Fong, W.-P.; Ng, D. K. P. Org. Biomol. Chem. 2008, $6,2173-2181$.

[87] Kimani, S. G.; Shmigol, T. A.; Hammond, S.; Phillips, J. B.; Bruce, J. I.; MacRobert, A. J.; Malakhov, M. V.; Golding, J. P. Photochem. Photobiol. 2013, 89, 139-149.

[88] Aggarwal, A.; Singh, S.; Zhang, Y.; Anthes, M.; Samaroo, D.; Gao, R.; Drain, C. M. Tetrahedron Lett. 2011, 52, 5456-5459.

[89] Garcia, G.; Hammerer, F.; Poyer, F.; Achelle, S.; Teulade-Fichou, M.-P.; Maillard, P. Bioorg. Med. Chem. 2013, 21, 153-165.

[90] Hammerer, F.; Garcia, G.; Chen, S.; Poyer, F.; Achelle, S.; Fiorini-Debuisschert, C.; TeuladeFichou, M.-P.; Maillard, P. J. Org. Chem. 2014, 79, 1406-1417.

[91] Tatman, D.; Liddell, P. A.; Moore, T. A.; Gust, D.; Moore, A. L. Photochem. Photobiol. 1998, 68, 459-466.

[92] Maisch, T.; Szeimies, R.-M.; Jori, G.; Abels, C. Photochem. Photobiol. Sci. 2004, 3, 907917.

[93] Liu, K.; Liu, Y.; Yao, Y.; Yuan, H.; Wang, S.; Wang, Z.; Zhang, X. Angew. Chem. Int. Ed. 
2013, 52, 8285-8289.

[94] Roy, I.; Shetty, D.; Hota, R.; Baek, K.; Kim, J.; Kim, C.; Kappert, S.; Kim, K. Angew. Chem. Int. Ed. 2015, 54, 15152-15155.

[95] Xing, C.; Xu, Q.; Tang, H.; Liu, L.; Wang, S. J. Am. Chem. Soc. 2009, 131, 13117-13124.

[96] Sol, V.; Branland, P.; Granet, R.; Kaldapa, C.; Verneuil, B.; Krausz, P. Bioorg. Med. Chem. Lett. 1998, 8, 3007-3010.

[97] Tomé, J. P.; Neves, M. G.; Tomé, A. C.; Cavaleiro, J. A.; Mendonca, A. F.; Pegado, I. N.; Duarte, R.; Valdeira, M. L. Bioorg. Med. Chem. 2005, 13, 3878-3888.

[98] Ringot, C.; Sol, V.; Granet, R.; Krausz, P. Mater. Lett. 2009, 63, 1889-1891.

[99] Feese, E.; Sadeghifar, H.; Gracz, H. S.; Argyropoulos, D. S.; Ghiladi, R. A. Biomacromolecules 2011, 12, 3528-3539.

[100] Kelkar, S. S.; Reineke, T. M. Bioconjugate Chem. 2011, 22, 1879-1903.

[101] Patel, N. J.; Chen, Y.; Joshi, P.; Pera, P.; Baumann, H.; Missert, J. R.; Ohkubo, K.; Fukuzumi, S.; Nani, R. R.; Schnermann, M. J.; Chen, P.; Zhu, J.; Kadish, K. M.; Pandey, R. K. Bioconjugate Chem. 2016, 27, 667-680.

[102] Kejik, Z.; Briza, T.; Kralova, J.; Pouckova, P.; Kral, A.; Martasek, P.; Kral, V. Bioorg. Med. Chem. Lett. 2011, 21, 5514-5520.

[103] Zhang, J. et al. ACS Nano 2015, 9, 9741-9756.

[104] Dou, W.-T.; Zhang, Y.; Lv, Y.; Wu, J.; Zang, Y.; Tan, C.; Li, J.; Chen, G.-R.; He, X.-P. Chem. Commun. 2016, 52, 3821-3824. 


\section{2}

\section{Synthesis of Glycoconjugated Porphyrins}

Four different zinc porphyrin derivatives were synthesized and functionalized at the mesoposition with either (a) one tetraethylene glycol side chain, (b) one side chain with a mannose moiety, (c) one side chain with a galactose moiety, or (d) four side chains, each containing a mannose moiety. For the coupling of the side chains to the porphyrins microwave-assisted copper(I)-catalyzed click chemistry was applied, which required a short reaction time and gave an increase in yield. The structure of the porphyrins was confirmed by ${ }^{1} H$ NMR, ${ }^{13} C$ NMR, 2D NMR spectroscopy and mass spectrometry. 


\subsection{Introduction}

Porphyrins are flat aromatic systems consisting of four pyrrole units connected by methylene bridges. The basic porphin can be substituted to introduce new functionalities either in the meso- and/or $\beta$-positions (Fig. 2.1a).

The first porphyrin syntheses have been described by Hans Fischer in the 1920s [1-3]. In the 1930s Rothemund carried out porphyrin syntheses by heating a sealed tube wherein the reaction between pyrrole and aldehyde took place [4, 5]. Adler and Longo proposed in the 1960s a simple approach to synthesize meso-substituted porphins by reacting a pyrrole with the substituted aldehyde in refluxing propionic acid. Although the yield was not high, the advantage was the simplicity of the procedure and purification by column chromatography [6]. Boiling propionic acid, however, is a harsh condition in the case of sensitive side chains. Lindsey et al. developed 20 years later a more gentle reaction. Working at room temperature they first converted the aldehyde and the pyrrole in acid into a porphyrinogen. Subsequent oxidation with 2,3-dichloro-5,6-dicyano-1,4-benzoquinone (DDQ) or $p$-chloranil led to the porphyrin in this 2-step-1-flask reaction [7]. To create asymmetric porphyrins different aldehydes or pyrroles are used, which leads to a dramatic decrease of the reaction yields, since the combination occurs statistically with all possible products being formed.

Regardless, if the desired porphyrin is meso- or $\beta$-substituted, there are two different approaches to obtain functionalized porphyrins, as can be seen in figure $2.1 \mathrm{~b}$, 1) the cyclomerization of already functionalized starting compounds or 2) the modification of the porphyrin after tetramerization. However, both methods have drawbacks resulting in low yields. In the first case the steric hindrance of bulky groups during the cyclomerization limits the yield. In the second case the modification of porphyrins produces a mixture of porphyrins with different substitution patterns, leading to a low yield of the desired molecule [8].

To circumvent these drawbacks, click chemistry can be applied to porphyrins to introduce substituents [9]. A possible modification method is the most common click reaction, the copper-catalyzed azide-alkyne cycloaddition (CuAAC). The coupling of an azide and an alkyne compound results in a 1,2,3-triazole. Due to the copper catalysis only the 1,4regioisomer is formed. Apart from the copper ions no toxic conditions are needed and furthermore a wide range of solvents is possible [10]. The necessary functional groups for the $\mathrm{CuAAC}$, azide and alkyne, are small and do not disturb the tetramerization process. Furthermore it has been reported that the formed triazole is not toxic and quite stable against metabolic degradation [11].

The typical solvent for the $\mathrm{CuAAC}$ is a mixture of tert-butanol $\left({ }^{t} \mathrm{BuOH}\right)$ and water $\left(\mathrm{H}_{2} \mathrm{O}\right)$. However, porphyrins are poorly soluble in those solvents. Therefore other solvents 
or solvent mixtures in which all reaction partners are soluble have been selected, such as dimethylformamide (DMF), tetrahydrofuran (THF) or mixtures of an organic solvent and a polar co-solvent (e.g. ethanol, water) [12].

The main limitation of applying the copper-assisted click chemistry to obtain tetrapyrrolic derivatives is the undesired copper insertion into the porphyrin core during the reaction [10]. Using for example zinc-metallated porphyrins prevents the insertion of copper and after the synthesis zinc can be simply removed, if required. There are only a few examples where authors have performed copper-catalyzed click reactions with unmetallated porphyrins where no copper insertion was reported [13, 14]. In contrast the group of Okada described not only that copper inserted in their octa- $\beta$-lactosylated porphyrin during the click reaction, but in addition these authors showed that $\mathrm{Cu}$ (II) insertion was prioritized over the copper(II) reduction, necessary for the catalysis of the coupling reaction [8].

In this chapter, we describe the synthesis of three asymmetric zinc porphyrins and one symmetric zinc porphyrin. Modification of the porphyrins with tetraethylene-glycol chains and monosaccharide moieties was carried out by Huisgen 1,3-dipolar cycloaddition.

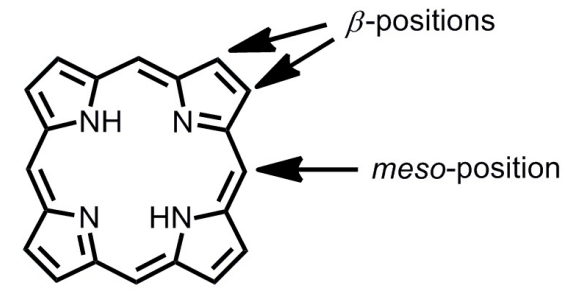

(a)

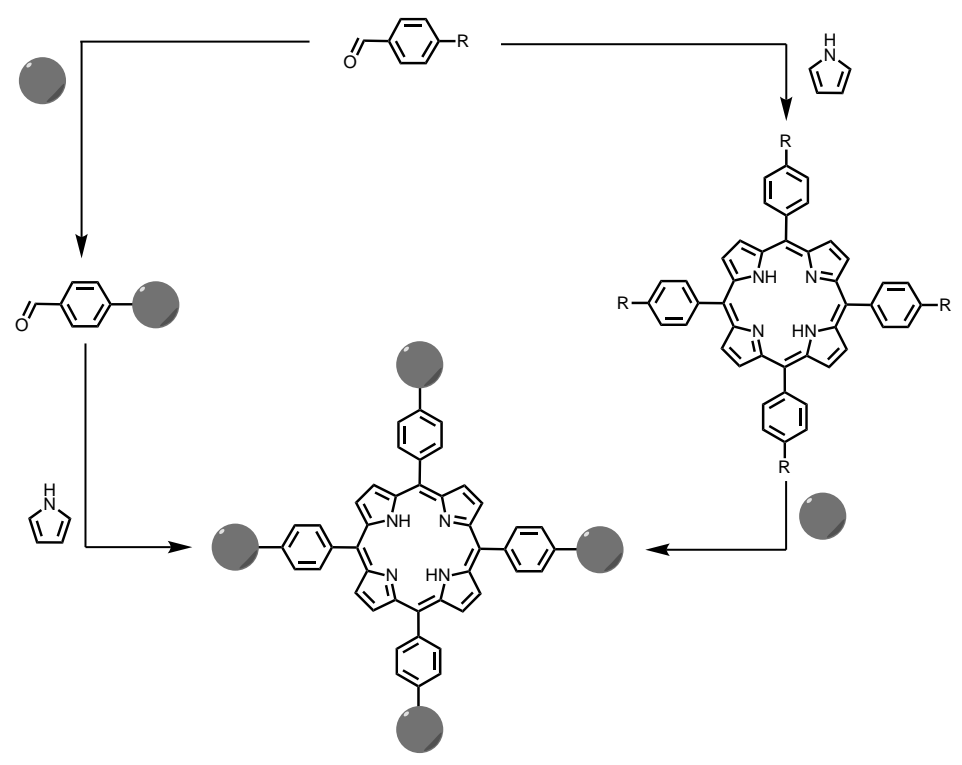

(b)

Figure 2.1 - Chemical structure of porphin with $\beta$ - and meso-position as indicated (a). Possibilities to functionalize porphyrins at the meso-position (b): 1) Functionalization of the aldehyde and subsequent tetramerization (anticlockwise path) or 2) tetramerization with aldehydes containing only small functional groups and modification afterwards (clockwise path). $\mathrm{R}$ represents small functional groups, while the grey balls illustrate the final, more bulky substituents. 


\subsection{Results and discussion}

\subsubsection{Synthesis of porphyrin alkyne derivatives}

Inspired by the work of Vicente and co-workers [15] two different molecules were synthesized, a mono- and a tetrasubstituted porphyrin with alkyne functionalities. In the following synthetic step ligands can be coupled to the porphyrins via $\mathrm{Cu}(\mathrm{I})$-catalyzed click chemistry.

The synthesis scheme to obtain the monopropargyl-substituted porphyrin platform is shown in figure 2.2. Porphyrin 1 was synthesized using a procedure of Griesbeck et al. that employs Adler conditions and $\mathbf{1}$ was obtained as purple powder in $7 \%$ yield in agreement with Griesbeck's yield [16]. To obtain the monoalkylated derivative $\mathbf{2}, \mathbf{1}$ was reacted with propargyl bromide in a 1:1 ratio. The mass spectrum and the thin layer chromatography (TLC) of the crude showed the presence of all four substituted molecules: mono-, di-, tri- and tetrasubstituted. Purifying the crude by column chromatography gave derivative $\mathbf{2}$ as purple solid in $15 \%$ yield and subsequent zinc metalation of $\mathbf{2}$ resulted in zinc porphyrin $\mathbf{3}$ in $80 \%$ yield.

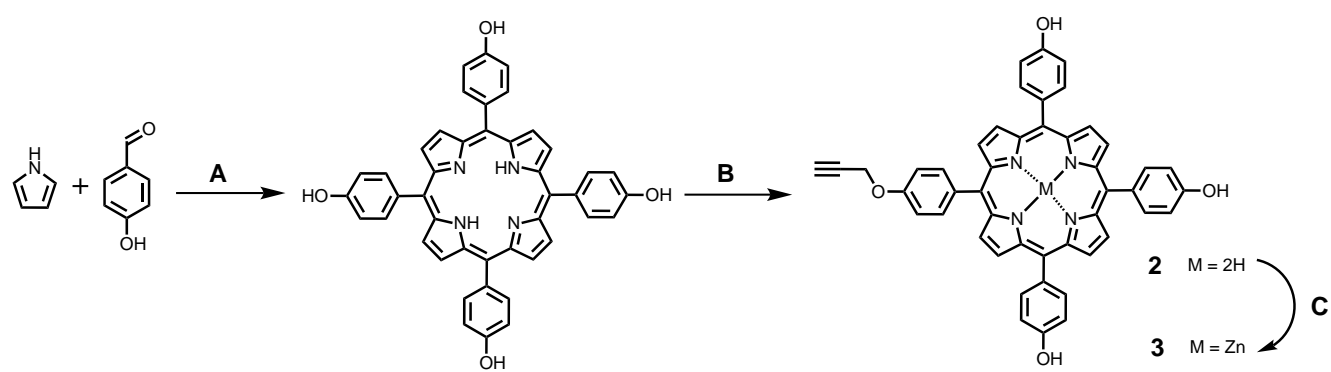

1

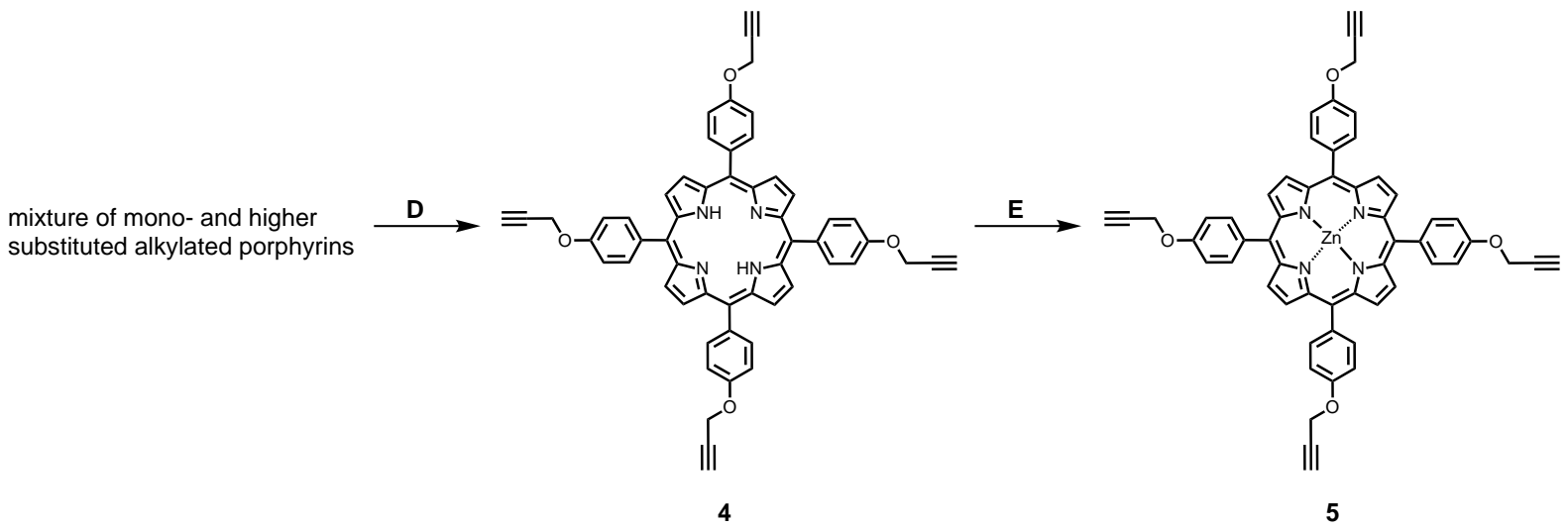

Figure 2.2 - Synthesis of the monoalkylated and the tetraalkylated porphyrin. A) Propionic acid, 1 h, 7 \%. B) Propargyl bromide, $\mathrm{K}_{2} \mathrm{CO}_{3}$, DMSO, 18 h, $15 \%$. C) $\mathrm{Zn}(\mathrm{OAc})_{2}$, $\mathrm{MeOH} / \mathrm{CHCl}_{3}, 1 \mathrm{~h}, 80 \%$. D) Propargyl bromide, $\mathrm{K}_{2} \mathrm{CO}_{3}$, DMSO, 18 h. E) $\mathrm{Zn}(\mathrm{OAc})_{2}, \mathrm{MeOH} / \mathrm{CHCl}_{3}, 1 \mathrm{~h}, 63 \%$. 
Side-products from the synthesis of $\mathbf{2}$, di-, tri- and tetrasubstituted porphyrins, as well as remaining monosubstituted porphyrin were then further alkylated using an excess of propargyl bromide to mainly obtain the tetrasubstituted derivative 4 (Fig. 2.2), as confirmed by TLC and NMR. After purification zinc was inserted to obtain tetrasubstituted zinc porphyrin 5 as purple solid in $63 \%$ yield.

\subsubsection{Synthesis of azido-modified carbohydrates}

Introducing monosaccharides into the porphyrin structure makes bio-targeting possible and increases the hydrophilic character of the entire molecule. Between the hydrophobic porphyrin and the hydrophilic carbohydrate moiety a hydrophilic tetraethylene glycol (TEG) spacer was used. The azide compound $\mathbf{6}$ was obtained from tetraethylene glycol via a monomesylated intermediate in $35 \%$ yield over two reaction steps (Fig. 2.3) [17]. The stereochemical diverse monosaccharides mannose (Man) and galactose (Gal) target different receptors [18] and were chosen to be attached to the porphyrins. The alcohol groups of D-mannose were first protected with acetic anhydride in good yield (92 \%), whereas galactose was purchased as $\beta$-D-galactose pentaacetate (Fig. 2.3). Mannose pentaacetate 7 and galactose pentaacetate were selectively deprotected at the anomeric position using benzylamine. In the next step the alcohols were transformed into the trichloroimidates 9 and 12 [19]. During the reaction to the trichloroimidate only the $\alpha$-mannopyranoside $\mathbf{9}$ was formed in agreement with literature [20]. The isolated imidates 9 and 12 were reacted with the azido tetraethylene glycol 6 by using the Lewis acid trimethylsilyl trifluoromethanesulfonate (TMSOTf) as catalyst, yielding $\mathbf{1 0}$ and $\mathbf{1 3}$ in $22 \%$ and $65 \%$, respectively. The deprotection of the carbohydrates takes place after

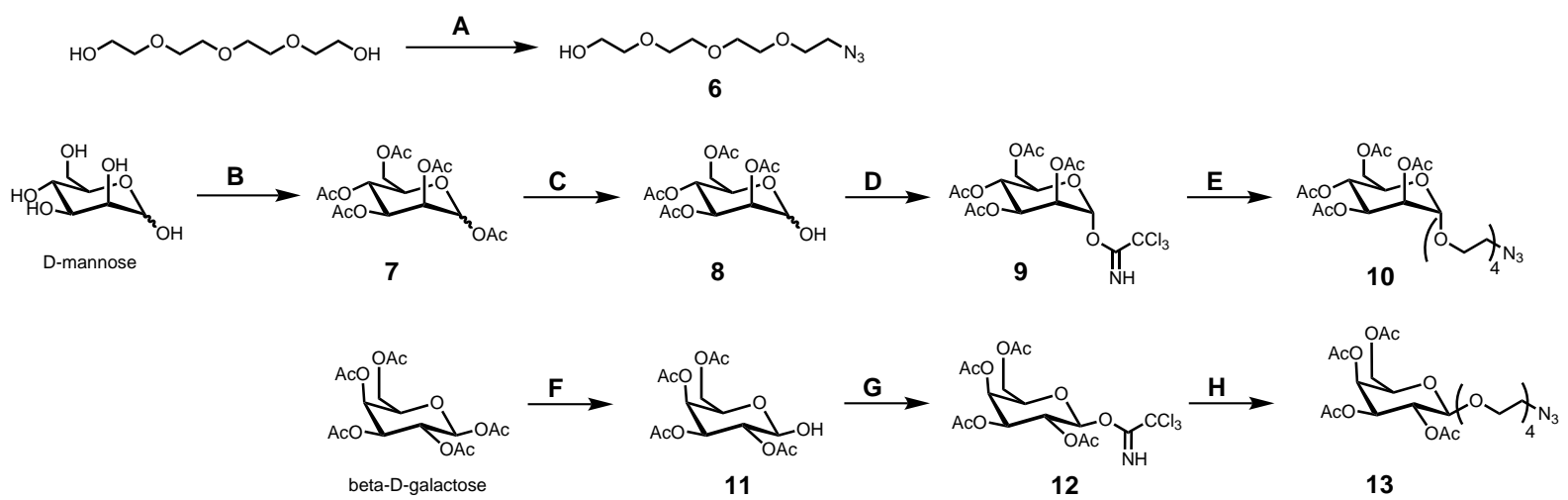

Figure 2.3 - Overview of the synthesis of the azido-modified tetraethylene glycol, mannose and galactose derivatives. A) 1. $\mathrm{MsCl}, \mathrm{Et}_{3} \mathrm{~N}, \mathrm{Et}_{2} \mathrm{O}, 2 \mathrm{~h} ; 2 . \mathrm{NaN}_{3}, \mathrm{EtOH}, 18 \mathrm{~h}, 35 \%$ over 2 steps. B) $\mathrm{Ac}_{2} \mathrm{O}$, NaOAc, 4 h, $92 \%$. C) $\mathrm{PhCH}_{2} \mathrm{NH}_{2}$, THF, 18 h. D) $\mathrm{CCl}_{3} \mathrm{CN}$, DBU, DCM, 2 h, $72 \%$ over 2 steps (C and D). E) 6, TMSOTf, DCM, 2.5 h, $22 \%$. F) $\mathrm{PhCH}_{2} \mathrm{NH}_{2}$, THF, 18 h. G) $\mathrm{CCl}_{3} \mathrm{CN}$, DBU, DCM, 2 h, $44 \%$ over 2 steps (F and G). H) 6, TMSOTf, DCM, 2 h, $65 \%$. 
their coupling to the alkyne-functionalized porphyrin derivatives $\mathbf{3}$ and $\mathbf{5}$.

\subsubsection{Copper(I)-catalyzed azide-alkyne cycloaddition of monosaccharides to porphyrins}

A disadvantage of applying $\mathrm{CuAAC}$ to porphyrins is the reaction time of in some cases several days [13, 14]. However, microwave (MW) assistance can shorten the reaction time considerably and also increase the yield [21]. Using MW-assisted click chemistry makes it possible to introduce substituents to the porphyrin core fourfold [22]. Since porphyrins are poorly soluble in the usual $\mathrm{CuAAC}$ solvents ${ }^{t} \mathrm{BuOH}$ and $\mathrm{H}_{2} \mathrm{O}$, THF was added as co-solvent to obtain a homogenous solution.

The monoalkylated zinc porphyrin 3 was coupled to the azido components $\mathbf{6}, 10$ and 13 (Fig. 2.4). The reaction mixtures were treated for ten minutes in the microwave. The purification by column chromatography allowed the separation of the product from the starting compounds and the THF stabilizer butylated hydroxytoluene (BHT). The porphyrin P-TEG was obtained in this way in $26 \%$ yield.

Incomplete deacetylation of the monosaccharides by Lewis acid-catalyzed hydrolysis of the esters was observed in the NMR spectra after the click reaction. After the deprotection under Zemplén conditions [23, 24] of the remaining acetyl groups the final molecules $\mathbf{P}$ TEG-Man and P-TEG-Gal were obtained in $54 \%$ and $79 \%$ yield, respectively.

Tetraalkyne porphyrin 5 was reacted with 7 equivalents of mannose azido tetraethylene glycol 10 and after deprotection the final compound P-(TEG-Man) $)_{4}$ was obtained in $29 \%$ yield over the two reaction steps (Fig. 2.4).

\subsubsection{Characterization of the porphyrins}

The progress of the reactions and purifications was mainly monitored by TLC. The natural intensive colour of the porphyrins made stainings or use of a UV lamp unneccessary for detection. The structural identification was done by NMR spectroscopy and mass spectrometry.

In the ${ }^{1} \mathrm{H}$ NMR spectrum of P-TEG all integrals and positions of signals were found correctly (Fig. 2.5a). Comparing the IR spectra of the product with the azido TEG 6 illustrates the complete loss of the azide signal (Fig. 2.5b). In the mass spectrum the molecular ion was found at $m / z 999.0[\mathrm{M}+\mathrm{H}]^{+}$. The combination of the three analysis techniques confirmed the formation of P-TEG.

Introduction of the carbohydrate moieties has little effect on the ${ }^{1} \mathrm{H}$ NMR peaks of the porphyrin core, however, the signals of TEG and carbohydrate overlap. Two-dimensional (2D) NMR spectroscopy was used to verify the molecular structure in more detail (Fig.2.6). The $\left({ }^{1} \mathrm{H},{ }^{1} \mathrm{H}\right)$ correlated (COSY) NMR spectrum of P-TEG-Man shows the proton spec- 

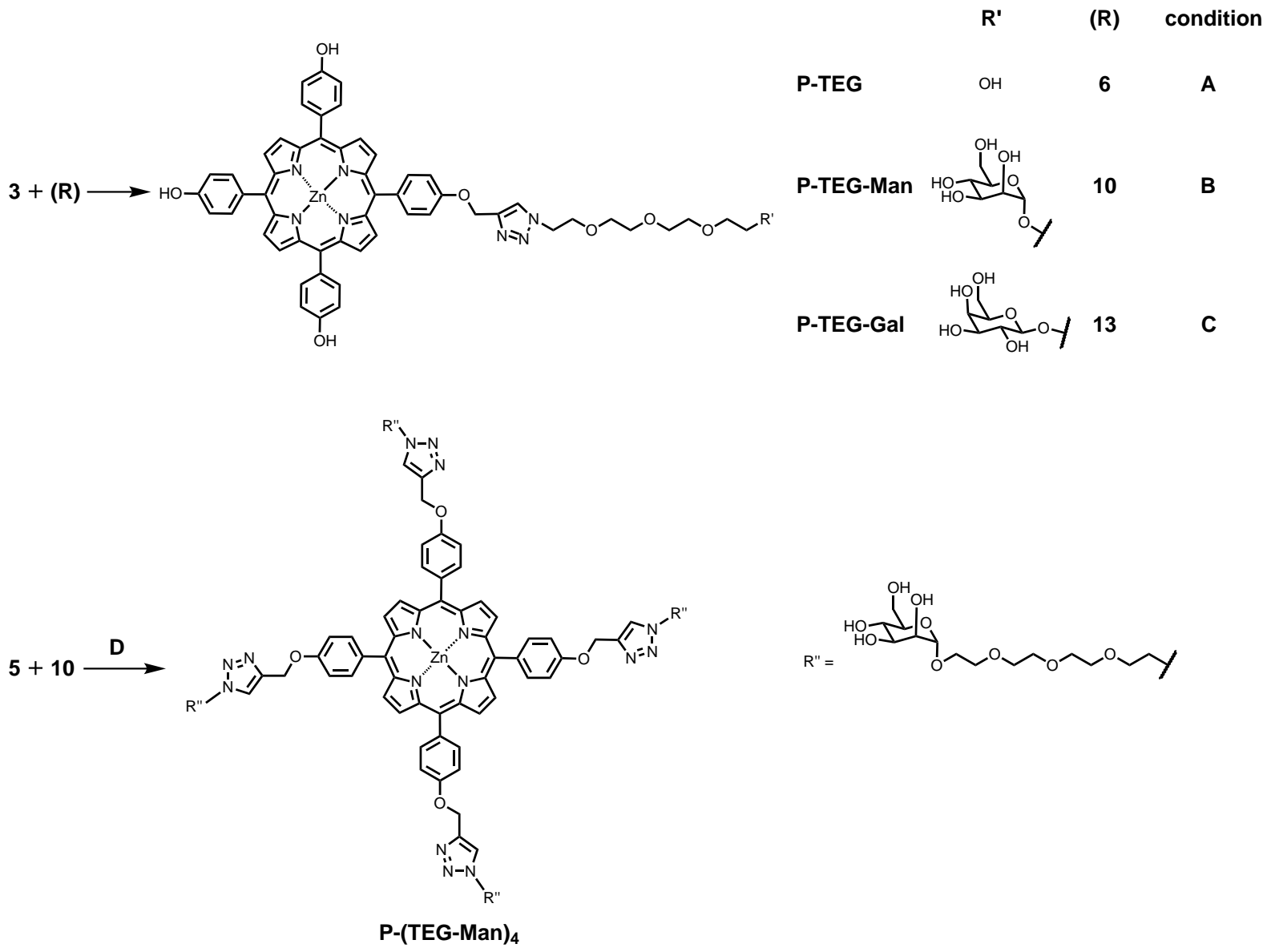

Figure 2.4 - Synthesis of the tetraethylene glycol porphyrin P-TEG, the mannose porphyrin P-TEG-Man, the galactose porphyrin P-TEG-Gal, and the tetrasubstituted mannose porphyrin P-(TEG-Man) $)_{4}$. A) $\mathrm{CuSO}_{4}$, sodium ascorbate, $\mathrm{THF} /{ }^{t} \mathrm{BuOH} / \mathrm{H}_{2} \mathrm{O} 3 / 2 / 1,18 \mathrm{~h}(10 \mathrm{~min} \mathrm{MW}), 26 \%$. B) $1 . \mathrm{CuSO}_{4}$, sodium ascorbate, $\mathrm{THF} /{ }^{t} \mathrm{BuOH} / \mathrm{H}_{2} \mathrm{O} 3 / 2 / 1,2 \mathrm{~h}$ (10 min MW), $51 \%$; 2. NaOMe, $\mathrm{MeOH}$, $2.5 \mathrm{~h}, 54 \%$. C) $1 . \mathrm{CuSO}_{4}$, sodium ascorbate, $\mathrm{THF} /{ }^{t} \mathrm{BuOH} / \mathrm{H}_{2} \mathrm{O} 3 / 2 / 1,18 \mathrm{~h}(10$ min $\mathrm{MW}), 46 \%$; 2. NaOMe, $\mathrm{MeOH}, 3$ h, $79 \%$. D) $1 . \mathrm{CuSO}_{4}$, sodium ascorbate, $\mathrm{THF} /{ }^{t} \mathrm{BuOH} / \mathrm{H}_{2} \mathrm{O} 3 / 2 / 1,18 \mathrm{~h}(10$ min MW), 38 \%; 2 . NaOMe, MeOH, 2 d, $76 \%$.

trum on both axes yielding diagonal and cross peaks (Fig. 2.6a). While the diagonal peaks are not of further interest in this case, the cross peaks indicate coupling of protons of neighbouring groups. The pyrrole signal at $8.92 \mathrm{ppm}$ has no cross peaks, but the phenyl $\mathrm{CH}$ groups give a cross peak with each other since they are neighbouring groups. The peak at $5.23 \mathrm{ppm}$ with an integral of 2 protons features only a diagonal peak indicating the isolated $\mathrm{CH}_{2}$ group between the phenyl and triazole moieties. The two peaks at $4.58 \mathrm{ppm}$ and $3.90 \mathrm{ppm}$, both with an integral of 2 protons, produced a cross peak indicating they are two neighbouring $\mathrm{CH}_{2}$ groups, isolated by hetero atoms from others, as they are present in the TEG chain. The two multiplets around $3.55 \mathrm{ppm}$ and $3.34 \mathrm{ppm}$ show clustered peaks around the diagonal implying that next to the diagonal peaks also cross peaks are present. The cross peaks are so close to the diagonal since the signals are 


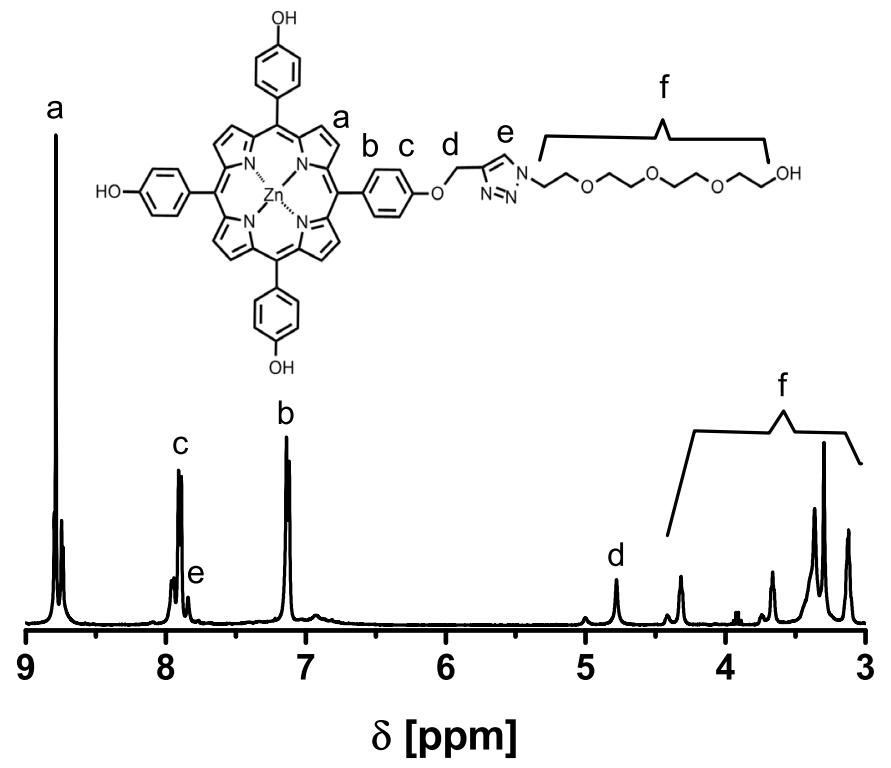

(a)

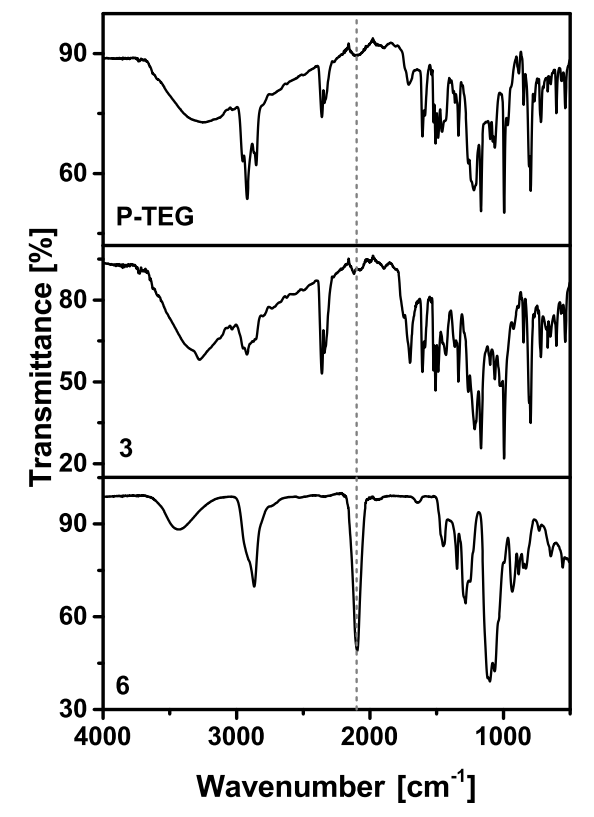

(b)

Figure 2.5 $-{ }^{1} \mathrm{H}$ NMR spectrum of P-TEG in acetone- $\mathrm{d}_{6}$ with assigned signals (a). IR spectra of P-TEG and the starting materials 3 and $\mathbf{6}$ (b). Dotted line marks the position of the azide signal.

adjacent to each other. Those peaks represent the TEG and mannose functionality of the molecule.

The $\left({ }^{1} \mathrm{H},{ }^{13} \mathrm{C}\right.$ ) heteronuclear multiple-quantum correlated (HMQC) spectrum of P-TEGMan with ${ }^{1} \mathrm{H}$ and ${ }^{13} \mathrm{C}$ NMR spectra on the axes shows directly-bonded proton and carbon atoms (Fig. 2.6b). The aromatic signals of the ${ }^{1} \mathrm{H}$ NMR spectrum (pyrrole, phenyl, triazole) give, as expected, peaks with signals in the aromatic region of the ${ }^{13} \mathrm{C}$ NMR spectrum. The isolated $\mathrm{CH}_{2}$ group at $5.23 \mathrm{ppm}\left({ }^{1} \mathrm{H}\right)$ has a distinctive ${ }^{13} \mathrm{C}$ signal since it has a lower

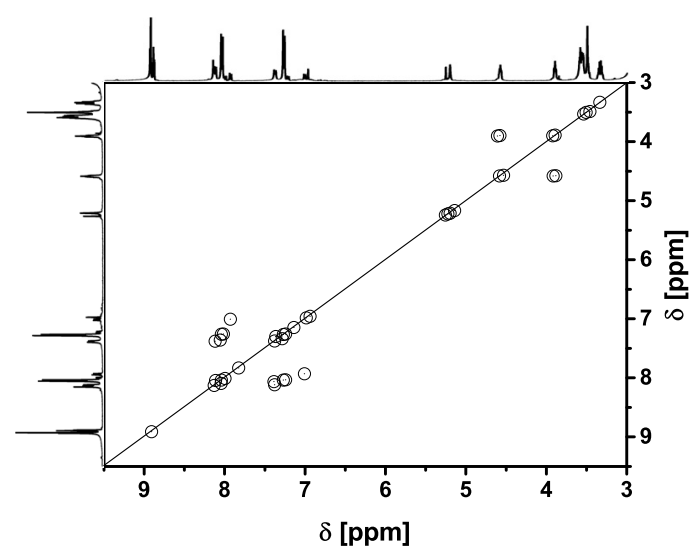

(a)

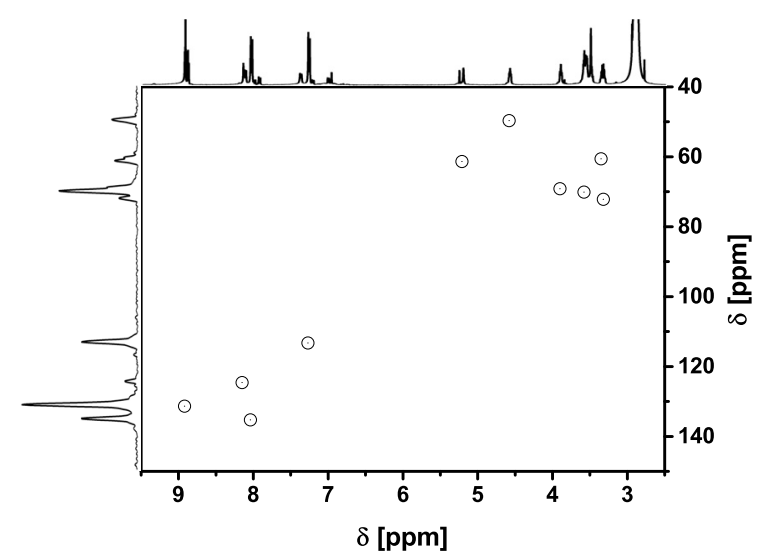

(b)

Figure 2.6 - 2D NMR spectra of P-TEG-Man: $\left({ }^{1} \mathrm{H},{ }^{1} \mathrm{H}\right)$ COSY spectrum $(\mathrm{a})$ and $\left({ }^{1} \mathrm{H},{ }^{13} \mathrm{C}\right)$ HMQC spectrum (b) in acetone- $\mathrm{d}_{6}$. 
chemical shift (61.37 ppm) than the clustered TEG and Man signals (around $70 \mathrm{ppm}$ ). The peak at 4.58/49.65 ppm originated from the $\mathrm{CH}_{2}$ group of the TEG located next to the triazole $\left(\mathrm{N}-\mathrm{CH}_{2}\right)$. It is possible to assign this signal to this group because the same characteristic shift of about $50 \mathrm{ppm}$ was observed in ${ }^{13} \mathrm{C}$ NMR spectra of 6 and 13. Based on this information and together with the observed cross peak in the COSY spectrum, the peak at $3.90 / 69.13 \mathrm{ppm}$ was assigned to the $\mathrm{CH}_{2}$ group located two positions away from the triazole unit $\left(\mathrm{N}-\mathrm{CH}_{2}-\mathrm{CH}_{2}\right)$.

The characteristic peak combinations of the 2D NMR spectra were also identified in the case of P-TEG-Gal and P-(TEG-Man) $)_{4}$. Due to solubility issues, convenient deuterated solvent acetone- $\mathrm{d}_{6}$ was not used. In these cases $\mathrm{CD}_{3} \mathrm{OD}$ and DMSO- $\mathrm{d}_{6}$ were used instead, but these solvents produced ${ }^{1} \mathrm{H}$ NMR signals that overlap with signals originating from the porphyrins. The use of HMQC NMR is here particularly beneficial since the peak of the solvent is in the ${ }^{13} \mathrm{C}$ NMR at a different chemical shift than the peaks of the porphyrin. However, integrals for the proton NMR spectrum of the porphyrins cannot be calculated using HMQC NMR spectra.

In the MALDI-TOF spectrum of P-TEG-Gal the molecular ion peak of $\mathrm{m} / z 1159$ was observed along with signals that were attributed to fragmentation (Fig. 2.7a, signal assignment see 2.5.2). For P-(TEG-Man $)_{4}$ no molecular signal was observed while several other signals were found (Fig. 2.7b). A relevant signal at $m / z 1792$ was detected which was related to the molecular mass of P-(TEG) $)_{4}$. This observation indicates the formation of a porphyrin molecule to which four arms were added via the Huisgen click reaction. Further fragmentation of the porphyrin occurred into fractions of lower mass representing the porphyrin with three or less substituents (signal assignment see 2.5.2). The symmetry of this molecule is also supported by the absorption spectra shown in chapter 3 .

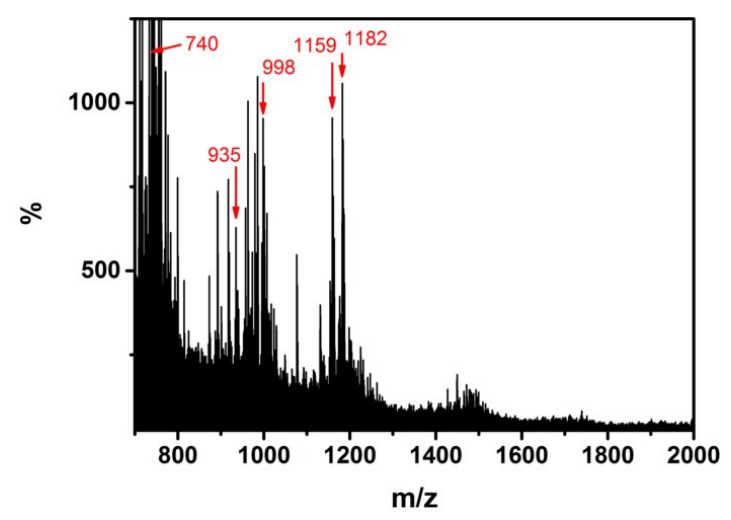

(a)

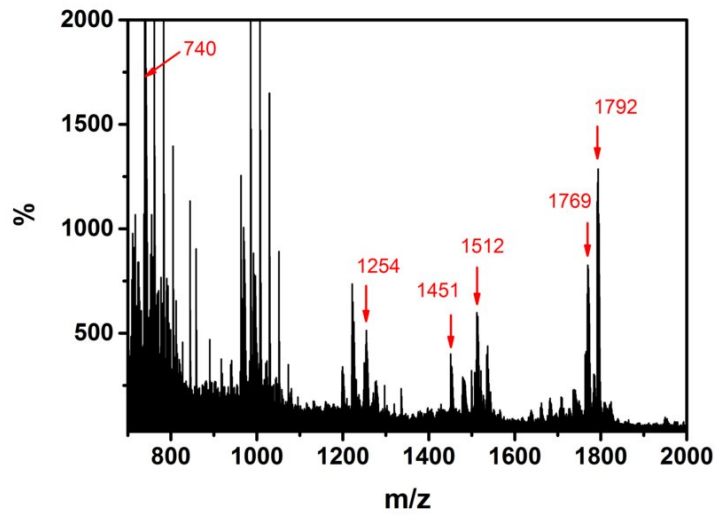

(b)

Figure 2.7 - MALDI-TOF spectra of P-TEG-Gal (a) and P-(TEG-Man) $)_{4}$ (b). 


\subsection{Conclusions}

Four different porphyrin derivatives, of which three have been substituted with monosaccharide functionalities, were successfully synthesized. For the coupling of the porphyrin core with the azide functionalized substituents microwave-assisted Huisgen click reaction has been applied. In chapter 3 the self-assembly properties of the four porphyrins will be studied using spectroscopy and microscopy.

\subsection{Acknowledgments}

Regine van der Hee (Universiteit Twente) and Dr. Matthias Letzel (Westfälische WilhelmsUniversität Münster) are gratefully acknowledged for the measuring of the MALDI-TOF spectra. Jun.-Prof. Dr. Jens Voskuhl (Universität Duisburg-Essen) is thankfully acknowledged for his advice and the fruitful discussions.

\subsection{Experimental section}

\subsubsection{Materials and equipment}

All solvents and reagents were obtained from Sigma Aldrich, Acros Organics, ACtuall Chemicals, Merck, VWR Chemicals, Alfa Aesar and Riedel-De HaËn and were used without further purification, if not mentioned otherwise.

The microwave-assisted reactions were carried out in a CEM Liberty1 microwave peptide synthesizer that is equipped with a module to be used for organic synthesis. The $10 \mathrm{ml}$ sealed reaction vessel was equipped with a stirring bar.

Analytical thin layer chromatography (TLC) was carried out using MERCK precoated silica gel plates on aluminium $\left(60 \mathrm{~F}_{254}\right)$. The TLC plates were investigated by ultraviolet light irradiation at a wavelength of $\lambda=254$ or $366 \mathrm{~nm}$, natural intensive colour (porphyrins), heat (carbohydrates) or staining with basic $\mathrm{KMnO}_{4}$ solution (TEG). For column chromatography MERCK silica gel 60 (230 - 400 mesh) was used.

Electrospray Ionization (ESI) mass spectra were recorded on a WATERS LCT mass spectrometer. Mixtures of dichloromethane and methanol were used as solvents. For the final porphyrin molecules matrix assisted laser desorption/ time of flight (MALDITOF) mass spectra were measured on a Voyager DE-RP (Universiteit Twente) or on a Bruker Daltonics Autoflex speed (Westfälische Wilhelms-Universität Münster). 2,5dihydroxybenzoic acid (DHB), trans-2-[3-(4-tert-butylphenyl)-2-methyl-2-propenylidene]malononitrile (DCTB) or sinapic acid were used as matrix. In the description of the spectra $\mathrm{M}_{W}$ refers to the molecular weight, while $\mathrm{M}_{E}$ refers to the exact mass. 
Infrared spectra were recorded on a THERMO SCIENTIFIC Monolayer IR spectrometer.

${ }^{1} \mathrm{H}$ NMR and ${ }^{13} \mathrm{C}$ NMR spectra were recorded on a BRUKER Ascend NMR spectrometer (400 MHz for ${ }^{1} \mathrm{H}$ NMR, $100 \mathrm{MHz}$ for ${ }^{13} \mathrm{C}$ NMR) at $298 \mathrm{~K}$. Chemical shifts are given as $\delta$ in parts per million (ppm), relative to tetramethylsilane using the deuterated solvent as internal standard [25]. Abbreviations used for splitting patterns are $\mathrm{s}=$ singlet, $\mathrm{sd}$ $=$ singlet of doublets, $\mathrm{st}=$ singlet of triplets, $\mathrm{d}=$ doublet, $\mathrm{dd}=$ doublet of doublets, $\mathrm{t}=$ triplet, $\mathrm{qd}=$ quartet of doublets, $\mathrm{m}=$ multiplet and $\mathrm{br}=$ broad. In case of ${ }^{13} \mathrm{C}$ signals from a HMQC spectrum the solubility of the molecule was not high enough to obtain a regular carbon spectrum. It has to be mentioned that HMQC spectra show no quarternary carbon peaks.

\subsubsection{Synthetic procedures}

Compound 6 [17] was synthesized according to a literature procedure.

\section{5,10,15,20-Tetra(4-hydroxy phenyl)porphyrin 1}

The synthesis was carried out following a literature procedure with minor adjustments [16]. Commercially available 4-hydroxybenzaldehyde (3.69 g, $30.2 \mathrm{mmol})$ was dissolved in $150 \mathrm{ml}$ propionic acid. Freshly distilled pyrrole $(2.11 \mathrm{ml}, 30.4 \mathrm{mmol})$ was added slowly to the refluxing solution. The mixture was refluxed for $1 \mathrm{~h}$. Afterwards the solvent was removed, the residue was dissolved in dichloromethane and filtered. The filtrate was purified by column chromatography (eluent DCM/EtOAc 7/3). Since the product fraction still exhibited the smell of propionic acid, a portion of $0.1 \mathrm{M} \mathrm{NaOH}$ was added. The aqueous solution was extracted with EtOAc until the aqueous solution was colourless. The organic phase was washed once with water and then dried over $\mathrm{Na}_{2} \mathrm{SO}_{4}$. The product was obtained as purple solid. $350 \mathrm{mg}(0.52 \mathrm{mmol}, 7 \%)$.

${ }^{1} \mathrm{H}$ NMR (acetone- $\left.\mathrm{d}_{6}\right): \delta[\mathrm{ppm}]=8.75\left(\mathrm{~s}, 8 \mathrm{H}, \mathrm{CH}_{\text {pyrrole }}\right), 7.88(\mathrm{~d}, J=8.4 \mathrm{~Hz}, 8 \mathrm{H}$, $\mathrm{CH}_{\text {phenyl }}$ ), 7.11 (d, $\left.J=8.4 \mathrm{~Hz}, 8 \mathrm{H}, \mathrm{CH}_{\text {phenyl }}\right), 3.21$ (br s, $\left.4 \mathrm{H}, \mathrm{OH}\right),-2.85$ (s, 2H, NH). ESI-MS $\left(\mathrm{M}_{W}=678.7\right): m / z=679.8[\mathrm{M}+\mathrm{H}]^{+}$.

\section{Monoalkylated 5,10,15,20-tetra(4-hydroxy phenyl)porphyrin 2}

The synthesis was carried out following a literature procedure with minor adjustments [15]. 5,10,15,20-Tetra(4-hydroxy phenyl)porphyrin $\mathbf{1}(175.8 \mathrm{mg}, 0.26 \mathrm{mmol})$ was dissolved in $40 \mathrm{ml}$ anhydrous DMSO and potassium carbonate $(282.8 \mathrm{mg}, 2.0 \mathrm{mmol})$ was added. The mixture was stirred at $60{ }^{\circ} \mathrm{C}$ under argon for $20 \mathrm{~min}$ before propargyl bromide $(47 \mathrm{mg}$ of 
a $80 \mathrm{wt} \%$ solution in toluene, $0.32 \mathrm{mmol}$ ) was added. The mixture was stirred at $60{ }^{\circ} \mathrm{C}$ under argon overnight. After the solution was cooled down to room temperature it was poured into $200 \mathrm{ml}$ brine and extracted with ethyl acetate. The organic phase was dried over $\mathrm{Na}_{2} \mathrm{SO}_{4}$, filtered and concentrated. The crude was purified by column chromatography (eluent DCM/EtOAc 7/3). $27.0 \mathrm{mg}$ (0.038 mmol, $15 \%$ ).

${ }^{1} \mathrm{H}$ NMR (acetone- $\left.\mathrm{d}_{6}\right): \delta[\mathrm{ppm}]=9.01-8.60\left(\mathrm{~m}, 8 \mathrm{H}, \mathrm{CH}_{\text {pyrrole }}\right), 8.07-7.75\left(\mathrm{~m}, 8 \mathrm{H}, \mathrm{CH}_{\text {phenyl }}\right)$, 7.32-6.84 (m, 8H, CH $\left.H_{\text {phenyl }}\right), 4.95$ (d, $\left.J=2.4 \mathrm{~Hz}, 2 \mathrm{H}, \mathrm{Ph}-\mathrm{O}-\mathrm{CH}_{2}\right),-2.84$ (s, 2H, NH); Signal for $\mathrm{C} \equiv \mathrm{C} H$ was hidden under water signal. ESI-MS $\left(\mathrm{M}_{W}=716.8\right): m / z=717.7[\mathrm{M}$ $+\left.\mathrm{H}\right|^{+}$.

\section{Monoalkylated zinc-metallated 5,10,15,20-tetra(4-hydroxy phenyl)porphyrin 3}

The synthesis was carried out following a literature procedure with minor adjustments [15]. The monoalkylated 5,10,15,20-tetra(4-hydroxy phenyl)porphyrin 2 (27 mg, $0.038 \mathrm{mmol})$ was dissolved in $20 \mathrm{ml}$ chloroform and then zinc acetate dihydrate (540.6 mg, $2.95 \mathrm{mmol}$ ), which was dissolved in $10 \mathrm{ml}$ methanol, was added. The mixture was refluxed for $1 \mathrm{~h}$. The solvent was removed and the crude was purified by column chromatography (eluent $\mathrm{DCM} / \mathrm{MeOH} 19 / 1)$. The product was obtained as violet solid. $23.6 \mathrm{mg}$ (0.030 mmol, $80 \%)$.

${ }^{1} \mathrm{H}$ NMR (acetone- $\left.\mathrm{d}_{6}\right): \delta[\mathrm{ppm}]=8.80-8.70\left(\mathrm{~m}, 8 \mathrm{H}, \mathrm{CH}_{\text {pyrrole }}\right), 7.99(\mathrm{~d}, J=8.4 \mathrm{~Hz}, 2 \mathrm{H}$, $\mathrm{C}_{\text {phenyl }}$ ), 7.89 (d, $\left.J=8.0 \mathrm{~Hz}, 6 \mathrm{H}, \mathrm{CH}_{\text {phenyl }}\right), 7.27$ (d, $\left.J=8.4 \mathrm{~Hz}, 2 \mathrm{H}, \mathrm{C} H_{\text {phenyl }}\right), 7.12$ $\left(\mathrm{d}, J=8.1 \mathrm{~Hz}, 6 \mathrm{H}, \mathrm{C} H_{\text {phenyl }}\right), 4.94\left(\mathrm{~s}, 2 \mathrm{H}, \mathrm{Ph}-\mathrm{O}-\mathrm{C} H_{2}\right), 3.11(\mathrm{~s}, 1 \mathrm{H}, \mathrm{C} \equiv \mathrm{CH})$. ESI-MS $\left(\mathrm{M}_{W}=780.2, \mathrm{M}_{E}=778.2\right): m / z=778.0[\mathrm{M}]^{+}$.

\section{Tetraalkylated 5,10,15,20-tetra(4-hydroxy phenyl)porphyrin 4}

The synthesis was carried out as detailed for porphyrin 2 . The crude of the reaction between potassium carbonate $(2.41 \mathrm{~g}, 17.4 \mathrm{mmol}$ ), propargyl bromide (1.07 $\mathrm{g}$ of a $80 \mathrm{wt} \%$ solution in toluene, $7.2 \mathrm{mmol}$ ) and $151 \mathrm{mg}$ mixture of mono-, di-, tri- and tetraalkylated $5,10,15,20$-tetra(4-hydroxy phenyl)porphyrins in $60 \mathrm{ml}$ anhydrous DMSO was purified by column chromatography (eluent DCM). $76.6 \mathrm{mg}$ (0.092 mmol).

${ }^{1} \mathrm{H} \mathrm{NMR}\left(\mathrm{CDCl}_{3}\right): \delta[\mathrm{ppm}]=8.78\left(\mathrm{~s}, 8 \mathrm{H}, \mathrm{CH}_{\text {pyrrole }}\right), 8.04\left(\mathrm{~d}, J=8.6 \mathrm{~Hz}, 8 \mathrm{H}, \mathrm{CH}_{\text {phenyl }}\right)$, $7.25\left(\mathrm{~d}, J=8.6 \mathrm{~Hz}, 8 \mathrm{H}, \mathrm{CH}_{\text {phenyl }}\right.$ ), 4.87 (sd, $J=2.3 \mathrm{~Hz}, 8 \mathrm{H}, \mathrm{Ph}-\mathrm{O}-\mathrm{CH} H_{2}$ ), 2.60 (st, $J$ $=2.4 \mathrm{~Hz}, 4 \mathrm{H}, \mathrm{C} \equiv \mathrm{CH}),-2.85(\mathrm{~s}, 2 \mathrm{H}, \mathrm{N} H)$. ESI-MS $\left(\mathrm{M}_{W}=830.9, \mathrm{M}_{E}=830.3\right): \mathrm{m} / z=$ 
$830.4[\mathrm{M}]^{+}$.

\section{Tetraalkylated zinc-metallated 5,10,15,20-tetra(4-hydroxy phenyl)porphyrin 5}

The synthesis was carried out as given for porphyrin 3. Recorded NMR signals are in accordance with [22]. The crude of the reaction between $4(76.6 \mathrm{mg}, 0.092 \mathrm{mmol})$ and zinc acetate dihydrate $(1.33 \mathrm{~g}, 7.2 \mathrm{mmol})$ was purified by column chromatography (eluent $\mathrm{DCM} / \mathrm{n}$-hexane $4 / 1)$. The product was obtained as violet solid. $51.8 \mathrm{mg}(0.058 \mathrm{mmol}$, $63 \%)$.

${ }^{1} \mathrm{H} \mathrm{NMR}\left(\mathrm{CDCl}_{3}\right): \delta[\mathrm{ppm}]=8.89\left(\mathrm{~s}, 8 \mathrm{H}, \mathrm{CH}_{\text {pyrrole }}\right), 8.07\left(\mathrm{~d}, J=6.6 \mathrm{~Hz}, 8 \mathrm{H}, \mathrm{CH}_{\text {phenyl }}\right)$, $7.28\left(\mathrm{~d}, J=6.6 \mathrm{~Hz}, 8 \mathrm{H}, \mathrm{CH}_{\text {phenyl }}\right), 4.91$ (s, 8H, Ph-O-C $\left.H_{2}\right), 2.62(\mathrm{~s}, 4 \mathrm{H}, \mathrm{C} \equiv \mathrm{CH})$. ESI-MS $\left(\mathrm{M}_{W}=894.3, \mathrm{M}_{E}=892.2\right): m / z=892.2[\mathrm{M}]^{+}$.

\section{1,2,3,4,6-Penta- $O$-acetyl- $\alpha / \beta$-D-mannopyranose 7}

The synthesis was carried out following a literature procedure with minor adjustments [26]. Recorded NMR signals are in accordance with [27]. To D-mannose (1.814 g, $10.1 \mathrm{mmol})$ and sodium acetate $(1.077 \mathrm{~g}, 13.1 \mathrm{mmol})$ was added $9.5 \mathrm{ml}$ acetic anhydride. The mixture was stirred at $80{ }^{\circ} \mathrm{C}$ for $4 \mathrm{~h}$. After cooling down it was poured into $70 \mathrm{ml}$ saturated $\mathrm{NaHCO}_{3}$ solution and stirred for two more hours. Extraction was done with DCM and the organic phase was dried over $\mathrm{Na}_{2} \mathrm{SO}_{4}$. Purification by column chromatography (eluent gradient from EtOAc/n-hexane 1/4 to EtOAC) yielded the product. $3.61 \mathrm{~g}(9.26 \mathrm{mmol}$, $92 \%)$.

${ }^{1} \mathrm{H} \mathrm{NMR}\left(\mathrm{CDCl}_{3}\right): \delta[\mathrm{ppm}]=6.02\left(\mathrm{~s}, 1 \mathrm{H}, \mathrm{CH}_{\text {anomeric }}\right), 5.28(\mathrm{~d}, J=6.1 \mathrm{~Hz}, 2 \mathrm{H}, \mathrm{O}-\mathrm{CH})$, 5.22-5.16 (m, 1H, O-CH), 4.25-4.18 (m, 1H, O-CH $2.12\left(\mathrm{~s}, 3 \mathrm{H}, \mathrm{C}(\mathrm{O})-\mathrm{CH}_{3}\right), 2.11\left(\mathrm{~s}, 3 \mathrm{H}, \mathrm{C}(\mathrm{O})-\mathrm{CH}_{3}\right), 2.03$ (s, 3H, C(O)-CH $\left.H_{3}\right), 1.99$ (s, 3H, $\left.\mathrm{C}(\mathrm{O})-\mathrm{CH}_{3}\right), 1.94\left(\mathrm{~s}, 3 \mathrm{H}, \mathrm{C}(\mathrm{O})-\mathrm{C} H_{3}\right)$.

\section{2,3,4,6-Tetra- $O$-acetyl- $\alpha / \beta$-D-mannopyranose 8 and}

\section{2,3,4,6-tetra- $O$-acetyl- $\alpha$-D-mannopyranosyl-trichloroimidate 9}

The syntheses were carried out following literature procedures with minor adjustments 19 , 28]. D-Mannose pentaacetate 7 (1320 mg, $3.38 \mathrm{mmol})$ was dissolved in $12 \mathrm{ml}$ BHTstabilized THF. Then benzylamine $(0.95 \mathrm{ml}, 8.7 \mathrm{mmol})$ was added. The mixture was stirred at room temperature overnight. The TLC (EtOAc/DCM 1/4) showed full con- 
version. The reaction mixture was diluted with $30 \mathrm{ml} \mathrm{DCM}$ and washed with $1 \mathrm{M} \mathrm{HCl}$, saturated $\mathrm{NaHCO}_{3}$ solution and water. After drying over $\mathrm{MgSO}_{4}, 8$ was concentrated and used without further purification or characterization. Sugar $8(3.38 \mathrm{mmol})$ was dissolved in $30 \mathrm{ml} \mathrm{DCM}$ and cooled to $0{ }^{\circ} \mathrm{C}$ under argon. Then trichloroacetonitrile $\mathrm{CCl}_{3} \mathrm{CN}$ (11.6 ml, $116 \mathrm{mmol}$ ) and 1,8-diazabicyclo[5.4.0]undec-7-en (DBU) (0.13 ml, $0.87 \mathrm{mmol})$ in DCM were added and the reaction was stirred for $2 \mathrm{~h}$ at $0{ }^{\circ} \mathrm{C}$ before the solvent was removed. The crude was purified by column chromatography (eluent EtOAc/n-hexane $2 / 3$ ). The second fraction was the product. $852.3 \mathrm{mg}$ ( $2.45 \mathrm{mmol}, 72 \%$ over 2 steps).

${ }^{1} \mathrm{H} \operatorname{NMR}\left(\mathrm{CDCl}_{3}\right): \delta[\mathrm{ppm}]=8.74(\mathrm{~s}, 1 \mathrm{H}, \mathrm{NH}), 6.22\left(\mathrm{~d}, J=1.9 \mathrm{~Hz}, 1 \mathrm{H}, \mathrm{CH}_{\text {anomeric }}\right)$, 5.60-5.15 (m, 3H, O-CH), 4.30-3.95 (m, 3H, O-CH, O-CH $H_{2}$, 2.20-1.90 (m, 12H, C(O)$\left.\mathrm{CH}_{3}\right)$.

\section{2-(2-(2-(2-Azidoethoxy)ethoxy)ethoxy)ethoxy-2,3,4,6-tetra- $O$-acetyl- $\alpha$-D- mannopyranose 10}

The mannose tetraethylene glycol azide was synthesized according to [19, 29] in water-free conditions. Therefore DCM was dried over molecular sieve (MS $4 \AA$ ) for at least $2 \mathrm{~d}$ and powdered MS $4 \AA$ was activated by heating with the heatgun under vacuum for 15 min. The mannose trichloracetimidate $9(840.6 \mathrm{mg}, 1.71 \mathrm{mmol})$ and monoazido tetraethylene glycol 6 (386.4 mg, $1.76 \mathrm{mmol}$ ) were dissolved in $22.5 \mathrm{ml}$ DCM under argon and powdered MS $4 \AA$ was added. The mixture was cooled to $-18{ }^{\circ} \mathrm{C}(\mathrm{NaCl}$ and ice) before TMSOTf $(160 \mu \mathrm{l}, 0.88 \mathrm{mmol})$ was added and the mixture was stirred at $-18^{\circ} \mathrm{C}$ for $2.5 \mathrm{~h}$. Afterwards saturated $\mathrm{NaHCO}_{3}$ solution was added and the mixture was extracted with DCM. The organic phase was dried over $\mathrm{MgSO}_{4}$ and concentrated under vacuum. The crude was purified by column chromatography (eluent EtOAc/n-hexane 2/3). $203.3 \mathrm{mg}(0.37 \mathrm{mmol}$, $22 \%)$.

${ }^{1} \mathrm{H} \mathrm{NMR}\left(\mathrm{CDCl}_{3}\right): \delta[\mathrm{ppm}]=5.33-5.27\left(\mathrm{~m}, 1 \mathrm{H}, \mathrm{CH}_{\text {anomeric }}\right), 5.23-5.08(\mathrm{~m}, 3 \mathrm{H}, \mathrm{O}-\mathrm{CH})$, 4.17-4.10 (m, 2H, O-C $\left.H_{2}\right), 4.06-3.97(\mathrm{~m}, 1 \mathrm{H}, \mathrm{O}-\mathrm{CH}), 3.61-3.51\left(\mathrm{~m}, 16 \mathrm{H}, \mathrm{O}-\mathrm{CH}_{2}\right), 3.27$ (t, $\left.J=5.1 \mathrm{~Hz}, 2 \mathrm{H}, \mathrm{N}_{3}-\mathrm{CH}_{2}\right), 2.04\left(\mathrm{~s}, 3 \mathrm{H}, \mathrm{C}(\mathrm{O})-\mathrm{CH} H_{3}\right), 1.98\left(\mathrm{~s}, 3 \mathrm{H}, \mathrm{C}(\mathrm{O})-\mathrm{CH}_{3}\right), 1.93(\mathrm{~s}, 3 \mathrm{H}$, $\left.\mathrm{C}(\mathrm{O})-\mathrm{CH}_{3}\right), 1.88\left(\mathrm{~s}, 3 \mathrm{H}, \mathrm{C}(\mathrm{O})-\mathrm{CH}_{3}\right)$. ESI-MS $\left(\mathrm{M}_{W}=549.5\right): m / z=551.3[\mathrm{M}+\mathrm{H}]^{+}$. 


\section{2,3,4,6-Tetra- $O$-acetyl- $\beta$-D-galactopyranose 11 and}

\section{2,3,4,6-tetra- $O$-acetyl- $\beta$-D-galactopyranosyl-trichloroimidate 12}

The syntheses were carried out as given for 8 and 9. 1,2,3,4,6-Penta-O-acetyl- $\beta$-D-galactopyranoside (4.0 g, $10.25 \mathrm{mmol})$ and benzylamine $(2.3 \mathrm{ml}, 21.1 \mathrm{mmol})$ were reacted in 29 $\mathrm{ml}$ THF. Product $\mathbf{1 1}$ was used without further purification or characterization. Sugar 11 $(10.25 \mathrm{mmol})$ was reacted with $\mathrm{CCl}_{3} \mathrm{CN}(12.2 \mathrm{ml}, 122 \mathrm{mmol})$ and $\mathrm{DBU}(0.14 \mathrm{ml}, 0.94$ $\mathrm{mmol}$ ) in $30 \mathrm{ml}$ DCM. The crude was purified by column chromatography (eluent EtOAc/nhexane $3 / 7)$. The second fraction was the product. $2.213 \mathrm{~g}$ ( $4.49 \mathrm{mmol}, 44 \%$ over 2 steps).

${ }^{1} \mathrm{H} \mathrm{NMR}\left(\mathrm{CDCl}_{3}\right): \delta[\mathrm{ppm}]=8.68($ br. s, $1 \mathrm{H}, \mathrm{NH}), 6.56\left(\mathrm{~s}, 1 \mathrm{H}, \mathrm{C} H_{\text {anomeric }}\right), 5.53(\mathrm{dd}, J$ $=3.0,1.0 \mathrm{~Hz}, 1 \mathrm{H}, \mathrm{O}-\mathrm{CH}), 5.36(\mathrm{qd}, J=12.5,3.3 \mathrm{~Hz}, 2 \mathrm{H}, \mathrm{O}-\mathrm{CH}), 4.41(\mathrm{t}, J=6.6 \mathrm{~Hz}, 1 \mathrm{H}$, $\mathrm{O}-\mathrm{CH}), 4.17-4.02\left(\mathrm{~m}, 2 \mathrm{H}, \mathrm{O}-\mathrm{CH}_{2}\right), 2.14$ (s, 3H, C(O)-CH3 $), 2.01-1.98$ (m, 9H, C(O)-C $\left.H_{3}\right)$.

\section{2-(2-(2-(2-Azidoethoxy)ethoxy)ethoxy)ethoxy-2,3,4,6-tetra- $O$-acetyl- $\beta$-D- galactopyranose 13}

The synthesis was carried out following a literature procedure with minor adjustments [29] under water-free conditions. Therefore DCM was dried over molecular sieve (MS $4 \AA$ ) for at least $2 \mathrm{~d}$ and powdered MS $4 \AA$ was activated by heating with the heatgun under vacuum for $15 \mathrm{~min}$. The galactose trichloracetimidate 12 (1.007 g, $2.04 \mathrm{mmol})$ and monoazido tetraethylene glycol 6 (1.348 g, $6.15 \mathrm{mmol})$ were dissolved in $10 \mathrm{ml}$ DCM under argon and powdered MS $4 \AA$ was added. The mixture was cooled to $-15{ }^{\circ} \mathrm{C}(\mathrm{NaCl}$ and ice) before TMSOTf $\left(66 \mu \mathrm{l}, 0.36 \mathrm{mmol}\right.$ ) was added and the mixture was stirred at $-12{ }^{\circ} \mathrm{C}$ for $2 \mathrm{~h}$. Afterwards saturated $\mathrm{NaHCO}_{3}$ solution was added and stirred for 20 min, then HyFlo Super Cel (Celite) was added and the mixture was filtered through a Büchner funnel and rinsed with DCM. The filtered solution was concentrated and purified by column chromatography (eluent gradient from EtOAc/n-hexane $3 / 7$ to $1 / 1$ to $100 \%$ EtOAc). 726.9 mg (1.32 mmol, $65 \%)$.

${ }^{1} \mathrm{H} \mathrm{NMR}\left(\mathrm{CDCl}_{3}\right): \delta[\mathrm{ppm}]=5.31\left(\mathrm{~d}, J=2.7 \mathrm{~Hz}, 1 \mathrm{H}, \mathrm{C} H_{\text {anomeric }}\right), 5.16-5.08(\mathrm{~m}, 1 \mathrm{H}$, O-CH ) , 4.98-4.92 (m, 1H, O-CH), 4.53 (d, $J=8.0 \mathrm{~Hz}, 1 \mathrm{H}, \mathrm{O}-\mathrm{CH}), 4.08$ (dd, $J=6.6$, $\left.2.4 \mathrm{~Hz}, 2 \mathrm{H}, \mathrm{O}-\mathrm{CH}_{2}\right), 3.93-3.84(\mathrm{~m}, 1 \mathrm{H}, \mathrm{O}-\mathrm{CH}), 3.74-3.50\left(\mathrm{~m}, 14 \mathrm{H}, \mathrm{O}-\mathrm{C} H_{2}\right), 3.33(\mathrm{t}, J=$ $\left.5.2 \mathrm{~Hz}, 2 \mathrm{H}, \mathrm{N}_{3}-\mathrm{CH}_{2}\right), 2.08\left(\mathrm{~s}, 3 \mathrm{H}, \mathrm{C}(\mathrm{O})-\mathrm{CH}_{3}\right), 1.99\left(\mathrm{~s}, 3 \mathrm{H}, \mathrm{C}(\mathrm{O})-\mathrm{CH} H_{3}\right), 1.98(\mathrm{~s}, 3 \mathrm{H}, \mathrm{C}(\mathrm{O})-$ $\left.\mathrm{CH}_{3}\right), 1.91\left(\mathrm{~s}, 3 \mathrm{H}, \mathrm{C}(\mathrm{O})-\mathrm{CH}_{3}\right) .{ }^{13} \mathrm{C} \mathrm{NMR}\left(\mathrm{CDCl}_{3}\right): \delta[\mathrm{ppm}]=170.60,170.45,170.31$, 170.12, 90.59, 70.93, 70.67, 70.63, 70.54, 70.03, 69.10, 68.37, 68.22, 67.28, 66.09, 63.61, 61.80, 50.65, 20.94, 20.81, 20.70, 20.63. 


\section{Monosubstituted tetraethylene glycol porphyrin P-TEG}

In a microwave vial porphyrin 3 (44.6 $\mathrm{mg}, 0.057 \mathrm{mmol}$ ) was dissolved in $1.5 \mathrm{ml} \mathrm{THF}$ and the azido tetraethylene glycol $6(36.1 \mathrm{mg}, 0.165 \mathrm{mmol})$ in $0.9 \mathrm{ml}$ tert-butanol was added. $\mathrm{CuSO}_{4} \cdot 5 \mathrm{H}_{2} \mathrm{O}(8.3 \mathrm{mg}, 0.032 \mathrm{mmol}$ ) and sodium ascorbate $(16.4 \mathrm{mg}, 0.083 \mathrm{mmol}$ ) were dissolved in $0.45 \mathrm{ml}$ water and added to the reaction mixture. The mixture was treated in the microwave $\left(\mathrm{T}=45^{\circ} \mathrm{C}, \mathrm{p}=250 \mathrm{psi}, \mathrm{P}=200 \mathrm{~W}, \mathrm{t}=10 \mathrm{~min}\right)$ and was afterwards stirred at rt overnight. After water was added and precipitation occurred, the mixture was extracted with ethyl acetate. The combined organic phases were washed with brine and water and dried over $\mathrm{Na}_{2} \mathrm{SO}_{4}$. Purification was done by column chromatography (eluent gradient from EtOAc to EtOAc/MeOH 9/1) to achieve the product as purple solid. $15.2 \mathrm{mg}(0.015 \mathrm{mmol}, 26 \%)$.

${ }^{1} \mathrm{H}$ NMR (acetone- $\left.\mathrm{d}_{6}\right): \delta[\mathrm{ppm}]=8.81-8.72\left(\mathrm{~m}, 8 \mathrm{H}, \mathrm{CH}_{\text {pyrrole }}\right), 7.95(\mathrm{~d}, J=7.0 \mathrm{~Hz}, 2 \mathrm{H}$, $\left.\mathrm{CH}_{\text {phenyl }}\right), 7.90\left(\mathrm{~d}, J=7.2 \mathrm{~Hz}, 6 \mathrm{H}, \mathrm{CH}_{\text {phenyl }}\right), 7.84$ (s, $\left.1 \mathrm{H}, \mathrm{C} H_{\text {triazole }}\right), 7.13$ (d, $J=7.5 \mathrm{~Hz}$, $\left.8 \mathrm{H}, \mathrm{CH}_{\text {phenyl }}\right), 4.78$ (s, 2H, Ph-O-C $\left.H_{2}\right), 4.32$ (t, $\left.J=4.0 \mathrm{~Hz}, 2 \mathrm{H}, \mathrm{N}-\mathrm{CH} H_{2}\right), 3.66$ (t, $J=4.3$ $\left.\mathrm{Hz}, 2 \mathrm{H}, \mathrm{N}-\mathrm{CH}_{2}-\mathrm{CH}_{2}\right), 3.45-3.26\left(\mathrm{~m}, 10 \mathrm{H}, \mathrm{O}-\mathrm{CH}_{2}\right), 3.15-3.10\left(\mathrm{~m}, 2 \mathrm{H}, \mathrm{O}-\mathrm{CH}_{2}\right) .{ }^{13} \mathrm{C} \mathrm{NMR}$ $\left(\right.$ acetone- $\left.\mathrm{d}_{6}\right): \delta[\mathrm{ppm}]=158.93,158.01,157.97,157.88,151.29,151.24,151.06,136.88$, $136.33,136.25,135.44,135.42,132.39,132.33,132.29,132.18,125.24,121.54,121.44$, 120.81, 114.30, 114.24, 113.68, 73.12, 71.11, 71.05, 71.00, 70.95, 69.94, 62.23, 61.64, 50.77. ESI-MS $\left(\mathrm{M}_{W}=999.4, \mathrm{M}_{E}=997.3\right): m / z=1020.4[\mathrm{M}+\mathrm{Na}]^{+}$. MALDI: matrix DHB: $m / z=958.4[(\mathrm{M}-\mathrm{Zn}+2 \mathrm{H})+\mathrm{Na}]^{+}$, $936.4[(\mathrm{M}-\mathrm{Zn}+2 \mathrm{H})+\mathrm{H}]^{+}$; matrix sinapinic acid: $m / z=999.0[\mathrm{M}+\mathrm{H}]^{+}, 936.1[(\mathrm{M}-\mathrm{Zn}+2 \mathrm{H})+\mathrm{H}]^{+}$.

\section{Monosubstituted mannose porphyrin P-TEG-Man}

\section{Cycloaddition between 3 and 10}

Before the reaction the solvents stabilized THF and water were degassed. Furthermore the ethyl acetate used in the purification process was distilled beforehand. In a microwave vial porphyrin 3 (40.0 $\mathrm{mg}, 0.051 \mathrm{mmol}$ ) was dissolved in $3.2 \mathrm{ml}$ THF and the azido tetraethylene glycol mannose $10(65.0 \mathrm{mg}, 0.12 \mathrm{mmol})$ in $2 \mathrm{ml}$ tert-butanol was added. $\mathrm{CuSO}_{4} \cdot 5 \mathrm{H}_{2} \mathrm{O}$ (7.6 mg, $0.030 \mathrm{mmol}$ ) and sodium ascorbate (14.4 mg, $0.073 \mathrm{mmol}$ ) were dissolved in $1 \mathrm{ml}$ water and added to the reaction mixture. A layer of argon was added before the microwave vial was closed. The mixture was treated in the microwave $(\mathrm{T}=$ $38{ }^{\circ} \mathrm{C}, \mathrm{p}=250 \mathrm{psi}, \mathrm{P}=200 \mathrm{~W}, \mathrm{t}=10 \mathrm{~min}$ ) and was afterwards stirred at rt for $2 \mathrm{~h}$. After water was added, the mixture was extracted twice with ethyl acetate. The combined organic phases were washed with brine and dried over $\mathrm{Na}_{2} \mathrm{SO}_{4}$. Purification was done by column chromatography (eluent EtOAc) to achieve the product as purple solid. $35.0 \mathrm{mg}$ 
(0.026 mmol, $51 \%)$.

${ }^{1} \mathrm{H}$ NMR (acetone- $\left.\mathrm{d}_{6}\right): \delta[\mathrm{ppm}]=8.88-8.74\left(\mathrm{~m}, 8 \mathrm{H}, \mathrm{C} H_{\text {pyrrole }}\right), 8.02-7.78\left(\mathrm{~m}, 8 \mathrm{H}, \mathrm{C} H_{\text {phenyl }}\right)$, 7.61 (s, 1H, CH $\left.H_{\text {triazole }}\right), 7.22-7.02\left(\mathrm{~m}, 8 \mathrm{H}, \mathrm{CH}_{\text {phenyl }}\right), 4.27$ (s, 2H, Ph-O-CH $\left.H_{2}\right), 4.14(\mathrm{~s}, 2 \mathrm{H}$, $\left.\mathrm{N}-\mathrm{CH}_{2}\right), 3.95(\mathrm{t}, J=4.7 \mathrm{~Hz}, 3 \mathrm{H}, \mathrm{O}-\mathrm{CH}), 3.54\left(\mathrm{~s}, 3 \mathrm{H}, \mathrm{N}-\mathrm{CH}_{2}-\mathrm{CH}_{2}, \mathrm{O}-\mathrm{CH}\right), 3.44$ (t, $\left.J=4.7 \mathrm{~Hz}, 3 \mathrm{H}, \mathrm{O}-\mathrm{CH}_{2}\right), 3.38-3.26\left(\mathrm{~m}, 12 \mathrm{H}, \mathrm{O}-\mathrm{CH}_{2}, \mathrm{O}-\mathrm{CH}\right), 1.92-1.74(\mathrm{~m}, 4 \mathrm{H}, \mathrm{C}(\mathrm{O})-$ $\left.\mathrm{CH}_{3}\right)$; Remaining $\mathrm{C}(\mathrm{O})-\mathrm{CH}_{3}$ peaks not found due to possible deprotection during reaction. ${ }^{13} \mathrm{C}$ peaks from HMQC NMR $\left(\right.$ acetone- $\left._{6}\right): \delta[\mathrm{ppm}]=135.30\left(\mathrm{CH}_{\text {phenyl }}\right), 131.30$ ( $\left.\mathrm{CH}_{\text {pyrrole }}\right), 124.06$ ( $\left.\mathrm{CH}_{\text {triazole }}\right), 113.38$ ( $\left.\mathrm{CH}_{\text {phenyl }}\right), 70.10\left(\mathrm{O}-\mathrm{CH}_{2}, \mathrm{O}-\mathrm{CH}\right), 69.30$ (O- $\mathrm{CH}_{2}$, $\mathrm{O}-\mathrm{CH}), 69.05\left(\mathrm{~N}_{-} \mathrm{CH}_{2}-\mathrm{CH}_{2}, \mathrm{O}-\mathrm{CH}\right), 63.06(\mathrm{O}-\mathrm{CH}), 61.16\left(\mathrm{Ph}-\mathrm{O}-\mathrm{CH}_{2}\right), 49.73\left(\mathrm{~N}-\mathrm{CH}_{2}\right)$, $19.82\left(\mathrm{C}(\mathrm{O})-C_{3}\right)$. MALDI $\left(\mathrm{M}_{W}=1329.7, \mathrm{M}_{E}=1327.4\right): m / z=1182.8[(\mathrm{M}-4 \mathrm{Ac}+4$ $\mathrm{H})+\mathrm{Na}]^{+}$.

\section{Deprotection of the acetyl groups of the mannose functionalized zinc por- phyrin}

The porphyrin of the previous reaction $(35.0 \mathrm{mg}, 0.026 \mathrm{mmol})$ was dissolved in $7 \mathrm{ml}$ dry methanol. Under argon atmosphere sodium methoxide $(7.4 \mathrm{mg}, 0.14 \mathrm{mmol})$ was added and the reaction mixture was stirred for $2.5 \mathrm{~h}$. Afterwards ion exchanger Amberlite IR120 was added until the $\mathrm{pH}$ was neutral. After filtration the solvent was removed. The crude was purified by column chromatography (eluent EtOAc/MeOH 19/1). The product fraction was concentrated, dissolved in a minimum amount of methanol and precipitated by heptane addition. The purple solid was dried under vacuum. $16.6 \mathrm{mg}(0.014 \mathrm{mmol}, 54 \%)$.

${ }^{1} \mathrm{H}$ NMR (acetone- $\left.\mathrm{d}_{6}\right): \delta[\mathrm{ppm}]=8.98-8.85\left(\mathrm{~m}, 8 \mathrm{H}, \mathrm{CH}_{\text {pyrrole }}\right), 8.19-8.01\left(\mathrm{~m}, 8 \mathrm{H}, \mathrm{CH}_{\text {phenyl }}\right)$, 8.01-7.89 (m, 1H, CH triazole $)$, 7.45-7.24 (m, 8H, CH $\left.\mathrm{Chenyl}_{\mathrm{l}}\right), 5.27-5.19$ (m, 2H, Ph-O$\left.\mathrm{CH}_{2}\right), 4.61-4.56\left(\mathrm{~m}, 2 \mathrm{H}, \mathrm{N}-\mathrm{CH} H_{2}\right), 3.90\left(\mathrm{t}, J=4.6 \mathrm{~Hz}, 2 \mathrm{H}, \mathrm{N}-\mathrm{CH}_{2}-\mathrm{CH}_{2}\right), 3.64-3.46$ (m, $\left.15 \mathrm{H}, \mathrm{O}-\mathrm{CH}_{2}, \mathrm{O}-\mathrm{CH}\right), 3.38-3.30\left(\mathrm{~m}, 4 \mathrm{H}, \mathrm{O}-\mathrm{CH} \mathrm{H}_{2}, \mathrm{O}-\mathrm{CH}\right) .{ }^{13} \mathrm{C}$ peaks from HMQC NMR $\left(\right.$ acetone-d $\left._{6}\right): \delta[\mathrm{ppm}]=135.26\left(\mathrm{CH}_{\text {phenyl }}\right), 131.33\left(\mathrm{CH}_{\text {pyrrole }}\right), 124.57\left(\mathrm{CH}_{\text {triazole }}\right), 113.27$ $\left(\mathrm{CH}_{\text {phenyl }}\right), 72.14\left(\mathrm{O}-\mathrm{CH}_{2}, \mathrm{O}-\mathrm{CH}\right), 70.10\left(\mathrm{O}-\mathrm{CH}_{2}, \mathrm{O}-\mathrm{CH}\right), 69.13\left(\mathrm{~N}_{-} \mathrm{CH}_{2}-\mathrm{CH}_{2}\right), 61.37(\mathrm{Ph}-$ O- $\left.\mathrm{CH}_{2}\right), 60.59\left(\mathrm{O}-\mathrm{CH}_{2}\right.$, O- $\left.\mathrm{CH}\right), 49.65\left(\mathrm{~N}-\mathrm{CH}_{2}\right)$. MALDI $\left(\mathrm{M}_{W}=1191.6, \mathrm{M}_{E}=1189.3\right)$ : matrix DCTB: $m / z=1995.4[2(\mathrm{M}-\mathrm{Man})]^{+}, 1020.2[(\mathrm{M}-\mathrm{Man})+\mathrm{Na}]^{+}, 997.2[\mathrm{M}-$ Man $]^{+}$; matrix sinapinic acid: $m / z=1020.2[(\mathrm{M}-\mathrm{Man})+\mathrm{Na}]^{+}, 958.3[(\mathrm{M}-\mathrm{Man}-\mathrm{Zn}$ $+2 \mathrm{H})+\mathrm{Na}]^{+}, 936.4[(\mathrm{M}-\mathrm{Man}-\mathrm{Zn}+2 \mathrm{H})+\mathrm{H}]^{+}$.

\section{Monosubstituted galactose porphyrin P-TEG-Gal}

\section{Cycloaddition between 3 and 13}

Before the reaction the solvents stabilized THF and water were degassed. Furthermore the 
ethyl acetate used in the purification process was distilled beforehand. In a microwave vial porphyrin 3 (38.5 mg, $0.049 \mathrm{mmol}$ ) was dissolved in $3 \mathrm{ml} \mathrm{THF}$ and the azido tetraethylene glycol mannose $\mathbf{1 3}(68.0 \mathrm{mg}, 0.12 \mathrm{mmol})$ in $2 \mathrm{ml}$ tert-butanol was added. $\mathrm{CuSO}_{4} \cdot 5 \mathrm{H}_{2} \mathrm{O}$ $(7.4 \mathrm{mg}, 0.030 \mathrm{mmol})$ and sodium ascorbate $(14.9 \mathrm{mg}, 0.075 \mathrm{mmol})$ were dissolved in $1 \mathrm{ml}$ water and added to the reaction mixture. The mixture was treated in the microwave ( $\mathrm{T}$ $=38^{\circ} \mathrm{C}, \mathrm{p}=250 \mathrm{psi}, \mathrm{P}=200 \mathrm{~W}, \mathrm{t}=10 \mathrm{~min}$ ) and was afterwards stirred at rt overnight. After water was added, the mixture was extracted twice with ethyl acetate. The combined organic phases were washed with brine and dried over $\mathrm{Na}_{2} \mathrm{SO}_{4}$. Purification was done by column chromatography (eluent EtOAc) to achieve the product as purple solid. $29.9 \mathrm{mg}$ (0.022 mmol, $46 \%)$.

${ }^{1} \mathrm{H}$ NMR (acetone- $\left.\mathrm{d}_{6}\right): \delta[\mathrm{ppm}]=8.81-8.72\left(\mathrm{~m}, 8 \mathrm{H}, \mathrm{C} H_{\text {pyrrole }}\right), 8.00-7.85\left(\mathrm{~m}, 8 \mathrm{H}, \mathrm{CH}_{\text {phenyl }}\right)$, $7.78\left(\mathrm{~s}, 1 \mathrm{H}, \mathrm{C} H_{\text {triazole }}\right), 7.12\left(\mathrm{~d}, J=8.2 \mathrm{~Hz}, 8 \mathrm{H}, \mathrm{CH}_{\text {phenyl }}\right), 4.99-4.86$ (m, 2H, O-CH), 4.65-4.47 (m, 3H, Ph-O-C $\left.H_{2}, \mathrm{CH}_{\text {anomeric }}\right), 4.26\left(\mathrm{t}, J=5.0 \mathrm{~Hz}, 2 \mathrm{H}, \mathrm{N}-\mathrm{CH}_{2}\right), 3.92-3.87(\mathrm{~m}$, $2 \mathrm{H}, \mathrm{O}-\mathrm{CH}_{2}$ ), 3.65-3.60 (m, 2H, N-CH$-\mathrm{CH}_{2}$ ), 3.49-3.28 (m, $\left.14 \mathrm{H}, \mathrm{O}-\mathrm{CH} \mathrm{H}_{2}, \mathrm{O}-\mathrm{CH}\right), 1.87-1.66$ $\left(\mathrm{m}, 12 \mathrm{H}, \mathrm{C}(\mathrm{O})-\mathrm{CH}_{3}\right) \cdot{ }^{13} \mathrm{C}$ NMR (acetone- $\left.d_{6}\right): \delta[\mathrm{ppm}]=170.75,170.55,170.27,169.86$, $158.88,157.99$, 151.30, 151.24, 151.05, 136.93, 136.34, 135.44, 132.40, 132.33, 132.29, 132.16, 125.18, 125.10, 121.53, 121.42, 120.78, 114.31, 113.63, 101.84, 71.68, 71.30, 71.14, 71.06, 70.98, 70.81, 69.85, 69.70, 68.26, 64.11, 62.06, 60.57, 50.75, 20.75, 20.53.

\section{Deprotection of the acetyl groups of the galactose functionalized zinc por- phyrin}

The porphyrin of the previous reaction $(29.9 \mathrm{mg}, 0.022 \mathrm{mmol}$ ) was dissolved in $10 \mathrm{ml}$ dry methanol. Under argon atmosphere sodium methoxide (14.0 mg, $0.26 \mathrm{mmol}$ ) was added and the reaction mixture was stirred for $3 \mathrm{~h}$. Afterwards ion exchanger Amberlite IR120 was added until the $\mathrm{pH}$ was neutral. After filtration the solvent was removed. The crude was purified by column chromatography (eluent EtOAc/ MeOH 9/1). The product fraction was concentrated, dissolved in a minimum amount of methanol and precipitated by heptane addition. The purple solid was dried under vacuum. $20.7 \mathrm{mg}(0.018 \mathrm{mmol}, 79 \%)$.

${ }^{1} \mathrm{H}$ and ${ }^{13} \mathrm{C}$ peaks from HMQC NMR $\left(\mathrm{CD}_{3} \mathrm{OD}\right): \delta[\mathrm{ppm}]=8.88 / 131.00\left(\mathrm{CH}_{\text {pyrrole }}\right), 8.00 /$ 135.05 ( $\left.\mathrm{CH}_{\text {phenyl }}\right), 7.84 / 125.07\left(\mathrm{CH}_{\text {triazole }}\right), 7.19 / 112.91\left(\mathrm{CH}_{\text {phenyl }}\right), 5.20 / 60.98$ (Ph-O$\left.\mathrm{CH}_{2}\right), 4.57 / 49.84\left(\mathrm{~N}-\mathrm{CH}_{2}\right), 4.16 / 102.52\left(\mathrm{CH}_{\text {anomeric }}\right), 3.80 / 69.00\left(\mathrm{~N} \mathrm{CH}_{2}-\mathrm{CH}_{2}\right), 3.72 / 60.87$ $\left(\mathrm{O}-\mathrm{CH}_{2}, \mathrm{O}-\mathrm{CH}\right), 3.66 / 69.36\left(\mathrm{O}-\mathrm{CH}_{2}\right.$, O- $\left.\mathrm{CH}\right), 3.61 / 62.49\left(\mathrm{O}-\mathrm{CH}_{2}, \mathrm{O}-\mathrm{CH}\right), 3.51 / 74.48(\mathrm{O}-$ $\mathrm{CH}_{2}$, O- $\left.\mathrm{CH}\right), 3.46 / 69.36\left(\mathrm{O}-\mathrm{CH}_{2}\right.$, O- $\left.\mathrm{CH}\right)$. MALDI $\left(\mathrm{M}_{W}=1161.5, \mathrm{M}_{E}=1159.3\right): \mathrm{m} / z$ $=1182.3[\mathrm{M}+\mathrm{Na}]^{+}, 1159.3[\mathrm{M}]^{+}, 998.3[\mathrm{M}-\mathrm{Gal}+\mathrm{H}]^{+}, 935.2[\mathrm{M}-\mathrm{Gal}-\mathrm{Zn}+2 \mathrm{H}]^{+}$, $740.1[(\mathrm{M}-\mathrm{Gal}-\mathrm{TEG})]^{+}$. 


\section{Tetrasubstituted mannose porphyrin P-(TEG-Man) ${ }_{4}$}

\section{Cycloaddition between 5 and 10}

Before the reaction the solvents stabilized THF and water were degassed. Furthermore the ethyl acetate used in the purification process was distilled beforehand. In a microwave vial porphyrin 5 (30.6 mg, $0.034 \mathrm{mmol}$ ) was dissolved in $3 \mathrm{ml}$ THF and the azido tetraethylene glycol mannose 10 (132.4 mg, $0.24 \mathrm{mmol})$ in $2 \mathrm{ml}$ tert-butanol was added. $\mathrm{CuSO}_{4} \cdot 5 \mathrm{H}_{2} \mathrm{O}$ (5.2 $\mathrm{mg}, 0.021 \mathrm{mmol}$ ) and sodium ascorbate (10.2 $\mathrm{mg}, 0.051 \mathrm{mmol}$ ) were dissolved in $1 \mathrm{ml}$ water and added to the reaction mixture. The mixture was treated in the microwave $(\mathrm{T}$ $=38{ }^{\circ} \mathrm{C}, \mathrm{p}=250 \mathrm{psi}, \mathrm{P}=200 \mathrm{~W}, \mathrm{t}=10 \mathrm{~min}$ ) and was afterwards stirred at rt overnight. After water was added, the mixture was extracted twice with ethyl acetate. The combined organic phases were washed with brine and dried over $\mathrm{Na}_{2} \mathrm{SO}_{4}$. Purification was done by column chromatography (eluent gradient from EtOAc to EtOAc/ MeOH 9/1) to achieve the product as purple solid. $38.9 \mathrm{mg}$ (0.013 mmol, $37 \%)$.

${ }^{1} \mathrm{H}$ NMR (acetone- $\left.d_{6}\right): \delta[\mathrm{ppm}]=8.75\left(\mathrm{~s}, 8 \mathrm{H}, \mathrm{C} H_{\text {pyrrole }}\right), 7.91\left(\mathrm{~s}, 8 \mathrm{H}, \mathrm{C} H_{\text {phenyl }}\right), 7.77$ (s, $\left.4 \mathrm{H}, \mathrm{C} H_{\text {triazole }}\right), 7.10-7.00\left(\mathrm{~m}, 8 \mathrm{H}, \mathrm{CH}_{\text {phenyl }}\right), 4.67$ (s, 8H, Ph-O-CH 2$), 4.28$ (s, 8H, N-CH $H_{2}$ ), $3.94\left(\mathrm{t}, J=4.9 \mathrm{~Hz}, 8 \mathrm{H}, \mathrm{N}-\mathrm{CH}_{2}-\mathrm{CH}_{2}\right), 3.83-2.99$ (m, 76H, O-C H, O-CH), 1.85-1.65 (m, $\left.20 \mathrm{H}, \mathrm{C}(\mathrm{O})-\mathrm{CH}_{3}\right)$. Remaining $\mathrm{C}(\mathrm{O})-\mathrm{CH}_{3}$ signals not found due to possible deprotection during reaction. ${ }^{13} \mathrm{C}$ peaks from HMQC NMR $\left(\right.$ acetone- $\left.\mathrm{d}_{6}\right): \delta[\mathrm{ppm}]=135.34\left(\mathrm{CH}_{\text {phenyl }}\right)$, 131.20 ( $\left.\mathrm{CH}_{\text {pyrrole }}\right), 124.58$ ( $\left.\mathrm{CH}_{\text {triazole }}\right), 113.66\left(\mathrm{CH}_{\text {phenyl }}\right), 72.08\left(\mathrm{O}-\mathrm{CH}_{2}, \mathrm{O}-\mathrm{CH}\right), 70.08$ $\left(\mathrm{O}-\mathrm{CH}_{2}, \mathrm{O}-\mathrm{CH}\right), 69.17\left(\mathrm{~N}_{-} \mathrm{CH}_{2}-\mathrm{CH}_{2}\right), 61.51\left(\mathrm{Ph}-\mathrm{O}-\mathrm{CH}_{2}\right), 60.96\left(\mathrm{O}-\mathrm{CH}_{2}, \mathrm{O}-\mathrm{CH}\right), 50.86$ $\left(\mathrm{N}-\mathrm{CH}_{2}\right), 20.82\left(\mathrm{C}(\mathrm{O})-\mathrm{CH}_{3}\right)$.

\section{Deprotection of the acetyl groups of the tetramannose functionalized zinc por- phyrin}

The porphyrin of the previous reaction $(38.9 \mathrm{mg}, 0.013 \mathrm{mmol})$ was dissolved in $15 \mathrm{ml}$ dry methanol. Under argon atmosphere sodium methoxide (300 $\mathrm{mg}, 5 \mathrm{mmol}$ ) was added and the reaction mixture was stirred for $2 \mathrm{~d}$, in the end at $40{ }^{\circ} \mathrm{C}$. Afterwards ion exchanger Amberlite IR120 was added until the $\mathrm{pH}$ was neutral. After filtration the solvent was removed. The crude was purified by column chromatography (eluent EtOAc/ $\mathrm{MeOH}$ 9/1). The product fraction was concentrated, dissolved in a minimum amount of methanol and precipitated by adding heptane. The purple solid product was dried under vacuum. $24.0 \mathrm{mg}(0.010 \mathrm{mmol}, 76 \%)$.

${ }^{1} \mathrm{H}$ NMR $\left(\right.$ DMSO-d $\left._{6}\right): \delta[\mathrm{ppm}]=8.80\left(\mathrm{~s}, 8 \mathrm{H}, \mathrm{CH}_{\text {pyrrole }}\right), 8.41\left(\mathrm{~s}, 4 \mathrm{H}, \mathrm{C} H_{\text {triazole }}\right), 8.10$ $\left(\mathrm{d}, J=8.4 \mathrm{~Hz}, 8 \mathrm{H}, \mathrm{C} H_{\text {phenyl }}\right), 7.47$ (d, $\left.J=8.6 \mathrm{~Hz}, 8 \mathrm{H}, \mathrm{CH} H_{\text {phenyl }}\right), 5.45$ (s, 8H, Ph-O$\mathrm{CH}_{2}$ ), $4.65\left(\mathrm{t}, J=5.0 \mathrm{~Hz}, 8 \mathrm{H}, \mathrm{N}-\mathrm{CH}_{2}\right), 3.92\left(\mathrm{t}, J=5.1 \mathrm{~Hz}, 8 \mathrm{H}, \mathrm{N}-\mathrm{CH}_{2}-\mathrm{CH}_{2}\right), 3.63-3.45$ $\left(\mathrm{m}, 76 \mathrm{H}, \mathrm{O}-\mathrm{CH}_{2}, \mathrm{O}-\mathrm{CH}\right) \cdot{ }^{13} \mathrm{C}$ peaks from HMQC NMR $\left(\mathrm{DMSO}_{-} \mathrm{d}_{6}\right): \delta[\mathrm{ppm}]=135.40$ 
$\left(\mathrm{CH}_{\text {phenyl }}\right), 131.60$ ( $\left.\mathrm{CH}_{\text {pyrrole }}\right), 124.52$ ( $\left.\mathrm{CH}_{\text {triazole }}\right), 113.17\left(\mathrm{CH}_{\text {phenyl }}\right), 72.69$ (O- $\mathrm{CH}_{2}, \mathrm{O}-$ $\mathrm{CH}), 70.24\left(\mathrm{O}-\mathrm{CH}_{2}, \mathrm{O}-\mathrm{CH}\right), 70.03\left(\mathrm{O}-\mathrm{CH}_{2}, \mathrm{O}-\mathrm{CH}\right), 69.21\left(\mathrm{O}-\mathrm{CH}_{2}, \mathrm{O}-\mathrm{CH}\right), 69.01(\mathrm{~N}-$ $\left.\mathrm{CH}_{2}-\mathrm{CH}_{2}\right), 61.84\left(\mathrm{Ph}-\mathrm{O}-\mathrm{CH}_{2}\right), 60.61\left(\mathrm{O}-\mathrm{CH}_{2}, \mathrm{O}-\mathrm{CH}\right), 49.76\left(\mathrm{~N}-\mathrm{CH}_{2}\right) \cdot$ MALDI $\left(\mathrm{M}_{W}=\right.$ 2419.8, $\left.\mathrm{M}_{E}=2416.9\right): m / z=1791.7[(\mathrm{M}-4 \mathrm{Man})+\mathrm{Na}]^{+}, 1768.7[(\mathrm{M}-4 \mathrm{Man})+\mathrm{H}]^{+}$, $1707.6[(\mathrm{M}-4 \mathrm{Man}-\mathrm{Zn})+\mathrm{H}]^{+}, 1511.55[(\mathrm{M}-4 \mathrm{Man}-1 \mathrm{TEG})]^{+}, 1450.5[(\mathrm{M}-4 \mathrm{Man}-$ $1 \mathrm{TEG}-\mathrm{Zn})+\mathrm{H}]^{+}, 1254.4[(\mathrm{M}-4 \mathrm{Man}-2 \mathrm{TEG})]^{+}, 740.1[(\mathrm{M}-4 \mathrm{Man}-4 \mathrm{TEG})]^{+}$.

\subsection{Bibliography}

[1] Fischer, H. Verfahren zur Darstellung von Porphyrinen. 28th of January 1930 (filed 11th of June 1926).

[2] Fischer, H. Verfahren zur Darstellung von Porphyrinen. 29th of October 1930 (filed 14th of March 1928).

[3] Fischer, H. Nobel Lectures Chemistry 1922-1941, On Haemin and the Relationships between Haemin and Chlorophyll, 1930.

[4] Rothemund, P. J. Am. Chem. Soc. 1935, 57, 2010-2011.

[5] Rothemund, P. J. Am. Chem. Soc. 1936, 58, 625-627.

[6] Adler, A. D.; Longo, F. R.; Finarelli, J. D.; Goldmacher, J.; Assour, J.; Korsakoff, L. J. Org. Chem. 1967, 32, 476-476.

[7] Lindsey, J. S.; Schreiman, I. C.; Hsu, H. C.; Kearney, P. C.; Marguerettaz, A. M. J. Org. Chem. 1987, 52, 827-836.

[8] Okada, M.; Kishibe, Y.; Ide, K.; Takahashi, T.; Hasegawa, T. International Journal of Carbohydrate Chemistry 2009, 1, ID 305276.

[9] Titov, D. V.; Gening, M. L.; Tsvetkov, Y. E.; Nifantiev, N. E. Russ. Chem. Rev. 2014, 83, $523-554$.

[10] Dumoulin, F.; Ahsen, V. JPP 2011, 15, 481-504.

[11] Garcia, G.; Naud-Martin, D.; Carrez, D.; Croisy, A.; Maillard, P. Tetrahedron 2011, 67, 4924-4932.

[12] Lang, N. Multiple "Click" Reactions on Porphyrins. Ph.D. thesis, Friedrich-AlexanderUniversität Erlangen-Nürnberg, 2010.

[13] Punidha, S.; Sinha, J.; Kumar, A.; Ravikanth, M. J. Org. Chem. 2007, 73, 323-326.

[14] Elmer, S. L.; Man, S.; Zimmerman, S. C. Eur. J. Org. Chem. 2008, 2008, 3845-3851.

[15] Hao, E.; Jensen, T. J.; Vicente, M. G. H. JPP 2009, 13, 51-59.

[16] Griesbeck, A. G.; Schäfer, M.; Uhlig, J. Adv. Synth. Catal. 2008, 350, 2104-2108.

[17] Kayushin, A.; Demekhina, A.; Korosteleva, M.; Miroshnikov, A.; Azhayev, A. Nucleosides Nucleotides Nucleic Acids 2011, 30, 490-502.

[18] Miura, Y.; Hoshino, Y.; Seto, H. Chem. Rev. 2016, 116, 1673-1692.

[19] Michel, O. Zuckerchips mittels „Click“-Chemie auf Oberflächen. M.Sc. thesis, Westfälische Wilhelms-Universität Münster, 2008.

[20] Ekholm, F. S.; Poláková, M.; Pawlowicz, A. J.; Leino, R. Synthesis 2009, 567-576.

[21] Bakleh, M.; Sol, V.; Estieu-Gionnet, K.; Granet, R.; Déléris, G.; Krausz, P. Tetrahedron 2009, 65, 7385-7392.

[22] Vedala, H.; Chen, Y.; Cecioni, S.; Imberty, A.; Vidal, S.; Star, A. Nano Lett. 2010, 11, 170-175.

[23] Wang, Z. Comprehensive Organic Name Reactions and Reagents; John Wiley \& Sons, Inc., 2010.

[24] Ren, B.; Wang, M.; Liu, J.; Ge, J.; Zhang, X.; Dong, H. Green Chem. 2015, 17, 1390-1394. 
[25] Gottlieb, H. E.; Kotlyar, V.; Nudelman, A. J. Org. Chem. 1997, 62, 7512-7515.

[26] Su, Y.; Xie, J.; Wang, Y.; Hu, X.; Lin, X. Eur. J. Med. Chem. 2010, 45, 2713-2718.

[27] Watt, J. A.; Williams, S. J. Org. Biomol. Chem. 2005, 3, 1982-1992.

[28] Daly, R.; Vaz, G.; Davies, A. M.; Senge, M. O.; Scanlan, E. M. Chem. Eur. J. 2012, 18, 14671-14679.

[29] Schaeffer, E.; Dehuyser, L.; Sigwalt, D.; Flacher, V.; Bernacchi, S.; Chaloin, O.; Remy, J.-S.; Mueller, C. G.; Baati, R.; Wagner, A. Bioconjugate Chem. 2013, 24, 1813-1823. 



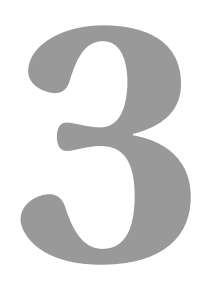

\section{Self-Assembly Properties of Glycoconjugated Porphyrins}

The self-assembly properties of one symmetric and three asymmetric porphyrin derivatives with slightly different hydrophilic profiles were studied. Upon changing the solvent from polar organic to water self-assembly of the porphyrins occurred, which was accompanied by a loss in fluorescence emission intensity of the porphyrins. In water the molecules self-assemble into round-shaped objects of about $50 \mathrm{~nm}$ in diameter. 


\subsection{Introduction}

The extended $\pi$-system of porphyrins has been used in different applications: as light harvesting units in organic solar cells [1, 2], for photodynamic therapy [3, 4], or as biochemical model receptors [5-8]. Porphyrins can assemble into different shapes, such as nanotubes, -rods, -fibers, -sheets or -particles [9].

Several interactions are responsible for the self-assembly of porphyrins. One of the strongest interactions is the metal coordination with the metal ion bound either in the center of the porphyrin (regular metalloporphyrin) or, in case of a too large metal ion, situated atop the center (SAT metalloporphyrin) [10]. Using metal coordination it is possible to build porphyrinic supramolecular polymers [11, 12]. Another important interaction between porphyrins is $\pi-\pi$-stacking caused by the quadrupole moments of the large $\pi$-system [10]. Apart from $\pi$ - $\pi$ interactions hydrophobic forces can play an important role during the self-assembly. The strength of the hydrophobic forces is strongly dependent on the solvent used. Stronger hydrophobic forces are expected in aqueous media when compared to organic solvents [13]. Drain and co-workers used a mixed solvent approach to produce porphyrin nanoparticles, i.e. the dissolution of the molecules in a "good" solvent and the addition of a "bad" solvent in excess under vigorous stirring. After subsequent sonication the produced nanoparticles had a size between $10-80 \mathrm{~nm}$ [14, 15]. The nanoparticle assemblies are also a result of balancing the hydrophobic (porphyrin platform) and hydrophilic (side chains, e.g. poly(ethylene glycol) (PEG), carbohydrate substituents or charged functionalities) character of the molecule. When the hydrophilic part of the molecule is too large the molecules can remain dissolved in aqueous media. If the molecule is too hydrophobic the assemblies are not stable in water and precipitation can occur.

Due to the 18 delocalized $\pi$-electrons of the porphyrin macrocycle the gap between the highest occupied molecular orbital (HOMO) and the lowest unoccupied molecular orbital (LUMO) is rather small. This results in absorption in the visible range of the spectrum. In absorption spectra of porphyrins two different types of bands can be detected: Soret and $\mathrm{Q}$ bands $[16]$. The Soret band, also called B band, is a highly intense band in the wavelength $(\lambda)$ range between $\lambda=380 \mathrm{~nm}$ and $\lambda=500 \mathrm{~nm}[10]$. This band represents the transition from the ground state to the second excited state $\left(\mathrm{S}_{0} \rightarrow \mathrm{S}_{2}\right)$. Its specific wavelength of maximum absorbance depends on the exact structure of the molecule and the type of bound metal [17]. The Q bands are less intense and located at higher wavelengths $(\lambda=500-750 \mathrm{~nm})$ in the visible region [10]. The Q bands are caused by a transition from the ground state to the first excited state $\left(\mathrm{S}_{0} \rightarrow \mathrm{S}_{1}\right)$. The free-base porphyrin shows four different $\mathrm{Q}$ bands: with increasing $\lambda \mathrm{Q}^{I V}, \mathrm{Q}^{I I}, \mathrm{Q}^{I I}, \mathrm{Q}^{I}[17]$. The absorbance ratio of the bands depends on the peripheral substitution [10]. Upon metal binding only two $Q$ 
bands remain due to the higher symmetry compared with the free-base derivative [16]. The fluorescence emission of the porphyrins occurs between $\lambda=600 \mathrm{~nm}$ and $\lambda=750 \mathrm{~nm}$. The aggregation of porphyrins has a strong influence on their spectral properties [18]. Close proximity of two molecules leads to the interaction of their transition dipole moments. The porphyrins can stack face-to-face ( $H$-aggregation), which causes a blue-shift in the absorption spectra [19, 20]. In contrast the head-to-tail stacking ( $J$-aggregation) leads to a red-shift [21]. Splitting of bands in the spectrum occurs if the molecules are stacked edge-to-edge, when solvent interactions with the hydrogen-bond providing side chains are directive and stronger than the $\pi$ - $\pi$-stacking of the core ring system.

In this chapter the self-assembly properties of symmetric and asymmetric glycoconjugated porphyrins are studied using absorption and emission spectroscopy, electron microscopy and dynamic light scattering. The zinc porphyrins P-TEG, P-TEG-Man, P-TEG-Gal and P-(TEG-Man) $)_{4}$, whose syntheses have been described in chapter 2 , feature a different number of side chains (one or four) and differ in the type of sugar moieties (mannose or galactose) (Fig. 3.1). Those variations result in different hydrophilic to hydrophobic balances in these molecules.

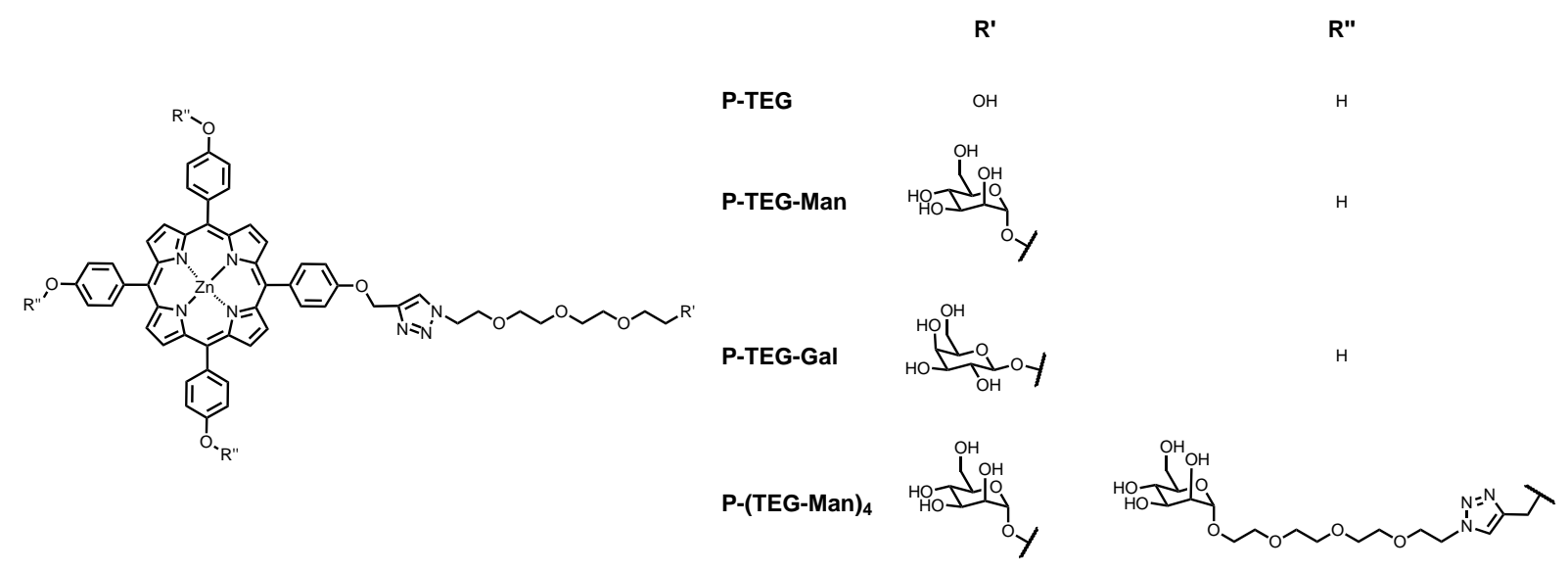

Figure 3.1 - Chemical structures of the porphyrins P-TEG, P-TEG-Man, P-TEG-Gal and P-(TEG-Man) $)_{4}$.

\subsection{Results and discussion}

\subsubsection{Optical properties of porphyrin self-assemblies in water}

The spectral properties of porphyrins are sensitive to the state of the molecules in solution. A change from the monomeric to a self-assembled state is visible in the absorption and fluorescence spectra by a change in the wavelength maxima $\left(\lambda_{\max , a b s}\right.$ and $\left.\lambda_{\max , e m}\right)$. Measuring the absorption spectra of P-TEG in different methanol-water mixtures resulted in the typical porphyrin spectra with Soret and Q bands (Fig. 3.2a). For high methanol con- 
tent the Soret band is narrow, intense and located at $\lambda=424 \mathrm{~nm}$, representing monomeric species in solution. With increasing water content the absorbance decreases and the band broadens. This is an indication for aggregating porphyrin species [15, 18]. Furthermore the wavelength of the maximum absorbance red-shifted to about $\lambda=430 \mathrm{~nm}$ when increasing the water content from $60 \%$ to $85 \%$, indicative of $J$-type aggregation [22]. Higher water content did not result in further changes. Around $\lambda=600 \mathrm{~nm}$ the $\mathrm{Q}$ bands of the porphyrin were found, which bathochromically shifted when the solvent was changed from methanol to water (Fig. 3.2a, left inset). All four synthesized porphyrins feature only two instead of four Q bands due to their higher symmetry caused by the inserted zinc ion.

For the other two asymmetrical porphyrins P-TEG-Man and P-TEG-Gal, who similar to P-TEG also possess one side chain, the observed behaviour was similar (Fig. $3.2 \mathrm{~b}$ ) and

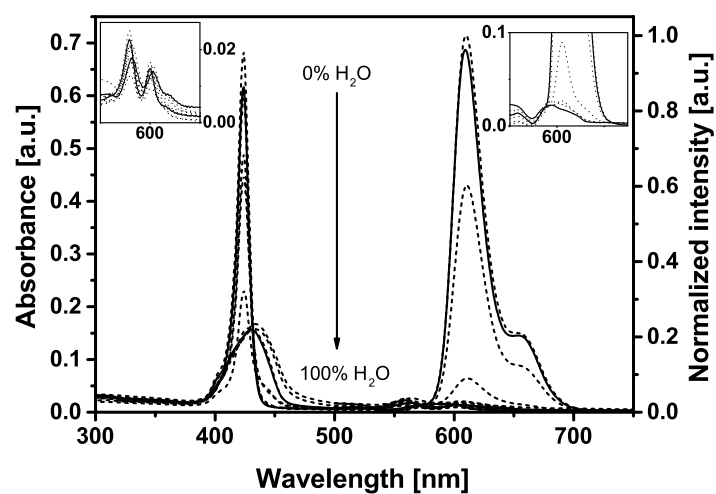

(a)

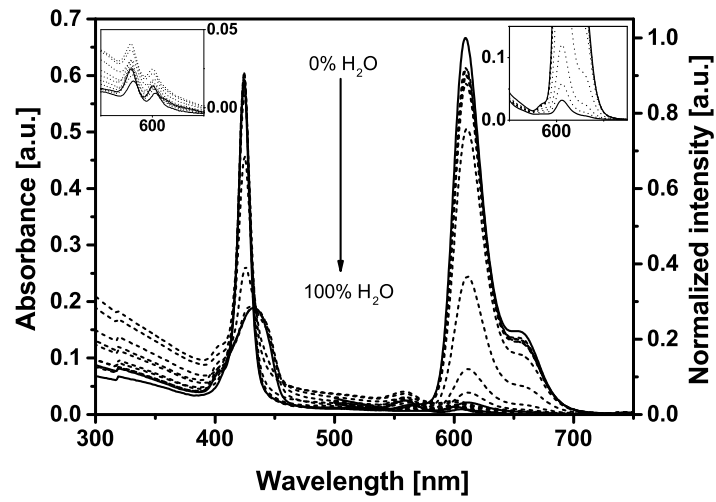

(c)

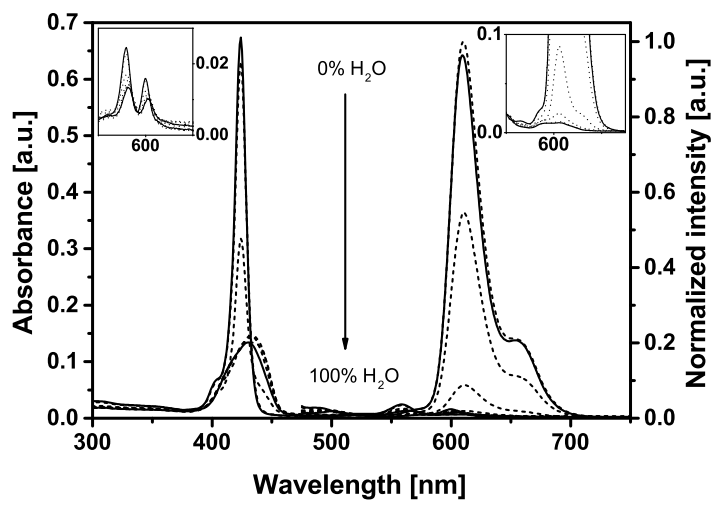

(b)

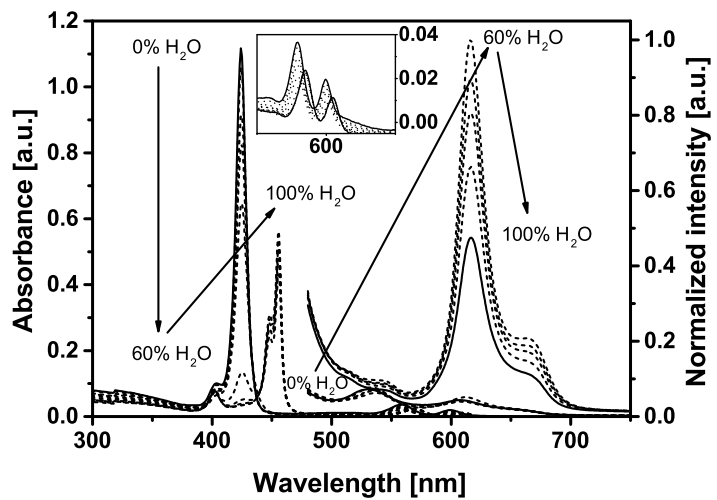

(d)

Figure 3.2 - Absorption and fluorescence spectra in methanol-water mixtures of (a) P-TEG $\left(\lambda_{e x c}=430 \mathrm{~nm}\right)$, (b) P-TEG-Man $\left(\lambda_{e x c}=430 \mathrm{~nm}\right)$, (c) P-TEG-Gal $\left(\lambda_{e x c}\right.$ $=425 \mathrm{~nm})$, and $(\mathrm{d}) \mathbf{P}$-(TEG-Man $)_{4}\left(\lambda_{e x c}=455 \mathrm{~nm}\right)$. The left inset shows the $\mathrm{Q}$ bands of the porphyrins. The right inset in (a), (b) and (c) shows the emission maximum at high water content in a smaller part of the fluorescence spectrum. The concentrations of the absorption samples were $2 \mu \mathrm{M}$ for P-TEG and P-(TEG-Man $)_{4}$ and $1 \mu \mathrm{M}$ for P-TEG-Man and P-TEG-Gal. For the fluorescence samples $1 \mu \mathrm{M}$ was chosen for P-TEG, P-TEG-Man and P-TEGGal and $2 \mu \mathrm{M}$ for P-(TEG-Man $)_{4}$. 
3.2c). In contrast assemblies of the symmetrical four-armed P-(TEG-Man) $)_{4}$ showed different changes in the absorption spectra (Fig. 3.2d). Although the Soret band at high methanol content was also narrow and intense at $\lambda=425 \mathrm{~nm}$, at high water content the Soret band remained narrow but now located at $\lambda=456 \mathrm{~nm}$ and with a vibronic shoulder at $\lambda=448 \mathrm{~nm}$. At $60 \%$ water content the spectrum showed the peak at $\lambda=425 \mathrm{~nm}$, which represents monomeric species, and the peak at $\lambda=456 \mathrm{~nm}$, which represents aggregated species. The two $\mathrm{Q}$ bands of the symmetrical porphyrin red-shifted with increasing the water content (Fig. 3.2d, inset).

Next, fluorescence spectra of asymmetrical and symmetrical porphyrins were recorded upon changing the ratio of methanol and water (Fig. 3.2). The asymmetrical porphyrins (P-TEG, P-TEG-Man, P-TEG-Gal), excited at $\lambda=425 \mathrm{~nm}$ or $430 \mathrm{~nm}$, showed in methanol a band at $\lambda=610 \mathrm{~nm}$ with a vibronic shoulder around $\lambda=650 \mathrm{~nm}$. With increasing water content the emission intensity decreased, which is related to quenching effects within the forming assembly. The wavelength of the emission maximum was not significantly shifted while the shoulder at $\lambda=650 \mathrm{~nm}$ disappeared (Fig. 3.2a $+3.2 \mathrm{c}$, right insets). These observations are in agreement with $J$-type organized molecules.

In the case of the symmetrical porphyrin P-(TEG-Man $)_{4}$ no emission was recorded in pure methanol when the solution was excited at $\lambda=455 \mathrm{~nm}$, while upon increasing the water content the emission rose, reaching a maximum emission intensity at $60 \%$ water content (Fig. 3.2d). The band has its maximum at $\lambda=616 \mathrm{~nm}$ with a vibronic shoulder around $\lambda=660 \mathrm{~nm}$. The shape of the band remained unchanged until reaching $100 \%$ water but the emission intensity decreased. The observed differences in the fluorescence spectra of the porphyrins, especially the absence of highly emissive species in methanol for $\mathbf{P}$-(TEG-Man $)_{4}$ in contrast to the asymmetrical derivatives, can be explained by the different wavelengths used for excitation. To select the excitation wavelength, the wavelength position of the maximum absorbance in water was considered, as this represents aggregated species. For the three asymmetric porphyrins P-TEG, P-TEG-Man and P-TEG-Gal these excitation wavelengths $\left(\lambda_{\text {exc }}=425\right.$ or $\left.430 \mathrm{~nm}\right)$ are also exciting molecularly dissolved species. However, for the symmetric porphyrin P-(TEG-Man $)_{4}$ the selected excitation wavelength $\left(\lambda_{e x c}=455 \mathrm{~nm}\right)$ is not exciting such species (the onset of the absorption spectra in methanol of all porphyrins in this study is at $\lambda=450 \mathrm{~nm}$ ). To visualize the change from the monomeric to the aggregated state $\lambda_{\text {max abs }}$ and the molar absorption coefficient $(\epsilon)$ at $\lambda_{\max , a b s}$ were plotted as a function of the water content (Fig. 3.3). The maximum molar absorption coefficient $\epsilon_{\max }$ was calculated according to the equation

$$
\epsilon_{\max }=\frac{A_{\max }}{c_{P} \cdot d}
$$




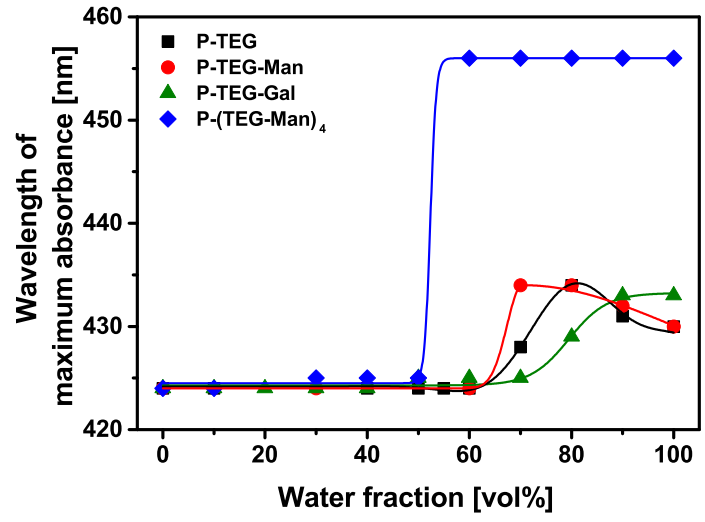

(a)

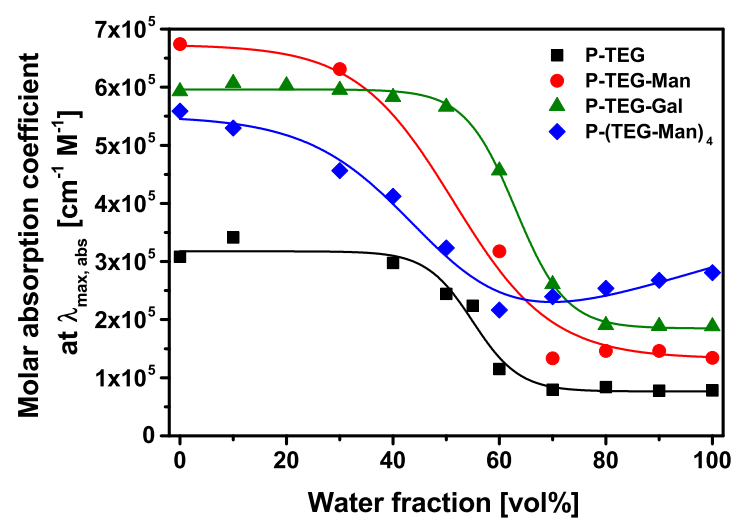

(b)

Figure 3.3 - Wavelength of maximum absorbance $\lambda_{\text {max abs }}$ (a) and maximum molar absorption coefficient $\epsilon_{\max }$ (b) as a function of the water fraction in methanol-water mixtures of the porphyrin absorption spectra. Marks are experimental values, trendlines are given to guide the eye.

wherein $\mathrm{A}_{\max }$ is the absorbance at $\lambda_{\max , a b s}, \mathrm{c}_{P}$ is the porphyrin concentration and $\mathrm{d}$ is the cuvette diameter of $1 \mathrm{~cm}$. In the wavelength plot a sharp transition is present for all porphyrins (Fig. 3.3a). For P-TEG and P-TEG-Man the change occurs around $70 \%$ water fraction, while for P-TEG-Gal the change occurs at $80 \%$ and for P-(TEG-Man) at $60 \%$. The assembly of P-(TEG-Man) $)_{4}$ at already $60 \%$ water content is unexpected since the presence of four hydrophilic tetraethylene glycol chains and mannose moieties would suggest a higher hydrophilicity and therefore a later assembly in comparison with the three asymmetrical porphyrin derivatives. The plots of $\epsilon_{\max }$ as a function of the water fraction show the change from monomeric to assembled state for all porphyrins happening around $60 \%$ (Fig. 3.3b).

\subsubsection{Morphology properties of porphyrin self-assemblies in water}

Small volumes $(3 \mu \mathrm{l})$ of an aqueous solution of each of the porphyrins were deposited on a silicon wafer or copper grid and inspected by scanning electron microscopy (SEM) to study the shape and size of the assemblies. The SEM images show the presence of roundshaped objects (Fig. 3.4). The sizes range from $34 \pm 11 \mathrm{~nm}$ for P-(TEG-Man) ${ }_{4}$ and 34 $\pm 10 \mathrm{~nm}$ for P-TEG-Gal over $56 \pm 24 \mathrm{~nm}$ for P-TEG to $66 \pm 28 \mathrm{~nm}$ for P-TEG-Man (Tab. 3.1). In the case of a silicon wafer as the substrate (Fig. 3.4a, 3.4b and 3.4c) these objects appeared closely together, while in the case of a copper grid as the substrate (Fig. 3.4d) these objects were present more sparsely distributed. The differences could be caused by the different affinities of the assemblies with the substrates. For example, the observed low affinity of P-(TEG-Man $)_{4}$ for the silicon wafer might be due to its higher 


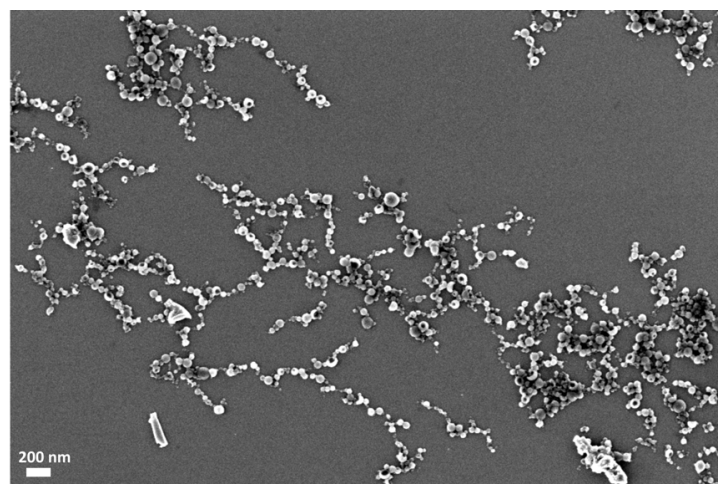

(a)

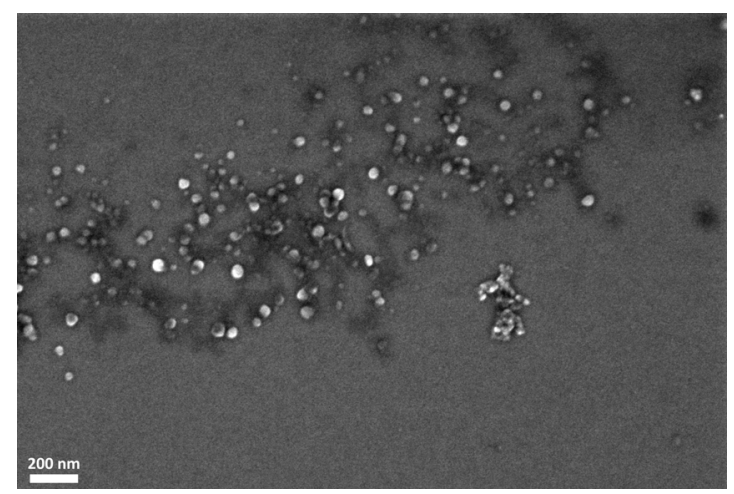

(c)

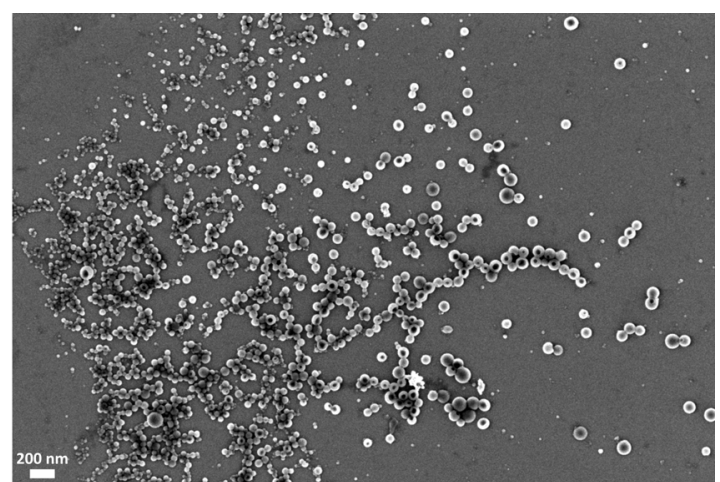

(b)

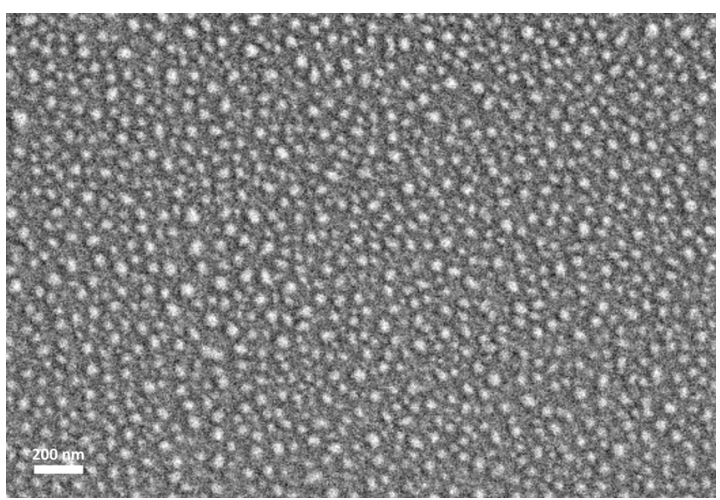

(d)

Figure 3.4 - SEM images of P-TEG (a), P-TEG-Man (b) (both $c_{P}=2 \mu \mathrm{M}, 10$ min resting time), P-TEG-Gal (c) and P-(TEG-Man) $)_{4}$ (d) (both $\mathrm{c}_{P}=10 \mu \mathrm{M}, 6$ min resting time). (a), (b) and (c) show samples on silicon wafers, (d) shows a sample on copper grid.

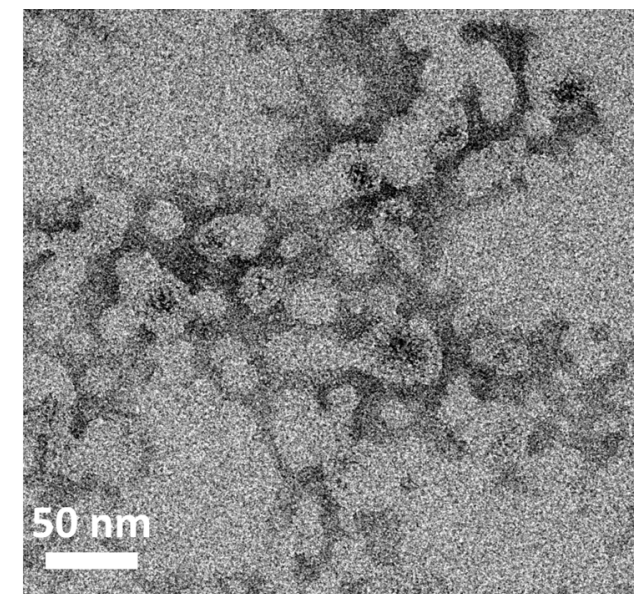

(a)

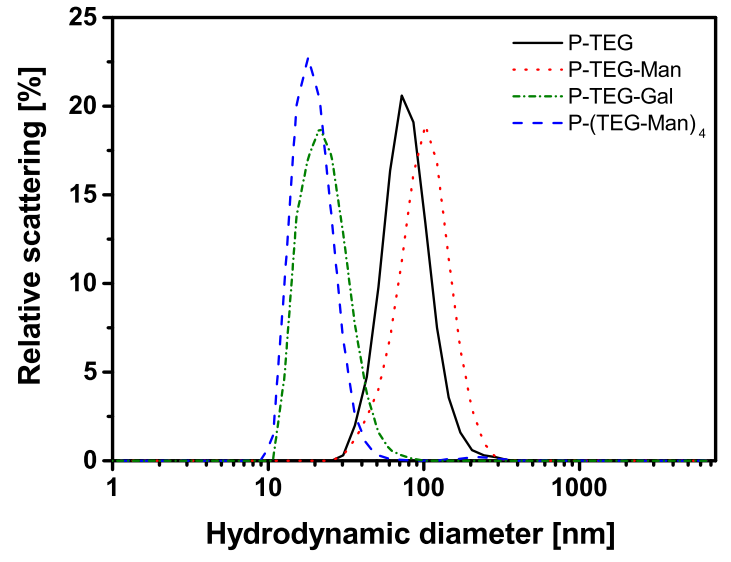

(b)

Figure 3.5 - TEM image, negatively stained with $1 \mathrm{wt} \%$ uranyl acetate, of $2 \mu \mathrm{M}$ aqueous solution of P-TEG (a). DLS graphs of $5 \mu \mathrm{M}$ aqueous solutions of P-TEG, PTEG-Man, P-TEG-Gal and P-(TEG-Man) $)_{4}$ (b). 
Table 3.1 - Diameters of self-assembled aggregates of the porphyrins in nm, obtained by SEM, TEM and DLS.

\begin{tabular}{l|ccc}
\hline & \multicolumn{3}{|c}{ Aggregates diameter [nm] } \\
& SEM & TEM & DLS \\
\hline P-TEG & $56 \pm 24$ & $28 \pm 7$ & $75 \pm 8$ \\
P-TEG-Man & $66 \pm 28$ & & $97 \pm 14$ \\
P-TEG-Gal & $34 \pm 10$ & & $39 \pm 23$ \\
P-(TEG-Man $)_{4}$ & $34 \pm 11$ & $21 \pm 4$ \\
\hline
\end{tabular}

hydrophilicity.

The transmission electron microscopy (TEM) images of P-TEG show round-shaped objects that appeared filled (Fig. 3.5a). The average size found was $28 \mathrm{~nm}$, which is in the same size range as what was found in the SEM images of P-TEG.

Dried objects might differ from the assemblies that are formed in solution. For this reason the porphyrin assemblies were investigated in solution using dynamic light scattering (DLS) (Fig. 3.5b). The measured sizes and size distributions are similar among the porphyrins with an average size of $58 \mathrm{~nm}$ in diameter. While P-(TEG-Man) $)_{4}$ resulted in the smallest assemblies with $21 \pm 4 \mathrm{~nm}$, in the solutions of P-TEG-Man the largest assemblies with a size of $97 \pm 14 \mathrm{~nm}$ were observed.

When comparing the results from the morphological studies it can be concluded that the porphyrins assemble with similar shape and size (Tab. 3.1). The data suggests that $\mathbf{P}$ TEG-Man is forming the largest and P-(TEG-Man $)_{4}$ the smallest aggregates. The size range observed here is comparable with related studies where the spontaneous assembly of sugar-coated porphyrins and phthalocyanines into aggregates of $10-50 \mathrm{~nm}$ in diameter was observed [22]. The authors stated that these particle sizes are small enough to be, for example, endocytosed by cancer cells [22].

\subsubsection{Stability of porphyrin assemblies}

After the confirmation of the presence of assemblies, their stability was investigated. For applications in biological milieu it is important to know if a change of a few parameters leads to dissolution of the assemblies.

Increasing the temperature of an aqueous solution of P-TEG-Man from room temperature (ca. $20{ }^{\circ} \mathrm{C}$ ) to $37{ }^{\circ} \mathrm{C}$ did not alter $\lambda_{\max , e m}$ and only led to a decrease in emission intensity (Fig. 3.6). Based on this observation the stability of the assemblies at temperatures relevant for biological studies was assured. The same behaviour was observed for the other three porphyrins.

Dilution experiments of the porphyrins in water in the concentration range between $0.005 \mu \mathrm{M}$ and $10 \mu \mathrm{M}$ showed neither a change of $\lambda_{\text {max,abs }}$ nor of $\lambda_{\text {max,em }}$ (shown for 
P-(TEG-Man) $)_{4}$ for $0.125 \mu \mathrm{M}-2 \mu \mathrm{M}$ in figure 3.7a). The absorbance at $\lambda_{\text {max,abs }}$ is linearly decreasing upon decreasing the concentration for all four porphyrins (Fig. 3.7b). The lack of a shift in wavelength suggests porphyrin assemblies are present in water over a wide concentration range from $10 \mu \mathrm{M}$ to $50 \mathrm{nM}$.

We were interested if circumstances could be created to disassemble the porphyrin assemblies in solutions with high water content. Changing the temperature to $37^{\circ} \mathrm{C}$ gave no disassembly while the introduction of $10 \%$ methanol has also no effect on the stability of the assemblies since the absorption spectra still displayed the same $\lambda_{\text {max abs }}$ (shown for P-(TEG-Man $)_{4}$ in Fig. 3.7C). Only when $60 \%$ water volume fraction was chosen for P-(TEG-Man $)_{4}$, spectra resembling that of monomeric species were recorded during dilution, showing a shift to lower wavelengths (Fig. 3.7d). The change from organized to monomeric dissolved state occurred at a concentration of $1 \mu \mathrm{M}$.

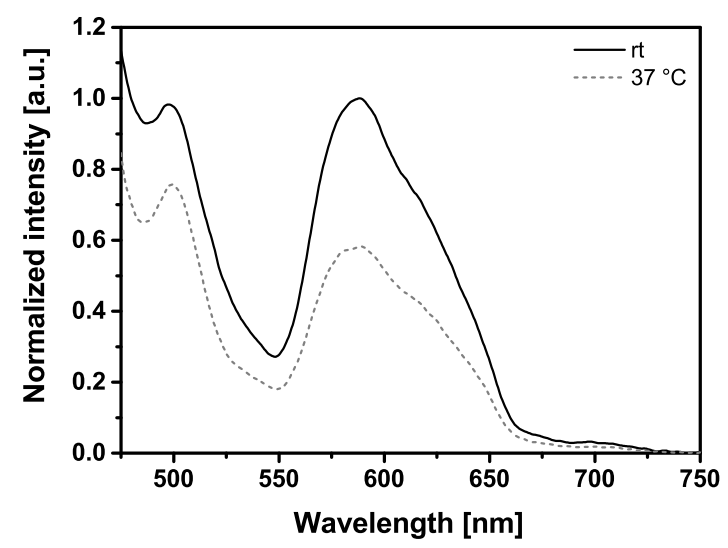

Figure 3.6 - Fluorescence spectra of $0.5 \mu \mathrm{M}$ P-TEG-Man, recorded after $2 \mathrm{~h}$ at room temperature or after $2 \mathrm{~h}$ at $37^{\circ} \mathrm{C}$.

\subsection{Conclusions}

All four porphyrin derivatives self-assemble in water into spherical objects that are in the size range of 20 - $100 \mathrm{~nm}$. The self-assemblies are stable over a wide concentration range and at temperatures suitable for biological experiments. Addition of a good solvent, such as methanol, could break up the aggregates. Distinct spectral characteristics of symmetric and asymmetric porphyrin derivatives were measured. The type of peripheral substitution of the porphyrin derivatives showed no influence on the photophysical properties or shape of the self-assemblies. 

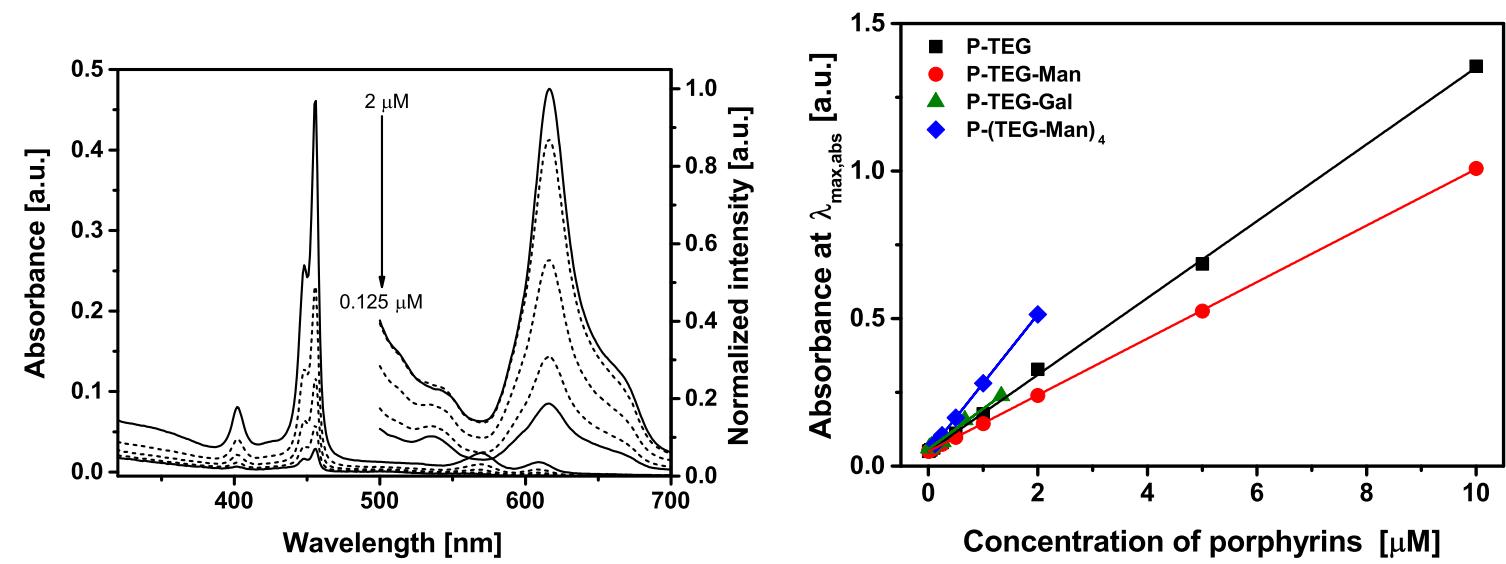

(a)

(b)

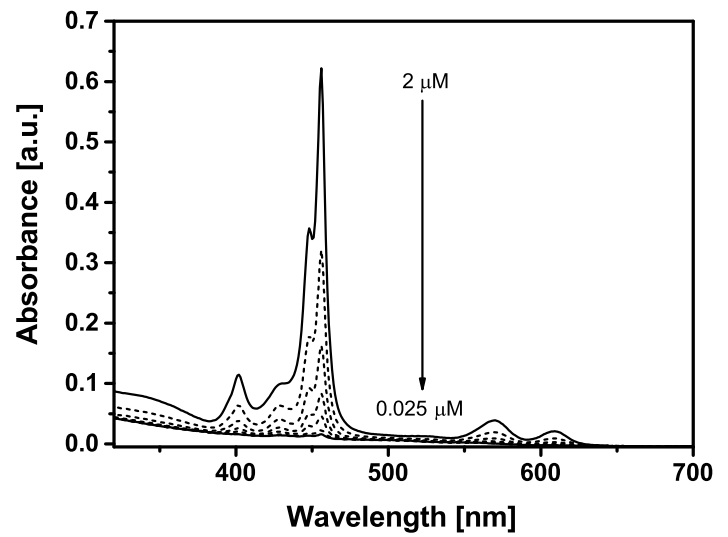

(c)

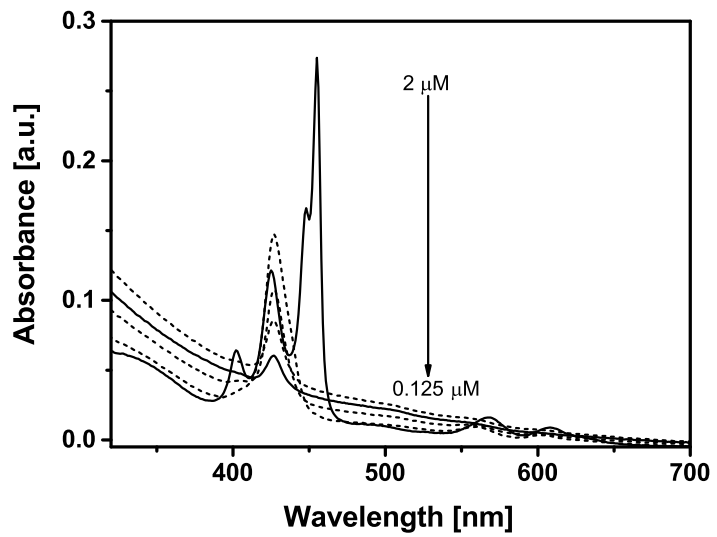

(d)

Figure 3.7 - Absorption and fluorescence spectra of P-(TEG-Man $)_{4}$ in water in the concentration range from $0.125 \mu \mathrm{M}$ to $2 \mu \mathrm{M}$ (a). Absorbance as a function of porphyrin concentration at $\lambda_{\text {max } a b s}$ (b). Porphyrin concentrations range from $50 \mathrm{nM}$ to $10 \mu \mathrm{M}$. Marks are experimental values, trendlines are given to guide the eye. Absorption spectra of P-(TEG-Man $)_{4}$ in (c) $90 \%$ water-10\% methanol in the concentration range from $0.025 \mu \mathrm{M}$ to $2 \mu \mathrm{M}$ and in (d) $60 \%$ water- $40 \%$ methanol in the concentration range from $0.125 \mu \mathrm{M}$ to $2 \mu \mathrm{M}$.

\subsection{Acknowledgments}

Mark Smithers and Dr. Rico Keim (Universiteit Twente) are gratefully acknowledged for their help with SEM and TEM imaging, respectively.

\subsection{Experimental section}

\subsubsection{Materials and equipment}

Chemicals were purchased from Sigma Aldrich, Actu-all Chemicals, Merck and ACROS ORganics and used without further purification. The syntheses of the used por- 
phyrins have been described in chapter 2 ,

UV/Vis absorption spectra were measured on a PERKIN ELMER Lambda 850 spectrophotometer. The UV/Vis absorption spectra were measured against air and corrected for the solvent. Fluorescence spectra were recorded on a PERKIN ELMER LS 55 Fluorescence Spectrophotometer. As excitation wavelengths $\lambda_{\text {exc }}=425 \mathrm{~nm}$ (P-TEG-Gal), $\lambda_{\text {exc }}$ $=430 \mathrm{~nm}$ (P-TEG, P-TEG-Man) and $\lambda_{e x c}=455 \mathrm{~nm}\left(\mathbf{P}-(\text { TEG-Man })_{4}\right)$ were used. The slit widths were kept at $10 \mathrm{~nm}$ for all measurements. Only for the water dilution series of P-TEG and P-TEG-Man an emission slit width of $15 \mathrm{~nm}$ was used. For both techniques, absorption and fluorescence spectroscopy, quartz cuvettes with a $10 \mathrm{~mm}$ light path and $1.5 \mathrm{ml}$ minimal volume were used.

The TEM measurements were carried out on a PHILIPS CM300ST-FEG TEM machine by Dr. Rico Keim. The SEM measurements were carried out on a ZEISS Merlin Scanning Electron Microscope by Mark Smithers.

DLS experiments were performed with a Nanotrac wave by ANASPEC operating with a Microtrac FLEX Operating Software at $25{ }^{\circ} \mathrm{C}$ using a laser wavelength of $780 \mathrm{~nm}$ at a scattering angle of $90^{\circ}$. The observed sizes and standard deviations were based on the average number distributions of ten individiual measurements per sample. As refractive index 1.465 was used. The run time was $180 \mathrm{~s}$.

\subsubsection{Methods}

\section{General sample preparation for aqueous samples}

Samples were prepared from a $1 \mathrm{mM}$ THF/MeOH stock solution by injection of the required volume quickly into water. Samples in organic solvents were obtained by diluting the stock solution.

\section{Absorption and fluorescence spectroscopy}

The samples for the methanol-water mixtures studies were prepared by mixing the appropriate portions of a solution of the porphyrins in methanol and in water. The concentrations of the porphyrins for the absorption spectra were $2 \mu \mathrm{M}$ for P-TEG and P-(TEGMan $)_{4}$ and $1 \mu \mathrm{M}$ for P-TEG-Man and P-TEG-Gal. The mixtures for the absorption spectra contained the following volume fractions: for P-TEG: $\mathrm{MeOH} / \mathrm{H}_{2} \mathrm{O}$ 100/0, 90/10, 60/40, 50/50, 45/55, 40/60, 30/70, 20/80, 10/90, 0/100; for P-TEG-Man: $\mathrm{MeOH} / \mathrm{H}_{2} \mathrm{O}$ 100/0, 70/30, 40/60, 30/70, 20/80, 10/90, 0/100; for P-TEG-Gal: $\mathrm{MeOH} / \mathrm{H}_{2} \mathrm{O} 100 / 0$, $90 / 10,80 / 20,70 / 30,60 / 40,50 / 50,40 / 60,30 / 70,20 / 80,10 / 90,0 / 100$; for P-(TEGMan) $)_{4}: \mathrm{MeOH} / \mathrm{H}_{2} \mathrm{O} 100 / 0,90 / 10,70 / 30,60 / 40,50 / 50,40 / 60,30 / 70,20 / 80,10 / 90$, $0 / 100$. The concentrations of the porphyrins for the emission spectra were $1 \mu \mathrm{M}$ for 
P-TEG, P-TEG-Man and P-TEG-Gal and $2 \mu \mathrm{M}$ for P-(TEG-Man) $)_{4}$. The same volume fractions as in the absorption spectra were used in the case of P-TEG-Man, PTEG-Gal and P-(TEG-Man) $)_{4}$. For P-TEG the following volume fractions were used for the emission spectra: $\mathrm{MeOH} / \mathrm{H}_{2} \mathrm{O} 100 / 0,70 / 30,40 / 60,30 / 70,20 / 80,10 / 90,0 / 100$. The dilution series were prepared from a $10 \mu \mathrm{M}$ or $2 \mu \mathrm{M}$ water solution, a $2 \mu \mathrm{M} 90 \%$ water-10\% methanol solution and a $2 \mu \mathrm{M} 60 \%$ water- $40 \%$ methanol solution, respectively. The different samples were obtained by diluting the previous sample with water, $90 \%$ water- $10 \%$ methanol or $60 \%$ water- $40 \%$ methanol after the measurement. The used concentrations for the water series were: for P-TEG and P-TEG-Man: $10 \mu \mathrm{M}$, $5 \mu \mathrm{M}, 2 \mu \mathrm{M}, 1 \mu \mathrm{M}, 0.5 \mu \mathrm{M}, 0.25 \mu \mathrm{M}, 0.1 \mu \mathrm{M}, 0.05 \mu \mathrm{M}, 0.025 \mu \mathrm{M}, 0.01 \mu \mathrm{M}, 0.005 \mu \mathrm{M}$; for P-TEG-Gal: $1.3 \mu \mathrm{M}, 0.7 \mu \mathrm{M}, 0.27 \mu \mathrm{M}, 0.13 \mu \mathrm{M}, 0.07 \mu \mathrm{M}, 0.03 \mu \mathrm{M}, 0.017 \mu \mathrm{M}$; for P-(TEG-Man) $)_{4}: 2 \mu \mathrm{M}, 1 \mu \mathrm{M}, 0.5 \mu \mathrm{M}, 0.25 \mu \mathrm{M}, 0.125 \mu \mathrm{M}$. The used concentrations for the $90 \%$ water-10 \% methanol series were: for P-TEG: $2 \mu \mathrm{M}, 1 \mu \mathrm{M}, 0.1 \mu \mathrm{M}, 0.01 \mu \mathrm{M}$, $0.001 \mu \mathrm{M}$; for P-TEG-Man and P-(TEG-Man) $)_{4}: 2 \mu \mathrm{M}, 1 \mu \mathrm{M}, 0.5 \mu \mathrm{M}, 0.25 \mu \mathrm{M}$, $0.125 \mu \mathrm{M}$. The used concentrations for the $60 \%$ water- $40 \%$ methanol series of P-(TEGMan $)_{4}$ were: $2 \mu \mathrm{M}, 1 \mu \mathrm{M}, 0.5 \mu \mathrm{M}, 0.25 \mu \mathrm{M}, 0.125 \mu \mathrm{M}, 0.05 \mu \mathrm{M}, 0.025 \mu \mathrm{M}$.

For the fluorescence spectra concerning the temperature dependency two $0.5 \mu \mathrm{M}$ aqueous solutions in HEPES buffer ( $\mathrm{pH}=7.2,10 \mathrm{mM}$ HEPES) were prepared. One was kept $2 \mathrm{~h}$ at room temperature and the other one was treated $2 \mathrm{~h}$ in a water bath $\left(37^{\circ} \mathrm{C}\right)$.

\section{Transmission electron microscopy (TEM)}

The solution of P-TEG ( $2 \mu \mathrm{l}$ of $2 \mu \mathrm{M}$ in water) were deposited on 200 mesh copper grids for $15 \mathrm{~min}$. After drying the samples, they were stained for 1 min with $5 \mu \mathrm{l}$ of an uranyl acetate solution (1 wt\% in water).

\section{Scanning electron microscopy (SEM)}

The solutions of porphyrins in water were deposited on silicon wafers for a certain resting time before gently removing the remaining solution. Exact parameters concerning concentration of porphyrin solution, deposited volume and resting time can be found in table 3.2 .

\section{Dynamic light scattering (DLS)}

The used concentration for the porphyrin samples was $5 \mu \mathrm{M}$. 
Table 3.2 - Parameters of SEM sample preparation.

\begin{tabular}{l|ccc}
\hline & Concentration $[\mu \mathrm{M}]$ & Volume $[\mu \mathrm{l}]$ & Resting time $[\mathrm{min}]$ \\
\hline P-TEG & 2 & 3 & 10 \\
& 2 & 3 & 6 \\
\multirow{3}{*}{ P-TEG-Man } & 10 & 3 & 6 \\
\multirow{3}{*}{ P-TEG-Gal } & 2 & 3 & 10 \\
& 10 & 3 & 6 \\
P-(TEG-Man) & 10 & 3 & 10 \\
& 10 & 3 & 6 \\
& 10 & 3 & 6 \\
& 10 & 3 & (copper grid) \\
& 10 & 1 & air-dried \\
\hline
\end{tabular}

\subsection{Bibliography}

[1] Solladié, N.; Hamel, A.; Gross, M. Tetrahedron Lett. 2000, 41, 6075-6078.

[2] Hasobe, T.; Saito, K.; Kamat, P. V.; Troiani, V.; Qiu, H.; Solladie, N.; Kim, K. S.; Park, J. K.; Kim, D.; D'Souza, F.; Fukuzumi, S. J. Mater. Chem. 2007, 17, 4160-4170.

[3] Nyst, H. J.; Tan, I. B.; Stewart, F. A.; Balm, A. J. Photodiagn. Photodyn. 2009, 6, 3-11.

[4] Bristow, C.-A.; Hudson, R.; Paget, T. A.; Boyle, R. W. Photodiagn. Photodyn. 2006, 3, 162-167.

[5] Kalenius, E.; Koivukorpi, J.; Kolehmainen, E.; Vainiotalo, P. Eur. J. Org. Chem. 2010, 6, $1052-1058$.

[6] Tomas, S.; Milanesi, L. J. Am. Chem. Soc. 2009, 131, 6618-6623.

[7] Tomas, S.; Milanesi, L. Nat. Chem. 2010, 2, 1077-1083.

[8] Ibrahim, H.; Kasselouri, A.; Raynal, B.; Pansu, R.; Prognon, P. J. Luminesc. 2011, 131, $2528-2537$.

[9] Medforth, C. J.; Wang, Z.; Martin, K. E.; Song, Y.; Jacobsen, J. L.; Shelnutt, J. A. Chem. Commun. 2009, 7261-7277.

[10] Giovannetti, R. In The Use of Spectrophotometry UV-Vis for the Study of Porphyrins, Macro To Nano Spectroscopy; Uddin, D. J., Ed.; InTech, 2012.

[11] Gomes, A. T.; Almeida Paz, F. A.; Neves, M. G.; Tomé, A. C.; Silva, A. M.; de Souza, M. C. B.; Ferreira, V. F.; Cavaleiro, J. A. Tetrahedron Lett. 2011, 52, 4741-4744.

[12] Huijser, A.; Suijkerbuijk, B. M. J. M.; Klein Gebbink, R. J. M.; Savenije, T. J.; Siebbeles, J. Am. Chem. Soc. 2008, 130, 2485-2492.

[13] Drain, C. M.; Varotto, A.; Radivojevic, I. Chem. Rev. 2009, 109, 1630-1658.

[14] Drain, C. M.; Smeureanu, G.; Patel, S.; Gong, X. C.; Garno, J.; Arijeloye, J. New J. Chem. 2006, 30, 1834-1843.

[15] Gong, X.; Milic, T.; Xu, C.; Batteas, J. D.; Drain, C. M. J. Am. Chem. Soc. 2002, 124, 14290-14291.

[16] Gouterman, M. J. Mol. Spectrosc. 1961, 6, 138-163.

[17] Bakleh, M.; Sol, V.; Estieu-Gionnet, K.; Granet, R.; Déléris, G.; Krausz, P. Tetrahedron 2009, 65, 7385-7392.

[18] Maiti, N. C.; Mazumdar, S.; Perisamy, N. JPP 1998, 2, 369-376.

[19] Czikklely, V.; Forsterling, H.; Kuhn, H. Chem. Phys. Lett. 1970, 6, 207-210.

[20] Nüesch, F.; Grätzel, M. Chem. Phys. 1995, 193, 1-17.

[21] Ohno, O.; Kaizu, Y.; Kobayashi, H. J. Chem. Phys. 1993, 99, 4128-4139. 
[22] Singh, S.; Aggarwal, A.; Bhupathiraju, N. V. S. D. K.; Arianna, G.; Tiwari, K.; Drain, C. M. Chem. Rev. 2015, 115, 10261-10306. 


\section{4 Photoinduced Activity and Binding Study of Glycoconjugated Porphyrins}

The ability to generate singlet oxygen using assemblies of glycoconjugated porphyrins was investigated. The obtained singlet oxygen quantum yields were 0.21 in organic solvents and 0.42 in water. In lectin binding studies $\boldsymbol{P}-\boldsymbol{T E} \boldsymbol{G}-\boldsymbol{M a n}$ and $\boldsymbol{P}-\boldsymbol{T E} \boldsymbol{G}-\boldsymbol{G a l}$ showed preferred binding to ConA and PNA, respectively. The reduction in growth of E. coli bacterial colonies by light exposure in the presence of the porphyrin assemblies was unfortunately not observed. 


\subsection{Introduction}

Singlet molecular oxygen $\left({ }^{1} \mathrm{O}_{2},{ }^{1} \Delta_{g}\right)$ is created from triplet molecular oxygen $\left({ }^{3} \mathrm{O}_{2},{ }^{3} \Sigma_{g}^{-}\right)$ by inverting the spin of one of the HOMO electrons (spin pairing) [1]. According to the Hund rules triplet molecular oxygen is the ground state of molecular oxygen and singlet molecular oxygen is the excited state which is in contrast to most other compounds [2]. Due to the necessity of the preservation of the total spin multiplicity, it is easier for singlet molecular oxygen to react with other molecules compared to triplet molecular oxygen [2]. As a result the lifetime of the singlet molecular oxygen is short and the reactivity is high. Reactive oxygen species ( $\mathrm{ROS} ; \mathrm{H}_{2} \mathrm{O}_{2}, \mathrm{HO}, \mathrm{O}_{2}^{--},{ }^{1} \mathrm{O}_{2}$ ) are known to cause oxidative stress in biological systems due to their high reactivity. This stress can result in a variety of diseases, such as cancer or Parkinson's disease [3, 4]. On the contrary ROS are able to kill pathogens. Increasing numbers of bacteria with antibiotic resistance have been reported. Development of new antibiotics leads to the occurrence of further resistances. On this account new treatment of bacterial infections, the so called photodynamic antimicrobial chemotherapy (PACT), has been studied [5, 6]. Killing pathogens using ${ }^{1} \mathrm{O}_{2}$ is a promising solution since a resistance development is unlikely because ROS are an integral part of microbial cells and employ a variety of pathways [7, 8]. Furthermore the disease is treated locally with a low systematic toxicity.

Photosensitizers are chromophoric molecules that, by absorbing light, transform into the excited state. Charge or energy transfer from the excited photosensitizer to the surrounding can induce chemcial changes in other organic substrates producing radicals (type I photochemical reaction) or generate ROS species (type II) [8, 9]. Porphyrins are a good choice for this purpose since their excitation wavelengths are within the range of visible light and their extended $\pi$-system enables a stable excited state [10 13]. The singlet oxygen quantum yield $\left(\Phi_{\Delta}\right)$ of a photosensitizer describes the ratio between absorbed photons and generated singlet oxygen and can be determined either directly or indirectly [14]. The direct way is the infrared luminescence technique, where the radiative transition of ${ }^{1} \mathrm{O}_{2}$ to ${ }^{3} \mathrm{O}_{2}$ is observed as emissive peak at a wavelength of $1270 \mathrm{~nm}$. However, special equipment is needed for this type of measurement. Using a simple absorption spectrophotometer the indirect method can be used. The generated singlet oxygen reacts with a scavenger and changes the scavenger's photophysical properties, so that the decrease in absorption of this scavenger is monitored [15]. Assuming a 1:1 ratio between the newly produced molecule and the generated singlet oxygen, the decrease in absorbance can be related to the amount of singlet oxygen and the intensity of light irradiation. For this reason it is important to choose an irradiation wavelength where the scavenger is not absorbing. Insertion of heavy metal ions into porphyrins, like zinc, can increase $\Phi_{\Delta}$ by intersystem crossing [14]. However, the opposite has also been reported [16]. 


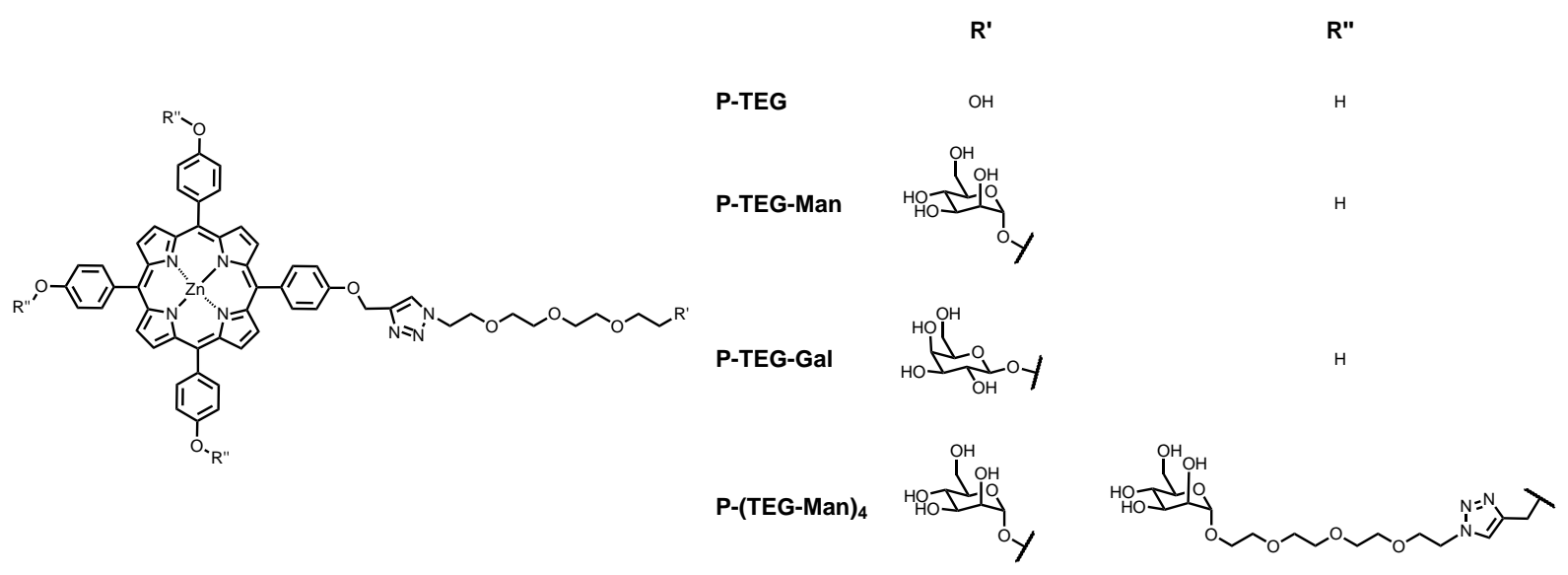

Figure 4.1 - Chemical structures of the porphyrins P-TEG, P-TEG-Man, P-TEG-Gal and P-(TEG-Man $)_{4}$.

The carbohydrate-protein interaction has an important role in biological systems, as described in chapter 1. Apart from the binding between carbohydrates and lectins, also the porphyrin core is able to bind to those proteins, for example in case of charged porphyrins that bind in a 1:1 manner to ConcanavalinA (ConA) [17]. Even in the presence of competitors like a-D-mannopyranoside ( $\alpha$ MMP) a negatively charged porphyrin was able to bind to ConA and pea lectin implying that the porphyrin is binding in a different way than the sugar [18, 19]. It was shown that the interactions between porphyrins and lectins are based on the hydrophobic forces between the aromatic porphyrin and hydrophobic protein residues [20]. Only the complete shielding of the porphyrin core by eight lactose units or the incorporation into liposomes prevented the unspecific binding and allowed only the specific carbohydrate-protein interaction [20, 21]. The binding of glycoconjugated porphyrins to lectins has been described as a two-step process: first, the porphyrin has to be present in its monomeric form, although in aqueous media the equilibrium would be on the side of the assembly; second, the association of both binding partners [22]. The presence of the porphyrin in its monomeric form suggests that an increase in emission intensity in the fluorescence spectra should be observed. However, a change in the wavelength of the maximum has not been observed [22].

The close proximity created by the binding between glycoconjugated porphyrins and cells is important for a successful photosensitized inactivation since the traveling distance of ${ }^{1} \mathrm{O}_{2}$ is small (ca. $0.02 \mu \mathrm{M}$ ) due to the high reactivity and short life time [23].

In this chapter we investigate the lectin binding and singlet oxygen production properties of assembled glycoconjugated porphyrins. The porphyrins P-TEG, P-TEG-Man, PTEG-Gal and P-(TEG-Man) $)_{4}$, whose syntheses have been described in chapter 2 and who assemble in water into spherical objects as described in chapter 3, feature a different number of side chains (one or four) and differ in the type of sugar moieties (none, mannose or galactose) (Fig. 4.1). These variations could lead to different interactions with proteins 
and bacteria, which are studied in this chapter.

\subsection{Results and discussion}

\subsubsection{Singlet oxygen quantum yield}

The singlet oxygen quantum yield $\left(\Phi_{\Delta}\right)$ of the porphyrins was determined indirectly using 1,3-diphenylisobenzofuran (DPBF) as scavenger. Different irradiation times (0 - $60 \mathrm{~s})$ resulted in a decreasing absorbance at $\lambda=410 \mathrm{~nm}$ (shown for P-TEG in water in figure 4.2a). The Soret band $(\lambda \approx 430 \mathrm{~nm})$ of the porphyrins is overlapping with the DPBF band. Therefore the $\mathrm{Q}$ bands $(\lambda \approx 600 \mathrm{~nm}$ ) of the porphyrins were excited for the experiment by using a $500 \mathrm{~nm}$ long pass filter between the light source and the sample. Due to the overlap of DPBF and Soret band a change was only observed on the shoulder of the band (Fig. 4.2a, inset). Determining the absorbance difference at $\lambda=410 \mathrm{~nm}$ as a function of the irradiation time (shown for water as solvent in figure $4.2 \mathrm{~b}$ ) and linearly fitting the data allowed the calculation of $\Phi_{\Delta}$ for the porphyrins using the following equation:

$$
\Phi_{\Delta}=\Phi_{\Delta}^{r e f} \cdot \frac{m \cdot\left(1-10^{-O D}\right)^{r e f}}{m^{r e f} \cdot\left(1-10^{-O D}\right)}
$$

wherein $m$ denotes the slope of the linear fit, $O D$ is the optical density at the irradiation

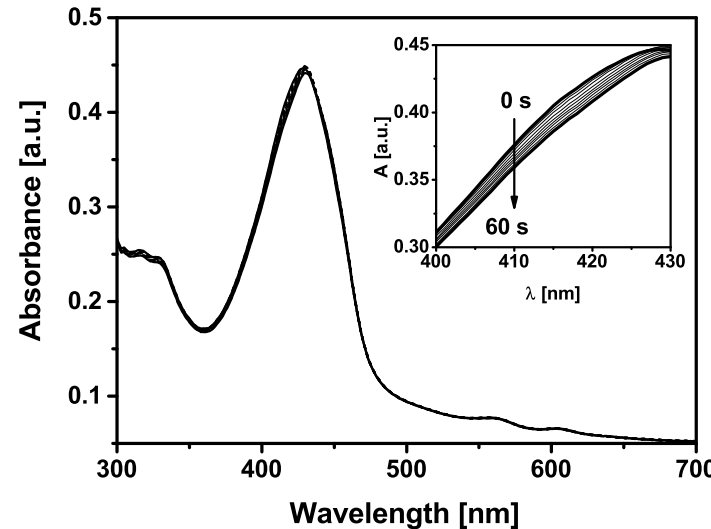

(a)

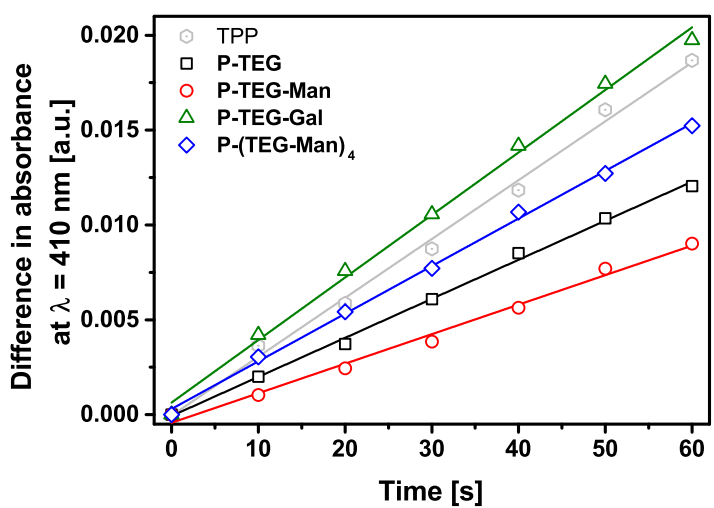

(b)

Figure 4.2 - Absorption spectra of $20 \mu \mathrm{M}$ DPBF in water in the presence of $1 \mu \mathrm{M}$ P-TEG upon irradiation for $0-60 \mathrm{~s}$ (a). The inset shows the change in absorbance in a smaller part of the spectrum. Absorbance differences at $\lambda=410 \mathrm{~nm}$ plotted as a function of the irradiation time for the reference tetraphenylporphyrin (TPP) and the porphyrins P-TEG, P-TEG-Man, P-TEG-Gal and P-(TEG-Man) $)_{4}$ $\left(\mathrm{c}_{P}=1 \mu \mathrm{M}\right)$ in water to determine the singlet oxygen production (b). Marks are experimental values, trendlines are linear fits of the data. 
Table 4.1 - Fluorescence quantum yields $\Phi_{F}$ and singlet oxygen quantum yields $\Phi_{\Delta}$ of the porphyrins P-TEG, P-TEG-Man, P-TEG-Gal and P-(TEG-Man $)_{4}$ in different solvents.

\begin{tabular}{l|c|ccc}
\hline & $\begin{array}{c}\Phi_{F} \\
\text { THF }\end{array}$ & $\mathrm{H}_{2} \mathrm{O}$ & $\begin{array}{c}\Phi_{\Delta} \\
\mathrm{MeOH}\end{array}$ & THF \\
\hline P-TEG & $0.088 \pm 0.001$ & $0.36 \pm 0.03$ & $0.18 \pm 0.08$ & 0.28 \\
P-TEG-Man & $0.110 \pm 0.001$ & $0.23 \pm 0.08$ & $0.28 \pm 0.15$ & 0.28 \\
P-TEG-Gal & $0.075 \pm 0.001$ & $0.53 \pm 0.04$ & $0.25 \pm 0.07$ & 0.21 \\
P-(TEG-Man $)_{4}$ & $0.074 \pm 0.007$ & $0.55 \pm 0.15$ & $0.10 \pm 0.08$ & 0.12 \\
\hline
\end{tabular}

wavelength $(\lambda=500 \mathrm{~nm})$ and the superscript "ref" represents the reference tetraphenylporphyrin (TPP) [14]. The obtained values for the porphyrins in different solvents are displayed in table 4.1. As solvents methanol and tetrahydrofuran, in which the porphyrins are present molecularly dissolved, and water, in which the porphyrins self-assemble, have been chosen (see results in chapter 3). To verify the results the photostability of the compounds was tested by carrying out the irradiation experiments without the presence of the scavenger. None of the molecules showed under these conditions a decrease in absorbance as described above.

While the singlet oxygen quantum yields in the organic solvents are around 0.21 , these values are double as high in water $\left(\Phi_{\Delta} \approx 0.42\right)$. Only P-TEG-Man has a slightly higher yield in organic solvents than in water $\left(\Phi_{\triangle, T H F, M e O H}=0.28\right.$ vs $\left.\Phi_{\triangle, H_{2} O}=0.23\right)$. The general observation, that higher yields are reported in water when compared to polar organic solvents, is in contrast to our expectation of a monomeric state, present in polar organic solvents, allowing higher quantum yields as compared to the assembled state, present in water [1, 24, 25]. Another effect that would be in favor of higher yields in polar organic solvents is the life time of singlet oxygen in different solvents: $7 \mu \mathrm{s}$ in methanol and $2 \mu \mathrm{s}$ in water [26]. On the contrary in Wilkinson's, Helman's and Ross' extensive data collection of singlet oxygen quantum yields [1] there are also other molecules reported that show higher yields in water than in methanol, e.g. fluorescein derivatives. Furthermore this data collection demonstrates that the determination of values is difficult, often depending on the exact used method. For example, for hematoporphyrin in oxygen-rich water values between 0.04 and 0.45 have been reported using different methods [1]. Without further investigations the reason for the observed results cannot be given. However, it can be stated that the studied porphyrins are able to produce singlet oxygen, necessary for further applications.

In addition, the fluorescence quantum yields $\left(\Phi_{F}\right)$ of the porphyrin derivatives were calculated by comparison with the reference TPP (Fig. 4.3) [9, 27]. Requiring same refractive 


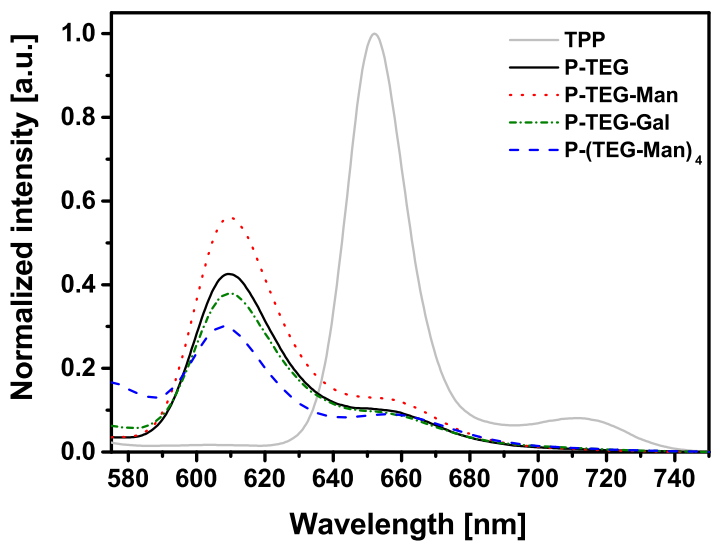

Figure 4.3 - Fluorescence spectra in THF of the reference tetraphenylporphyrin (TPP) and the porphyrins P-TEG, P-TEG-Man, P-TEG-Gal and P-(TEG-Man) $)_{4}\left(c_{P}\right.$ $=2 \mu \mathrm{M})$ to determine the fluorescence quantum yield $\Phi_{F}\left(\lambda_{e x c}=550 \mathrm{~nm}\right)$.

indices $\Phi_{F}$ was calculated with the following equation [27, 28]:

$$
\Phi_{F}=\Phi_{F}^{r e f} \cdot \frac{D \cdot\left(1-10^{-O D}\right)^{r e f}}{D^{r e f} \cdot\left(1-10^{-O D}\right)}
$$

wherein $D$ denotes the area under the emission spectrum, $O D$ is the optical density at the irradiation wavelength $(\lambda=550 \mathrm{~nm})$ and the superscript "ref" represents the reference tetraphenylporphyrin (TPP). The obtained values are given in table 4.1, They are comparable with reported values of other substituted zinc porphyrin derivatives [9, 14]. The slightly lower quantum yields of P-(TEG-Man) $)_{4}$ and P-TEG-Gal were probably caused by their lower solubility and partial aggregation in THF [9].

\subsubsection{Binding of porphyrin assemblies to lectins}

The binding of lectins to the porphyrin assemblies was investigated using fluorescence spectroscopy. All experiments were carried out in HEPES buffer containing calcium and manganese ions, which are necessary to maintain the active conformation of the binding loop of the lectin [29]. Two different concentrated porphyrin solutions $\left(\mathrm{c}_{P}=2 \mu \mathrm{M}, 10 \mu \mathrm{M}\right)$ were mixed with four different lectin concentrations $(\mathrm{c}=0.5,1,2,5 \mathrm{mg} / \mathrm{ml})$ to cover a molar ratio (lectin/porphyrin) ranging from 0.5 to 25 . Figure 4.4 shows the results for $10 \mu \mathrm{M}$ P-TEG-Gal and the lectins ConA and PNA, but similar spectra were found for the other porphyrin derivatives and lectin combinations. An increase in emission intensity was observed around $\lambda=610 \mathrm{~nm}$ with increasing lectin concentration (Fig. 4.4a). Upon binding to lectins the low-fluorescent porphyrin assemblies could loosen up into less wellstacked assemblies that are more emissive resulting in an intensity increase [22].

When emission spectra of PNA or ConA without porphyrins were recorded, using the same excitation wavelength and concentrations, spectral changes resembling those observed 


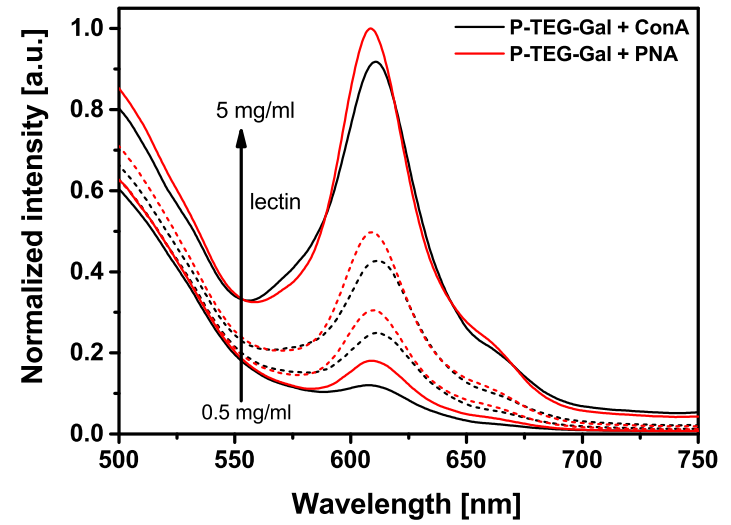

(a)

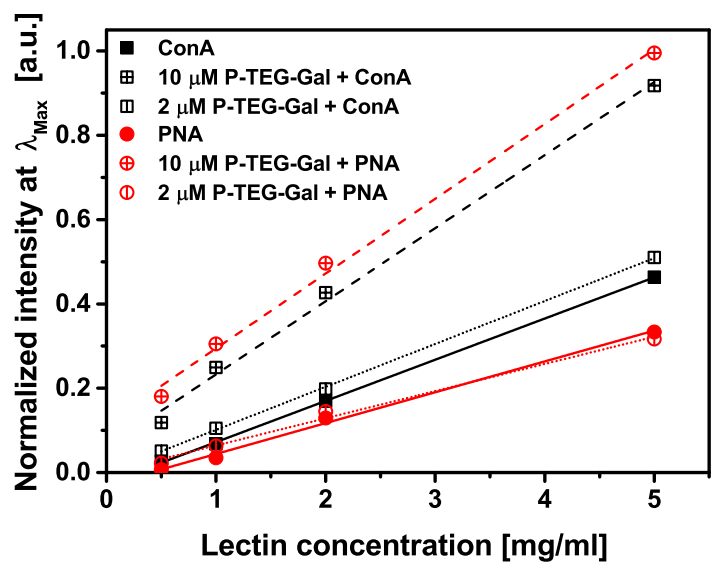

(b)

Figure 4.4 - Fluorescence spectra of $10 \mu \mathrm{M}$ P-TEG-Gal with different concentrations of the lectins ConA and PNA ( $c=0.5-5 \mathrm{mg} / \mathrm{ml}$ ) (a). Normalized intensity of $\mathbf{P}$ TEG-Gal-lectin spectra as a function of the lectin concentration (b). Marks are experimental values, trendlines are linear fits of the data. Values are normalized to the highest value in the P-TEG-Gal spectra.

with porphyrins at low $\mathrm{c}_{P}$ were found (Fig. 4.4b). To investigate the reason for the latter results we varied the excitation wavelength for solutions of ConA or PNA and could assign the observations to Raman scattering. This scattering increased with increasing lectin concentration. When relating this to observations described in literature, where similar solutions of ConA and glycoporphyrins were used, their findings become more difficult to interpret [22].

To gain insight whether the envisioned binding between galactose-modified porphyrin and PNA has an additional effect on the emission properties of the assemblies, beside the Raman scattering, the change in emission intensity at $\lambda=610 \mathrm{~nm}$ was plotted as a function of lectin concentration (Fig. 4.4b). As can be seen in figure 4.4b the changes in intensity are linear for all solutions. Interestingly, in the case of $10 \mu \mathrm{M} \mathbf{P}-\mathbf{T E G}-\mathrm{Gal}$ an additional increase in intensity is present whereas in the case of $2 \mu \mathrm{M}$ P-TEG-Gal the change in intensity coincides with the changes observed for the lectin solutions. The ratio $(r)$ between the slopes were calculated as quotient of porphyrin-lectin to lectin slopes:

$$
r=\frac{m^{P-l}}{m^{l}}
$$

wherein $m$ denotes the slope and the superscripts are describing lectins $(l)$ or porphyrinlectin $(P-l)$ samples. A ratio around $1( \pm 0.2)$ indicates that the observed increase in emission intensity was due to the Raman scattering, only higher ratios imply an additional porphyrinic emission intensity increase due to the binding process. For a porphyrin concentration of $2 \mu \mathrm{M}$ ratios are mainly around 1 and therefore no binding was detected 
Table 4.2 - Ratios $r$ of the slopes of the linear fits for the experiments with the porphyrins P-TEG, P-TEG-Man, P-TEG-Gal and P-(TEG-Man) $)_{4}$ and the lectins ConA and PNA. Two different porphyrin concentrations $\left(\mathrm{c}_{P}\right)$ were used.

\begin{tabular}{l|cccc}
\hline & \multicolumn{2}{|c}{$\mathrm{c}_{P}=10 \mu \mathrm{M}$} & \multicolumn{2}{c}{$\mathrm{c}_{P}=2 \mu \mathrm{M}$} \\
& $\mathrm{r}_{\text {ConA }}$ & $\mathrm{r}_{P N A}$ & $\mathrm{r}_{C o n A}$ & $\mathrm{r}_{P N A}$ \\
\hline P-TEG & 0.95 & 1.35 & 1.02 & 1.11 \\
P-TEG-Man & 3.52 & 1.57 & 1.72 & 1.21 \\
P-TEG-Gal & 1.77 & 2.42 & 1.04 & 0.88 \\
P-(TEG-Man) & 1.59 & 1.65 & 0.89 & 0.94 \\
\hline
\end{tabular}

(Tab. 4.2). In general, the porphyrin emission at this concentration might be too low to properly observe changes, whereas for porphyrin concentrations of $10 \mu \mathrm{M}$ the ratios are above 1 (Tab. 4.2). P-TEG as porphyrin without peripheral sugar showed the lowest ratios $\left(\mathrm{r}_{C o n A}=0.95, \mathrm{r}_{P N A}=1.35\right)$, indicating no or low binding occurred. It has to be kept in mind that the observed binding between the porphyrin derivatives and the lectins may originate from glycoconjugate ligand binding with its lectin receptor and/or from binding of the porphyrin core to lectins. P-TEG-Man and P-TEG-Gal demonstrated a preference for their expected lectin binding partner. P-TEG-Man showed with $\mathrm{r}_{C o n A}$ $=3.52$ the highest ratio for ConA, and P-TEG-Gal with $\mathrm{r}_{P N A}=2.42$ the highest for PNA. However, both show binding to the other lectin as well (Tab. 4.2). We conclude that the differences in ratios of $\Delta \mathrm{r}_{\mathbf{P}-\mathbf{T E G}-\mathbf{M a n}}=1.95$ and $\Delta \mathrm{r}_{\mathbf{P - T E G}-\mathbf{G a l}}=0.65$ indicate specific interactions between the peripheral sugars and the proteins in the case of P-TEG-ManConA and P-TEG-Gal-PNA. Unexpectedly this was not the case for P-(TEG-Man) $\left(\Delta \mathrm{r}_{\mathbf{P}-(\text { TEG-Man })_{4}}=0.06\right)$.

The observed results are not giving a detailed description of the specific and the unspecific contribution to the binding event. Experiments investigating the reversibility of the binding by adding competitive sugars, like methyl a-D-mannopyranoside ( $\alpha \mathrm{MMP})$ or $\mathrm{D}(+)$-galactose, would be interesting to gain further insight in the proportions of the binding parts. However, it seems that the use of porphyrin as the molecular building block is not recommendable for ligand-receptor binding applications.

\subsubsection{Photoinduced activity of porphyrin assemblies in the presence of $E$. coli bacteria cells}

The porphyrin assemblies were added to cultures of $E$. coli strains that either express a mannose-binding protein (FimH receptor; ORN 178) or not (ORN 208) [30]. Under the brightfield microscope only a few bacteria clusters on a large area were observed when $5 \mu \mathrm{M}$ P-TEG-Man was mixed with ORN 178 (clusters indicated in figure 4.5a). However, none of these clusters were observed when the porphyrin assemblies were mixed 


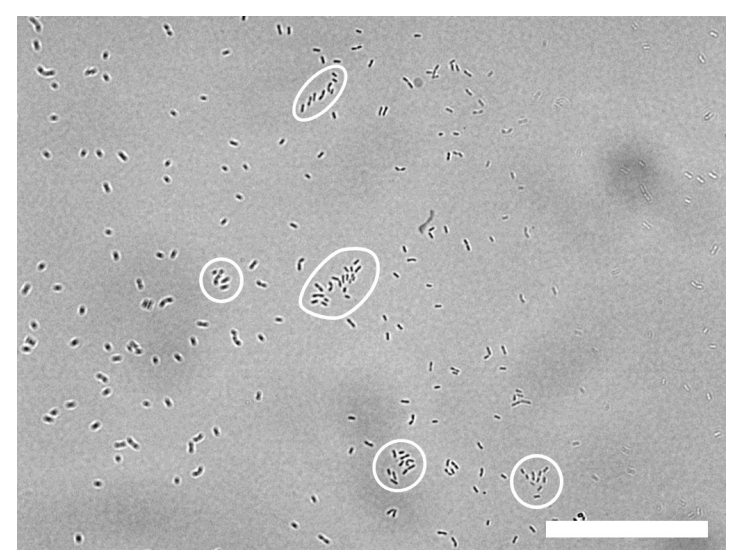

(a)

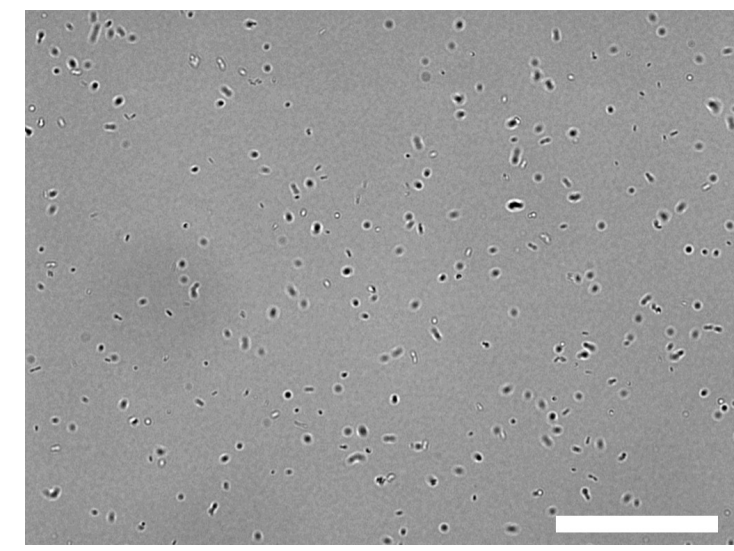

(b)

Figure 4.5 - Bright field microscope images of $5 \mu \mathrm{M}$ P-TEG-Man mixed with (a) ORN 178 and (b) ORN 208 and incubated for $1 \mathrm{~h}$ at $37^{\circ} \mathrm{C}$. White circles indicate possible bacteria clusters. Scale bars are $50 \mu \mathrm{m}$.

with ORN 208 (Fig. 4.5b). Cluster formation might indicate binding between porphyrin assemblies and bacteria. A fluorescence microscopy study to evaluate the binding ability of the porphyrin assemblies to the bacteria would have been interesting but under the fluorescence microscope no emission was observed.

The assemblies of P-(TEG-Man) $)_{4}$ were incubated with E. coli strains, irradiated with visible light for $30 \mathrm{~min}$ and cultivated on agar plates (Fig. 4.6). Depending on the chosen parameters different numbers of colonies were counted on the plates. The survival rates of

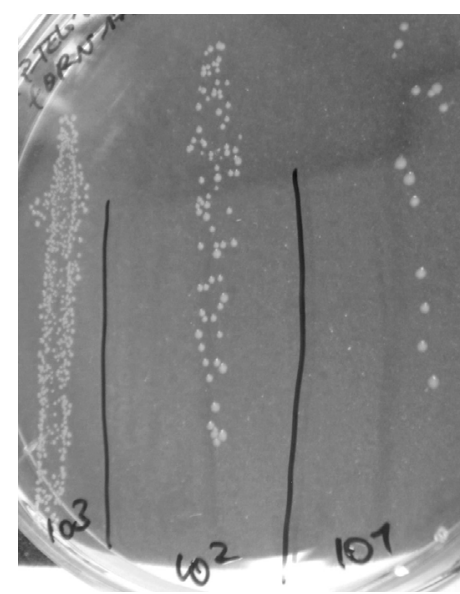

(a)

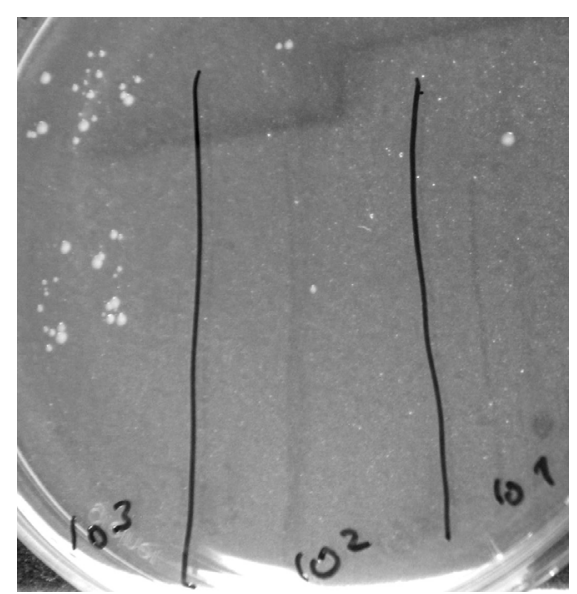

(b)

Figure 4.6 - Bacterial viability test. E. coli bacteria incubated and cultivated on LB mediumagar plates (tetracycline hydrochlorid as selective antibiotic): ORN 178 was incubated with $10 \mu \mathrm{M}$ P-(TEG-Man $)_{4}$ for $30 \mathrm{~min}$, exposed to visible light $(\lambda \geq$ $500 \mathrm{~nm}$ ) for $30 \mathrm{~min}$ and cultivated on agar plates on the same day (a) or after an incubation time of $24 \mathrm{~h} \mathrm{(b).} \mathrm{The} \mathrm{values} \mathrm{below} \mathrm{the} \mathrm{lanes} \mathrm{indicate} \mathrm{the} \mathrm{number} \mathrm{of}$ bacterial cells per $10 \mu \mathrm{l}$. 
the bacteria cells were documented as a function of porphyrin concentration, incubation time, light intensity and wavelength filter (Fig. 4.7). No effect on the survival rate of the ORN strains either in the presence or absence of irradiation was found when the samples were examined directly after irradiation, independent of the porphyrin type and concentration or type of ORN strain (Fig. 4.7a and 4.7b, black data). The amount of counted colonies was in the same range as for the negative control which contained only HEPES buffer and bacteria $\left(c_{P}=0 \mu \mathrm{M}\right)$. Neither using a $400 \mathrm{~nm}$ long pass filter, which excites both $\mathrm{Q}$ and Soret bands of the porphyrin derivatives, nor changing the light intensity showed differences (Fig. 4.7c).

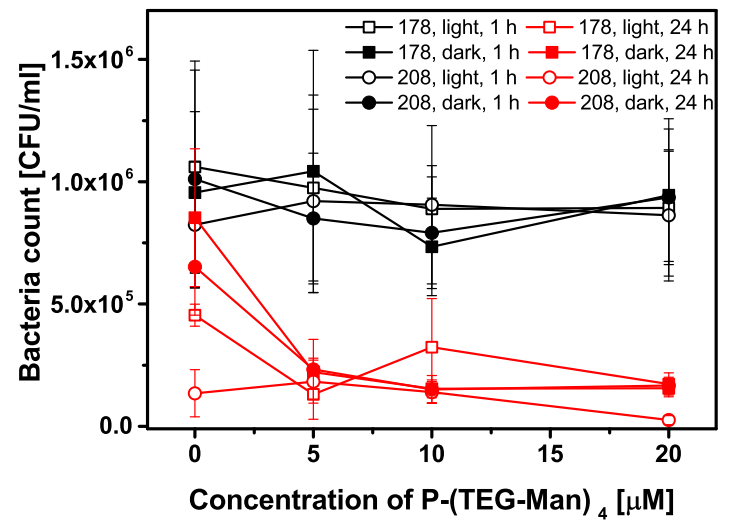

(a)

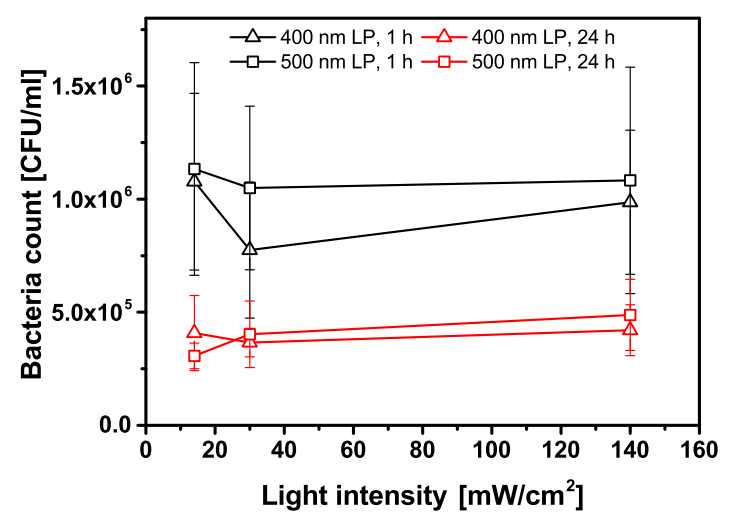

(c)

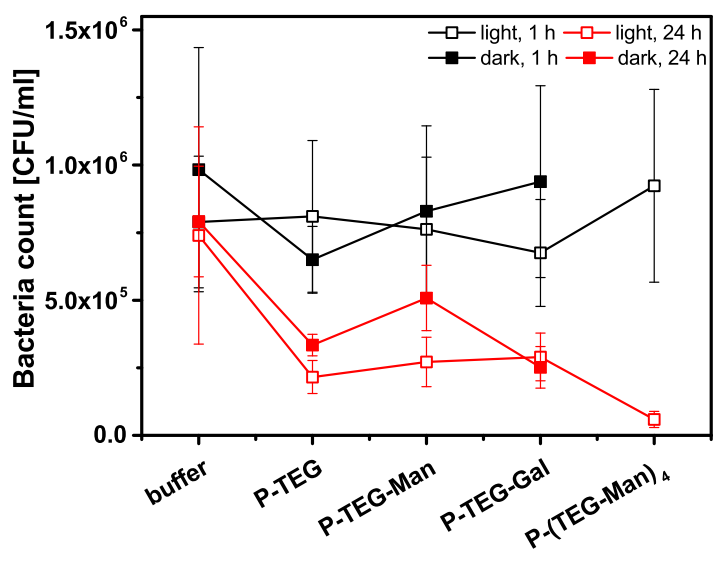

(b)

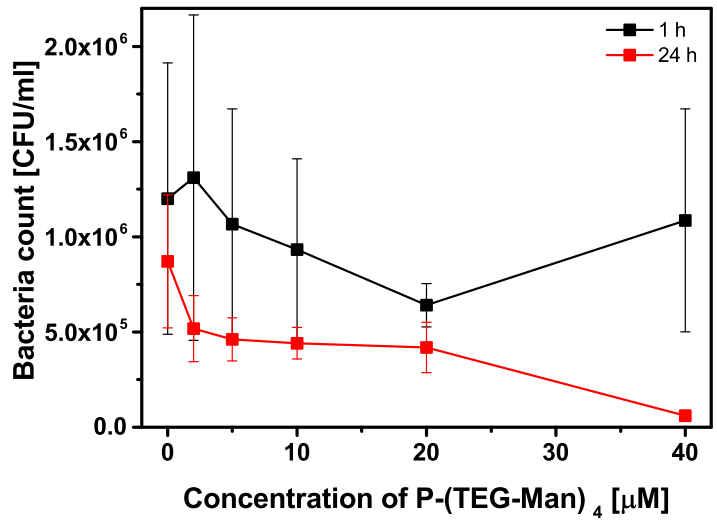

(d)

Figure 4.7 - Survival curves of E. coli incubated with different porphyrins at $37^{\circ} \mathrm{C}$ for $30 \mathrm{~min}$ in the dark, subsequent exposure to light or dark for 30 min and cultivation on agar plates (black data). Survival curves of the same samples after another incubation period of $24 \mathrm{~h}$ at $37^{\circ} \mathrm{C}$ and re-cultivation on agar plates (red data): (a) Different concentrations $\left(\mathrm{c}_{P}=0-20 \mu \mathrm{M}\right)$ of P-(TEG-Man $)_{4}$ incubated either with ORN 178 or ORN 208. (b) Porphyrins $\left(c_{P}=10 \mu \mathrm{M}\right)$ P-TEG, P-TEG-Man, P-TEGGal, and P-(TEG-Man) $)_{4}$ incubated with ORN 178. (c) P-(TEG-Man $)_{4}\left(c_{P}\right.$ $=10 \mu \mathrm{M})$ incubated with ORN 178, treated with different light intensities (14 $\left.140 \mathrm{~mW} / \mathrm{cm}^{2}\right)$ and filters $(400 / 500 \mathrm{~nm} \mathrm{LP})$. (d) Different concentrations $\left(\mathrm{c}_{P}=0\right.$ - $40 \mu \mathrm{M})$ of P-(TEG-Man) $)_{4}$ incubated with ORN 178, without light exposure. 
After an incubation period of $24 \mathrm{~h}$ there was an observable effect on the survival rate of the bacteria cells when compared to the negative control (Fig. 4.7a and 4.7b, red data). However, in the control experiments without light irradiation we noted severe dark toxicity of the porphyrins, resulting in almost no bacterial colonies left at $40 \mu \mathrm{M} \mathrm{P}$-(TEG-Man) 4 (Fig. 4.7d).

Although the porphyrins showed the ability to produce singlet oxygen (see section 4.2.1), agglomeration of bacteria occurred only on a small scale when porphyrin assemblies were present and no photoinactivation of the bacteria in the presence of the porphyrins was observed. There are indications in literature that not only an extracellular binding but a subsequent uptake would be necessary for successfully photoinactivating bacteria, so that the distance between photosensitizer and bacteria is smaller than the diffusion range of ${ }^{1} \mathrm{O}_{2}[5,31]$. The uptake of neutral and negatively charged porphyrins by Gram(-)-negative bacteria, like E. coli, is more challenging than the uptake of cationic porphyrins due to the composition of the cell membrane of Gram(-)-negative bacteria [5, 9, 32]. Therefore comparable studies of the porphyrin assemblies with Gram(+)-positive bacteria, such as $S$. aureus, would be desirable. However, in another case glycoporphyrins have been reported that showed singlet oxygen generation and uptake into cells but still no phototoxicity [33].

\subsection{Conclusions}

The singlet oxygen and the fluorescence quantum yields of the glycoconjugated porphyrins were determined and the values were comparable to values reported for similar porphyrins. The monosubstituted porphyrins with mannose and galactose showed preferred binding to their corresponding lectins. Unexpectedly, the tetrasubstituted mannose porphyrin did not show a strong preference for ConA but showed binding to both lectins. Unfortunately no successful photoinactivation of the chosen bacteria cells was detected but a high dark toxicity of the porphyrins after one day incubation was observed.

\subsection{Experimental section}

\subsubsection{Materials and equipment}

Chemicals were purchased from Sigma Aldrich, Merck, VWR Chemicals and Acros ORGANICS and used without further purification.

UV/vis absorption spectra were measured on a PERKIN ELMER Lambda 850 spectrophotometer. The UV/vis absorption spectra were measured against air and corrected for the solvent. For the irradiation of the samples in the singlet oxygen quantum yield experiment an EDMund Dolan-Jenner MI-150 Fiber Optic Illuminator, equipped with a flexible fiber 
optic light guide was used. The sample was placed $3 \mathrm{~cm}$ below the guide's end and light intensities of $19 \mathrm{~mW} / \mathrm{cm}^{2}$ and $30 \mathrm{~mW} / \mathrm{cm}^{2}$ at the treatment site were used. Between the lamp and the sample a Vision LIGHT TECH $500 \mathrm{~nm}$ long pass filter (LP500-D25) was installed.

Fluorescence spectra were recorded on a PERKIN ELMER LS 55 Fluorescence Spectrophotometer. For the determination of the fluorescence quantum yield the samples were excited at $\lambda_{\text {exc }}=550 \mathrm{~nm}$, with both slit widths at $10 \mathrm{~nm}$. For the experiments with lectins $\lambda_{\text {exc }}$ $=425 \mathrm{~nm}$ (P-TEG-Gal), $\lambda_{e x c}=430 \mathrm{~nm}$ (P-TEG, P-TEG-Man) and $\lambda_{e x c}=455 \mathrm{~nm}$ $\left(\mathbf{P}-(\text { TEG-Man })_{4}\right)$ were used as excitation wavelengths. The slit widths were kept for these measurements at $10 \mathrm{~nm}$ for the excitation and at $15 \mathrm{~nm}$ for the emission.

In all protein experiments a HEPES buffer was used: $\mathrm{pH}=7.2,10 \mathrm{mM}$ HEPES, $137 \mathrm{mM}$

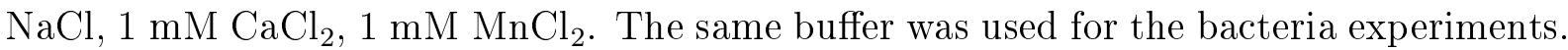
The bacteria themselves were cultivated in lysogeny broth (LB) as medium, with tetracycline hydrochlorid as selective antibiotic.

The microscopy pictures were recorded using an OLYMPUS IX71 microsope. The bright field images were recorded in monochrome mode with $50 \mathrm{~ms}$ exposure time.

For the irradiation in the experiments with bacteria cells the same setup as for the singlet oxygen quantum yield measurements was used. Additional an IR filter from VISION Light TECH was used to exclude wavelengths higher than $770 \mathrm{~nm}$ to reduce the impact of heat.

The bacterial strains E. coli ORN 178 and ORN 208 were kindly provided by Prof. Luc Brunsveld (Technische Universiteit Eindhoven).

\subsubsection{Methods}

\section{Singlet oxygen quantum yield $\Phi_{\Delta}$}

The whole experiment was carried out in the dark. Samples were mixed from stock solutions directly prior to the measurements. The exposure to the light was done additivly with the measurements in between. For the experiment optically matching solutions were used. The concentration of the compounds in the sample were: $1 \mu \mathrm{M}$ porphyrin and $20 \mu \mathrm{M}$ DPBF. The added up irradiation times were $10 \mathrm{~s}, 20 \mathrm{~s}, 30 \mathrm{~s}, 40 \mathrm{~s}, 50 \mathrm{~s}$, and $60 \mathrm{~s}$. The reference values for TPP were 0.64 in water [5], 0.62 in THF [12] and 0.36 in methanol (determined by comparison). The standard deviations in the cases of methanol or water as solvent were calculated from two or three measurements. 


\section{Fluorescence quantum yield $\Phi_{F}$}

The porphyrins and the reference TPP were dissolved in THF with a concentration of $2 \mu \mathrm{M}$. The reference value of TPP in THF is 0.10 [12]. The yields were determined by relative comparing of the graph areas and using equation 4.2. The standard deviations were calculated from three measurements.

\section{Lectin binding study}

A $50 \mu \mathrm{M}$ porphyrin solution in HEPES and a $10 \mathrm{mg} / \mathrm{ml}$ lectin solution in HEPES were freshly prepared. From those stock solutions the samples were mixed in Eppendorf vials. The vials were kept in a $37^{\circ} \mathrm{C}$ water bath in the dark for $2 \mathrm{~h}$. The samples were vortexed prior to the measurement. As porphyrin concentration $2 \mu \mathrm{M}$ and $10 \mu \mathrm{M}$ and as lectin concentration $0.5 \mathrm{mg} / \mathrm{ml}, 1 \mathrm{mg} / \mathrm{ml}, 2 \mathrm{mg} / \mathrm{ml}$ and $5 \mathrm{mg} / \mathrm{ml}$ were used in the samples.

\section{Brightfield microscopy}

The bacterial strains ORN 178 and ORN 208 were grown overnight in lysogeny broth (LB) as medium using tetracycline hydrochloride as the selective antibiotic. After measuring the $\mathrm{OD}_{600}$ value, samples containing 1 OD bacteria, $1 \mathrm{mM} \mathrm{MnCl}_{2}, 1 \mathrm{mM} \mathrm{CaCl}_{2}$ and $5 \mu \mathrm{M}$ P-TEG-Man were prepared and incubated for $1 \mathrm{~h}$ at $37^{\circ} \mathrm{C}$. A drop of the solution was placed between cover slips and investigated under the microscope.

\section{Photosensitized inactivation of bacteria cells}

The whole experiment was carried out in the dark. The E. coli bacteria strains ORN 178 and ORN 208 who were grown overnight were centrifuged, the medium was removed and the bacteria cells were transferred into HEPES buffer. Solutions containing $10^{6} \mathrm{cells} / \mathrm{ml}$ $\left(\mathrm{OD}_{600}=0.001\right)$ and different porphyrin concentrations $\left(\mathrm{c}_{P}=0,0.1,1,2,5,10,20\right.$, $40 \mu \mathrm{M})$ were incubated for $30 \mathrm{~min}$ at $37^{\circ} \mathrm{C}$ in the dark. Then the samples were either irradiated by light or kept in the dark for $30 \mathrm{~min}$. For the irradiation the samples were transferred into a 96-well plate and usually a $500 \mathrm{~nm}$ long pass filter and a light intensity of $30 \mathrm{~mW} / \mathrm{cm}^{2}$ at the treatment site was used. In other cases a $400 \mathrm{~nm}$ long pass filter and light intensities of $14 \mathrm{~mW} / \mathrm{cm}^{2}$ or $140 \mathrm{~mW} / \mathrm{cm}^{2}$ were used (deviation stated in the text). After the treatment the samples were cultivated on LB medium-agar plates (tetracycline hydrochlorid added as selective antibiotic). Then the samples were incubated for another $24 \mathrm{~h}$ and the plate cultivation was repeated. For the cultivation the samples were diluted to $10^{5}, 10^{4}$ and $10^{3}$ cells $/ \mathrm{ml}$. From these solutions $10 \mu \mathrm{l}$ were placed as drops on top of the agar plates before the plates were tilted to form 3 streams which quickly dried. The plates were kept at $37^{\circ} \mathrm{C}$ overnight before the colonies were counted the next day. 


\subsection{Bibliography}

[1] Wilkinson, F.; Helman, W. P.; Ross, A. B. J. Phys. Chem. Ref. Data 1993, 22, 113-262.

[2] Adam, W. Chem. Unserer Zeit 1981, 15, 190-196.

[3] Halliwell, B. Biochem. J. 2007, 401, 1-11.

[4] Hwang, O. Exp. Neurobiol. 2013, 22, 11-17.

[5] Meng, S.; Xu, Z.; Hong, G.; Zhao, L.; Zhao, Z.; Guo, J.; Ji, H.; Liu, T. Eur. J. Med. Chem. 2015, 92, 35-48.

[6] Bristow, C.-A.; Hudson, R.; Paget, T. A.; Boyle, R. W. Photodiagn. Photodyn. 2006, 3, 162-167.

[7] Konopka, K.; Goslinski, T. J. Dent. Res. 2007, 86, 694-707.

[8] Maisch, T.; Szeimies, R.-M.; Jori, G.; Abels, C. Photochem. Photobiol. Sci. 2004, 3, 907917.

[9] Spesia, M. B.; Lazzeri, D.; Pascual, L.; Rovera, M.; Durantini, E. N. FEMS Immunology 86 Medical Microbiology 2005, 44, 289-295.

[10] Tatman, D.; Liddell, P. A.; Moore, T. A.; Gust, D.; Moore, A. L. Photochem. Photobiol. 1998, 68, 459-466.

[11] Sibrian-Vazquez, M.; Hao, E.; Jensen, T. J.; Vicente, M. G. H. Bioconjugate Chem. 2006, $17,928-934$.

[12] Elisa Milanesio, M.; Morán, F. S.; Ines Yslas, E.; Gabriela Alvarez, M.; Rivarola, V.; Durantini, E. N. Bioorg. Med. Chem. 2001, 9, 1943-1949.

[13] Vedachalam, S.; Choi, B.-H.; Pasunooti, K. K.; Ching, K. M.; Lee, K.; Yoon, H. S.; Liu, X.W. Med. Chem. Commun. 2011, 2, 371-377.

[14] Marydasan, B.; Nair, A. K.; Ramaiah, D. J. Phys. Chem. B 2013, 117, 13515-13522.

[15] Krieg, M. J. Biochem. Biophys. Methods 1993, 27, 143-149.

[16] Mathai, S.; Smith, T. A.; Ghiggino, K. P. Photochem. Photobiol. Sci. 2007, 6, 995-1002.

[17] Polska, K.; Radzki, S. Opt. Mater. 2008, 30, 1644-1654.

[18] Bhanu, K.; Komath, S. S.; Maiya, B. G.; Swamy, M. J. Curr. Sci. 1997, 73, 598-602.

[19] Kavitha, M.; Swamy, M. J. IUBMB Life 2006, 58, 720-730.

[20] Okada, M.; Kishibe, Y.; Ide, K.; Takahashi, T.; Hasegawa, T. International Journal of Carbohydrate Chemistry 2009, 1, ID 305276.

[21] Makky, A.; Michel, J.; Maillard, P.; Rosilio, V. Biochim. Biophys. Acta 2011, 1808, 656-666.

[22] Makky, A.; Michel, J. P.; Kasselouri, A.; Briand, E.; Maillard, P.; Rosilio, V. Langmuir 2010, 26, 12761-12768.

[23] Singh, S.; Aggarwal, A.; Bhupathiraju, N. V. S. D. K.; Arianna, G.; Tiwari, K.; Drain, C. M. Chem. Rev. 2015, 115, 10261-10306.

[24] Merchat, M.; Spikes, J.; Bertoloni, G.; Jori, G. J. Photochem. Photobiol. B 1996, 35, 149157.

[25] Figueiredo, T. L. C.; Johnstone, R. A. W.; Sørensen, A. M. P. S.; Burget, D.; Jacques, P. Photochem. Photobiol. 1999, 69, 517-528.

[26] Merkel, P. B.; Kearns, D. R. J. Am. Chem. Soc. 1972, 94, 1029-1030.

[27] Crosby, G. A.; Demas, J. N. J. Phys. Chem. 1971, 75, 991-1024.

[28] Strassert, C. A.; Bilmes, G. M.; Awruch, J.; Dicelio, L. E. Photochem. Photobiol. Sci. 2008, 7, 738-747.

[29] Vedala, H.; Chen, Y.; Cecioni, S.; Imberty, A.; Vidal, S.; Star, A. Nano Lett. 2011, 11, $170-175$.

[30] Harris, S.; Spears, P.; Havell, E.; Hamrick, T.; Horton, J.; Orndorff, P. J. Bacteriol. 2001, 183, 4099-4102.

[31] Grüner, M.; Tuchscherr, L.; Löffler, B.; Gonnissen, D.; Riehemann, K.; Staniford, M. C.; Kynast, U.; Strassert, C. A. ACS Appl. Mater. Interfaces 2015, 7, 20965-20971. 
[32] Galstyan, A.; Block, D.; Niemann, S.; Grüner, M. C.; Abbruzzetti, S.; Oneto, M.; Daniliuc, C. G.; Hermann, S.; Viappiani, C.; Schäfers, M.; Löffler, B.; Strassert, C. A.; Faust, A. Chem. Eur. J. 2016, 22, 5243-5252.

[33] Daly, R.; Vaz, G.; Davies, A. M.; Senge, M. O.; Scanlan, E. M. Chem. Eur. J. 2012, 18, 14671-14679. 



\section{Aggregation-Induced Emission Properties of 4,5-Bis(phenylthio)phthalonitriles}

In this chapter the synthesis and properties of a novel class of aggregation-induced emissive compounds have been described. The bis(phenylthio)phthalonitriles (SPn) were equipped with either tetraethylene glycol units or mannose moieties for selective targeting of lectins and bacteria. Photophysical and morphological studies showed that above a threshold concentration of $1 \mu M$ SPn aggregated into fluorescent spherical objects with an average diameter of about $196 \mathrm{~nm}$ in solution and of about $26 \mathrm{~nm}$ in the dried state. A structurally similar phenoxy analogue (OPn) equipped with tetraethylene glycol chains was synthesized. No aggregation-induced emission was observed upon self-assembly of these OPn molecules into spherical objects. 


\subsection{Introduction}

Self-assembled aggregates that exhibit strong fluorescence in water and in the solid state have been used for a range of purposes, such as organic light emitting diodes [1-4], sensors for metal ions [5] and explosives [6], mapping of cell viscosity [7] and cell targeting [8] as well as interactions with bacteria [9] and proteins [10]. Especially when those assemblies are fluorescent in buffered media and specifically interact with biological and medical samples high interest is assured of biomedical and bioanalytical researchers since easily accessible fluorescent read-out is provided.

Unfortunately a lot of organic dyes, like the porphyrins described in the chapters 2 - 4, feature only low fluorescence intensity in the aggregated state, e.g. in aqueous media, while they show strong emission in the molecularly dissolved state, often in polar organic solvents. This aggregation-caused quenching (ACQ) is due to $\pi$ - $\pi$-stacking and hydrophobic forces, resulting in clustering [11, 12]. In 2001 Tang and co-workers described opposing observations: a molecule, which is non-emissive in organic solvents in the molecularly dissolved state but showed significant emission in water upon formation of nanoscopic aggregates. The authors called this phenomenon "aggregation-induced emission" (AIE) [1]. Since the appearance of first examples of molecules with aggregation-induced emission properties, this phenomenon has attracted lots of interest [13, 14]. In the early years especially the mechanism of the AIE was a major point of discussion. One of the first ideas discussed for the cause of AIE was coplanarity, inspired by a report on the coplanarisation of chromophores introduced by aggregation [15]. When peripheral phenyl rings turn into the same plane as the core of the dye molecule a maximum conjugation is achieved, while rings that remain out-of-plane, e.g. at $90^{\circ}$, show minimum conjugation [1]. However, in crystal structures and theoretical calculations of AIEgens no coplanarity was found but angles up to $80^{\circ}[4,16,17]$. Another suggestion was that $J$-aggregation in the case of the AIE molecules contributed to stiffening of the molecular conformation thereby blocking nonradiative relaxation pathways that lead to a radiative decay [18]. Nowadays mainly the restriction of intramolecular rotation (RIR) has been proposed as the mechanism for AIE [12]. The free rotation of the rotor part, usually phenyl rings, provides a nonradiative channel to decay excited species. If this rotation is hindered, e.g. upon aggregation, the nonradiative pathway is inhibited and other, radiative states will be populated [7, 19]. The mechanism has been proven by cooling (down to $-196{ }^{\circ} \mathrm{C}$ ) and thickening experiments (with glycerol) that are both slowing down the intramolecular rotation [2, 16]. Other evidence has been produced by studying the difference between AIEgens and their counterparts with the phenyl blades covalently locked by ring closure [4, 17]. The locked form showed ACQ properties and theoretical calculations of the isolated molecules demonstrated that for the locked form the only free ring did not participate in the frontier orbitals 
which excluded nonradiative pathways [4].

In comparison with traditional organic dyes AIEgens possess more rotatable parts and have been described as propeller-like [7]. Typical molecules that are prone to exhibit AIE bear phenyl rings which are able to rotate out of plane of the central unit and annihilate excitons in solution [2, 4, 11, 18]. The simplicity in structure and accessibility in synthesis were the reasons for the fast expansion of hydrocarbonic AIEgens [14]. Examples are tetraphenylbutadienes, diphenyldibenzofulvenes and tetraphenylethenes. However, the possibilities of structural variations are limited for pure hydrocarbonic systems. For this reason research has turned to heteroatom-containing AIEgens [14, 17]. In this category siloles, Schiff bases, hydrogen-bonding systems and nitrile compounds have been reported. The rigidity of the nitrile bond can enhance twisted conformations leading to AIE properties [14, 20].

Here we report a facile synthesis route to 4,5-bis(phenylthio)phthalonitriles (SPn) and the phenoxy analogue 4,5-bis(phenyoxy)phthalonitrile (OPn) featuring either a sulfur or an oxygen atom in the rotational part of the molecule. Using photophysical measurements, microscopy and dynamic light scattering the self-assembly characteristics of the phthalonitrile $(\mathrm{Pn})$ molecules were studied.

\subsection{Results and Discussion}

\subsubsection{Synthesis of phthalonitriles}

The synthesis started from commercially available 4,5-dichlorophthalonitrile $\mathbf{6}$, which was coupled to 4-mercaptophenol in a thioetherification or to hydroquinone in a etherification under basic conditions in good yields (Fig. 5.1). The thioether diol 7 and ether diol $\mathbf{9}$ were then coupled in a substitution reaction to tetraethyleneglycol derivatives $\mathbf{1}$ and 3. The reaction time was at least one day to assure completion of the reaction and to minimize the monosubstituted side-product. SPn-TEG $\mathbf{S}_{2}$ and $\mathbf{O P n}-\mathbf{T E G} \mathbf{G}_{2}$ were obtained with $54 \%$ and $40 \%$ yield, respectively. Azide-terminated bis(phenylthio)phthalonitrile 8 was obtained with $50 \%$ yield. Finally, 8 was used in a copper(I)-assisted azide-alkyne click (CuAAC) reaction with an alkyne-terminated carbohydrate in its protected form $\mathbf{5}$. $\alpha$-D-mannose was selected since it bears the opportunity to bind actively to FimH receptors of E. Coli strains and to carbohydrate selective proteins, so called lectins. After deprotection by sodium methoxide and purification by column chromatography the final compound SPn-(TEG-Man) 2 was isolated in good yield (79 \%). The structures of the final compounds were confirmed by mass spectrometry and ${ }^{1} \mathrm{H}$ and ${ }^{13} \mathrm{C}$ NMR spectroscopy (see 5.5.2). 

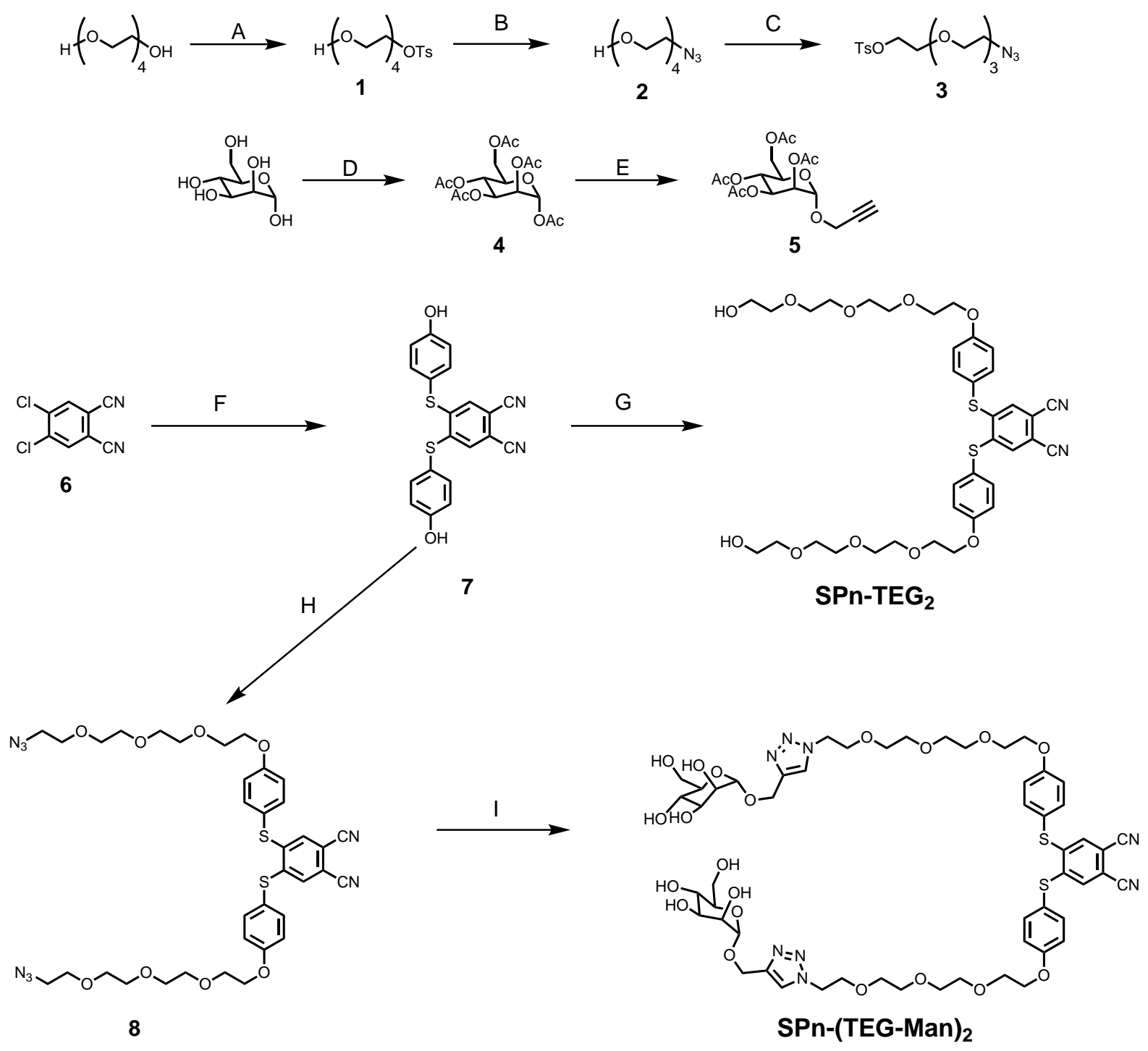

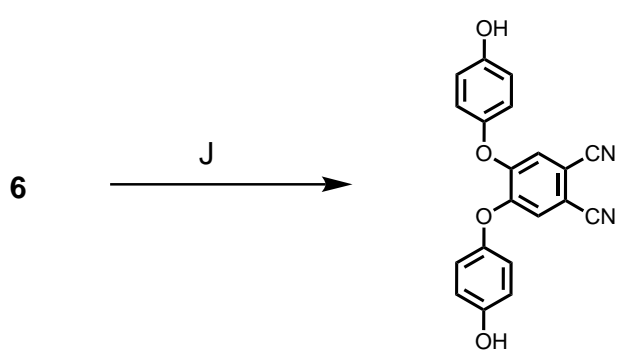

9

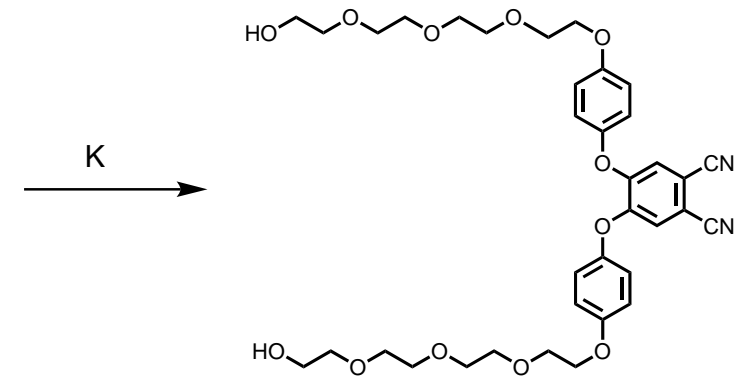

OPn-TEG

Figure 5.1 - Synthetic route to bis(phenylthio)phthalonitriles SPn-TEG S $_{2}$ and SPn-(TEGMan $)_{2}$ and bis(phenoxy)phthalonitrile OPn-TEG $\mathbf{O}_{2}$. A) TsCl, Et ${ }_{3} \mathrm{~N}$, DMAP, $\mathrm{CH}_{2} \mathrm{Cl}_{2}, 18$ h, 70 \%. B) $\mathrm{NaN}_{3}$, DMF, 18 h, $95 \%$. C) TsCl, Et ${ }_{3} \mathrm{~N}, \mathrm{DMAP}, \mathrm{CH}_{2} \mathrm{Cl}_{2}$, 18 h, 71 \%. D) $\mathrm{Ac}_{2} \mathrm{O}, \mathrm{NaOAc}, 4 \mathrm{~h}, 67 \%$. E) Propargyl alcohol, $\mathrm{SnCl}_{4}, \mathrm{CH}_{2} \mathrm{Cl}_{2}$, 4 h, $43 \%$. F) 4-Mercaptophenol, $\mathrm{K}_{2} \mathrm{CO}_{3}$, DMF, 24 h, $95 \%$. G) $\mathbf{1}, \mathrm{K}_{2} \mathrm{CO}_{3}$, acetonitrile, $24 \mathrm{~h}, 54 \%$. H) $\mathbf{3}, \mathrm{K}_{2} \mathrm{CO}_{3}$, acetonitrile, $24 \mathrm{~h}, 50 \%$. I) 1. 5, $\mathrm{CuSO}_{4}$, ascorbic acid, DMF, 48 h, 60 \%; 2. NaOMe, MeOH, 4 h, 79 \%. J) Hydroquinone, $\mathrm{K}_{2} \mathrm{CO}_{3}$, DMSO, 24 h, $54 \%$ K) 1, $\mathrm{K}_{2} \mathrm{CO}_{3}$, acetonitrile, $3 \mathrm{~d}, 40 \%$. 


\subsubsection{Photophysical properties of phthalonitriles}

Dissolving compound SPn-(TEG-Man) $)_{2}$ in tetrahydrofuran (THF)-water mixtures led upon increasing the water content to solutions that exhibit strong fluorescence visible to the naked eye when excited at a wavelength $(\lambda)$ of $330 \mathrm{~nm}$ (Fig. 5.2a). Until a water:THF ratio of 80:20 no fluorescence emission was visible in the vials. However, when exceeding a 90:10 ratio, the emission rapidly increased until a maximum intensity was reached in pure water. When the SPn compounds were dissolved in THF or methanol faint fluorescence was detected. The transition between the fluorescent and non-fluorescent state was studied by measuring the absorption and fluorescence spectra of a series of SPn-(TEG-

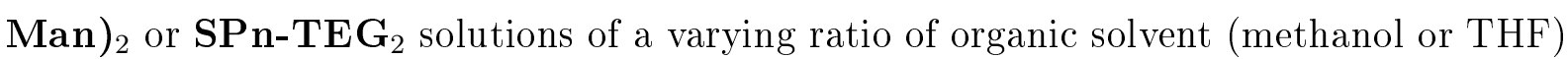
and water at constant SPn concentration $\left(\mathrm{c}_{S P n}=100 \mu \mathrm{M}\right.$, Fig. 5.2b 5.2e). In the fluorescence spectra in figure $5.2 \mathrm{~b}$ the emission intensity increases with increasing water fraction. The wavelength of the emission maximum in water is at $\lambda=490 \mathrm{~nm}$. The solutions with higher THF fraction show a peak around $\lambda=405 \mathrm{~nm}$, which was attributed to the stabilizer butylated hydroxytoluene (BHT) in THF. In methanol, which is non-emissive, SPn-(TEG-Man $)_{2}$ gives a barely recognizable emission maximum around $\lambda=425 \mathrm{~nm}$ (Fig. $5.2 \mathrm{~d}$ ). The red-shift of the emission maximum of $65 \mathrm{~nm}$ might indicate a change in the molecular organization resembling a $J$-type aggregation in the aqueous solutions. The fluorescence spectra of $\mathbf{S P n - T E G} \mathbf{F}_{2}$ in the THF-water and methanol-water mixtures are comparable to the mannose SPn (Fig. $5.2 \mathrm{c}$ and $5.2 \mathrm{e}$ ). The fluorescence quantum yields in water were $2 \%$ for SPn-(TEG-Man) $)_{2}$ and $6 \%$ for $\mathbf{S P n - T E G} \mathbf{F}_{2}$.

The absorption spectra of SPn-(TEG-Man) $)_{2}$ show an absorbance maximum at $\lambda=$ $275 \mathrm{~nm}$ and a vibronic shoulder at $\lambda=325 \mathrm{~nm}$. With increasing water content the absorbance decreases (Fig. 5.2b and 5.2d). The decrease in absorbance is caused by the assembly of the molecules and the resulting reduced effective concentration of free, molecularly dissolved molecules [1]. The optical changes when increasing the water content in solutions of $\mathbf{S P n}-\mathbf{T E G} \mathbf{F}_{2}$ were similar to those observed for the other SPn. Only the decrease of the absorbance was stronger, especially for the maximum around $\lambda=275 \mathrm{~nm}$ (Fig. 5.2c and 5.2e). The stronger decrease could be related to the lower solubility of SPn-TEG ${ }_{2}$ resulting in more intense clustering and therefore a lower effective concentration of molecularly dissolved species. In contrast to SPn-TEG $_{2}, \mathbf{S P n}-(\mathbf{T E G}-\mathbf{M a n})_{2}$ is more soluble in water as expected from the mannose moieties.

Both SPn derivatives show similar spectral changes indicating that peripheral substitution of the molecules has little effect on the photophysical properties. The presence of

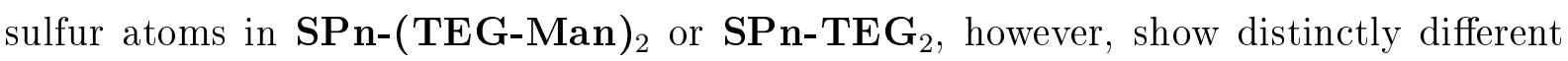
photophysical properties when compared to the oxygen containing analogue OPn-TEG $\mathbf{O}_{2}$. Comparison of the absorption spectra of $100 \mu \mathrm{M}$ aqueous solutions of SPn-TEG $\mathbf{F}_{2}$ and OPn-TEG ${ }_{2}$ shows that for the latter the maximum is $60 \mathrm{~nm}$ blue-shifted in contrast to 


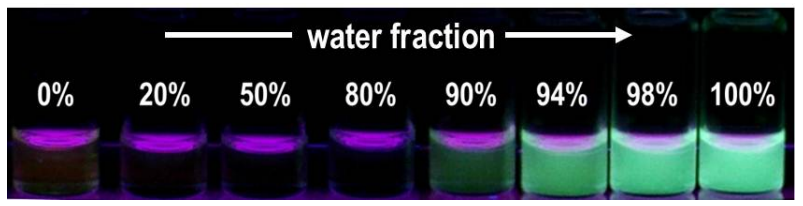

(a)

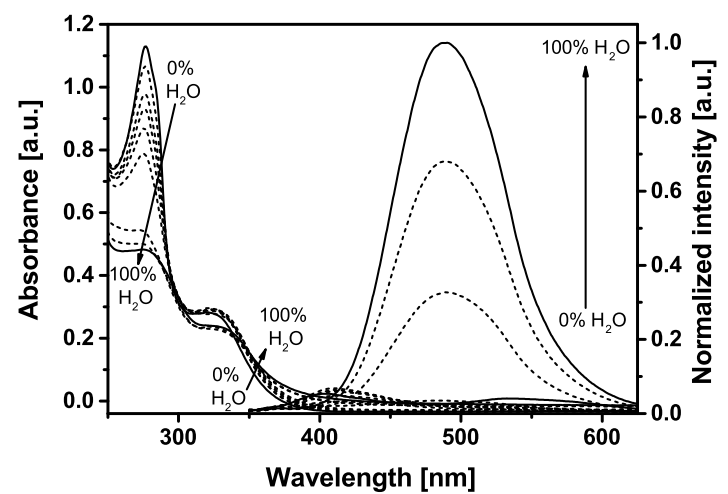

(b)

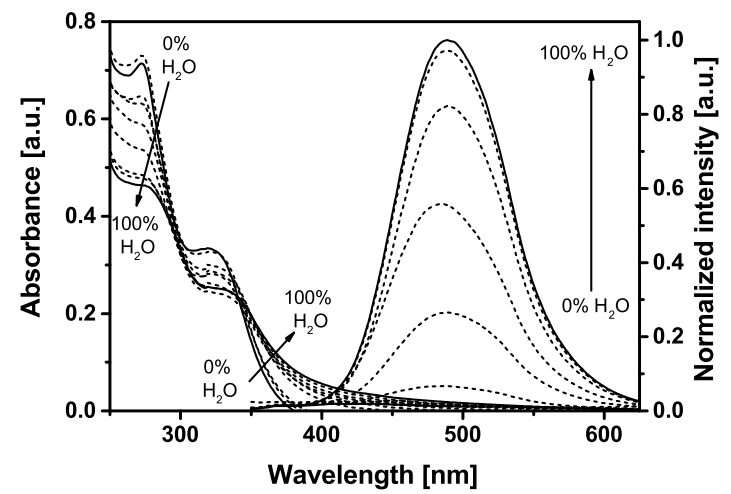

(d)

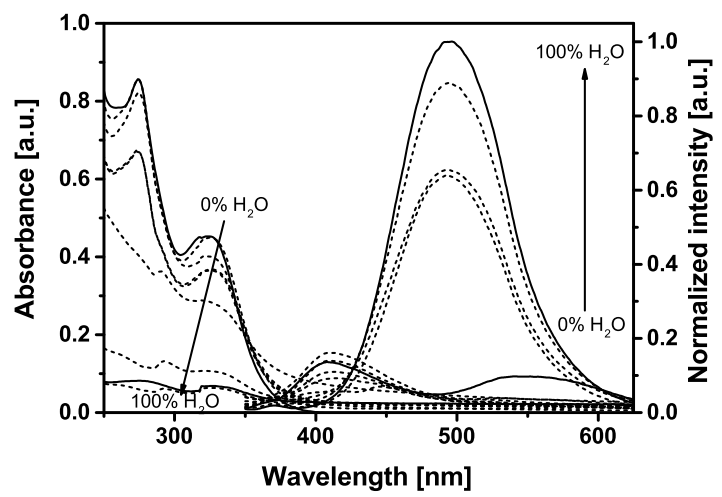

(c)

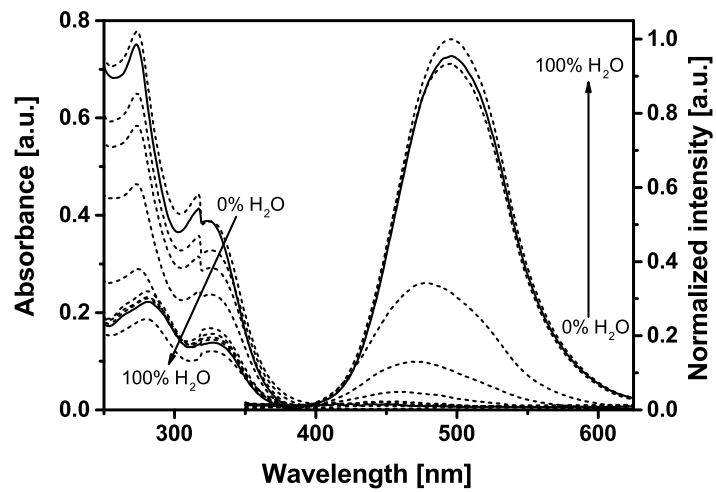

(e)

Figure 5.2 - Photograph of $100 \mu \mathrm{M}$ SPn-(TEG-Man) $)_{2}$ in water-THF mixtures with increasing water fraction under illumination of a handheld UV lamp (a). Absorption and fluorescence spectra in THF-water mixtures of (b) SPn-(TEG-Man) $)_{2}$ and (c) $\mathbf{S P n}_{\mathbf{T}} \mathbf{T E G}_{2}\left(\mathrm{c}_{S P n}=100 \mu \mathrm{M}\right)$. Absorption and fluorescence spectra in methanolwater mixtures of (d) SPn-(TEG-Man $)_{2}$ and (e) $\mathbf{S P n}-\mathbf{T E G}_{2}\left(\mathrm{c}_{S P n}=100 \mu \mathrm{M}\right)$.

the SPn spectra (Fig. 5.3a). The maximum absorbance in the OPn spectrum is located at $\lambda=215 \mathrm{~nm}$ while a vibronic shoulder is situated at $\lambda=280 \mathrm{~nm}$. Presumably a bigger band gap exists between the HOMO and LUMO in the case of OPn-TEG $\mathbf{G}_{2}$. The recorded absorption spectra of methanol-water mixtures show similarity to the ones for the SPns with a decrease in absorbance upon increasing water content (Fig. 5.3c). A clear decrease in absorbance was not observed in the absorption spectra of $\mathbf{O P n}-\mathbf{T E G} \mathbf{G}_{2}$ in THF-water mixtures (Fig. 5.3b). In fact the absorbance first increases before it decreases with further addition of water. The blue-shift and higher absorptivity of the $\mathbf{O P n}-\mathbf{T E G}_{2}$ spectra might indicate a lower conjugation length [3]. Octaalkylamino substituted zinc(II) phthalocyanines bearing oxygen or sulfur as covalent linkers showed a comparable shift [21]. 
The authors state that the sulfur-containing phthalocyanines showed a higher tendency towards aggregation since their increased molecular weight causes stronger van der Waals interactions [21].

For the fluorescence studies of $100 \mu \mathrm{M}$ solutions of the oxygen species in methanol-water or THF-water mixtures an excitation wavelength of $\lambda=330 \mathrm{~nm}$ was used to allow for a better comparability with the SPn spectra, since at this wavelength $\mathbf{O P n}-\mathbf{T E G}_{2}$ shows a similar absorbance as $\mathbf{S P n -} \mathbf{T E G}_{2}$. The fluorescence spectra of the THF-water mixtures of $100 \mu \mathrm{M}$ OPn-TEG ${ }_{2}$ only show the emission of the THF stabilizer BHT around $\lambda=$ $405 \mathrm{~nm}$ which decreases upon decreasing the THF content (Fig. 5.3b). No other signals appeared upon increasing the fraction of water. In the case of methanol-water mixtures first an increase in the emission intensity was observed until a 1:1 ratio of the two solvents was reached (Fig. 5.3c). The wavelength of maximum emission shifted from $\lambda=$ $400 \mathrm{~nm}(\mathrm{MeOH})$ to $\lambda=370 \mathrm{~nm}\left(\mathrm{MeOH} / \mathrm{H}_{2} \mathrm{O} 1 / 1\right)$. Further increasing the fraction of water resulted in a decreasing emission intensity and a shift of the emission maximum to $\lambda=450 \mathrm{~nm}$. None of the two solvent mixtures showed an increase in emission intensity as was observed in the case of the SPn derivatives. Also exciting solutions of OPn-TEG $\mathbf{O}_{2}$

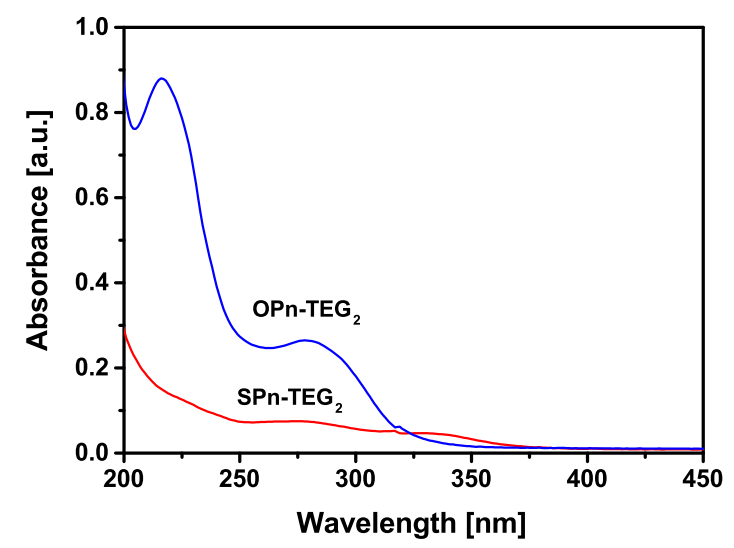

(a)

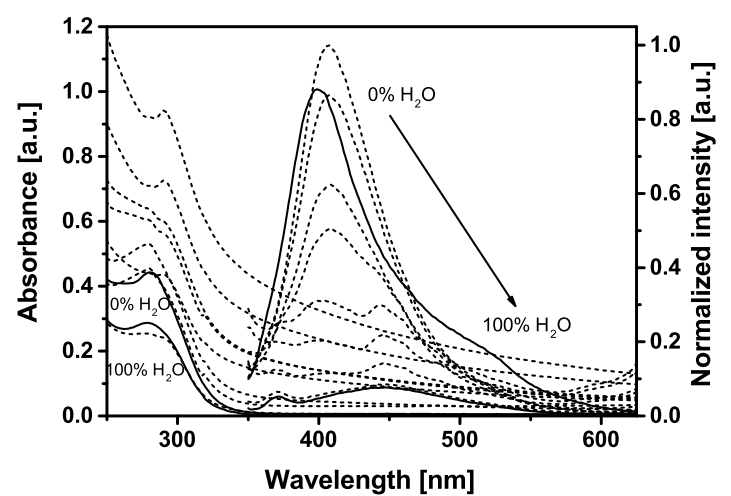

(b)

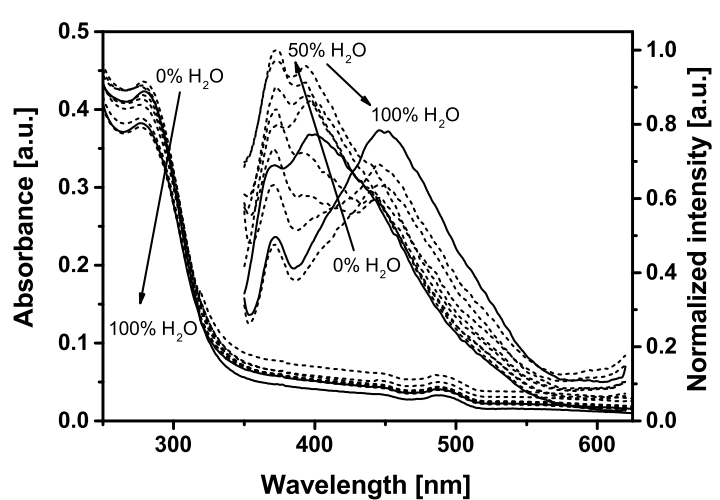

(c)

Figure 5.3 - Absorption spectra of $\mathbf{S P n - T E G}$ and $\mathbf{O P n}-\mathbf{T E G}_{2}$ in water $\left(c_{P n}=100 \mu \mathrm{M}\right)$ (a). Absorption and fluorescence spectra of $\mathbf{O P n}-\mathbf{T E G}_{2}\left(\mathrm{c}_{O P n}=100 \mu \mathrm{M}\right)$ in THF-water mixtures (b) and in methanol-water mixtures (c). 
at its vibronic shoulder $(\lambda=280 \mathrm{~nm})$ did not yield aggregation-induced emission spectra. When the change in emission intensity at $\lambda_{\max }=488 \mathrm{~nm}$ of the SPn was plotted against the water fraction, a sudden rise in emission intensity can be easily discerned (Fig. 5.4a). While in the THF-water mixtures the rise in emission appeared beyond a water fraction of $80 \%$, in methanol-water mixtures the rise in emission appeared at a water fraction of $60 \%$ verifying that the polarity of the solvent is driving the assembly of SPn. For OPn no increase was observed over the whole range (Fig. 5.4b).

As described in the introduction to this chapter an experiment to verify restricted intramolecular rotation as mechanism of the AIE is the titration of glycerol into a methanolic

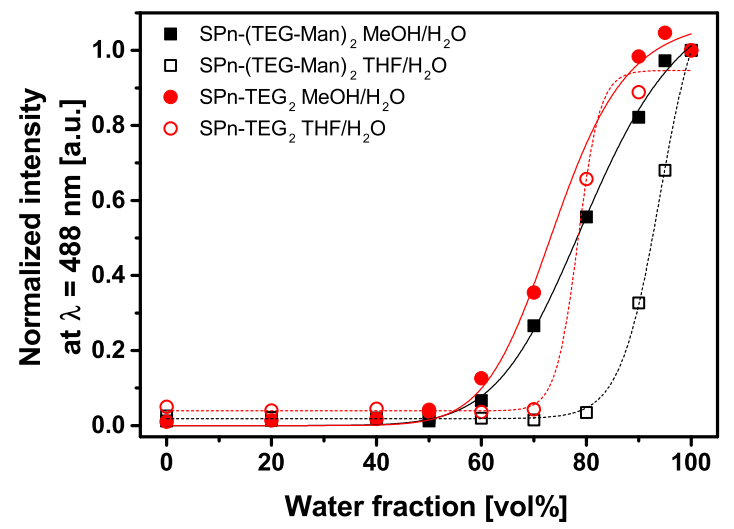

(a)

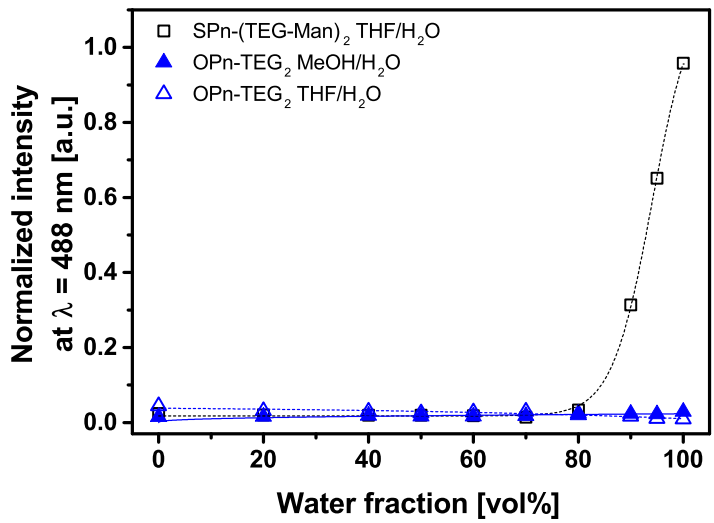

(b)

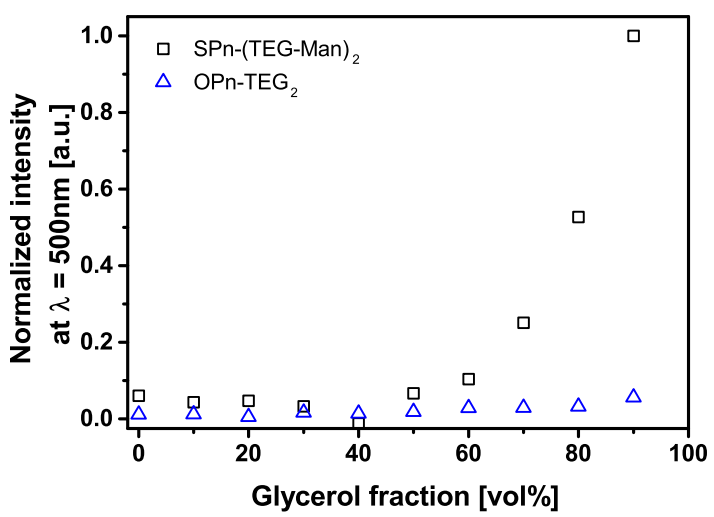

(c)

Figure 5.4 - Normalized fluorescence emission intensity at $\lambda=488 \mathrm{~nm}$ as a function of the water fraction in methanol-water and THF-water mixtures of the previously shown SPn fluorescence spectra (a). Normalized fluorescence emission intensity at $\lambda=488$ $\mathrm{nm}$ as a function of the water fraction in methanol-water and THF-water mixtures of the previously shown OPn fluorescence spectra in comparison with THF-water mixtures of SPn-(TEG-Man) $)_{2}$ (b). Marks are experimental values, trendlines are given to guide the eye. Data have been normalized to the intensity value of SPn-(TEG-Man) $)_{2}$ at 100 vol-\% water. Normalized fluorescence emission intensity at $\lambda=500 \mathrm{~nm}$ as a function of the glycerol volume fraction in methanolglycerol mixtures $\left(\mathrm{c}_{P n}=100 \mu \mathrm{M}\right)(\mathrm{c})$. Data have been normalized to the intensity value of SPn-(TEG-Man) $)_{2}$ at 90 vol- $\%$ glycerol. 
solution up to a volume fraction of 90 vol-\% glycerol [11, 16]. Glycerol is a highly viscous solvent and is therefore able to slow down the intramolecular rotation which should result in an increased emission intensity. Figure $5.4 \mathrm{c}$ shows a strong increase in the fluorescence intensity beyond 60 vol-\% glycerol for SPn-(TEG-Man) $)_{2}$. However, for OPn-TEG OPo $_{2}$ rapid increase in fluorescence intensity was observed indicating that neither by assembly in water nor by slowing down the intramolecular rotation in glycerol an AIE effect was detected.

In another experiment the ionic strength of a $88 \mu \mathrm{M}$ solution of SPn-(TEG-Man) $)_{2}$ in HEPES buffer ( $\mathrm{pH}=7.2,10 \mathrm{mM}$ HEPES) was varied from $0.1 \mathrm{M}$ to $1 \mathrm{M} \mathrm{NaCl}$. A linear increase in the fluorescence emission intensity occurred with a maximum increase of 1.2 times. The rise of the ionic strength may cause an increasing hydrophobic effect that stabilizes the self-assemblies and hinders the intramolecular rotation [22].

Although the three discussed molecules have a similar structure, the presence of sulfur instead of oxygen has a clear influence on the photophysical properties. In crystal structures of AIE featuring molecules with persulfurated benzene cores a syn-periplanar alignment of the lone pair of the sulfur atom with the $\pi$-system of the benzene ring was observed [23]. The authors discussed these observations as a reason for the strong phosphorescence in the confined state. This phenomenon might also explain our observations. In contrast the oxygen atom might be too small for interactions between its lone pair and the benzene $\pi$-system or due to a lower polarizability causing a smaller push-pull character. However, without further investigations, such as crystal structure analysis or detailed calculations, the exact explanation remains unclear.

\subsubsection{Morphological properties of phthalonitrile assemblies}

The aqueous solutions studied in the previous section were clear solutions. When minute amounts of $100 \mu \mathrm{M}$ solutions of SPn-(TEG-Man) $)_{2}$ or SPn-TEG $\mathbf{S}_{2}$ in water were deposited onto copper grids and negatively stained (1 wt\% uranyl acetate), inspection of the samples using transmission electron microscopy (TEM) revealed spherical objects (Fig. 5.5) . The objects were not evenly distributed over the grid but observed in high density in particular areas on the grids, e.g. the corners, as a consequence of the drying process. The average size in the case of SPn-(TEG-Man) $)_{2}$ was $13 \pm 2 \mathrm{~nm}$ while aggregates of $\mathbf{S P n}-\mathbf{T E G}_{2}$ were slightly bigger $(19 \pm 4 \mathrm{~nm})$ (Tab. 5.1).

Similarly, $100 \mu \mathrm{M}$ water solutions of the phthalonitriles were deposited on silicon wafers and inspected using a scanning electron microscope (SEM, Fig. 5.6a - 5.6c). The SEM images show round-shaped objects in agreement with observations made by TEM microscopy. The average size obtained by SEM is bigger than the one obtained by TEM (Tab. 5.1). 


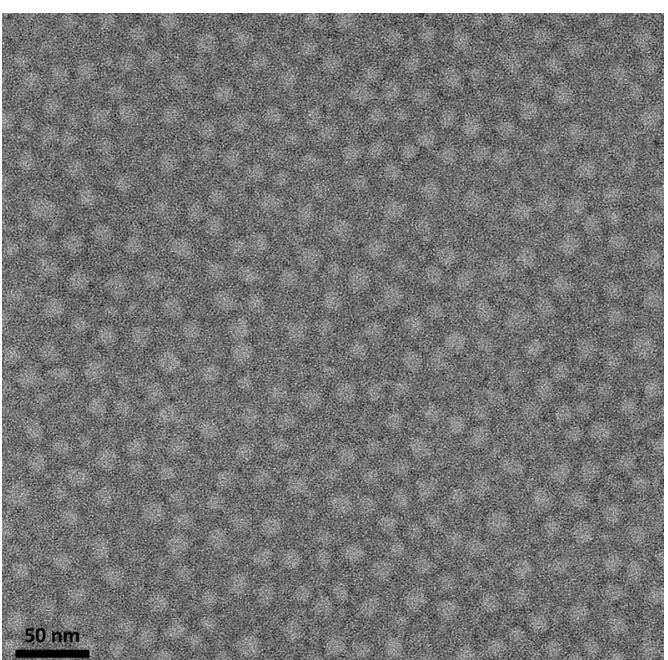

(a)

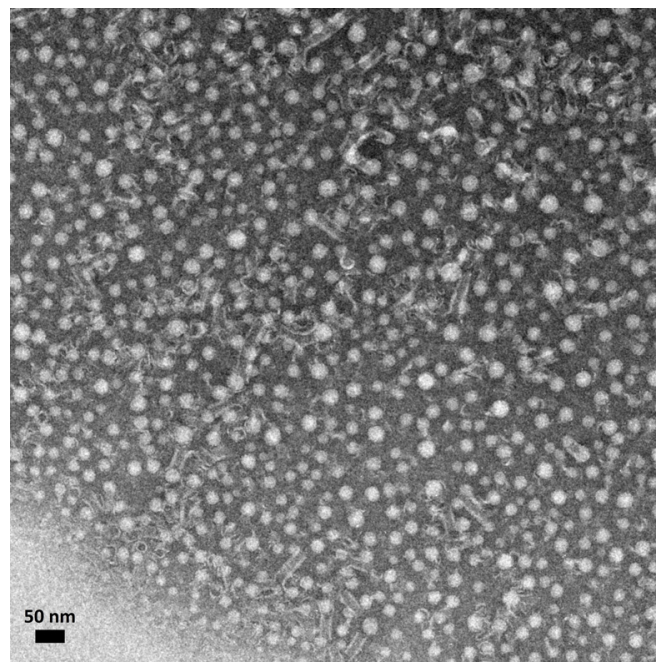

(b)

Figure 5.5 - TEM images, negatively stained with $1 \mathrm{wt} \%$ uranyl acetate, of $100 \mu \mathrm{M}$ aqueous solution of (a) SPn-(TEG-Man) $)_{2}$ and (b) SPn-TEG $_{2}$.

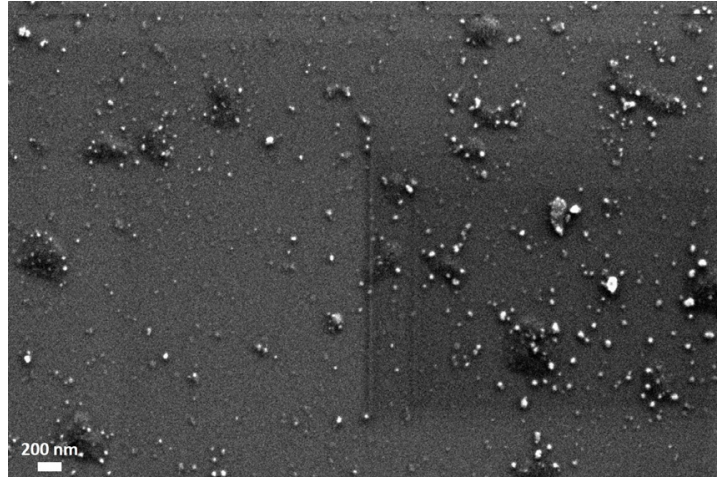

(a)

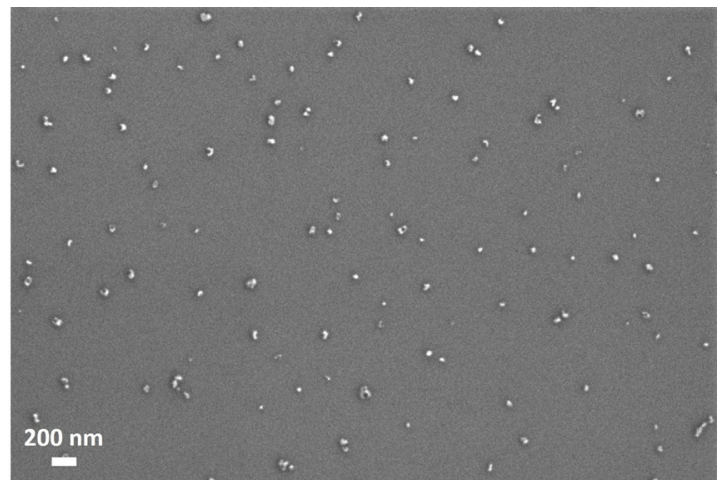

(c)

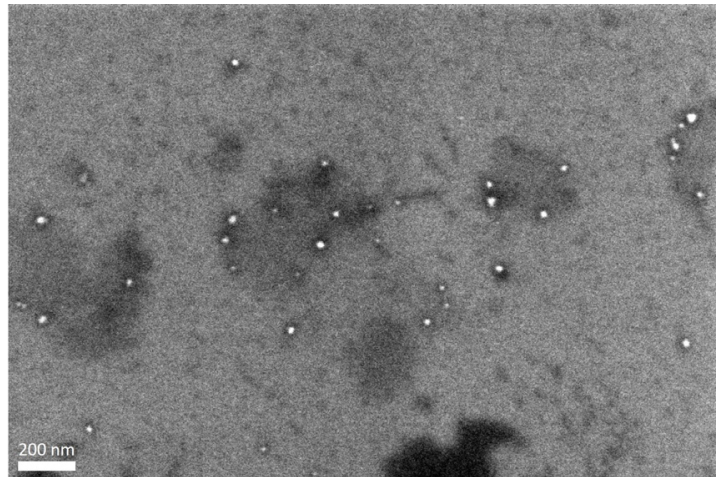

(b)

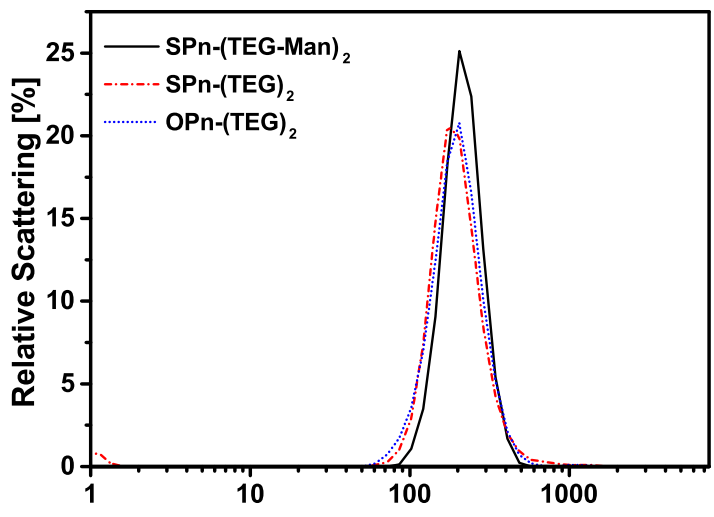

Hydrodynamic diameter [nm]

(d)

Figure 5.6 - SEM images of $100 \mu \mathrm{M}$ aqueous solution of (a) SPn-(TEG-Man) $)_{2}$, (b) SPn$\mathbf{T E G}_{2}$, and (c) $\mathbf{O P n}_{\mathbf{T}} \mathbf{T E G}_{2}$. DLS graphs of $100 \mu \mathrm{M}$ aqueous solutions of SPn(TEG-Man $)_{2}$, SPn-TEG $_{2}$, and OPn-TEG $_{2}(\mathrm{~d})$. 
Table 5.1 - Diameters of self-assembled aggregates of the phthalonitriles in $\mathrm{nm}$, obtained by SEM, TEM and DLS.

\begin{tabular}{l|ccc}
\hline & \multicolumn{3}{|c}{ Aggregates diameter [nm] } \\
& SEM & TEM & DLS \\
\hline SPn-(TEG-Man) $_{2}$ & $25 \pm 11$ & $13 \pm 2$ & $202 \pm 5$ \\
SPn-TEG $_{2}$ & $48 \pm 23$ & $19 \pm 4$ & $190 \pm 20$ \\
OPn-TEG $_{2}$ & $63 \pm 21$ & & $192 \pm 15$ \\
\hline
\end{tabular}

Furthermore the density of the particles was lower in comparison with the TEM images. A different affinity of the molecules towards copper mesh and silicon wafers could influence the drying process and result in different amounts of adsorbed aggregates.

Dried objects could differ from aggregates in solution since supramolecular objects depend on the interactions with the surrounding solvent. Therefore we studied the aggregates also by dynamic light scattering (DLS) in water. As can be seen in figure $5.6 \mathrm{~d}$ and table 5.1 , $100 \mu \mathrm{M}$ solutions of the three phthalonitriles in water gave similar results regarding size and size distribution.

The estimated sizes show a large discrepancy between the dried and the wet state. Those estimated by DLS are three to eight times as large as those estimated by TEM and SEM. The loss of water during the drying process certainly causes a reduction in size.

Although there is a gap between the sizes in the dried and in the wet state, the difference among the Pn within one analysis method is insignificant (Tab. 5.1). Even though the phthalonitriles have different photophysical properties, neither the extra subunits of mannose nor the different heteroatom result in a significant difference in size or shape of the aggregated form in water.

\subsubsection{Manipulating the phthalonitrile assemblies}

TritonX-100 is a nonionic surfactant with a hydrophilic polyethylene oxide chain and an aromatic hydrocarbon group. As surfactant TritonX-100 is able to interact with assemblies based on non-covalent forces. Upon adding increasing amounts of the surfactant TritonX100 to an aqueous solution of SPn-(TEG-Man) $)_{2}$, the fluorescence emission intensity dropped significantly (Fig. 5.7). The decrease started in the presence of $250 \mu \mathrm{M}$ TritonX100 and continues rapidly until $1 \mathrm{mM}$ of TritonX-100 was added after which the decrease slowed down and reached a plateau at around $3 \mathrm{mM}$ (Fig. 5.7b). For all TritonX-100 concentrations the emission maximum remained around $\lambda=490 \mathrm{~nm}$ suggesting that the SPn assemblies were still present and no dissolution took place (Fig. 5.7a). This observation is presumably based on the expansion of the aggregates by the interference of TritonX-100 with supramolecular structures acting as a potent detergent as has been 


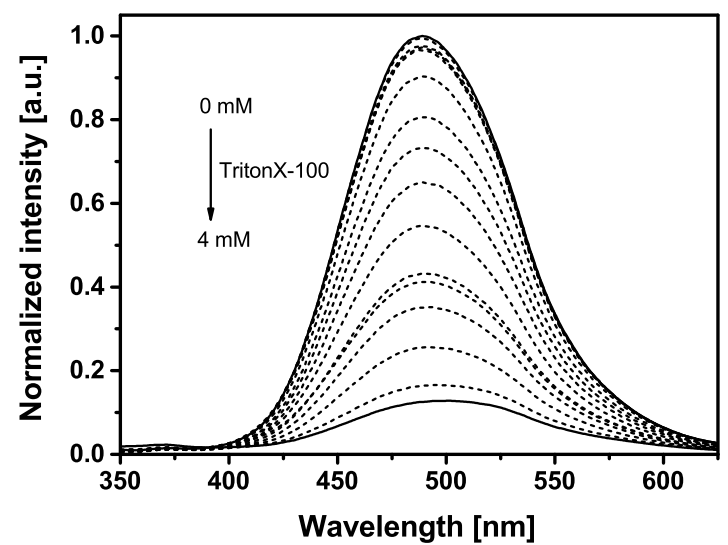

(a)

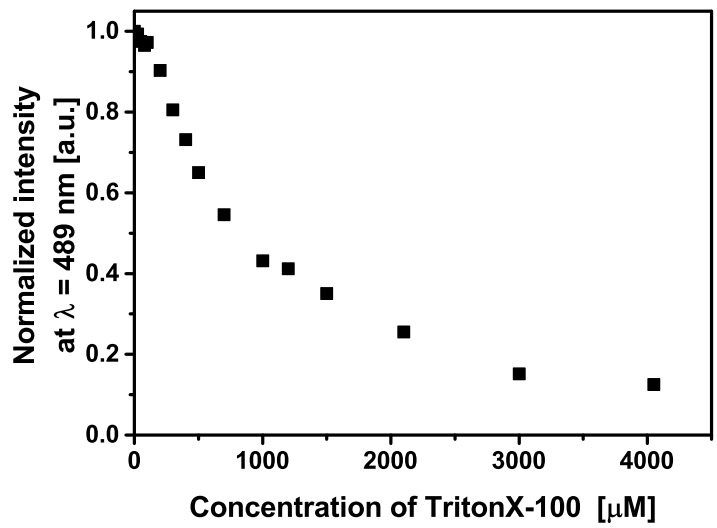

(b)

Figure 5.7 - Fluorescence spectra of $86 \mu \mathrm{M}$ SPn-(TEG-Man) $)_{2}$ in water with different amounts of TritonX-100 (a). Normalized emission intensity at $\lambda=489 \mathrm{~nm}$ as a function of the concentration of TritonX-100 (b).

described before [24, 25].

Figure 5.8a shows the hydrodynamic diameters measured by DLS on a dilution series from $100 \mu \mathrm{M}$ to $20 \mu \mathrm{M}$ phthalonitriles in water. When comparing the sizes of the aggregates no significant differences were observed between the different phthalonitrile derivatives, while over this concentration range the aggregates were constant in size.

To evaluate the critical aggregation concentration (CAC) at which the assemblies are formed, a $100 \mu \mathrm{M}$ solution of SPn compounds was diluted in steps while recording the emission spectra of each solution (Fig. 5.8b and 5.8c). From $100 \mu \mathrm{M}$ to $2.5 \mu \mathrm{M}$ the wavelength of the maximum emission of SPn-(TEG-Man) $)_{2}$ remained at $\lambda=490 \mathrm{~nm}$, while the emission intensity decreased linearly, showing that aggregates were even present at low concentrations. Upon diluting further to a final concentration of $50 \mathrm{nM}$, the emission maximum was blue-shifted $(\Delta \lambda=50 \mathrm{~nm})$, while the emission intensity remained nearly constant (Fig. 5.8b, inset). The observed sharp change in the emission maximum wavelength around $1 \mu \mathrm{M}$ can be interpreted as the CAC of SPn-(TEG-Man) $)_{2}$ in water (Fig. 5.8d). Aggregates of $\mathbf{S P n - T E G} \mathbf{F}_{2}$ showed a more gradual transition without a clear CAC but the transition occurred in the same concentration window as the aggregation of SPn-(TEG-Man) $)_{2}$ (Fig. 5.8d) . Below $20 \mu \mathrm{M}$ the emission maximum slowly shifted to lower wavelengths with a maximum shift of $\Delta \lambda=50 \mathrm{~nm}$ (Fig. $5.8 \mathrm{c}$, inset). The different behaviour could be due to the influence of the mannose moieties on the solubility and therefore the aggregation and dissolution process. Unfortunately it is not possible to use this method to determine the CAC of the OPn compound, since the lack of AIE results in a lack of a clear shift of the emission maximum (Fig. 5.8d, blue triangles).

A similar type of experiment was performed in the case of SPn-(TEG-Man) $)_{2}$ in $90 \%$ water-10\% methanol yielding a CAC that is 5.7 times higher as compared to the one in 


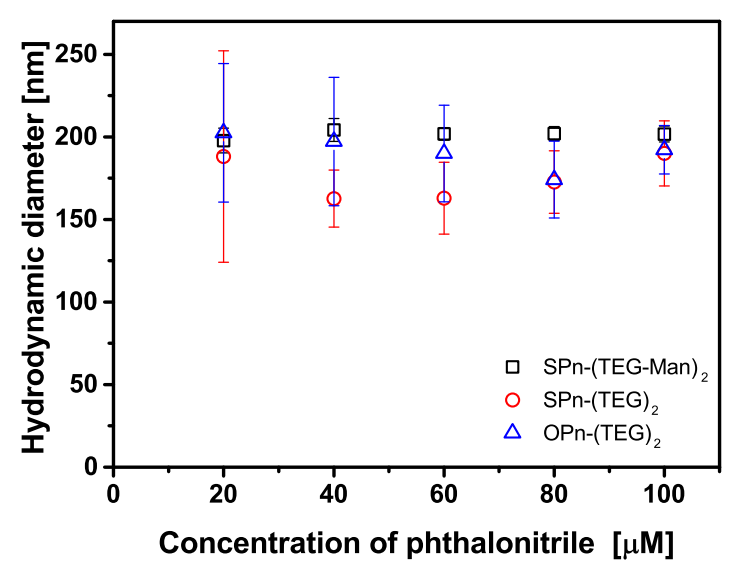

(a)

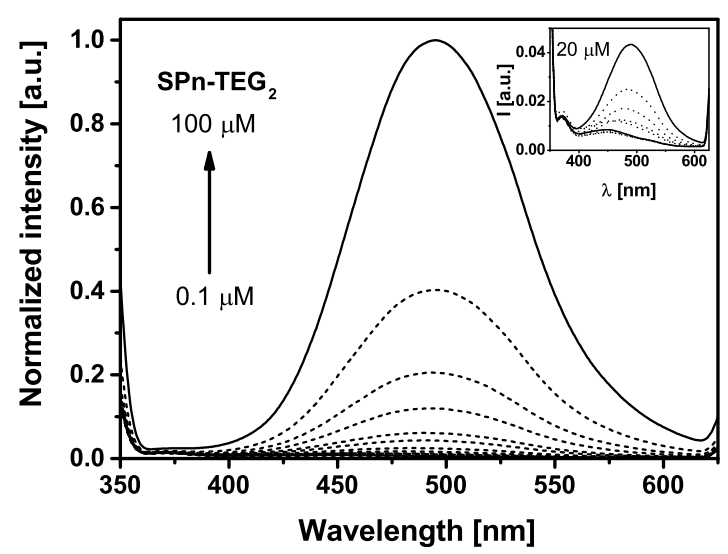

(c)

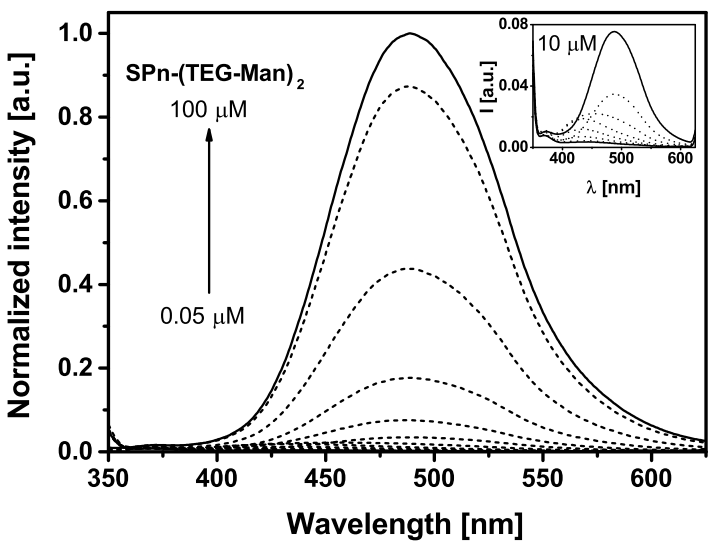

(e)

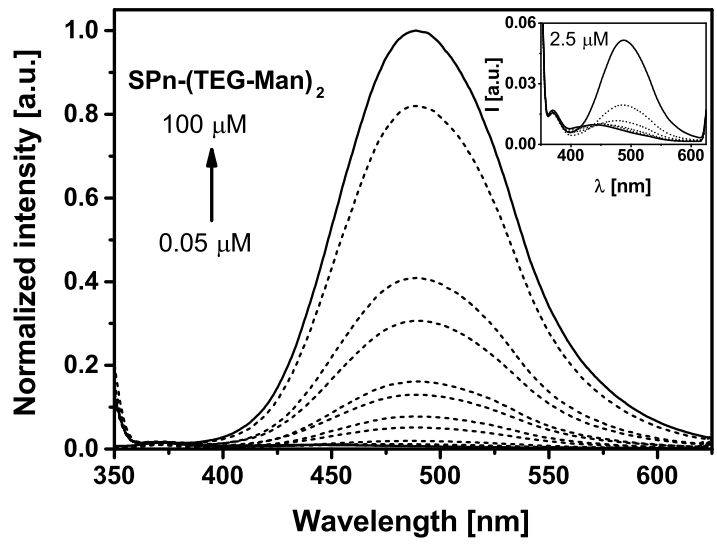

(b)

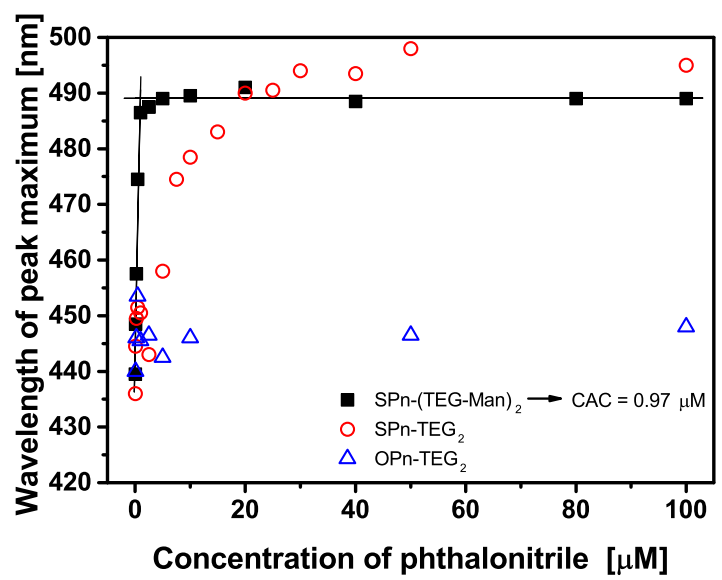

(d)

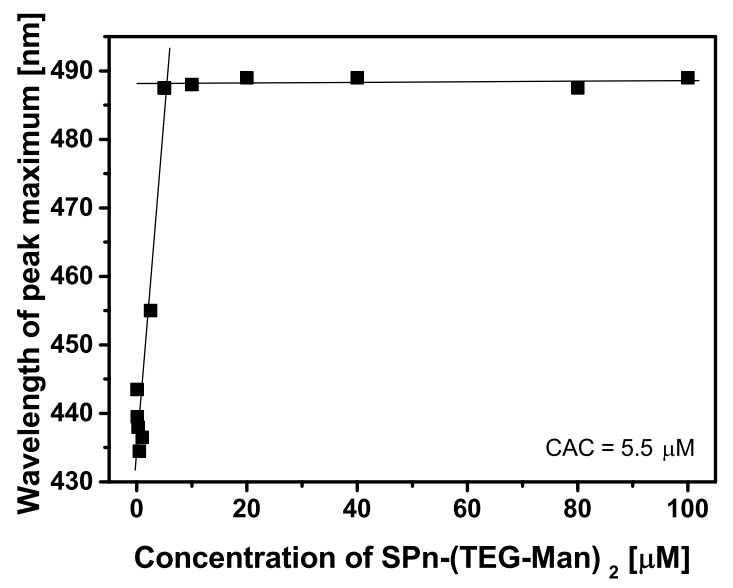

(f)

Figure 5.8 - Hydrodynamic diameter as a function of the Pn concentration, measured by DLS (a). Fluorescence spectra of (b) SPn-(TEG-Man) $)_{2}$ in the range of $0.05 \mu \mathrm{M}$ till $100 \mu \mathrm{M}$ and (c) $\mathbf{S P n}-\mathbf{T E G}_{2}$ in the range of $0.1 \mu \mathrm{M}$ till $100 \mu \mathrm{M}$ in water. Inset shows the spectra of the lower concentrations with the hypsochromic shift in emission maximum. Determination of the CAC from the dilution series of the phthalonitriles in water (d). Fluorescence spectra of SPn-(TEG-Man) $)_{2}$ in the range of $0.05 \mu \mathrm{M}$ till $100 \mu \mathrm{M}$ in $90 \%$ water-10\% methanol (e). Inset shows the spectra of the lower concentrations with the hypsochromic shift in emission maximum. Determination of the CAC from the dilution series of SPn-(TEG-Man) $)_{2}$ in $90 \%$ water-10\% methanol (f). Marks are experimental values, trendlines are given to guide to the eye. 
water (Fig. $5.8 \mathrm{e}$ and $5.8 \mathrm{f}$ ). This observation is in agreement with methanol being a good solvent for thiophthalonitriles.

\subsection{Conclusions}

A novel, synthetically facile system featuring aggregation-induced emission has been described. The system is based on phthalonitriles with one of the derivatives having a mannose moiety in the side chain. The phthalonitrile derivatives self-assemble in water and the aggregates are of similar particle size and shape irrespective of the heteroatom being sulfur or oxygen and irrespective whether mannose was present in the side chains. However, only the phthalonitrile derivatives containing the sulfur atom exhibit bright emission upon aggregation. Such fluorescent particles are of interest for biomedical applications (see chapter 6).

\subsection{Acknowledgments}

Jun.-Prof. Dr. Jens Voskuhl (Universität Duisburg-Essen) is thankfully acknowledged for providing the molecules SPn-(TEG-Man) $)_{2}$ and $\mathbf{S P n - T E G}{ }_{2}$ and for his advice on the experiments and the fruitful discussions. Dr. Christian Strassert and Linda Stegemann (Westfälische Wilhelms-Universität Münster) are gratefully acknowledged for the measurement of the quantum yields. Mark Smithers and Dr. Rico Keim (Universiteit Twente) are gratefully acknowledged for their help with SEM and TEM imaging, respectively.

\subsection{Experimental section}

\subsubsection{Materials and equipment}

Chemicals were purchased from Sigma Aldrich or from Acros Organics and used without further purification. Reactions were carried out using dried solvents and under an atmosphere of argon. Reactions were monitored by thin-layer chromatography (TLC), which was performed on $0.2 \mathrm{~mm}$ MERCK pre-coated silica gel $60 \mathrm{~F} 254$ aluminum sheets. Spots on TLC plates were visualized by treatment with basic $\mathrm{KMnO}_{4}$ solution or by viewing under the UV lamp $(\lambda=254 \mathrm{~nm}, 366 \mathrm{~nm})$. Column chromatography was carried out on silica gel 60 (0.063- $0.2 \mathrm{~mm})$ from MERCK. NMR spectra were recorded on a BRUKER spectrometer (AV400). The ${ }^{1} \mathrm{H}$ NMR spectra were recorded at $400 \mathrm{MHz}$ and the ${ }^{13} \mathrm{C}$ NMR spectra were recorded at $100 \mathrm{MHz}$. Both types of spectra were recorded at $298 \mathrm{~K}$. Chemical shifts $(\delta)$ are given in units of parts per million (ppm) and expressed relative 
to the signals of the deuterated solvents. Coupling constants $(\mathrm{J})$ are reported in Hertz $(\mathrm{Hz})$. Abbreviations used for splitting patterns are $\mathrm{s}=$ singlet, $\mathrm{d}=$ doublet, $\mathrm{t}=$ triplet and $\mathrm{m}=$ multiplet. Mass spectra were recorded on a WATERS LCT mass spectrometer or BRUKER MicroToF spectrometer. In the description of the spectra $\mathrm{M}_{W}$ refers to the molecular weight.

UV/Vis absorption spectra were measured on a PERKIN ELMER Lambda 850 spectrophotometer. The UV/vis absorption spectra were measured against air and corrected for the solvent. Fluorescence spectra were recorded on a PERKIN ELMER LS 55 Fluorescence Spectrophotometer using an excitation wavelength of $\lambda=330 \mathrm{~nm}$. Usually an excitation slit width of $10 \mathrm{~nm}$ and an emission slit width of $7 \mathrm{~nm}$ was used. For the methanol-water mixtures of OPn-TEG $\mathbf{O}_{2}$ and for the glycerol spectra both slits were kept at $10 \mathrm{~nm}$. For the dilution experiments the maximum slit widths was used ( $\left.\mathrm{d}_{e x}=15 \mathrm{~nm}, \mathrm{~d}_{e m}=20 \mathrm{~nm}\right)$. Luminescence quantum yields were measured with a HAMAMATSU Photonics absolute PL quantum yield measurement system (C9920-02) equipped with a L9799-01 CW Xenon light source $(150 \mathrm{~W})$, monochromator, C7473 photonic multi-channel analyzer, integrating sphere and employing U6039-05 PLQY measurement software (HAMAMATSU PHOTONICS, Ltd., Shizuoka, Japan). All solvents used were of spectrometric grade.

The TEM measurements were carried out on a PHILIPS CM300ST-FEG TEM machine. The SEM measurements were carried out on a ZEISS Merlin Scanning Electron Microscope.

DLS experiments were performed with a Nanotrac wave by ANASPEC operating with a Microtrac FLEX Operating Software at $25{ }^{\circ} \mathrm{C}$ using a laser wavelength of $780 \mathrm{~nm}$ at a scattering angle of $90^{\circ}$. The observed sizes and standard deviations were based on the average number distributions of ten individiual measurements per sample. As refractive index 1.465 was used. The run time was $180 \mathrm{~s}$.

\subsubsection{Synthetic procedures}

Compounds $\mathbf{1}$ [26], $\mathbf{2}$ [26], $\mathbf{3}$ [26], 4 [9], 5 [9] and $\mathbf{7}$ [27, 28] were synthesized according to literature procedures.

\section{4,5-Bis((4-(2-(2-(2-(2-hydroxyethoxy)ethoxy)ethoxy)ethoxy)phenyl)thio)- phthalonitrile $\left(\mathrm{SPn}-\mathrm{TEG}_{2}\right)$}

To a stirred solution of 7 (300 mg, $0.8 \mathrm{mmol})$ in $10 \mathrm{ml}$ acetonitrile was added $\mathrm{K}_{2} \mathrm{CO}_{3}(700$ $\mathrm{mg}, 4.8 \mathrm{mmol}$ ). The reaction mixture was heated to $90{ }^{\circ} \mathrm{C}$ for $30 \mathrm{~min}$ followed by the addition of $\mathbf{1}$ (900 mg, $2.4 \mathrm{mmol}$ ) in $10 \mathrm{ml}$ acetonitrile. Stirring was continued at $90{ }^{\circ} \mathrm{C}$ 
for $24 \mathrm{~h}$. The crude mixture was evaporated, re-dissolved in $30 \mathrm{ml} \mathrm{CHCl}_{3}$ and extracted twice with brine. The organic layer was dried over $\mathrm{MgSO}_{4}$ and evaporated. The residue was subjected to silica column chromatography using $\mathrm{CH}_{2} \mathrm{Cl}_{2} / \mathrm{MeOH} 9 / 1$ as eluent. The product was obtained as colorless waxy solid. $324 \mathrm{mg}$ (0.43 mmol, $54 \%$ ).

${ }^{1} \mathrm{H} \mathrm{NMR}\left(\mathrm{CDCl}_{3}\right): \delta[\mathrm{ppm}]=7.45\left(\mathrm{~d}, J=8.7 \mathrm{~Hz}, 4 \mathrm{H}, \mathrm{C} H_{\text {phenyl }}\right), 7.01(\mathrm{~d}, J=8.8 \mathrm{~Hz}$, $\left.4 \mathrm{H}, \mathrm{C} H_{\text {phenyl }}\right), 6.84\left(\mathrm{~s}, 2 \mathrm{H}, \mathrm{CH}_{\text {phenyl }}\right), 4.19\left(\mathrm{t}, J=5.0 \mathrm{~Hz}, 4 \mathrm{H}, \mathrm{O}-\mathrm{CH} H_{2}\right), 3.89$ (t, $J=5.1$ $\left.\mathrm{Hz}, 4 \mathrm{H}, \mathrm{O}-\mathrm{CH}_{2}\right), 3.74-3.66\left(\mathrm{~m}, 20 \mathrm{H}, \mathrm{O}-\mathrm{CH}_{2}\right), 3.59$ (t, $\left.J=5.1 \mathrm{~Hz}, 4 \mathrm{H}, \mathrm{O}-\mathrm{CH}_{2}\right), 2.49$ (s, $2 \mathrm{H}, \mathrm{OH}) .{ }^{13} \mathrm{C} \mathrm{NMR}\left(\mathrm{CDCl}_{3}\right): \delta[\mathrm{ppm}]=161.08,144.76,137.49,129.02,118.55,117.02$, 115.75, 111.29, 72.64, 71.02, 70.84, 70.76, 70.49, 69.71, 67.87, 61.93. ESI-MS $\left(\mathrm{M}_{W}=\right.$ 728.9): $m / z=751.2[\mathrm{M}+\mathrm{Na}]^{+}$.

\section{4,5-Bis((4-(2-(2-(2-(2-azidoethoxy)ethoxy)ethoxy)ethoxy)phenyl)thio)- phthalonitrile (8)}

To a stirred solution of 7 (300 mg, $0.8 \mathrm{mmol})$ in $10 \mathrm{ml}$ acetonitrile was added $\mathrm{K}_{2} \mathrm{CO}_{3}(700$ $\mathrm{mg}, 4.8 \mathrm{mmol}$ ). The reaction mixture was heated to $90{ }^{\circ} \mathrm{C}$ for $30 \mathrm{~min}$ followed by the addition of 3 (990 mg, $2.4 \mathrm{mmol}$ ) in $10 \mathrm{ml}$ acetonitrile. Stirring was continued at $90{ }^{\circ} \mathrm{C}$ for $24 \mathrm{~h}$. The crude mixture was evaporated, re-dissolved in $30 \mathrm{ml} \mathrm{CHCl}_{3}$ and extracted twice with brine. The organic layer was dried over $\mathrm{MgSO}_{4}$ and evaporated. The residue was subjected to silica column chromatography using $\mathrm{CH}_{2} \mathrm{Cl}_{2} / \mathrm{MeOH} 9 / 1$ as eluent. The product was obtained as colorless waxy solid. $300 \mathrm{mg}$ (0.39 mmol, 50 \%).

${ }^{1} \mathrm{H} \mathrm{NMR}\left(\mathrm{CDCl}_{3}\right): \delta[\mathrm{ppm}]=7.44\left(\mathrm{~d}, J=8.8 \mathrm{~Hz}, 4 \mathrm{H}, \mathrm{C} H_{\text {phenyl }}\right), 7.02(\mathrm{~d}, J=8.8 \mathrm{~Hz}$, $\left.4 \mathrm{H}, \mathrm{CH}_{\text {phenyl }}\right), 6.83$ (s, 2H, $\left.\mathrm{CH}_{\text {phenyl }}\right), 4.18$ (t, $\left.J=5.0 \mathrm{~Hz}, 4 \mathrm{H}, \mathrm{O}-\mathrm{CH} H_{2}\right), 3.88$ (t, $J=5.1$ $\left.\mathrm{Hz}, 4 \mathrm{H}, \mathrm{O}-\mathrm{CH}_{2}\right), 3.74-3.62\left(\mathrm{~m}, 20 \mathrm{H}, \mathrm{O}-\mathrm{CH}_{2}\right), 3.35$ (t, $\left.J=5.1 \mathrm{~Hz}, 4 \mathrm{H}, \mathrm{O}-\mathrm{CH}_{2}\right) .{ }^{13} \mathrm{C} \mathrm{NMR}$ $\left(\mathrm{CDCl}_{3}\right): \delta[\mathrm{ppm}]=161.31,150.75,147.16,139.62,128.59,127.82,124.96,124.84,123.43$, $123.26,114.98,72.60,71.01,70.62,70.50,69.86,69.75,67.78,61.93,61.91$. ESI-MS $\left(\mathrm{M}_{W}\right.$ $=778.9): m / z=801.2[\mathrm{M}+\mathrm{Na}]^{+}$.

\section{4,5-Bis((4-(2-(2-(2-(2-(4-( $\alpha$-D-mannosyl-methyl)-1H-1,2,3-triazol-1-yl)ethoxy)- ethoxy)ethoxy)ethoxy)phenyl)thio)phthalonitrile (SPn-(TEG-Man) $\left.)_{2}\right)$}

Compound 8 (50 mg, $0.065 \mathrm{mmol}$ ) was dissolved in $5 \mathrm{ml}$ DMF under argon atmosphere. 5 (120 mg, $0.143 \mathrm{mmol}$ ) was added followed by $100 \mu \mathrm{l}$ of a freshly prepared solution of ascorbic acid (10 mg, $0.057 \mathrm{mmol})$ and $\mathrm{CuSO}_{4}(3 \mathrm{mg}, 0.012 \mathrm{mmol})$ in $1 \mathrm{ml}$ water. The solution was stirred for $48 \mathrm{~h}$ at $40{ }^{\circ} \mathrm{C}$ followed by complete evaporation. The residue was 
re-dissolved in $\mathrm{CHCl}_{3}$ and extracted twice with brine. The organic layer was dried over $\mathrm{MgSO}_{4}$ and evaporated. The residue was subjected to silica column chromatography with $\mathrm{CH}_{2} \mathrm{Cl}_{2} / \mathrm{MeOH} 19 / 1$ as eluent. The product was obtained as high viscous, slightly yellow oil. $61 \mathrm{mg}(0.039 \mathrm{mmol}, 60 \%)$.

${ }^{1} \mathrm{H} \mathrm{NMR}\left(\mathrm{CDCl}_{3}\right): \delta[\mathrm{ppm}]=7.84\left(\mathrm{~s}, 2 \mathrm{H}, \mathrm{CH}_{\text {triazole }}\right), 7.47\left(\mathrm{~d}, J=8.7 \mathrm{~Hz}, 4 \mathrm{H}, \mathrm{CH}_{\text {phenyl }}\right)$, $7.03\left(\mathrm{~d}, J=8.8 \mathrm{~Hz}, 4 \mathrm{H}, \mathrm{C} H_{\text {phenyl }}\right), 6.85$ (s, 2H, $\left.\mathrm{CH}_{\text {phenyl }}\right), 5.35-5.19$ (m, 6H, O-CH , O-CH), 4.97 (s, 2H, O-CH), 4.88 (d, $\left.J=12.4 \mathrm{~Hz}, 2 \mathrm{H}, \mathrm{O}-\mathrm{CH}_{2}\right), 4.69$ (d, $J=12.1 \mathrm{~Hz}$, $\left.2 \mathrm{H}, \mathrm{O}-\mathrm{CH}_{2}\right), 4.56(\mathrm{t}, J=5.0 \mathrm{~Hz}, 4 \mathrm{H}, \mathrm{O}-\mathrm{CH}), 4.30(\mathrm{~d}, J=7.3 \mathrm{~Hz}, 2 \mathrm{H}, \mathrm{O}-\mathrm{CH}), 4.22-4.18$ (m, 5H, O-C $\left.H_{2}, \mathrm{O}-\mathrm{CH}\right), 4.15-4.05\left(\mathrm{~m}, 4 \mathrm{H}, \mathrm{O}-\mathrm{CH}_{2}\right), 3.95-3.82\left(\mathrm{~m}, 10 \mathrm{H}, \mathrm{O}-\mathrm{CH}_{2}, \mathrm{O}-\mathrm{CH}\right)$, 3.79-3.58 (m, 18H, O-C $\left.H_{2}, \mathrm{O}-\mathrm{CH}\right), 2.14$ (s, 6H, C(O)-C $\left.H_{3}\right), 2.11$ (s, 6H, C(O)-CH $\left.H_{3}\right), 2.02$ $\left(\mathrm{s}, 6 \mathrm{H}, \mathrm{C}(\mathrm{O})-\mathrm{CH}_{3}\right), 1.97\left(\mathrm{~s}, 6 \mathrm{H}, \mathrm{C}(\mathrm{O})-\mathrm{CH}_{3}\right) \cdot{ }^{13} \mathrm{C} \mathrm{NMR}\left(\mathrm{CDCl}_{3}\right): \delta[\mathrm{ppm}]=171.18,170.48$, 170.32, 170.15, 161.33, 145.02, 137.81, 129.29, 118.83, 117.25, 116.04, 111.55, 97.32, 71.90, 71.01, 70.99, 69.96, 69.86, 69.74, 69.52, 69.15, 68.16, 66.45, 66.29, 62.80, 61.26, 51.03, 21.34, 21.26, 21.16, 21.13. HRMS $(m / z)$ : calculated for $\left[\mathrm{C}_{70} \mathrm{H}_{86} \mathrm{~N}_{8} \mathrm{O}_{28} \mathrm{~S}_{2} \mathrm{Na}\right]^{+}:$1573.48927, found 1573.48852 .

To a stirred solution of the product of the click reaction $(60 \mathrm{mg}, 0.038 \mathrm{mmol}$ ) in dry methanol was added $50 \mathrm{mg}(0.926 \mathrm{mmol})$ of NaOMe. The solution was stirred for $4 \mathrm{~h}$ or until TLC showed completion. The solution was treated with ion exchange resin (Dowex $\mathrm{HCR} \mathrm{H}^{+}$form) until the mixture becomes slightly acidic $(\mathrm{pH}=4)$. After filtering the resin off the remaining solution was evaporated and the desired product was obtained as slightly yellow glassy solid. $38 \mathrm{mg}(0.031 \mathrm{mmol}, 79 \%)$.

${ }^{1} \mathrm{H} \mathrm{NMR}\left(\mathrm{CD}_{3} \mathrm{OD}\right): \delta[\mathrm{ppm}]=8.08\left(\mathrm{~s}, 2 \mathrm{H}, \mathrm{CH}_{\text {triazole }}\right), 7.51\left(\mathrm{~d}, J=8.7 \mathrm{~Hz}, 4 \mathrm{H}, \mathrm{CH}_{\text {phenyl }}\right)$, $7.11\left(\mathrm{~d}, J=8.8 \mathrm{~Hz}, 4 \mathrm{H}, \mathrm{C} H_{\text {phenyl }}\right), 6.94\left(\mathrm{~s}, 2 \mathrm{H}, \mathrm{C} H_{\text {phenyl }}\right), 4.82-4.78$ (m, 2H, O-CH $\left.H_{2}\right)$, $4.64\left(\mathrm{~d}, J=12.3 \mathrm{~Hz}, 2 \mathrm{H}, \mathrm{O}-\mathrm{CH}_{2}\right), 4.59-4.52(\mathrm{~m}, 4 \mathrm{H}, \mathrm{O}-\mathrm{CH}), 4.22-4.16(\mathrm{~m}, 4 \mathrm{H}, \mathrm{O}-\mathrm{CH})$, 3.95-3.85 (m, 10H, O-CH, O-CH$H_{2}$ ), 3.75-3.68 (m, 8H, O-CH $H_{2}$, 3.63-3.51 (m, 18H, O-CH $H_{2}$, $\mathrm{O}-\mathrm{CH}) .{ }^{13} \mathrm{C} \mathrm{NMR}\left(\mathrm{CDCl}_{3}\right): \delta[\mathrm{ppm}]=162.39,146.10,138.43,130.46,120.07,117.94$, 116.53, 112.46, 100.81, 74.93, 72.55, 72.03, 71.80, 71.57, 71.48, 70.70, 70.35, 69.00, 68.61, 62.98, 60.75, 51.53. HRMS $(m / z)$ : calculated for $\left[\mathrm{C}_{54} \mathrm{H}_{70} \mathrm{~N}_{8} \mathrm{O}_{20} \mathrm{~S}_{2} \mathrm{Na}\right]^{+}: 1237.40529$, found 1237.40400 .

\section{4,5-Bis(4-hydroxyphenoxy)phthalonitrile (9)}

The synthesis was carried out following a literature procedure with minor adjustments [29]. Hydroquinone (590 mg, $2.99 \mathrm{mmol})$ and $\mathrm{K}_{2} \mathrm{CO}_{3}(4.2 \mathrm{~g}, 30 \mathrm{mmol})$ were dissolved in $24 \mathrm{ml}$ DMSO and stirred at room temperature under argon for $30 \mathrm{~min}$. Then 4,5- 
dichlorophthalonitrile 6 (996 $\mathrm{mg}, 9.04 \mathrm{mmol}$ ) was added and the reaction mixture was stirred at $90{ }^{\circ} \mathrm{C}$ under argon for $1 \mathrm{~d}$. After cooling to room temperature the mixture was poured into $100 \mathrm{ml} 1 \mathrm{M} \mathrm{HCl}$. The precipitate was filtered and washed with cold water. Afterwards the solid was re-dissolved in ethyl acetate. The organic phase was washed with water and dried over $\mathrm{MgSO}_{4}$ and evaporated. The powdered solid was suspended in DCM and stirred vigorously for $20 \mathrm{~min}$. After filtering the solid was obtained as the product. $560.4 \mathrm{mg}(1.63 \mathrm{mmol}, 54 \%)$.

${ }^{1} \mathrm{H}$ NMR $\left(\right.$ DMSO-d $\left._{6}\right): \delta[\mathrm{ppm}]=9.57(\mathrm{~s}, 2 \mathrm{H}, \mathrm{OH}), 7.42\left(\mathrm{~s}, 2 \mathrm{H}, \mathrm{C} H_{\text {phenyl }}\right), 7.00(\mathrm{~d}, J=$ $\left.8.8 \mathrm{~Hz}, 4 \mathrm{H}, \mathrm{CH}_{\text {phenyl }}\right), 6.84$ (d, $\left.J=8.8 \mathrm{~Hz}, 4 \mathrm{H}, \mathrm{C} H_{\text {phenyl }}\right)$.

\section{4,5-Bis(4-(2-(2-(2-(2-hydroxyethoxy)ethoxy)ethoxy)ethoxy)phenoxy)- phthalonitrile (OPn-TEG ${ }_{2}$ )}

4,5-Bis(4-hydroxyphenoxy)phthalonitrile $9(16.5 \mathrm{mg}, 0.05 \mathrm{mmol})$ and fine pestled $\mathrm{K}_{2} \mathrm{CO}_{3}$ (180 $\mathrm{mg}, 1.3 \mathrm{mmol}$ ) were dissolved in $6 \mathrm{ml}$ acetonitrile and stirred at room temperature for $30 \mathrm{~min}$. Then 1 (59.0 $\mathrm{mg}, 0.17 \mathrm{mmol})$ was added and the reaction mixture was stirred at $80{ }^{\circ} \mathrm{C}$ for $3 \mathrm{~d}$. After cooling down the mixture was poured into brine and extracted with ethyl acetate. The organic phase was washed with water and dried over $\mathrm{Na}_{2} \mathrm{SO}_{4}$ before it was filtered and evaporated. The crude was purified by column chromatography (gradient elution EtOAc to EtOAc/MeOH 9/1). $14.1 \mathrm{mg}$ (0.02 mmol, 40 \%).

${ }^{1} \mathrm{H} \mathrm{NMR}\left(\mathrm{CDCl}_{3}\right): \delta[\mathrm{ppm}]=7.00-6.91\left(\mathrm{~m}, 10 \mathrm{H}, \mathrm{CH}_{\text {phenyl }}\right), 4.10(\mathrm{t}, J=4.8 \mathrm{~Hz}, 4 \mathrm{H}$, O-C $\left.H_{2}\right), 3.82\left(\mathrm{t}, J=4.7 \mathrm{~Hz}, 4 \mathrm{H}, \mathrm{O}-\mathrm{CH}_{2}\right), 3.70-3.60\left(\mathrm{~m}, 20 \mathrm{H}, \mathrm{O}-\mathrm{C} H_{2}\right), 3.55(\mathrm{t}, J=4.5$ $\left.\mathrm{Hz}, 4 \mathrm{H}, \mathrm{O}-\mathrm{CH}_{2}\right) .{ }^{13} \mathrm{C} \mathrm{NMR}\left(\mathrm{CDCl}_{3}\right): \delta[\mathrm{ppm}]=156.8,152.4,147.2,121.5,120.5,116.3$, 115.2, 109.7, 70.8, 70.7, 70.6, 70.3, 69.7, 68.0, 61.8. ESI-MS $\left(\mathrm{M}_{W}=696.7\right): \mathrm{m} / z=719.0$ $[\mathrm{M}+\mathrm{Na}]^{+}$.

\subsubsection{Methods}

\section{General sample preparation for aqueous samples}

Samples were prepared from a $1 \mathrm{mM} \mathrm{DCM} / \mathrm{MeOH}$ stock solution in the following way: The required volume of the stock solution was transferred into a glass vial. The solvent was evaporated at $60{ }^{\circ} \mathrm{C}$. Subsequently the required amount of water was added and these solutions were sonicated at $50{ }^{\circ} \mathrm{C}$ for at least $0.5 \mathrm{~h}$.

Samples in organic solvents were obtained by diluting the stock solution. 


\section{Absorption and fluorescence spectroscopy}

The samples for the solvent mixture studies (THF-water and methanol-water) were prepared by mixing the appropriate portions of a solution of the $\mathrm{Pn}$ in the organic solvent and in water. The concentration of the phthalonitriles was $100 \mu \mathrm{M}$ in all samples. The methanol-water mixtures contained the following volume fractions: $\mathrm{MeOH} / \mathrm{H}_{2} \mathrm{O} 100 / 0$, $80 / 20,60 / 40,50 / 50,40 / 60,30 / 70,10 / 90,5 / 95,0 / 100$. The same volume fractions were used for the THF-water mixtures of SPn-(TEG-Man) $)_{2}$ and SPn-TEG ${ }_{2}$. For the THFwater mixtures of $\mathbf{O P n}-\mathbf{T E G}_{2}$ the following volume fractions were used: $\mathrm{THF} / \mathrm{H}_{2} \mathrm{O}$ 100/0, 90/10, 70/30, 60/40, 50/50, 40/60, 30/70, 10/90, 0/100.

The dilution series were prepared from a $100 \mu \mathrm{M}$ water solution and a $100 \mu \mathrm{M} 90 \%$ water-10\% methanol solution, respectively. The different samples were obtained by diluting the previous sample with water or $90 \%$ water- $10 \%$ methanol after the measurement. The used concentrations were: for SPn-(TEG-Man) $)_{2}: 100 \mu \mathrm{M}, 80 \mu \mathrm{M}, 40 \mu \mathrm{M}, 20 \mu \mathrm{M}$, $10 \mu \mathrm{M}, 5 \mu \mathrm{M}, 2.5 \mu \mathrm{M}, 1 \mu \mathrm{M}, 0.5 \mu \mathrm{M}, 0.25 \mu \mathrm{M}, 0.1 \mu \mathrm{M}, 0.05 \mu \mathrm{M}$; for SPn-TEG : $_{2} 100 \mu \mathrm{M}$, $50 \mu \mathrm{M}, 40 \mu \mathrm{M}, 30 \mu \mathrm{M}, 25 \mu \mathrm{M}, 20 \mu \mathrm{M}, 15 \mu \mathrm{M}, 10 \mu \mathrm{M}, 7.5 \mu \mathrm{M}, 5 \mu \mathrm{M}, 2.5 \mu \mathrm{M}, 1 \mu \mathrm{M}$, $0.5 \mu \mathrm{M}, 0.25 \mu \mathrm{M}, 0.1 \mu \mathrm{M}$; for OPn-TEG 2 : $100 \mu \mathrm{M}, 50 \mu \mathrm{M}, 10 \mu \mathrm{M}, 5 \mu \mathrm{M}, 2.5 \mu \mathrm{M}, 1 \mu \mathrm{M}$, $0.5 \mu \mathrm{M}, 0.25 \mu \mathrm{M}, 0.1 \mu \mathrm{M}$.

For the glycerol-methanol mixtures $7 \mu \mathrm{l}$ of the $1 \mathrm{mM}$ stock solution was mixed with the appropriate volume of methanol and glycerol (MeOH/Glycerol 100/0, 90/10, 80/20, $70 / 30,60 / 40,50 / 50,40 / 60,30 / 70,20 / 80,10 / 90)$. The samples were vortexed to provide complete mixture of the fractions before the samples were measured.

Due to its high viscosity and water solubility TritonX-100 was diluted with water before an aquous SPn-(TEG-Man) $)_{2}$ solution was added. The concentration of the SPn was $86 \mu \mathrm{M}$. The TritonX-100 concentrations used were: $0 \mu \mathrm{M}, 25 \mu \mathrm{M}, 50 \mu \mathrm{M}, 80 \mu \mathrm{M}, 100 \mu \mathrm{M}$, $200 \mu \mathrm{M}, 300 \mu \mathrm{M}, 400 \mu \mathrm{M}, 500 \mu \mathrm{M}, 700 \mu \mathrm{M}, 1 \mathrm{mM}, 1.2 \mathrm{mM}, 1.5 \mathrm{mM}, 2.1 \mathrm{mM}, 3 \mathrm{mM}$, $4.05 \mathrm{mM}$.

\section{Transmission electron microscopy (TEM)}

The solutions of the SPns (3 $\mu \mathrm{l}$ of $100 \mu \mathrm{M}$ in water) were deposited on 200 mesh copper grids for $5 \mathrm{~min}$ before gently removing the remaining solution with filter paper. After drying the samples were stained for 1 min with $5 \mu \mathrm{l}$ of an uranyl acetate solution (1 wt\% in water).

\section{Scanning electron microscopy (SEM)}

The solutions of Pns ( $3 \mu \mathrm{l}$ of $100 \mu \mathrm{M}$ in water) were deposited on silicon wafers for $6 \mathrm{~min}$ before gently removing the remaining solution with filter paper. 


\section{Dynamic light scattering (DLS)}

The used concentrations of the phthalonitriles were $100 \mu \mathrm{M}, 80 \mu \mathrm{M}, 60 \mu \mathrm{M}, 40 \mu \mathrm{M}$, and $20 \mu \mathrm{M}$.

\subsection{Bibliography}

[1] Luo, J.; Xie, Z.; Lam, J. W. Y.; Cheng, L.; Chen, H.; Qiu, C.; Kwok, H. S.; Zhan, X.; Liu, Y.; Zhu, D.; Tang, B. Z. Chem. Commun. 2001, 1740-1741.

[2] Chen, J.; Xu, B.; Ouyang, X.; Tang, B. Z.; Cao, Y. J. Phys. Chem. A 2004, 108, 7522-7526.

[3] Huang, J.; Tang, R.; Zhang, T.; Li, Q.; Yu, G.; Xie, S.; Liu, Y.; Ye, S.; Qin, J.; Li, Z. Chem. Eur. J. 2014, 20, 5317-5326.

[4] Tong, H.; Dong, Y.; Hong, Y.; Häussler, M.; Lam, J. W. Y.; Sung, H. H.-Y.; Yu, X.; Sun, J.; Williams, I. D.; Kwok, H. S.; Tang, B. Z. J. Phys. Chem. C 2007, 111, 2287-2294.

[5] Zhang, L.; Hu, W.; Yu, L.; Wang, Y. Chem. Commun. 2015, 51, 4298-4301.

[6] Qin, A.; Lam, J. W. Y.; Tang, L.; Jim, C. K. W.; Zhao, H.; Sun, J.; Tang, B. Z. Macromolecules 2009, 42, 1421-1424.

[7] Chen, S.; Hong, Y.; Zeng, Y.; Sun, Q.; Liu, Y.; Zhao, E.; Bai, G.; Qu, J.; Hao, J.; Tang, B. Z. Chem. Eur. J. 2015, 21, 4315-4320.

[8] Zhang, Y.; Chen, Y.; Li, X.; Zhang, J.; Chen, J.; Xu, B.; Fu, X.; Tian, W. Polym. Chem. 2014, 5, 3824-3830.

[9] Müller, M.; Brunsveld, L. Angew. Chem. Int. Ed. 2009, 48, 2921-2924.

[10] Sanji, T.; Shiraishi, K.; Tanaka, M. ACS Appl. Mater. Interfaces 2009, 1, 270-273.

[11] Hong, Y.; Lam, J. W. Y.; Tang, B. Z. Chem. Commun. 2009, 4332-4353.

[12] Chen, M.; Li, L.; Nie, H.; Shi, Y.; Mei, J.; Wang, J.; Sun, J. Z.; Qin, A.; Tang, B. Z. Chem. Commun. 2015, 51, 10710-10713.

[13] Liang, J.; Tang, B. Z.; Liu, B. Chem. Soc. Rev. 2015, 44, 2798-2811.

[14] Mei, J.; Leung, N. L. C.; Kwok, R. T. K.; Lam, J. W. Y.; Tang, B. Z. Chem. Rev. 2015, $115,11718-11940$.

[15] Levitus, M.; Schmieder, K.; Ricks, H.; Shimizu, K. D.; Bunz, U. H. F.; Garcia-Garibay, M. A. J. Am. Chem. Soc. 2001, 123, 4259-4265.

[16] Chen, J.; Law, C. C. W.; Lam, J. W. Y.; Dong, Y.; Lo, S. M. F.; Williams, I. D.; Zhu, D.; Tang, B. Z. Chem. Mater. 2003, 15, 1535-1546.

[17] Qin, A.; Lam, J. W. Y.; Mahtab, F.; Jim, C. K. W.; Tang, L.; Sun, J.; Sung, H. H. Y.; Williams, I. D.; Tang, B. Z. Appl. Phys. Lett. 2009, 94, 253308-1-253308-3.

[18] Tong, H.; Hong, Y.; Dong, Y.; Ren, Y.; Häussler, M.; Lam, J. W. Y.; Wong, K. S.; Tang, B. Z. J. Phys. Chem. B 2007, 111, 2000-2007.

[19] Virgili, T.; Forni, A.; Cariati, E.; Pasini, D.; Botta, C. J. Phys. Chem. C 2013, 117, 2716127166.

[20] Yeh, H.-C.; Wu, W.-C.; Wen, Y.-S.; Dai, D.-C.; Wang, J.-K.; Chen, C.-T. J. Org. Chem. 2004, 69, 6455-6462.

[21] Strassert, C. A.; Bilmes, G. M.; Awruch, J.; Dicelio, L. E. Photochem. Photobiol. Sci. 2008, 7, 738-747.

[22] Kemper, B.; Hristova, Y. R.; Tacke, S.; Stegemann, L.; van Bezouwen, L. S.; Stuart, M. C. A.; Klingauf, J.; Strassert, C. A.; Besenius, P. Chem. Commun. 2015, 51, 5253-5256.

[23] Fermi, A.; Bergamini, G.; Peresutti, R.; Marchi, E.; Roy, M.; Ceroni, P.; Gingras, M. Dyes Pigm. 2014, 110, 113-122.

[24] Voskuhl, J.; Stuart, M. C. A.; Ravoo, B. J. Chem. Eur. J. 2010, 16, 2790-2796. 
[25] Voskuhl, J.; Fenske, T.; Stuart, M. C. A.; Wibbeling, B.; Schmuck, C.; Ravoo, B. J. Chem. Eur. J. 2010, 16, 8300-8306.

[26] Brunner, K.; Harder, J.; Halbach, T.; Willibald, J.; Spada, F.; Gnerlich, F.; Sparrer, K.; Beil, A.; Möckl, L.; Bräuchle, C.; Conzelmann, K.-K.; Carell, T. Angew. Chem. Int. Ed. 2015, 54, 1946-1949.

[27] Mayukh, M.; Lu, C.-W.; Hernandez, E.; McGrath, D. V. Chem. Eur. J. 2011, 17, 84728478.

[28] Frisch, H.; Spitzer, D.; Haase, M.; Basche, T.; Voskuhl, J.; Besenius, P. Org. Biomol. Chem. 2016, 10.1039/C6OB00292G.

[29] Li, M.; Khoshdel, E.; Haddleton, D. M. Polym. Chem. 2013, 4, 4405-4411. 



\section{Selective Targeting of Lectins and Bacteria by Supramolecular Assemblies of 4,5-Bis(phenylthio)phthalonitriles}

In this chapter the binding of the 4,5-bis(phenylthio)phthalonitriles with lectins and bacteria was investigated. The specificity of the interaction between mannose moieties on assemblies of SPn-(TEG-Man) $)_{2}$ and protein ConcanavalinA (ConA) or E. coli bacterial strain ORN 178 was evidenced by optical density measurements and fluorescence microscopy images, respectively. When mannose moieties were absent on the assemblies of $\boldsymbol{S P n - T E G _ { 2 }}$ no interactions with ConA and ORN 178 were observed. The aggregation of SPn assemblies and ConA was dependent on the amount of mannose-functionalized thiophtalonitriles that were mixed into the SPn assemblies. About $10 \%$ of SPn-(TEGMan $)_{2}$ was sufficient to introduce agglutination, which could be reversed by the addition of a competitor. The amount of mannose-functionalized SPn in the assemblies and the assembly concentration determined the overall size of the bacterial agglomerates. A 1:1

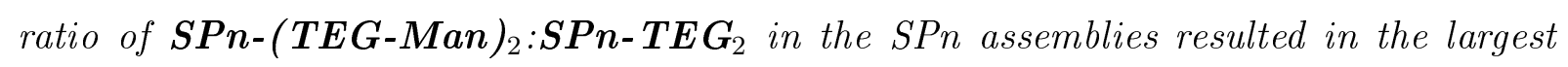
bacterial agglomerates. 


\subsection{Introduction}

Molecular recognition by carbohydrate-protein interactions plays an important role in living systems [1]. Other examples of recognition systems are protein-protein and antigenantibody interactions. All these interactions are based on non-covalent forces, e.g. hydrogen bonding or electrostatics. While monovalent carbohydrate-protein interactions are quite weak, the combination of several units by self-assembly leads to stronger, multivalent interactions [2, 3].

Carbohydrate-regulated recognitions are omnipresent in living systems. Cell-cell adhesion, cell recognition, cell differentiation and pathogen infection are a few examples of biological processes where carbohydrate-protein interactions are involved [1]. The stereochemical and conformational diversity of carbohydrates allows the coding of information and therefore enables specific targeting [3].

Carbohydrate-binding proteins are called lectins and the most thoroughly studied one is the plant lectin ConcanavalinA (ConA) [1]. Since it is present as a tetramer it offers four binding sites for the interaction with sugars. ConA specifically binds to $\alpha$-D-glucosyl and $\alpha$-D-mannosyl structures. In contrast to ConA the plant lectin peanut agglutinin (PNA) binds to galactosyl moieties. A carbohydrate-binding protein located on the E. coli pili is the type 1 fimbrial FimH adhesin [3]. Adhesins are responsible for attachement to other cells, e.g. to urothelium causing urinary tract infections. FimH receptors are D-mannose sensitive. Examples for specific targeting of human cells by sugars are galactose for hepatocytes, mannose for macrophages as well as glucose for cancer cells [1].

It has been demonstrated that mannose-covered self-assemblies were able to reversibly interact with ConA and bind as cylindrical or spheric objects to E. coli [4]. Galactosedecorated cyclodextrins that interact with polyviologen strings created a pseudo-rotaxane system that was able to inhibit T-cell agglutination upon sugar-cell interactions [5]. In another example maltose- or lactose-functionalized adamantane was used to decorate supramolecular cyclodextrin vesicles [6]. Upon binding to lectins agglutination was observed [6]. If the vesicles were not assembled no affinity was measured proving the importance of multivalency [6].

As described in chapter 5 the advantage of AIE molecules is the fluorescent nature of their aggregates in aqueous media, which provides an easy, non-invasive read-out system in biological experiments. Combining AIE and a carbohydrate functionality in one aggregate creates fluorescent assemblies that are able to target proteins, bacteria and cells.

Glycoconjugated AIE molecules have been reported for different applications. Carbohydrate-decorated phosphole oxides and tetraphenylethenes were used as "turn-on" sensors for lectins [7-9]. A displacement assay to study protein-protein interactions was realized with sugar-modified tetraphenylethenes [10]. Mannose-decorated supramolecular 


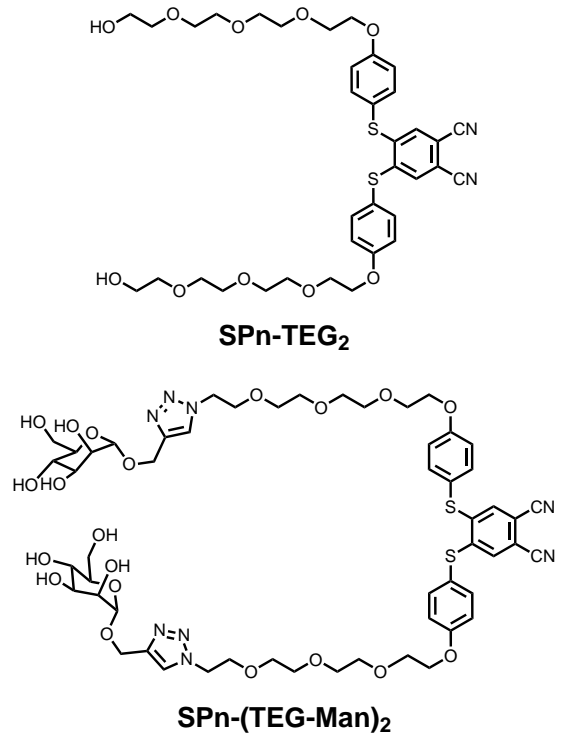

(a)

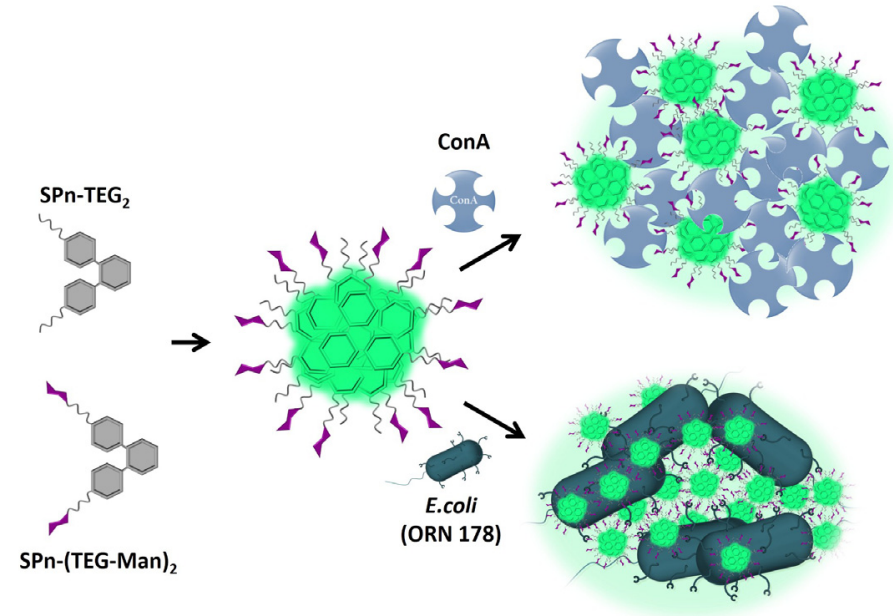

(b)

Figure 6.1 - Chemical structures of SPn-TEG S $_{2}$ and SPn-(TEG-Man) $)_{2}$ (a). Schematic presentation of the aggregation of lectins and bacteria in the presence of assemblies composed of SPn-TEG $\mathbf{~}_{2}$ and SPn-(TEG-Man) $)_{2}$ (b).

polymers were able to fluorescently detect and cluster bacteria [11].

In this chapter we investigate the targeting abilities of glycoconjugated AIEgens to ConA and E. coli. The bis(phenylthio)phthalonitriles SPn-TEG ${ }_{2}$ and SPn-(TEG-Man) $)_{2}$, whose syntheses have been described in chapter 5 , differ in the peripheral availability of mannose moieties (Fig. 6.1). In chapter 5 it was shown that above a threshold concentration of $1 \mu \mathrm{M}$ the molecules self-assemble in water into fluorescent, round-shaped objects.

\subsection{Results and discussion}

\subsubsection{Specific binding of SPn assemblies to ConcanavalinA}

Mixtures of SPn-(TEG-Man $)_{2}$ and $\mathbf{S P n - T E G} \mathbf{F}_{2}$ in different ratios and with an overall concentration of $20 \mu \mathrm{M}$ were incubated with $0.5 \mathrm{mg} / \mathrm{ml}$ ConA (20 $\mu \mathrm{M}$ monomeric ConA) in HEPES buffer (Fig. 6.2). Upon increasing the amount of SPn-(TEG-Man) $)_{2}$ in the SPn assemblies stronger agglutination was observed based on an increasing change in optical density. While in the mixture of 1:3 SPn-(TEG-Man) $)_{2}:$ SPn-TEG ${ }_{2}$ only a slight increase was visible, already at a 1:1 ratio agglutination was observed throughout the vial (Fig. 6.2a).

The agglutination process was studied in more detail using time-resolved absorption spectrophotometry. The different SPn mixtures were added after 5 min to a buffered ConA solution (Fig. 6.2b). In the first one to two minutes after the addition a rapid increase 
in the optical density was observed followed by a phase that showed a slower increase in optical density. The aggregation of SPn assemblies and ConA occurred instantly upon intermixing of the individual solutions and was dependent on the presence of mannose ligands in the aggregates. At $10 \%$ SPn-(TEG-Man) $)_{2}$ only a small change in optical density was measured, however, agglutination visible to the naked eye started only when a concentration of around $25 \%$ SPn-(TEG-Man) $)_{2}$ was present in the assemblies (Fig. 6.2a and 6.2b).

Methyl $\alpha$-D-mannopyranoside ( $\alpha \mathrm{MMP}$ ) is a competing monovalent ligand for the binding to ConA with a binding affinity of $10^{4} \mathrm{M}^{-1}[12]$. After addition of $\alpha \mathrm{MMP}(\mathrm{c}=10 \mathrm{mM})$ to the solution containing SPn-(TEG-Man) $)_{2}$-ConA clusters, the clumps were re-dissolved within 10 min signified by a decrease in optical density (Fig. 6.2c). These observations indicate the reversibility of the SPn-(TEG-Man) $)_{2}$-ConA binding. In contrast to the polyvalent SPn-(TEG-Man) $)_{2}$ assemblies, $\alpha$ MMP is present as a monovalent molecule that prevents the formation of agglutination upon its binding to ConA. However, the optical density did not drop to the background level, suggesting that not all ConA-SPn(TEG-Man $)_{2}$ aggregates were re-dissolved but that an equilibirium was reached between the polyvalent SPn assemblies, ConA and monovalent $\alpha \mathrm{MMP}$.

Figure 6.2d shows the absolute values of the maximum difference in optical density $\left(\mathrm{OD}_{\Delta M a x}\right)$ before and after $\alpha \mathrm{MMP}$ addition as a function of the concentration of $\alpha \mathrm{MMP}$ (1 - $30 \mathrm{mM})$. With increasing content of $\alpha \mathrm{MMP}$ the maximum difference is increasing. The values of $\mathrm{OD}_{\triangle M a x}$ for the assemblies composed of SPn-(TEG-Man) $)_{2}$ and of 3:1 SPn-(TEG-Man) $)_{2}:$ SPn-TEG $_{2}$ at $10 \mathrm{mM} \alpha \mathrm{MMP}$ are similar, suggesting that the observed effect is not depending on the mannose density on the SPn assemblies.

In another experiment monovalent competitor $\alpha \mathrm{MMP}$ was added to Con A before adding SPn-(TEG-Man) $)_{2}$. The observed increase in optical density was much lower in this case when compared to the experiments described above (Fig. 6.2c green dotted line). This experiment shows that although an excess of $\alpha \mathrm{MMP}(\mathrm{c}=10 \mathrm{mM})$ was present, a certain amount of SPn-(TEG-Man) $)_{2}$ was still binding to ConA, resulting in an equilibrium between the three compounds.

When the galactose-binding lectin PNA was used to interact with SPn-(TEG-Man) 2 assemblies, no agglutination and only a slight increase in optical density were observed (Fig. 6.2c, blue dotted line), which may be related to non-specific binding. In addition, when solutions of ConA and SPn-TEG $\mathbf{F}_{2}$ assemblies were mixed, no change in optical density was observed (Fig. 6.2c, red line). This observation confirms the specific binding of the mannose-modified thiophthalonitrile to ConA.

For the application of the SPn assemblies as a fluorescent read-out for biological interactions we next verified the emission properties of the SPn-(TEG-Man) $)_{2}$ assemblies upon interaction with ConA. After the combination of solutions of ConA and SPn the posi- 
tion of the emission maxima was unchanged $(\lambda=490 \mathrm{~nm})$ while the emission intensity increased slightly in comparison with the spectrum of a solution containing only SPn(TEG-Man $)_{2}$, mainly due to the scattering of the agglutinated mixture.

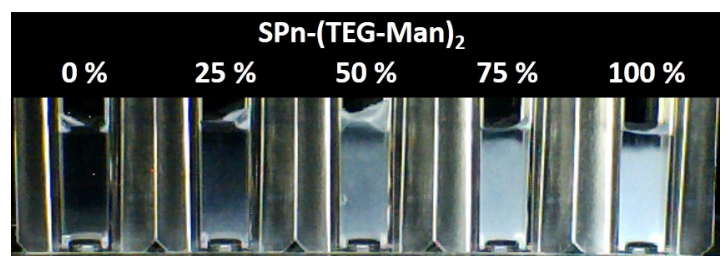

(a)

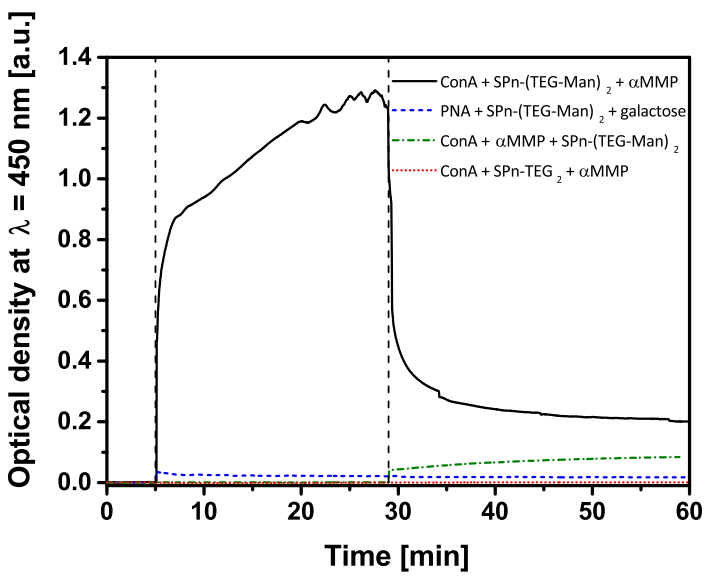

(c)

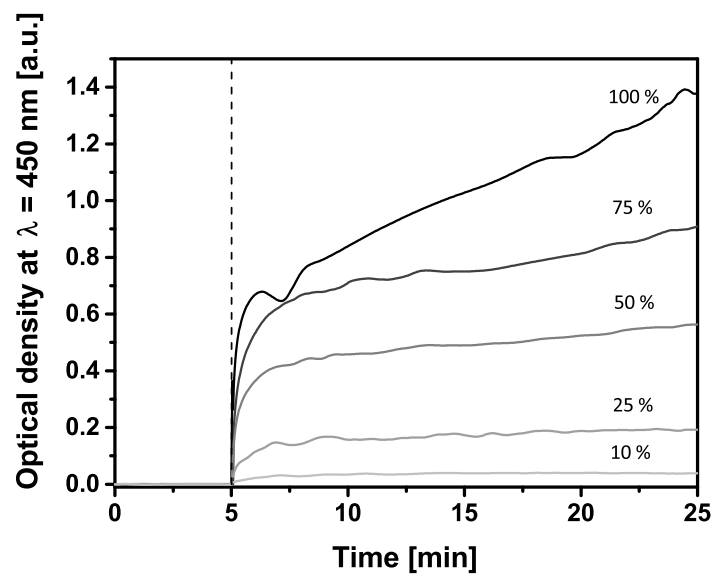

(b)

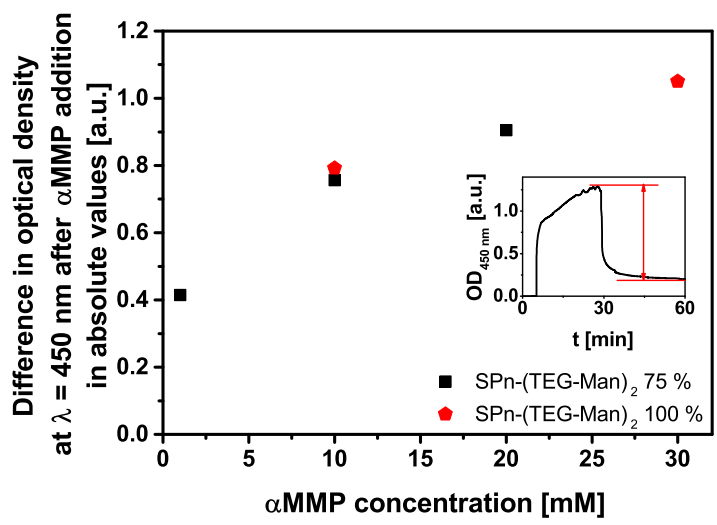

(d)

Figure 6.2 - Photograph of the agglutination of $0.5 \mathrm{mg} / \mathrm{ml}$ ConA in the presence of added aggregates composed of varying ratios of SPn-(TEG-Man) $)_{2}$ and SPn-TEG $_{2}$ $\left(c_{S P n}=20 \mu \mathrm{M}\right)$ after $2 \mathrm{~min}(\mathrm{a})$. Optical density measurement at $\lambda=450 \mathrm{~nm}$ as a function of time varying the ratio between SPn-(TEG-Man) $)_{2}$ and SPn$\mathbf{T E G}_{2}\left(\mathrm{c}_{S P n}=20 \mu \mathrm{M}\right)$, added to $0.5 \mathrm{mg} / \mathrm{ml}$ ConA after $5 \mathrm{~min}$ (b). Optical density measurements at $\lambda=450 \mathrm{~nm}$ as a function of time (c). After $5 \mathrm{~min}$ $20 \mu \mathrm{M}$ SPn was added to the $0.5 \mathrm{mg} / \mathrm{ml}$ lectin solution and after 29 min the competitive monosaccharide $(10 \mathrm{mM})$ was added. Difference in optical density at $\lambda=450 \mathrm{~nm}$ as a function of $\alpha \mathrm{MMP}$ concentration for SPn-(TEG-Man) $)_{2}$ and for 3:1 SPn-(TEG-Man) $)_{2}:$ SPn-TEG ${ }_{2}\left(\mathrm{c}_{S P n}=20 \mu \mathrm{M}, \mathrm{c}_{C o n A}=0.5 \mathrm{mg} / \mathrm{ml}\right)$ (d). The change in optical density is displayed as absolute values. The inset, representing subfigure $6.2 \mathrm{c}$, shows how values were obtained. 


\subsubsection{Specific binding of SPn assemblies to $E$. coli bacteria}

The interaction between mannose-functionalized SPn assemblies and bacteria was evaluated using two different strains of E. coli. Wild-type E. coli strain ORN 178 expresses FimH receptors and is able to bind mannose moieties [13]. Mutant E. coli strain ORN 208 bears no FimH receptors and is therefore not able to interact with the mannose SPn derivatives [14]. Since each SPn-(TEG-Man) ${ }_{2}$ assembly bears mannose moieties in a multivalent fashion, strong interaction with ORN 178 is expected, leading to bacterial aggregation.

First it was verified that the SPn compounds cause no cytotoxic response when added to the bacterial strains (Fig. 6.3). Even at higher concentrations no significant effect on the viability of the cells was observed.

From figure 6.4 it is apparent that ORN 208 neither clusters nor fluoresces upon incubation with $50 \mu \mathrm{M}$ SPn-(TEG-Man) $)_{2}$ aggregates for $2 \mathrm{~h}$, indicating that non-specific interactions do not lead to bacterial aggregation. In strong contrast, in the case of adding $50 \mu \mathrm{M}$ SPn-(TEG-Man) $)_{2}$ to ORN 178, large bacterial aggregates that span sizes of around $40 \mu \mathrm{m}$ in length were observed (Fig. 6.4a). Furthermore fluorescence images were recorded at the same location. The bacterial aggregates co-localized with the fluorescence showing the presence of SPn aggregates between individual bacteria (Fig. 6.4b and 6.4c). Effective aggregation of bacteria was found in less than $2 \mathrm{~h}$. From these experiments it can be concluded that the mannose moieties of SPn-(TEG-Man) $)_{2}$ are able to specifically bind to the FimH receptors of ORN 178.

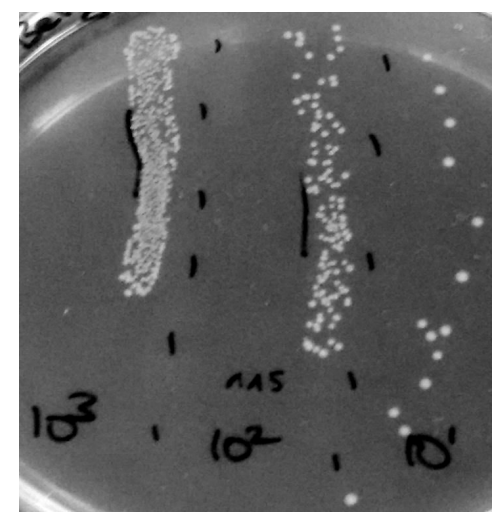

(a)

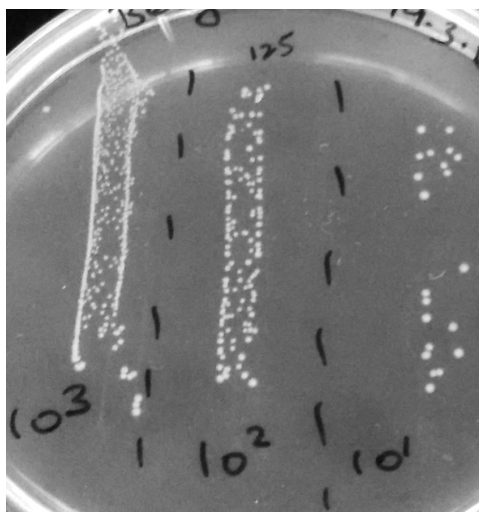

(b)

Figure 6.3 - Bacterial viability test. E. coli bacteria incubated and cultivated on LB mediumagar plates (tetracycline hydrochloride as selective antibiotics): ORN 178 was incubated for $1 \mathrm{~h}$ with SPn-(TEG-Man) 2 (a) or with water as control (b). The values below the lanes indicate the number of bacterial cells per $10 \mu \mathrm{l}$ 


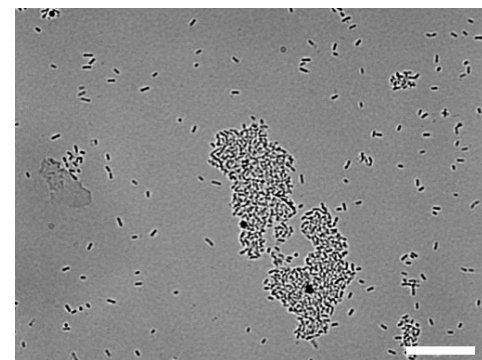

(a)

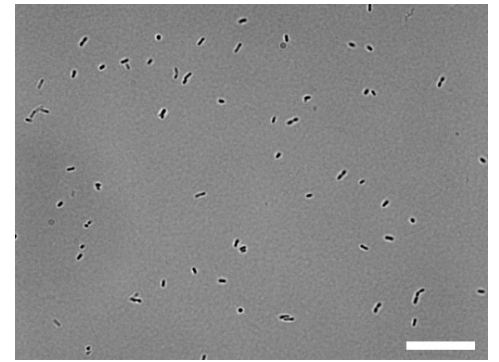

(d)

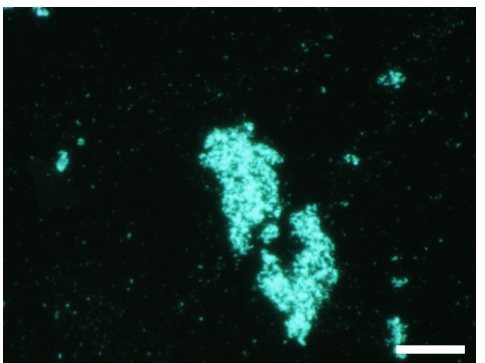

(b)

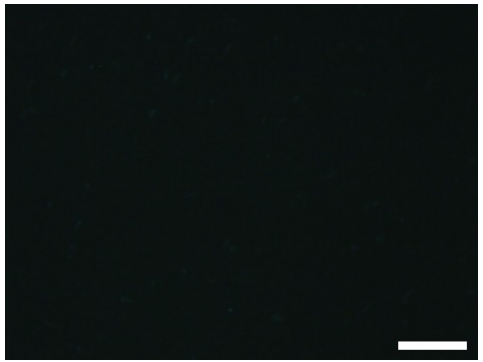

(e)

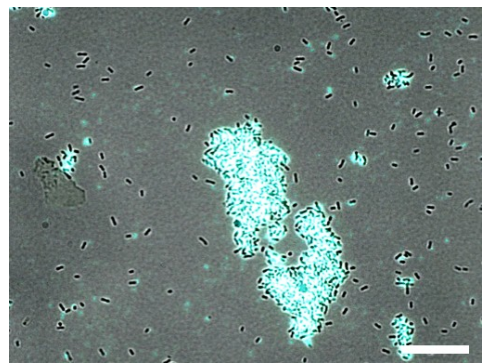

(c)

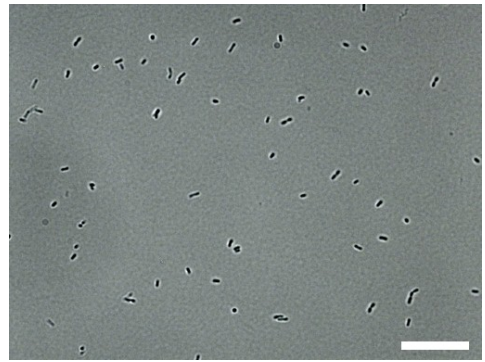

(f)

Figure 6.4 - Bacterial aggregation induced by $50 \mu \mathrm{M}$ SPn-(TEG-Man) $)_{2}$ in LB medium. (a) and (d) bright field images, (b) and (e) fluorescence microscopy images, (c) and (f) overlay of the first two photographs. Upper picture row (a, b, c) features strain ORN 178 and lower picture row (d, e, f) features strain ORN 208. Scale bars are $20 \mu \mathrm{m}$.

\subsubsection{Influence of SPn assembly concentration and mannose density on specific $E$. coli binding}

Overlapping bright field and fluorescence microscopy images show that bacterial cells aggregate together in the presence of fluorescent SPn assemblies (Fig. 6.4c). To verify whether the large fluorescent aggregates only occurred in combination with binding of the mannose SPn to FimH receptors, images of samples containing only SPn mixtures and no bacteria were recorded (Fig. 6.5). Independent from the mannose density mixed into the SPn assemblies there were fluorescent SPn assemblies observed in all samples. They were, however, smaller in size than the ones detected when bacteria were present. In experiments using control strain ORN 208 or using strain ORN 178 together with a low SPn-(TEG-Man $)_{2}$ content $(<25 \%)$ the same small fluorescent aggregates were found, but these were not adjacent to bacterial agglomerations. Those results prove SPn aggregate formation in aqueous media, as studied in chapter 5. Furthermore, the observations support the hypothesis that the formation of large bacterial agglomerations was only possible in the presence of SPn-(TEG-Man $)_{2}$. When mannose moieties were absent and

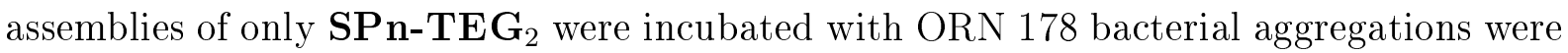
not observed. Taken together the experiments show that SPn-(TEG-Man) $)_{2}$ specifically binds to the FimH receptors leading to bacterial aggregation. 


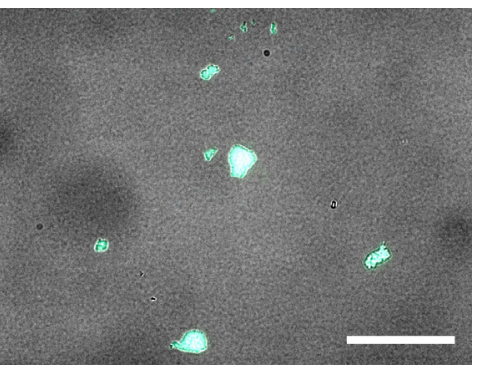

(a)

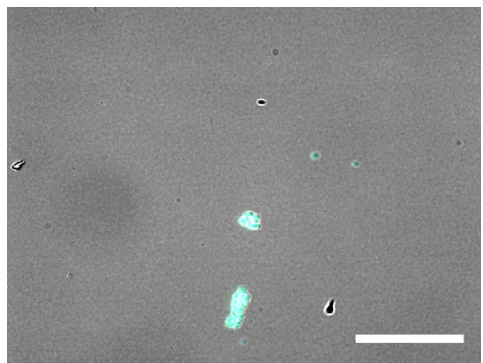

(b)

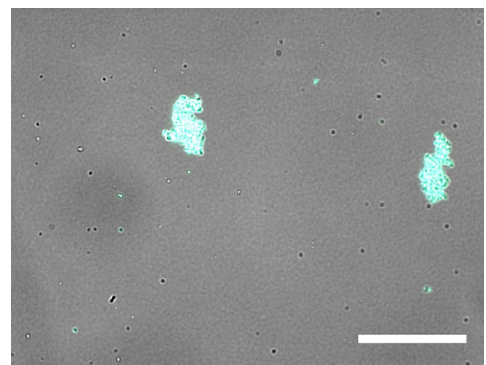

(c)

Figure 6.5 - Overlay of bright field and fluorescence microscopy images of SPn assemblies $\left(c_{S P n}\right.$ $=50 \mu \mathrm{M})$ with different $\mathbf{S P n}-(\mathbf{T E G}-\mathbf{M a n})_{2}: \mathbf{S P n}-\mathbf{T E G} \mathbf{G}_{2}$ ratios without bacteria incubation. Ratio of SPn-(TEG-Man) $)_{2}$ to $\mathbf{S P n - T E G} \mathbf{T}_{2}$ : (a) 0:1, (b) 1:1, (c) 1:0. Scale bars are $50 \mu \mathrm{m}$.

A series of bacteria samples were incubated with SPn assemblies containing both SPn(TEG-Man) $)_{2}$ and SPn-TEG ${ }_{2}$ in different ratios (Fig. 6.6a $6.6 \mathrm{~d}$ ). From the bright field images the sizes of bacterial aggregates were analyzed (Fig. 6.7a). Upon increasing the content of SPn-(TEG-Man) $)_{2}$ and therefore the mannose density in the SPn assemblies, the bacterial aggregation size changed. Interestingly, the maximum bacterial aggregate size of $17000 \mu \mathrm{m}^{2}$ was estimated using mixed assemblies of 1:1 SPn-(TEG-Man) $)_{2}$ :SPn$\mathbf{T E G}_{2}$ and not when mannose-only SPn-assemblies were used (Fig. 6.7a), indicating that crowding of carbohydrates is an important parameter when optimizing the interaction between bacteria and supramolecular SPn aggregates. Assemblies of SPn-(TEG-Man) and $\mathbf{S P n}-\mathbf{T E G}_{2}$, that are containing less than $25 \%$ SPn-(TEG-Man) $)_{2}$, did not show bacterial aggregation (aggregates defined as at least 10 bacteria cells teamed up).

Upon dilution of the SPn assembly concentration, the bacterial aggregate size was decreasing (Fig. 6.6e-6.6g and 6.7b). Just above the critical assembly concentration (CAC) of the SPn assemblies (1 $\mu \mathrm{M}$, see chapter 5) at $5 \mu \mathrm{M}$ SPn assemblies bacterial agglomerates were still formed (Fig. 6.6e). While at $1 \mu \mathrm{M}$ SPn only a few bacterial aggregates were detected, when using $0.5 \mu \mathrm{M}$ SPn assemblies no bacterial aggregation was observed, which resembles the results obtained with ORN 208. These observations confirm that assemblies of SPn with mannose functionalities are required for bacterial agglomeration.

\subsubsection{Reversibility of the specific binding of SPn-(TEG-Man) $)_{2}$ assemblies to E. coli}

The reversibility of the specific binding between ConA and mannose SPn was shown in section 6.2.1, It was investigated if this is also applicable for the specific binding to ORN 178. Solutions containing ORN 178 and $50 \mu \mathrm{M}$ 1:1 SPn-(TEG-Man) $)_{2}:$ SPn-TEG 2 showed large fluorescent bacterial aggregates (Fig.6.8a). After adding the competitor 


\section{Ratio of SPn-(TEG-Man) $)_{2}: \mathrm{SPn}_{-} \mathrm{TEG}_{2}$}

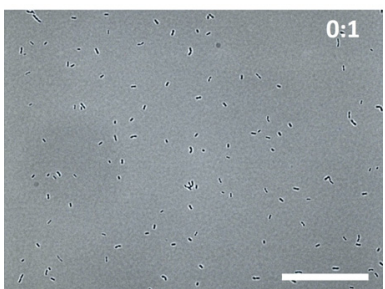

(a)

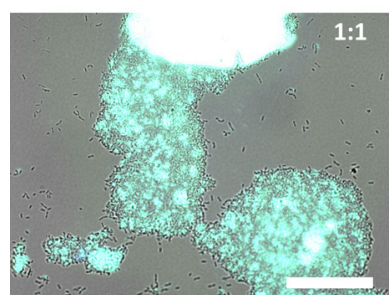

(b)

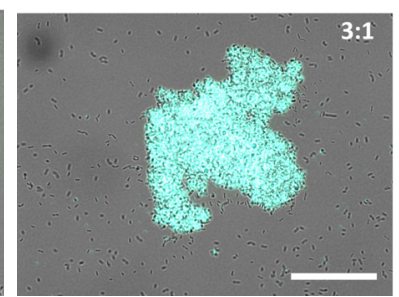

(c)

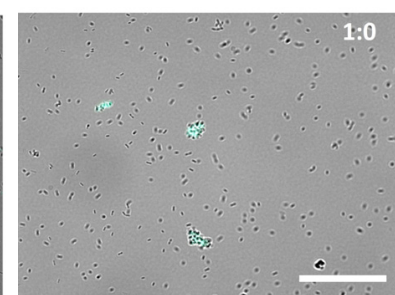

(d)

Concentration of SPn assemblies

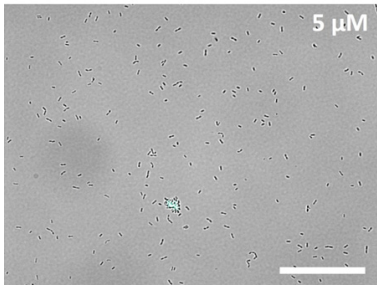

(e)

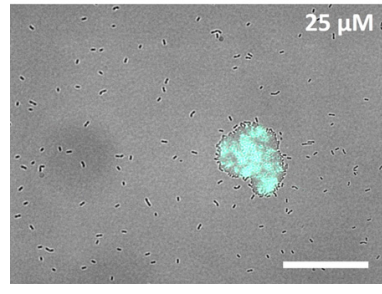

(f)

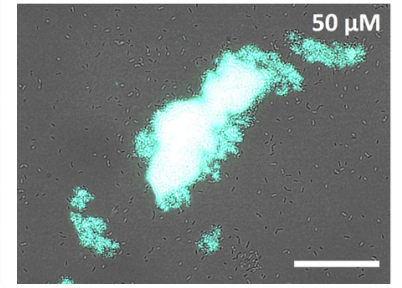

(g)

Figure 6.6 - Influence of mannose density (a-d). Overlay of bright field and fluorescence microscopy images of ORN $178\left(\mathrm{OD}_{600}=1\right)$ incubated with SPn assemblies $\left(\mathrm{c}_{S P n}\right.$ $=50 \mu \mathrm{M})$ with different ratios of SPn-(TEG-Man) $)_{2}$ to $\mathbf{S P n}-\mathbf{T E G}_{2}$ : (a) 0:1, (b) $1: 1$, (c) $3: 1$, (d) 1:0. Influence of SPn assembly concentration (e-g). Overlay of bright field and fluorescence microscopy images of ORN $178\left(\mathrm{OD}_{600}=1\right)$ incubated with 1:1 ratio of SPn-(TEG-Man) $)_{2}: \mathbf{S P n}_{\mathbf{T}} \mathbf{T E G}_{2}: \mathrm{c}_{S P n}=(\mathrm{e}) 5 \mu \mathrm{M},(\mathrm{f})$ $25 \mu \mathrm{M},(\mathrm{g}) 50 \mu \mathrm{M}$. Scale bars are $50 \mu \mathrm{m}$.

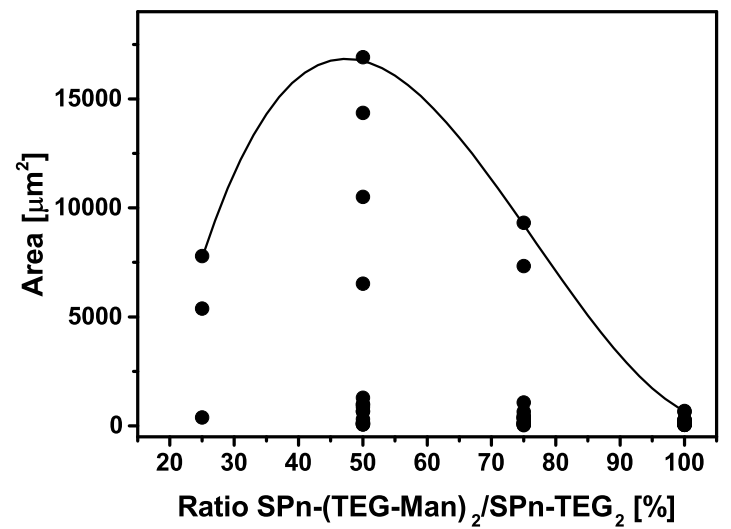

(a)

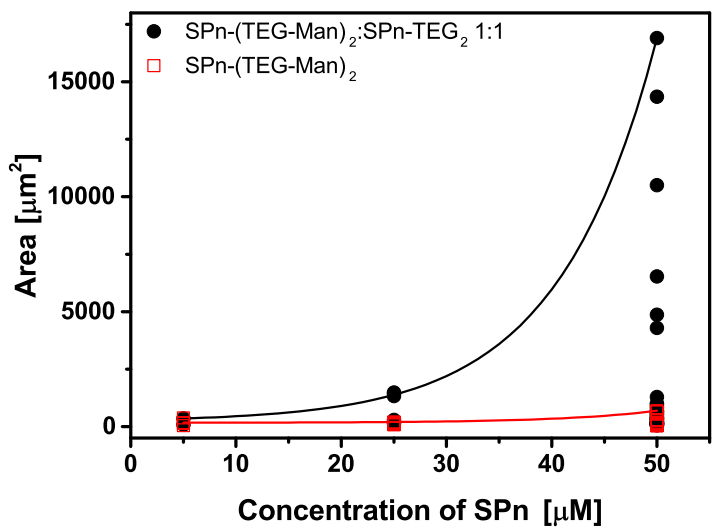

(b)

Figure 6.7 - Area distribution of bacterial aggregates in bright field images: (a) ratio distribution, (b) concentration distribution. Only samples containing bacterial aggregation are shown in the graph with aggregation being defined as at least 10 bacteria cells teamed up. Marks are experimental values, trendlines are given to guide the eye. 
$\alpha \operatorname{MMP}(\mathrm{c}=50 \mathrm{mM})$ to this solution and incubating for $1 \mathrm{~h}$ at $37^{\circ} \mathrm{C}$, large bacterial aggregates disappeared and only small aggregates were found (Fig. 6.8b). When $\alpha \mathrm{MMP}$ was added to SPn assemblies observed in figure 6.5 no influence was detected. The added $\alpha \mathrm{MMP}$ in the bacteria experiments is only interacting with the ORN 178 cells and replaces the bound SPn-(TEG-Man) 2 molecules. The experiments are confirming the reversibility of the interactions between mannose and FimH receptors upon addition of a competitor.

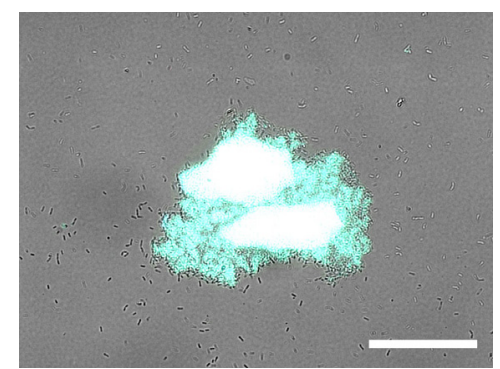

(a)

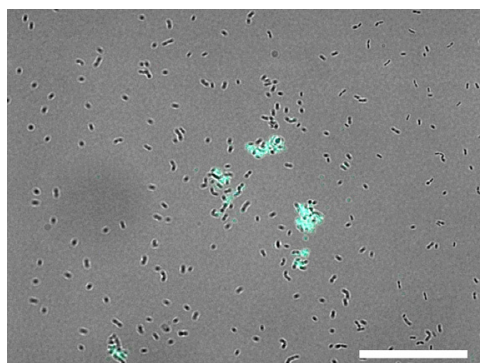

(b)

Figure 6.8 - Reversibility. Overlay of bright field and fluorescence microscopy images of ORN 178 incubated with 1:1 $50 \mu \mathrm{M}$ SPn-(TEG-Man) $)_{2}:$ SPn-TEG $_{2}$, before (a) and after (b) $\alpha \mathrm{MMP}$ incubation $\left(\mathrm{c}_{\alpha M M P}=50 \mathrm{mM}\right)$. Scale bars are $50 \mu \mathrm{m}$.

\subsection{Conclusions}

The interactions of the SPn assemblies with proteins and bacteria were investigated and showed a selective and reversible recognition by ConA and the FimH receptors for SPn(TEG-Man $)_{2}$. Other combinations with different lectins, bacteria cells and non-mannose containing SPn assemblies did not result in specific binding. Furthermore a dependency on the ratio of mannose versus non-mannose SPn in the SPn assemblies and SPn assembly concentrations was demonstrated. This new class of AIEgens bears the opportunity to be used in several biomedical applications since the modification of these compounds in the periphery with bioactive residues is facile.

\subsection{Acknowledgments}

Jun.-Prof. Dr. Jens Voskuhl (Universität Duisburg-Essen) is thankfully acknowledged for providing the molecules SPn-(TEG-Man) $)_{2}$ and SPn-TEG $\mathbf{S}_{2}$ and for his advice on the experiments and the fruitful discussions. Dr. Shrikrishnan Sankaran is gratefully thanked for the introduction to bacteria lab work and the fruitful discussions. 


\subsection{Experimental section}

\subsubsection{Materials and equipment}

All chemicals were purchased from Sigma-AldRICH and Thermo Fischer and used as received, unless otherwise stated.

In all protein experiments a HEPES buffer was used: $\mathrm{pH}=7.2,10 \mathrm{mM}$ HEPES, $137 \mathrm{mM}$ $\mathrm{NaCl}, 1 \mathrm{mM} \mathrm{CaCl}_{2}, 1 \mathrm{mM} \mathrm{MnCl}_{2}$. The same buffer was used for the $\mathrm{SPn}$ solutions in the bacteria experiments. The bacteria themselves and the bacterial experiments were carried out in lysogeny broth (LB) as medium, with tetracycline hydrochlorid as antibiotic.

Optical density spectra were measured on a PERKIN Elmer Lambda 850 spectrophotometer. The absorption spectra were measured against air and corrected for the solvent. Fluorescence spectra were recorded on a PERKIN ELMER LS 55 Fluorescence Spectrophotometer using an excitation wavelength of $\lambda=330 \mathrm{~nm}$. The emission and excitation slit widths were kept at $10 \mathrm{~nm}$.

The bacterial strains ORN 178 and ORN 208 were kindly provided by Prof. Luc Brunsveld (Technische Universiteit Eindhoven).

The microscopy pictures were recorded using an OLYMPUS IX71 microsope. The bright field pictures were recorded in monochrome mode with $50 \mathrm{~ms}$ exposure time. The fluorescence images were recorded using the following filter: excitation wavelength $\lambda_{e x}=$ $350 \mathrm{~nm}$, emission wavelength $\lambda_{e m}=420 \mathrm{~nm}$ with long pass filter. As exposure time 500 $\mathrm{ms}, 1000 \mathrm{~ms}$ or $5000 \mathrm{~ms}$ were used. The overlay images were created using the software ImageJ [15].

\subsubsection{Methods}

\section{Recording of cuvettes with SPn and ConA}

Five cuvettes were filled with $0.5 \mathrm{mg} / \mathrm{ml}$ ConA. Solutions with different ratios of SPn$(\text { TEG-Man })_{2}:$ SPn-TEG $_{2}$ were prepared $\left(c_{S P n}=200 \mu \mathrm{M}\right): 0: 1,1: 3,1: 1,3: 1$ and 1:0. From these solutions $40 \mu \mathrm{l}$ were added to each cuvette (total volume $400 \mu \mathrm{l}, \mathrm{c}_{S P n}=$ $20 \mu \mathrm{M})$. The agglutination was recorded as video. The shown image is after a total time of 2 min.

\section{Optical density measurements}

The samples were measured in absorption mode at $\lambda=450 \mathrm{~nm}$ for $1 \mathrm{~h}$. Every 2 seconds a value was recorded. The total volume in the cuvette was $1 \mathrm{ml}$ which consisted of $250 \mu \mathrm{l} 2 \mathrm{mg} / \mathrm{ml}$ ConA, $1 \mu \mathrm{l} 1 \mathrm{M} \mathrm{MnCl}_{2} / \mathrm{CaCl}_{2}, 649 \mu \mathrm{l}$ HEPES buffer and of $100 \mu \mathrm{l}$ 
$200 \mu \mathrm{M}$ thiophthalonitrile which was added after 5 min of recording. After $29 \min 10 \mu \mathrm{l}$ $1 \mathrm{M}$ sugar $(\alpha \mathrm{MMP}$ or $\mathrm{D}(+)$-galactose) was added. Concentrations and spectra were not corrected for dilution effects.

\section{Fluorescence spectra}

The different samples were prepared independently from each other but from the same $200 \mu \mathrm{M}$ buffered SPn-(TEG-Man) $)_{2}$ stock solution. The samples were measured directly after intermixing all compounds. The concentrations in the samples were $10 \mu \mathrm{M}$ SPn(TEG-Man) $)_{2}$ and $0.25 \mathrm{mg} / \mathrm{ml}$ ConA.

\section{Viability}

To test the bacterial viability E. coli bacteria strains ORN 178 and ORN 208 who were grown overnight were incubated for $1 \mathrm{~h}$ or $1 \mathrm{~d}$ at $37{ }^{\circ} \mathrm{C}$ with the thiophthalonitriles and cultivated on LB medium-agar plates (tetracycline hydrochloride added as selective antibiotic). The incubated solutions contained $10^{9}$ cells $/ \mathrm{ml}\left(\mathrm{OD}_{600}=1\right)$ and $50 \mu \mathrm{M} \mathrm{SPn}$. The control solution contained no thiophthalonitrile (only water). After incubation the samples were diluted to $10^{5}, 10^{4}$ and $10^{3}$ cells $/ \mathrm{ml}$. From these solutions $10 \mu \mathrm{l}$ were placed as drops on top of LB agar plates before the plates were tilted to form 3 streams which quickly dried. The plates were kept at $37^{\circ} \mathrm{C}$ overnight before the colonies were counted the next day.

\section{Fluorescence microscopy}

The bacterial strains ORN 178 and ORN 208 were grown overnight in lysogeny broth (LB) as medium using tetracycline hydrochloride as the selective antibiotic. After measuring the $\mathrm{OD}_{600}$ value, samples containing $1 \mathrm{OD}$ bacteria, $1 \mathrm{mM} \mathrm{MnCl}_{2}, 1 \mathrm{mM} \mathrm{CaCl}_{2}$ and a certain concentration of SPn in HEPES buffer were prepared and incubated for $60 \mathrm{~min}$. The samples in figure 6.4 were incubated for $2 \mathrm{~h}$. A drop of the solution was placed between cover slips and investigated under the fluorescence microscope.

For studies of the ratio dependency and reversibility $50 \mu \mathrm{M}$ SPn mixtures were used. The SPn solutions were pre-mixed before they were added to the bacteria solution. The used ratios for the ratio dependency were: SPn-(TEG-Man) ${ }_{2}$ :SPn-TEG $_{2}$ 0:1, 1:9, 1:3, 1:1, 3:1, 1:0. The SPn concentrations for the study of the concentration dependency were $5 \mu \mathrm{M}, 25 \mu \mathrm{M}$ and $50 \mu \mathrm{M}$. For the reversibility experiment $5 \mu \mathrm{l}$ of a $1 \mathrm{M} \alpha \mathrm{MMP}$ solution was added to the SPn-bacteria sample $\left(c_{\alpha M M P}=50 \mathrm{mM}\right)$ and incubated for $1 \mathrm{~h}$. 


\subsection{Bibliography}

[1] Miura, Y.; Hoshino, Y.; Seto, H. Chem. Rev. 2016, 116, 1673-1692.

[2] Barnard, A.; Smith, D. K. Angew. Chem. Int. Ed. 2012, 51, 6572-6581.

[3] Cecioni, S.; Imberty, A.; Vidal, S. Chem. Rev. 2015, 115, 525-561.

[4] Ryu, J.-H.; Lee, E.; Lim, Y.-b.; Lee, M. J. Am. Chem. Soc. 2007, 129, 4808-4814.

[5] Nelson, A.; Belitsky, J. M.; Vidal, S.; Joiner, C. S.; Baum, L. G.; Stoddart, J. F. J. Am. Chem. Soc. 2004, 126, 11914-11922.

[6] Voskuhl, J.; Stuart, M. C. A.; Ravoo, B. J. Chem. Eur. J. 2010, 16, 2790-2796.

[7] Sanji, T.; Shiraishi, K.; Tanaka, M. ACS Appl. Mater. Interfaces 2009, 1, 270-273.

[8] Sanji, T.; Shiraishi, K.; Nakamura, M.; Tanaka, M. Chem. Asian J. 2010, 5, 817-824.

[9] Wang, J.-X.; Chen, Q.; Bian, N.; Yang, F.; Sun, J.; Qi, A.-D.; Yan, C.-G.; Han, B.-H. Org. Biomol. Chem. 2011, 9, 2219-2226.

[10] Shiraishi, K.; Sanji, T.; Tanaka, M. Tetrahedron Lett. 2010, 51, 6331-6333.

[11] Müller, M.; Brunsveld, L. Angew. Chem. Int. Ed. 2009, 48, 2921-2924.

[12] Mandal, D. K.; Kishore, N.; Brewer, C. F. Biochemistry 1994, 33, 1149-1156.

[13] Voskuhl, J.; Sankaran, S.; Jonkheijm, P. Chem. Commun. 2014, 50, 15144-15147.

[14] Harris, S.; Spears, P.; Havell, E.; Hamrick, T.; Horton, J.; Orndorff, P. J. Bacteriol. 2001, 183, 4099-4102.

[15] Rasband, W. ImageJ. 1997-2014; http://imagej.nih.gov/ij/ 



\section{Summary}

Supramolecular assemblies of glycoconjugated dyes can be tailored with properties that make them attractive for use in biomedical applications. For example, when assemblies of glycoconjugated dyes are displaying carbohydrates on their periphery in a polyvalent manner, these assemblies can be used to study and visualize biological recognition events. Carbohydrates can selectively target cell membrane receptors and the polyvalency of the carbohydrate display on the supramolecular assemblies can strengthen the interaction with cells. In addition, some dyes assemble into fluorescent objects and some dyes can generate singlet oxygen. A combination of these properties results in a type of assemblies that can be used as a diagnostic and therapeutic tool. Fluorescence allows an easy, non-invasive read-out and is especially interesting for the detection and visualization of diseased cells or organs. Although singlet oxygen can be a reason for oxidative stress in healthy cells, it is also able to kill pathogens with low side effects and no resistance development.

In this thesis two different molecular systems have been developed and the photophysical properties of their assemblies, also in the context of possible use, have been studied. As a first system glycoconjugated porphyrins have been synthesized. The type and number of carbohydrates on the periphery of the porphyrins have been varied and their influence on the photophysical properties and the size of the assemblies has been investigated. Studies concerning their bactericidal nature have been performed. The second system consisted of thiophthalonitriles whose assemblies showed excellent fluorescent properties. Also in this case the photophysical character of the assemblies has been documented and the most remarkable result has been that the hetero atom in the dye is decisive for the observation of the aggregation-induced emission. The thiophthalonitrile assemblies featuring mannose moieties underwent specific and reversible interactions with protein binding partners and bacteria. Since the peripheral substitution had no influence on the photophysical properties, its binding to other biological receptors can be easily realized, independent from the characteristics of the dye. This opens up numerous possibilities to apply these fluorescent nanoparticles in diagnostic research. 



\section{Samenvatting}

Supramoleculaire assemblages van glycogeconjugeerde kleurstoffen kunnen voorzien worden van eigenschappen die hun gebruik in biomedische toepassingen verbeteren. Als assemblages van glycogeconjugeerde kleurstoffen bijvoorbeeld koolhydraten op een polyvalente manier presenteren, dan kunnen deze assemblages gebruikt worden om gerichte biologische herkenning te laten plaatsvinden en deze te bestuderen en te visualiseren. Koolhydraten kunnen zich selectief richten op celmembraanreceptoren waarbij de polyvalentie van de koolhydraten aan de supramoleculaire assemblages de interactie met cellen kan versterken. Daarnaast zijn er kleurstoffen die assembleren in fluorescente objecten en er zijn kleurstoffen die singlet zuurstof kunnen maken. Als deze twee eigenschappen worden gecombineerd in een kleurstof dan kunnen assemblages van dit type kleurstoffen als diagnostisch en therapeutisch middel gebruikt worden. Fluorescentie maakt een makkelijke, niet-invasieve observatie mogelijk en is vooral interessant voor de detectie en visualisatie van zieke cellen en organen. Hoewel singlet zuurstof een reden kan zijn voor oxidatieve stress in gezonde cellen, is het ook geschikt om ziekteverwekkers te doden met minder bijeffecten en zonder ontwikkeling van resistentie.

In dit proefschrift is de ontwikkeling van twee verschillende moleculaire systemen beschreven en worden de fotofysische eigenschappen van de assemblages, ook in de context voor mogelijke toepassingen, onderzocht. Het eerste systeem bestaat uit porfyrinen die geconjugeerd zijn met verschillende typen en een verschillend aantal koolhydraten. De invloed van deze variatie op de fotofysische eigenschappen en de grootte van de assemblages is onderzocht en studies wat betreft hun bacteriedodende eigenschappen zijn uitgevoerd. Het tweede systeem bestaat uit thioftalonitrilen, waarvan de assemblages uitstekende fluorescente eigenschappen toonden. Ook in dit geval werden de fotofysische eigenschappen van de assemblages gerapporteerd en het meest opmerkelijke resultaat was dat het heteroatoom van de kleurstof cruciaal is voor de observatie van aggregatie-geïnduceerde emissie. De mannose-thioftalonitril assemblages ondervonden specifieke en reversibele interacties met eiwitten en bacteriën. Doordat de perifere substituties geen invloed hebben op de fotofysische eigenschappen, kan hun binding met andere biologische receptoren makkelijk gerealiseerd worden, onafhankelijk van de kenmerken van de kleurstof. Dit opent talrijke 
mogelijkheden voor het toepassen van deze fluorescente, op thioftalonitril gebaseerde assemblages in diagnostisch onderzoek. 


\section{Acknowledgments}

"One is alone when the last one who remembers is gone." - A Murder Is Announced by Agatha Christie

Luckily I was not alone on my PhD journey and therefore I want to express my gratitude to a list of people.

Pascal I want to thank you for giving me the opportunity to do my $\mathrm{PhD}$ research in your group. I enjoyed the meetings and discussions of controversial results - certainly in the critical moments you always had the right ideas.

Jurriaan When I started my PhD studies, you were my promotor. Thank you for showing interest in the porphyrin synthesis and always asking the right, but uncomfortable questions identifying the weak points. I also want to thank you for being part of my committee.

Jens Vielen Dank für deinen Beitrag zu meiner Arbeit, für deine Ratschläge zu meinen vielen Synthesefragen und für die Zusammenarbeit am interessanten Phthalonitrilprojekt. Natürlich freu ich mich, dass du eingewilligt hast Teil meines Prüfungskomitees zu sein.

Committee I want to thank the other thesis committee members, Jeroen Cornelissen, Christian Strassert and Wim Verboom, for their time and effort.

Scientific staff Furthermore I want to thank the current (Nathalie Katsonis and Tibor Kudernac) and former (Melissa Besenius) scientific staff members for their input to the $\mathrm{MnF} / \mathrm{BNT}$ groups and their discussions during work colloquiums.

Technical staff Doing PhD research would not be possible without the support of the technical staff members: I want to thank Nicole and Izabel for all the help with the administrative stuff. Regine and Bianca I want to acknowledge for taking good care of the failure-prone mass and NMR spectrometers. It didn't matter if it is a broken light bulb or a chemical order, you always have an open ear for all problems: Thanks, Marcel! Richard, thank you for sharing your endless knowledge about lab stuff and thank you for returning my scissors and pens (most of the time). 
Paranymphs I would like to thank the two colleagues that agreed to be my paranymphs for their input in the last months! Janneke, je was bijna de hele tijd tijdens mijn promotietijd ook aanwezig, eerst als Sven's master studente en later met jouw eigen promotieonderzoek. Bedankt voor jouw hulp toen we samen practicum begeleiders waren en ik de één of andere vraag had en ook bedankt voor de gespreken over korfbal en frisbee tijdens het eten. Success met het afronden van jouw proefschrift! Maike, es hat mich sehr gefreut deine Bekanntschaft zu machen. Obwohl ich am Anfang etwas skeptisch war, ob du nicht ein bisschen zu viel Deutsch sprichst, hast du inzwischen deinen Weg gefunden und bringst selbst deinen italienischen Laborkollegen Deutsch bei. Unser gemeinsamer Trip zur Konferenz nach Strasbourg im letzten Jahr wird mir gut in Erinnerung bleiben, besonders die Rückfahrt bei $37^{\circ} \mathrm{C}$ und ohne Klimaanlage.

BMEL Next, I want to thank all current and former Pascal-group members that haven't been mentioned yet for the groups discussions, the scientific input and the pizza dinners: Angel, Dodo, Emanuela (Thanks for always being concerned about everyone's well-being and for organizing a lot of activities - All the best for the end of your PhD!), Erhan, Gülistan, Jasper, Jenny \& Shirish (My fellow-PhD-starters - I wish you two all the best for your future together, now first in Germany!), João, Jordi, Liulin, Mark V., Nicole, Tom, Tushar (Thanks for the almost four years of desk neighbourhood and that you gave me the chance to be your paranymph - I wish you and your wife all the best for your future!), Wies, and all Master and Bachelor students who joined the group!

Lab 2 Most of the lab time of my $\mathrm{PhD}$ research I spent in lab 2 and therefore I want to thank everyone who also spent a lot of time there: Mudassir, Nicolai, Kirsten, Xuemei, Vishwas, Andrea (Thanks for always being reliable and switching off the pump), the French postdocs Ben \& Wilfried \& Alexis, Christoph, He, Federico, and Leendert (Thanks for spending most of your Bachelor assignment in lab 2. Although I wasn't your actual supervisor, but it was interesting to introduce organic synthesis to you. I wish you all the best for your Master assignment now in lab 3!).

$\mathrm{MnF} / \mathrm{BNT}$ For everyone of the $\mathrm{MnF} / \mathrm{BNT}$-cluster who I have not mentioned yet, I still want to say "Thank you!" to: Aijie, Alberto, Alejandro, Amal, Alexander, Andreas, Anne, Carlo, Carmen (für deine ansteckende Fröhlichkeit), Chengfen, Daniele, Jacopo, Jiguang, Kim, Laura (you are almost there!), Liang, Maarten, Mark de R. (my new chicken-farm desk neighbour and bacteria-lab-questions answerer), Martijn, Melanie, Milou, Mitchel, Nico, Pieter, Piotr, Pramod, Rajesh (for just being you), Raquel (for being very welcoming to everyone), Rianne, Rick, Rik, Rindia, Roberto (for a good start of my PhD with Dutch classes and Friday night drinks), Robin, Sarah (for the office talks in the last months), Shyam, Shuqin, Stan, Supa, Supitch (for being always friendly and for your gifts from Thailand), Sven, Tadatsugu, Tetiana, Wei, Wouter, and to all the students and visitors! 
DDT A big thanks goes to everyone from the local Ultimate Frisbee Club DDT who I have met and played with since I joined in my first $\mathrm{PhD}$ week and everyone else who plays Frisbee in the Netherlands! Thanks for all the trainings, competitions, tournaments and free time activities!

Freunde Ausserdem möchte ich mich bei meinen "deutschen" Freunden aus Schule und Uni bedanken, dass sie sich immer noch mit mir treffen, wenn ich mich nach Dresden verirre - Dank geht an Theresa \& Martin, Susi \& Matthias, Marion, Julia, Uta, Tanja, Maria, Tobi und Kathleen.

Familie Unbedingt muss ich mich noch bei meinen Eltern und meiner Schwester (samt eigener Familie) dafür bedanken, dass sie es so gut aufgenommen haben, dass ich in den letzten Jahren nicht mehr in der Nähe gewohnt habe, und dass sie manchmal länger auf Antwort warten mussten, wenn ich mal wieder im Stress untergegangen bin. Vielen Dank für eure Unterstützung! Ook wil ik graag Sjouk, Piet en Dieuwke bedanken voor hun interesse in mijn onderzoek en voor de goede tijd!

Sjoerd Last, but for sure not least I want to thank you, Sjoerd! For just everything in the last four years - thanks for your love and support!

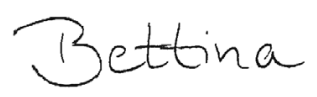

Enschede, May 2016. 



\section{About the author}

Bettina Schmidt studied chemistry at the Technische Universität Dresden, Germany, where she obtained her bachelor degree in 2009. During her master course in chemistry at the same university she spent four months as an Erasmus internship student dealing with the design and synthesis of metal-organic frameworks (MOFs) for separative and sensing applications under the supervision of Prof. Dr. Martin Schröder at the University of Nottingham, United Kingdom. In 2011 she graduated from the university in Dresden working on the synthesis and characterisation of flavonoid-based ligands and the investigation of their transition metal complexes under the direction of Prof. Dr. Karsten Gloe.

In October 2011 she started her PhD research under the supervision of Prof. Dr. Ir. Pascal Jonkheijm. The aim of her project was the synthesis of glycoconjugated dyes, formation of self-assemblies and the investigation of their photophysical and binding properties that might be interesting for biomedical applications. The results of this research are described in this thesis.

\section{List of Publications 1}

B. Schmidt and P. Jonkheijm, "Supramolecular assemblies based on symmetrical and asymmetrical glycoconjugated porphyrins", manuscript in preparation.

B. Schmidt, S. Sankaran, L. Stegemann, C.A. Strassert, P. Jonkheijm and J. Voskuhl, "Agglutination of bacteria using polyvalent nanoparticles of aggregation-induced emissive thiophthalonitrile dyes", J. Mater. Chem. B 2016, submitted.

J. Brinkmann\#, E. Cavatorta\#, S. Sankaran\#, B. Schmidt", J. van Weerd" and P. Jonkheijm, "About supramolecular systems for dynamically probing cells", Chem. Soc. Rev. 2014, 43, 4449-4469.

\footnotetext{
${ }^{1}$ \# equal authorship
} 


\section{Conference contributions}

B. Schmidt, J. Voskuhl, S. Sankaran and P. Jonkheijm, "Aggregation-Induced Emission (AIE) Properties of 4,5-Bis(phenylthio)phthalonitriles", $10^{\text {th }}$ International Symposium on Macrocyclic and Supramolecular Chemistry 2015, Strasbourg (F); GRS \& GRC Self-Assembly \& Supramolecular Chemistry 2015, Lucca-Barga (I); Symposium RUG/UT Self-Assembled Nanosystems: From Molecules to Materials 2015, Groningen (NL).

B. Schmidt and P. Jonkheijm, "Porphyrin-based Assemblies", IRTG Closing Symposium 2014, Münster (D); NWO Chains 2014, Veldhoven (NL).

T. Satav\#, S. Sankaran\#, B. Schmidt", J. Brinkmann\# and P. Jonkheijm, "Featuring supramolecular chemists' views on probing cell function", MESA+/SFB 765 MiniSymposium Multivalency in Chemistry and Supramolecular Chemistry 2012, Berlin (D). 


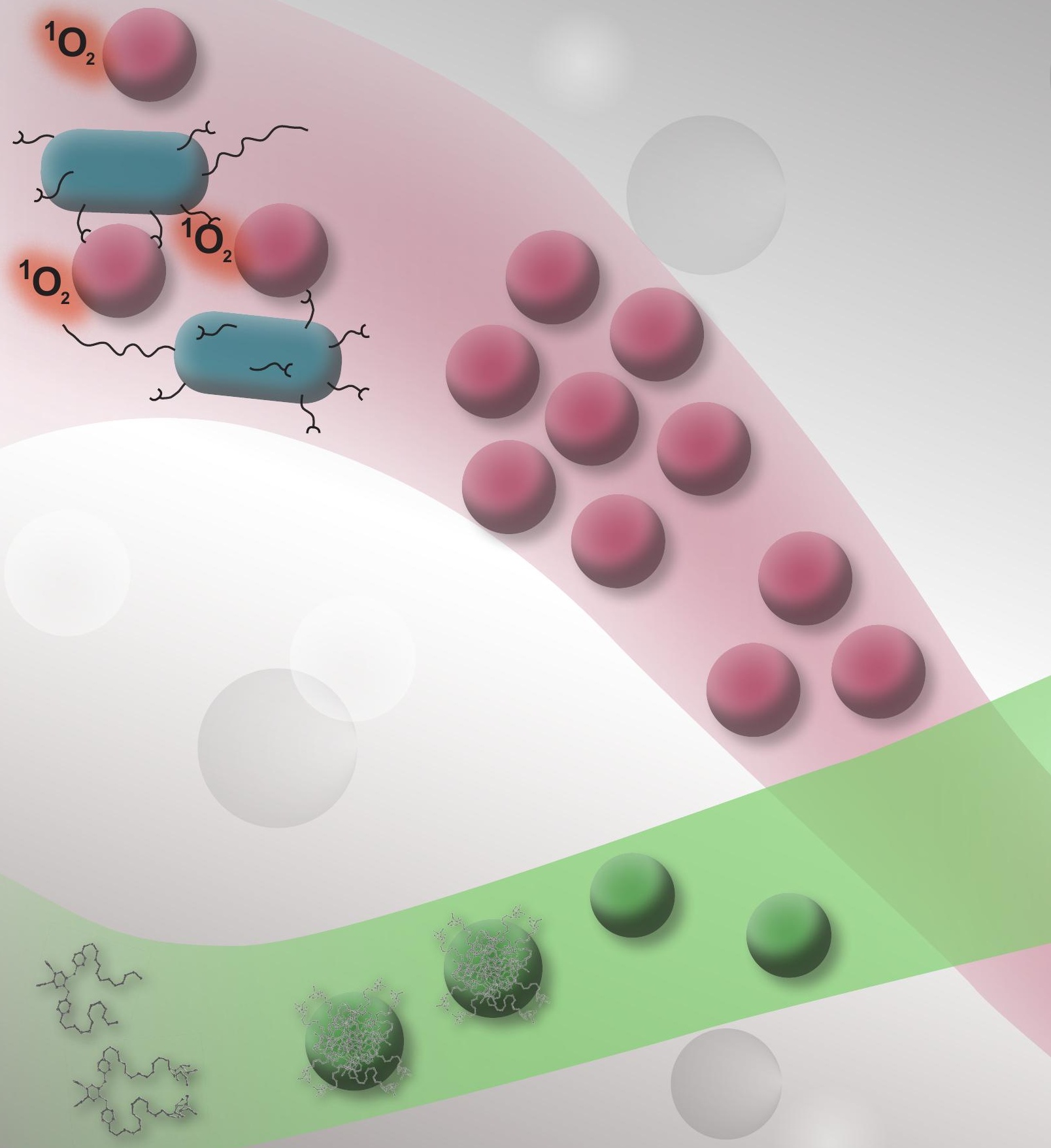

ISBN 978-90-365-4124-4 